Portland State University

PDXScholar

\title{
Evaluating the role of geogrids in the rehabilitation of cracked dams via numerical techniques
}

Kelly Dean Uhacz

Portland State University

Follow this and additional works at: https://pdxscholar.library.pdx.edu/open_access_etds

Part of the Civil and Environmental Engineering Commons Let us know how access to this document benefits you.

\section{Recommended Citation}

Uhacz, Kelly Dean, "Evaluating the role of geogrids in the rehabilitation of cracked dams via numerical techniques" (1991). Dissertations and Theses. Paper 4310.

https://doi.org/10.15760/etd.6193

This Thesis is brought to you for free and open access. It has been accepted for inclusion in Dissertations and Theses by an authorized administrator of PDXScholar. Please contact us if we can make this document more accessible: pdxscholar@pdx.edu. 
AN ABSTRACT OF THE THESIS OF Kelly Dean Uhacz for the Master of Science in Civil Engineering presented on May $31,1991$.

Title: Evaluating the Role of Geogrids in the Rehabilitation of Cracked Dams via Numerical Techniques.

APPROVED BY MEMBERS OF/FHE THESIS COMMITTEE:

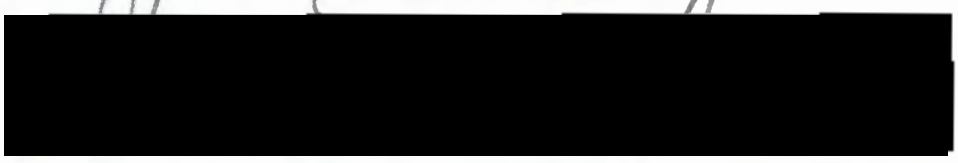

Trevor D. Smith, Chairman
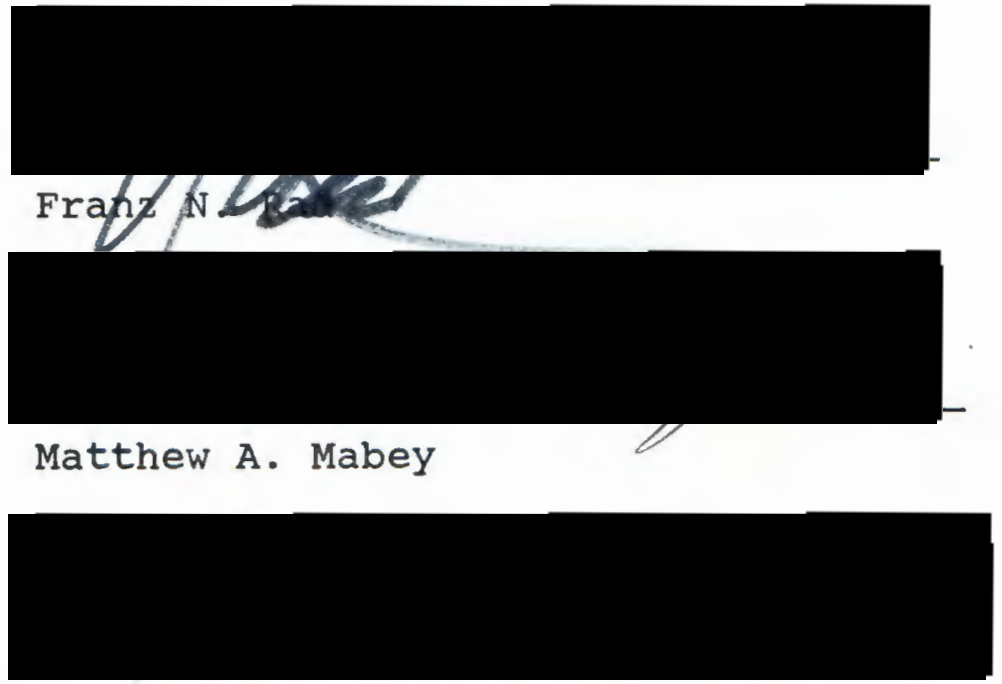

Scott Burns

Collapse and cracking of debris earth embankment dams is a serious problem in areas of the arid Western United states. The use of geogrids is evaluated in this 
thesis as a possible solution to prevent or reduce the amount of damage to the structures from collapse and cracking.

An apparatus was designed, constructed, and instrumented to electronically acquire data to evaluate the behavior of geogrids during pullout tests under various normal stresses. The pullout tests were also modelled using numerical techniques to correlate physical test data with numerical test data. Understanding the behavior of the geogrid, in both the physical and numerical pullout tests, allowed the geogrid model to be combined with a collapsing dam model to evaluate the effectiveness of reinforcement at reducing, or preventing, damage caused by collapse and cracking. Results from this model indicate that the effectiveness of the geogrid was minimal. The ineffectiveness of the geogrids, however, may be a result of numerical modelling problems associated with the computer program. 


\title{
EVALUATING THE ROLE OF GEOGRIDS IN THE REHABILITATION OF CRACKED DAMS \\ VIA NUMERICAL TECHNIQUES
}

\author{
by \\ KELLY DEAN UHACZ
}

A thesis submitted in partial fulfillment of the requirements for the degree of

MASTER OF SCIENCE

CIVIL ENGINEERING

Portland State University

1991 
TO THE OFFICE OF GRADUATE STUDIES:

The members of the committee approve the thesis of Kelly Dean Unacz presented May 31, 1991.

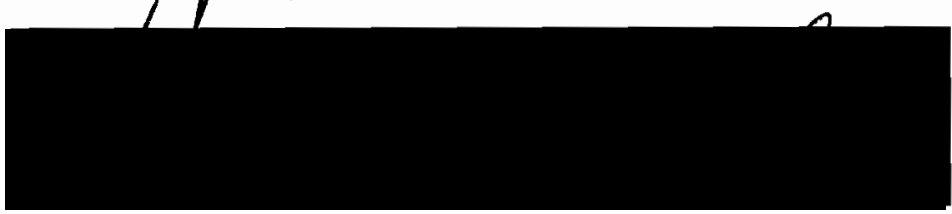

Trevor D. spith, Tpairman
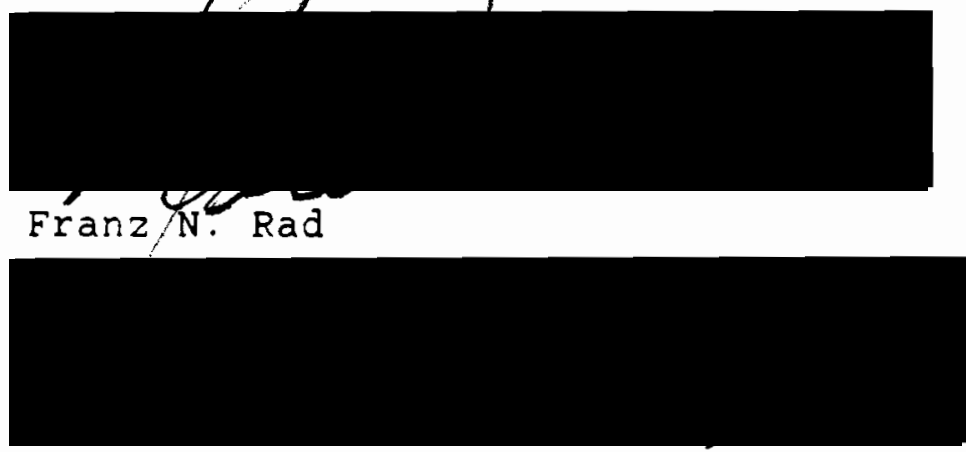

Mat thew A. Mabey

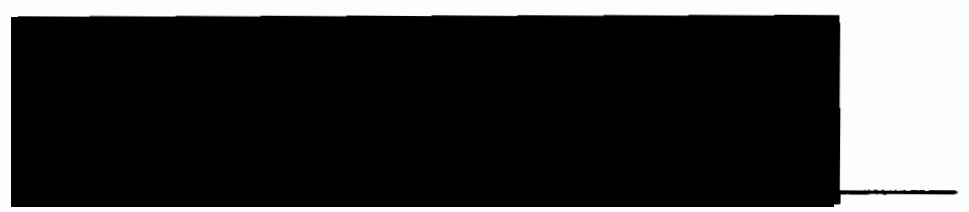

Scott Burns

APPROVED :

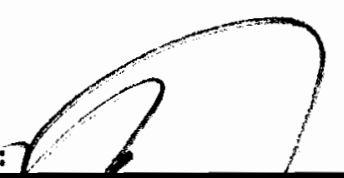

Frdnz N. Rad, Chair, Department of Civil Engineering

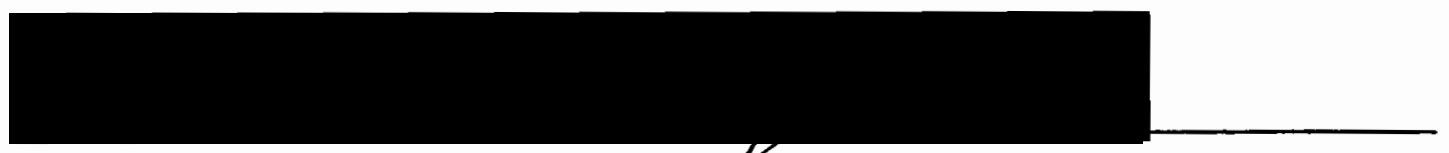

C. William Savery, Interim studies and Research

Kce Provost for Graduate 


\section{DEDICATION}

This thesis is dedicated to my parents, Gary and Janice Uhacz, whose support made this project possible. 


\section{ACKNOWLEDGMENTS}

Thanks to the Soil Conservation Service, Northwest Technical Center, Portland, Oregon, for sponsoring this research project, and to Mr. Cliff Deal for his personal interest in the project. Dr. Trevor Smith of Portland State University is also thanked for his instruction and guidance throughout the project. A special thank you is to Mr. Robert Slyh, whose knowledge and background made completion of this project possible. The Civil Engineering Department and the rest of the research group are also thanked for teir cooperation. I would also like to acknowledge Bay Mills, Tenax and Wellman Quline for their product donations to the project.

A special thank you also goes to my parents, Gary and Janice Uhacz, and my family for their support throughout my education. They have shared in my accomplishments and disappointments. My education would not have been possible without them. 
TABLE OF CONTENTS

PAGE

ACKNOWLEDGMENTS . . . . . . . . . . . . . . . . iii

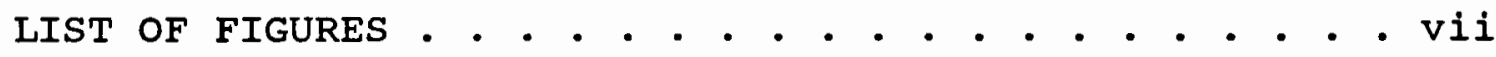

\section{CHAPTER}

INTRODUCTION. • • • • • • • • . • . • • . . 1

The Collapse Problem . . . . . . . . . 1

Current State of Investigation . . . . .6

Research Objective . . . . . . . 12

II MEChANICAL PUllout tests. . . . . . . . 14

Test Box Construction and

Instrumentation . . . . . . . . . .14

Pullout Test Results . . . . . . . 21

Summary of Geogrid Performance . . . . 32

III NUMERICAL EXPERIMENTS . . . . . . . . . 34

Input Model Selection. . . . . . . 34

Input Data Summary . . . . . . . 36

Output Data Summary. . . . . . . . 42

Model 1

Model 2

Model 3

Model 4 
PAGE

Implementation . . . . . . . . . . 51

Results. . . . . . . . . . . . 52

V OTHER REMEDIAL OPTIONS. . . . . . . . . . . . 61

Geomatrix. . . . . . . . . . . 61

Soil Grouting. . . . . . . . . . 62

Energy Input Technologies. . . . . . 64

other Geo-Products . . . . . . . 66

Recompaction . . . . . . . . . 66

The optimum Scenario . . . . . . . 68

VI CONCLUSIONS AND RECOMMENDATIONS • • • • • • 69

Physical Testing Conclusions . . . . . 69

Numerical Testing Conclusions. . . . . 70

Modelling Recommendations. . . . . . 71

Recommended Areas for Future Study . . . 71

REFERENCES 73

APPENDICES

A CALIBRATION CURVES • • . • • . • • • • . 76

B DENSITY AND DIRECT SHEAR DATA. • • • • • • • 79

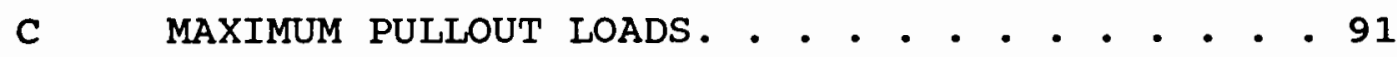

D LOAD VS. DISPLACEMENT GRAPHS . • • • • • • • 94

E EQUIVALENT MOdULUS VALUES . • • • • • • • • . . 131

F GEOGRID FRICTION ANGLES. . • . • . • • • . . . . 134

G MAXIMUM PULLOUT LOAD VS. EMBEDDED AREA GRAPHS . . . . . . . . . . . 136

H EARTH PRESSURE CELL DATA . . . . . . . . . . . . 140 
I EARTHPRESSURE CELL DATA FOR 6" $\times$ 6" AND 6" X 12" TEST SPECIMENS . . . . . . . 167

J RELAXATION TEST DATA . . . . . . . . . . 169

K COMPUTER MODEL NUMBER ONE. . . . . . . . . .173

L COMPUTER MODEL NUMBER TWO. . . . . . . . . . 184

M COMPUTER MODEL NUMBER THREE. . . . . . . . .195

N COMPUTER MODEL NUMBER FOUR . . . . . . . 206

O DRUCKER-PRAGER INPUT DATA. . . . . . . . . . 217

P ADJUSTED MODEL OUTPUT DATA . . . . . . . . . . 31

NOTATION AND ABBREVIATIONS . . . . . . . . . . . . . 238 


\section{LIST OF FIGURES}

F IGURE

PAGE

1. Theoretical Pullout Failure Mechanism . . . . . . .9

2. Side View of Pullout Test Box Apparatus. . . . 15

3. Plan View of Pullout Test Box Apparatus. . . . 16

4. Wiring Diagram. . . . . . . . . . . . . . . . . . 19

5. Fortrac Test Summary . . . . . . . . . . . . . . 22

6. Tenax 301 Test Summary . . . . . . . . . . . . . 23

7. Bay Mills 28502 Test Summary . . . . . . . . . 24

8. Pullout Test FEM Mesh . . . . . . . . . . . . . . . . . . .

9. Interface Parameters . . . . . . . . . . . . . . 39

10. Pullout Model Output. . . . . . . . . . . . 44

11. Dam FEM Mesh . . . . . . . . . . . . . . . . . . 54

12. First Principal Stresses With Body Force Loading Only . . . . . . . . . . . . . . 55

13. Horizontal Stresses, No Geogrids . . . . . . . 57

14. Total Displacements, No Geogrids . . . . . . . 58

15. Horizontal Stresses, Geogrids in Dam and Foundation. . . . . . . . . . . . . . . 59

16. Total Displacements, Geogrids in Dam and Foundation. . . . . . . . . . . . . 60 


\section{CHAPTER I}

\section{INTRODUCTION}

\section{THE COLLAPSE PROBLEM}

The development of foundation sinkholes and cracks in numerous earth debris embankment dams designed and constructed by the United States Department of Agriculture, Soil Conservation Service, ( $S C S$ ), are an important concern for sCS. The structures are typically constructed on, and of, metastable, collapsible alluvial deposits. These conditions may be present in as many as fifty earth embankment dams throughout the arid western United States. Typical dams are several thousand feet to five miles $(1 \mathrm{~km}$ to $8.1 \mathrm{~km})$ long and 20 feet to $50 \mathrm{feet}(6.1 \mathrm{~m}$ to $15.2 \mathrm{~m})$ high. Investigations previously conducted by SCS found that the soil moduli and soil strength decrease as the water content increases. The results of these SCS investigations are summarized as follows:

1) The foundation soil undergoes a drastic reduction in stiffness with an increase in moisture content.

2) The embankment soil experiences a slight reduction in stiffness with a change in soil moisture content . 
3) The dam slopes do not experience classical slope failure in a moist condition (Deal, 1986).

Desiccation is the process of drying of the soil. This decreases the moiture content of the soil and may cause cracking of the soil to occur.

As the moisture content increases the soil modulus drops causing collapse to occur. Collapse is the settlement of a soil column which is subjected to the reduced strength parameters from wetting. The collapse may cause a sinkhole to develop downstream, upstream, or beneath the dam. As the sinkhole expands, the dam may settle differentially. This causes areas of the structure to be subjected to tension forces which the soil is unable to support. The soil then cracks and the structure may experience piping failure when it is required to retain flood debris.

A report (Arrington, Stearns et al., 1979) on the investigation of structural deficiency of the Graveyard Wash Dam in Safford, Graham County, Arizona suggested several alternatives for correcting and avoiding the cracking problem at the Graveyard Wash Dam. They were as fol lows :

1) Remove low density foundation soils.

2) Relocate the dam to a more favorable location.

3) Cover the dam with a thick gravel blanket to protect against desiccation. 
4) Install embankment drains to protect against a piping failure through a crack.

5) Use irrigation or a protective covering to keep the core at placement moisture (Stearns et al. 1979).

Recommendations after investigating cracking at the Magma Flood Retention Structure in Arizona (Leckband, 1982) include; construction of a compacted buttress or stabilization fill over a cutof trench extending upstream from the base of the dam. Compaction and regrading of the structure was also recommended to reduce the permeabilities of the near surface soils. This is intended to reduce water inflow while maintaining the "in situ" soil moisture.

White Tanks No. 3 and No. 4, in Arizona, have been repaired by excavating a trench in the center of the dam to approximately three feet below the existing cracks and backfilling the trench with a granular material.

The Magma Dam study (Leckband, 1982) summarized several repair methods as follows:

1) Install a sand and gravel filter.

2) Install a narrow, reworked, compacted core, (which will likely crack again).

3) Install a narrow soil cement core, (which is likely too rigid).

4) Instigate a continuing program of cleaning and mud grouting. 
5) Install a cloth filter.

6) Lower the emergency spillways and install floodgates.

7) Segment the detention area with dikes (Leckband, 1982).

Several construction methods to control cracking were also summarized. They include:

1) Placement of a granular filter zone within the embankment to stop migration of fines and promote self healing of the crack.

2) Install 5 to 8 foot $(1.5 \mathrm{~m}$ to $2.4 \mathrm{~m})$ thick "shells" of granular material to break the capillary rise of moisture, and to insulate the dam from heat.

3) Install sand drains and an irrigation system to replace or remove moisture from the core of the dam as needed and to prevent buildup of higher capillary stresses.

4) Install a $12 \mathrm{mil}(.3 \mathrm{~mm})$ or thicker plastic or rubber sheeting around the core of the embankment to act as a vapor barrier.

5) Install vertical drains to act as a positive water cut-off (Leckband, 1982).

A final detailed alternative has been presented by Susanne Leckband of SCS (Leckband, 1984). The use of plastic sheeting as a barrier to flow was also suggested. By preventing moisture from flowing into the structure and 
foundation, collapse may be prevented or reduced.

Backfilling of cracks and regrading of the structure, or dam removal followed by recompaction of the dam and its foundation are the principal measures that SCS has taken to correct the collapse and cracking problems of their dams. These measures have met limited success. Cracks and collapse areas have continued to develop in areas repaired by these methods.

The use of geogrids as reinforcement in earth embankment dams constructed in collapsible soils has not been evaluated by SCS. The research performed was directed towards evaluating the effectiveness of geogrids in earth embankment dams. Geogrids placed in earth embankment dams are subjected to various normal stresses. The amount of pullout resistance a geogrid may offer is directly related to the normal stress. The available pullout resistance may allow the geogrid to carry the tensional forces developed in collapsible soils that cause cracks to develop in earth embankment dams. Soil is unable to carry tensional stresses, therefore, a crack develops.

It has become important to model this collapse phenomenon so that potential collapse and cracking damage may be avoided in the future by SCS. 


\section{CURRENT STATE OF INVESTIGATION}

By testing various geogrids in a pullout test at various normal stresses, the behavior of the geogrid may be evaluated when it is subjected to a particular normal stress. A homogeneous density sand was used for the tests performed in this study, however, various soil types may be tested using the same procedures. This sand was consistent with the type of sand used by other researchers for pullout testing and ensured repeatability of the test results. The collapsible soils have a wide range of grain sizes, ranging from clay sized particles to 2 foot $(.6 \mathrm{~m})$ diameter boulders. There are no American Society for Testing and Materials, (ASTM), tests available for geogrid pullout tests. There are, however, ASTM standards for wide width tensile testing of geotextiles, (D-4595).

Geogrids are a relatively new product and they have been in commercial use for less than 30 years. Little reported research work has been completed investigating the behavior of geogrids in soil. Early work (Ingold, 1983) was done using a $1.6 \mathrm{ft} .(500 \mathrm{~mm})$ long, .9 $\mathrm{ft} .(285 \mathrm{~mm})$ wide, and $1.0 \mathrm{ft} .(300 \mathrm{~mm})$ deep steel pullout box. A hydraulic jack was mounted horizontally at mid-height to pull the geogrid out. Constant pressure was applied to the soil using a $.3 \mathrm{ft}$. ( $(100 \mathrm{~mm})$ deep reinforced rubber bag pressurized with deareated water. Results of these tests 
concluded that

"pullout resistance is a function of the cumulative embedded area of the grid members normal to the direction of pullout and not the embedded plan area, (footprint), of the reinforcement" (Ingold, 1983).

Additional tests (Bergado, Bukkanasuta, and Balasubramaniam, 1987) were conducted using a reinforced concrete test box. A steel plate with a slot in it allowed the geogrid to be pulled out of the front of the test box. Normal stresses were applied by a hydraulic jack to a steel plate to simulate overburden pressures. The geogrid was clamped between two steel angles and pulled out by a second hydraulic jack. A pullout rate of .04 in/min $(1 \mathrm{~mm} / \mathrm{min})$ was used. Load and displacement data were collected from dial gauges at one minute intervals.

Undrained tests were conducted under normal pressures of $409.6 \mathrm{psf}(2 \mathrm{t} / \mathrm{sq} \cdot \mathrm{m})$ to $2048.1 \mathrm{psf}(10 \mathrm{t} / \mathrm{sq} \cdot \mathrm{m})$ on Tensar SS2 geogrids in a clayey sand and a weathered clay. Tests using bamboo grids were also conducted in these soil types. Results of these tests showed that the interaction between the soil and reinforcement is a function of

"the adhesion between soil and reinforcement on the surface area of the geogrid, and the bearing capacity of soil in front of all transverse members of the geogrids which behave as a strip footing embedded in the soil," (Bergado et al. 1987 ).

Generally, the predominant failure mechanism is a soil to soil failure. As the transverse rib is pulled through 
the soil, the soil "flows" around the rib. The mechanism is similar to a bearing capacity failure as shown in Figure 1 (Bergado et al. 1987).

Tests conducted by Westinghouse Environmental and Geotechnical Services, Inc, on Fortrac 80/20-30 geogrid were completed in 1989 (Bove, 1989). The tests performed were not true pullout tests, but rather were wide width tensile tests and direct shear tests. Wide width tensile tests are conducted with an 8 inch $(.2 \mathrm{~m})$ geogrid sample in pure tension, while direct shear tests measure the frictional resistance at the geogrid to soil interface. The direct shear tests were conducted in a 12 inch $(.3 \mathrm{~m})$ by 12 inch $(.3 \mathrm{~m})$ direct shear apparatus. Normal compressive stresses were $1500 \mathrm{psf}(72 \mathrm{kN} / \mathrm{sq} . \mathrm{m}), 2000 \mathrm{psf}(96 \mathrm{kN} / \mathrm{sq} \cdot \mathrm{m})$, and $2500 \mathrm{psf}(120 \mathrm{kN} / \mathrm{sq} \cdot \mathrm{m})$. A shear rate of .4 inches/minute $(10.2 \mathrm{~mm} / \mathrm{min})$ was used. A friction angle of 39 degrees and no cohesion was obtained for the soil to geogrid interface (Bove, 1989). A sandy fill soil was obtained from a project work site for use in these tests.

Proposed standards for geogrid pullout tests are presently being developed by the Geosynthetic Research Institute at Drexel University. Data sampling and test procedures are being evaluated (Geosynthetic Research Institute, 1990). The construction of a pullout test box based on the soil type and the aperture size of the geogrid 


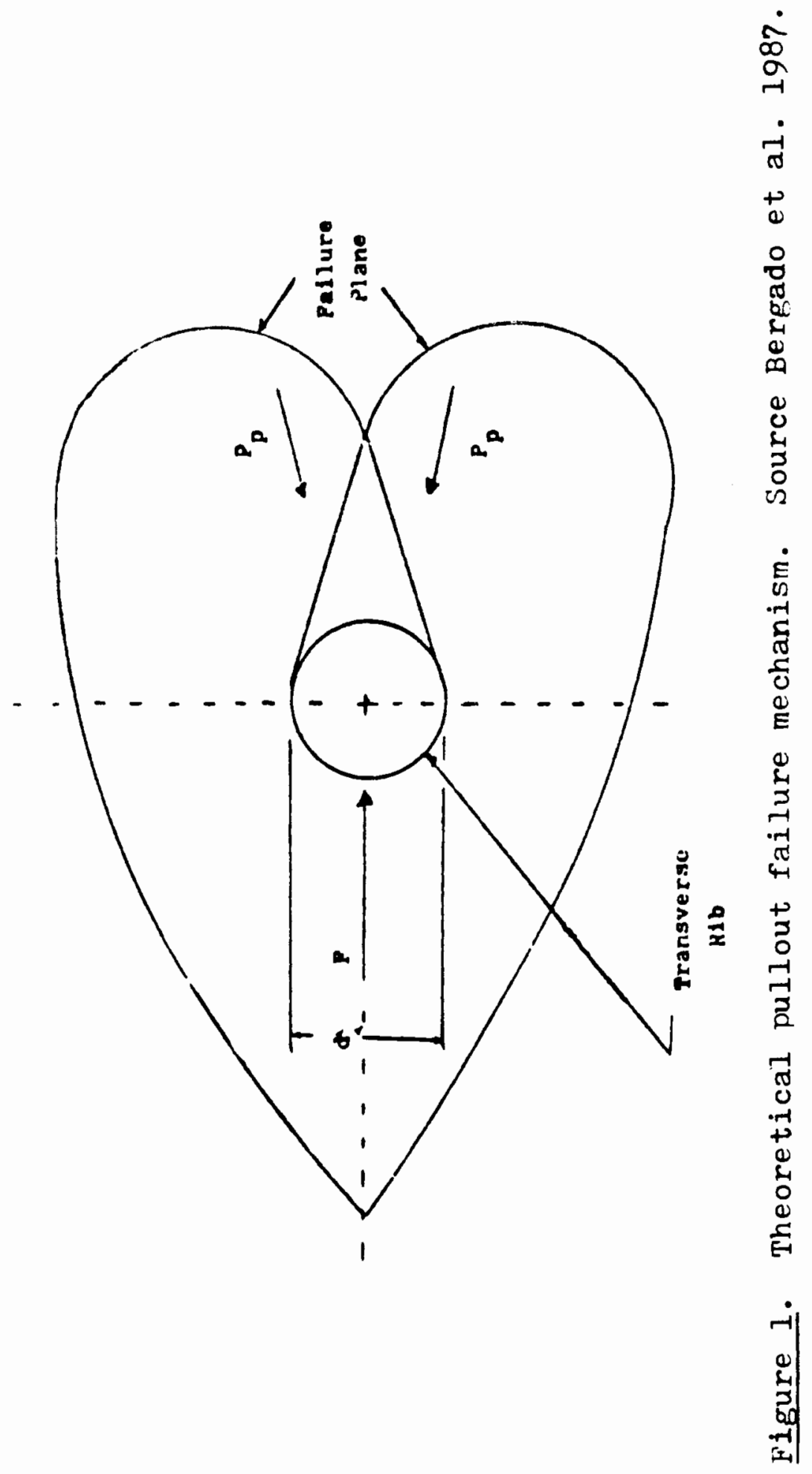


are under study. A minimum of 12 inches $(.3 \mathrm{~m})$ above and below the geogrid sample has been recommended. The recommended method of normal stress application is with a pneumatic or hydraulic diaphram loading device. This allows the applied normal stress to remain constant and uniform throughout the test.

In 1989 , STS Consultants evaluated the performance of Fortrac 50/30-20 geogrids. The pullout test box used by STS Consultants had inside dimensions of 27.5 inches $(.7 \mathrm{~m})$ wide, 52 inches $(1.3 \mathrm{~m})$ long and 18 inches $(.5 \mathrm{~m})$ deep. Test specimens were 2 feet $(.6 \mathrm{~m})$ wide and embedded 2 feet $(.6 \mathrm{~m})$ and 4 feet $(1.2 \mathrm{~m})$. Air pressure within an air bag was used to apply the normal stress. Tests were run at 440 psf $(21 \mathrm{kN} / \mathrm{sq} . \mathrm{m}), 660 \mathrm{psf}(32 \mathrm{kN} / \mathrm{sq}, \mathrm{m})$, and $880 \mathrm{psf}$ $(42 \mathrm{kN} / \mathrm{sq}$. m) with a pullout rate of $.04 \mathrm{in} / \mathrm{min}$ $(1 \mathrm{~mm} / \mathrm{min})$. Creep tests under constant load were also performed for 1000 hours (STS Consultants, Ltd., 1989). Load and displacement data was collected manually from dial gauges at "periodic" time intervals.

Hate Geotextiles also conducted a series of tests on the Fortrac series of geogrids. A $1.0 \mathrm{fi}$. (300mm) by $1.0 \mathrm{ft}$. ( $(300 \mathrm{~mm})$ direct shear box was used for shear and pullout tests to determine the "coefficient of interaction" between the Fortrac geogrid and the soil. The coefficient of interaction, $a$, was defined as: 
$a=\frac{\tan \delta^{\prime}}{\tan \Phi^{\prime}}$

where,

$$
\begin{aligned}
a= & \text { coefficient of interaction } \\
\delta^{\prime}= & \text { effective angle of soil-fabric bond stress } \\
\Phi^{\prime}= & \text { effective angle of shearing resistance for } \\
& \text { unreinforced soil }
\end{aligned}
$$

(Hate Geotextiles, 1990) and ranged from .85 for coarse gravel to 1.0 for sand. Ultra violet light stability, chemical resistance, and biological resistance were also studied.

Work completed in 1990 (Dembicki and Jermolowicz, 1991) investigates the interaction of soil and geotextiles. Anchorage lengths and friction mechanisms were evaluated. Bearing capacity of subsoil reinforced with geotextiles was evaluated. The test apparatus was essentially a $.8 \mathrm{ft} .(25 \mathrm{~cm})$ by $1.3 \mathrm{ft} .(40 \mathrm{~cm}) \mathrm{direct}$ shear box with the lower half being movable and the upper half being $f$ ixed in the horizontal direction. The lower half is allowed to move on wheels and a track. A hydraulic ram applies a normal load to the top of the upper half of the test box to apply the normal stress to the test soil. These tests were conducted on 5 different soil types using geotextiles only. No tests were performed on geogrids. The important conclusions reached in this study included the fact that the friction between soil and 
geotextile depends on the dimensions of the pores between fibers, the state of the surface in connection with grain sizes, their irregularity, the normal stress component and the density of the soil. The soil gradation was also found to influence the soil-geotextile friction value.

Creep and pullout resistance are currently being evaluated at the University of British Columbia. A pullout apparatus is currently in use which can test geogrid test specimens $3.9 \mathrm{ft}$. ( 1.2 meters) long and $2.0 \mathrm{ft} .(.6$ meters) wide. The soil depth is $2.0 \mathrm{ft}$. ( 0.6 meters $)$. Boundary condition effects will be evaluated with this test apparatus (Fannin, 1991).

A report (Juran, Knochenmus et al. 1988) summarizes the results of several researchers' tests. The report concludes that there are many factors that affect the pullout test results. The density of the soil, the confining pressure, the fine-grained portion of the soil, the interaction mechanisms, the grid orientation, the reinforcement extensibility, and the boundary conditions all proved to be important factors in the pullout tests evaluated.

RESEARCH OBJECTIVE

The objective of this research was to evaluate the behavior of geogrids under various normal stresses as they are subjected to tensile loading. The information obtain- 
ed from this evaluation was then used to evaluate the effectiveness of geogrids in earth embankment dams constructed on collapsible soils. This was accomplished by first constructing a physical geogrid pullout test apparatus. The pullout test was then modelled numerically to develop a correlation between the mechanical pullout tests and the computer model of the pullout test. The information obtained from the mechanical pullout tests was then incorporated into a collapsing model of an earth embankment dam to evaluate the effectiveness of geogrids at reducing cracking in the structure. 


\section{CHAPTER II}

\section{MECHANICAL PULLOUT TESTS}

A geogrid pullout test box was constructed and instrumented to electronically collect load and deflection data. A series of 33 tests on 6 different geogrid types produced by 3 different manufacturers was completed. Past work on physical geogrid pullout tests has been summarized in Chapter I.

\section{TEST BOX CONSTRUCTION AND INSTRUMENTATION}

The test apparatus is shown in Figure 2 and Figure 3 . The inside dimensions of the test box are 14 inches $(.4 \mathrm{~m})$ by 14 inches $(.4 \mathrm{~m})$, and 12 inches $(.3 \mathrm{~m}) \mathrm{high}$. This allows one square foot (.1 sq. m) of embedded geogrid sample to be tested. The box is constructed of 1-1/2" $\mathrm{X} 1-1 / 2$ " $(38 \mathrm{~mm} X 38 \mathrm{~mm})$ steel angles with $3 / 4 "(19 \mathrm{~mm})$ plastic coated particle board forming the walls. This was braced at several points so that deflection of the wood was not a problem. The top and bottom of the box is constructed of $3 / 16^{\prime \prime}(5 \mathrm{~mm})$ plate steel. The top is removable, and the top and bottom sections contain inflatable membranes which are used to simulate overburden pressures during the pullout test. 


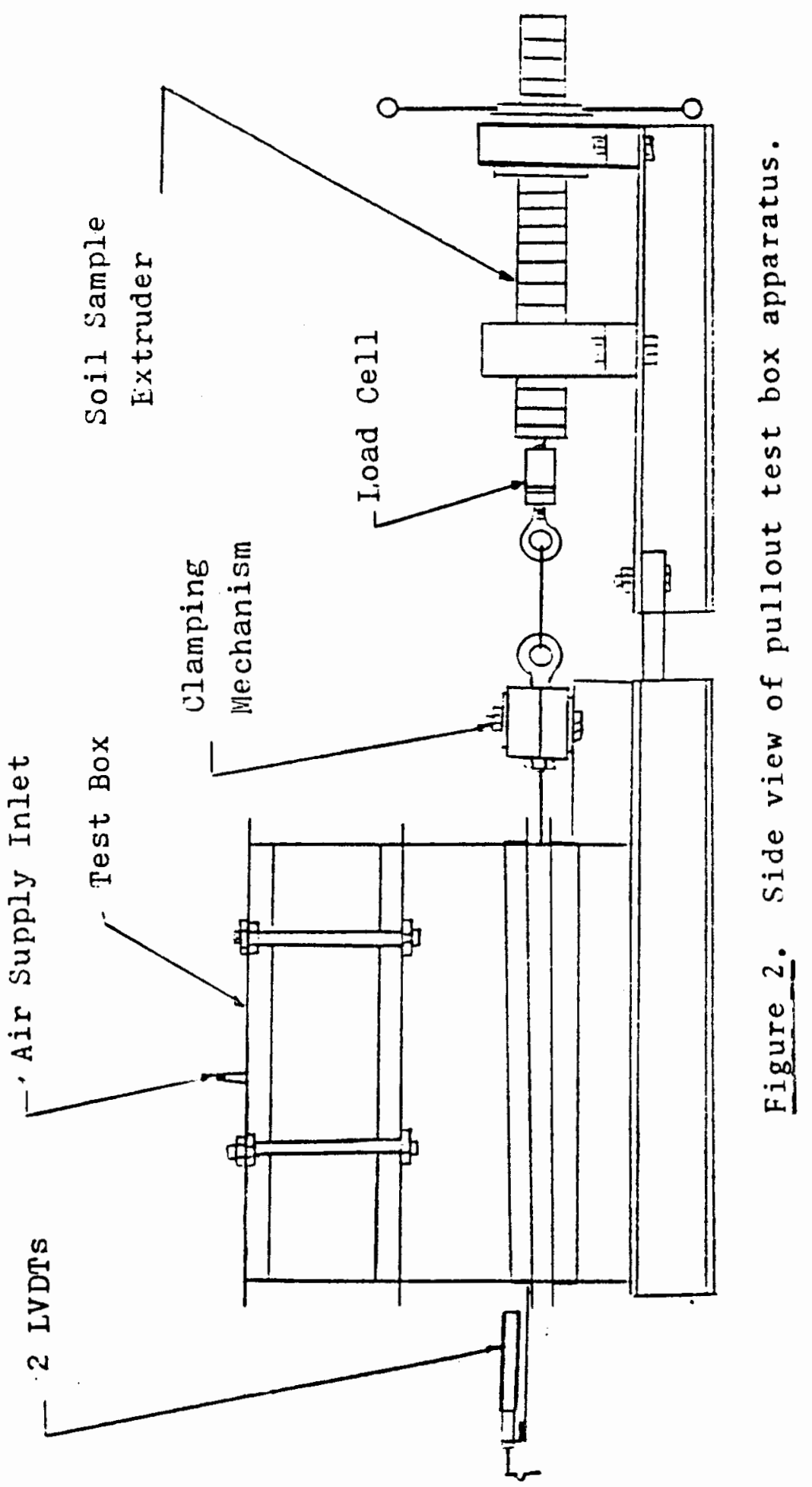




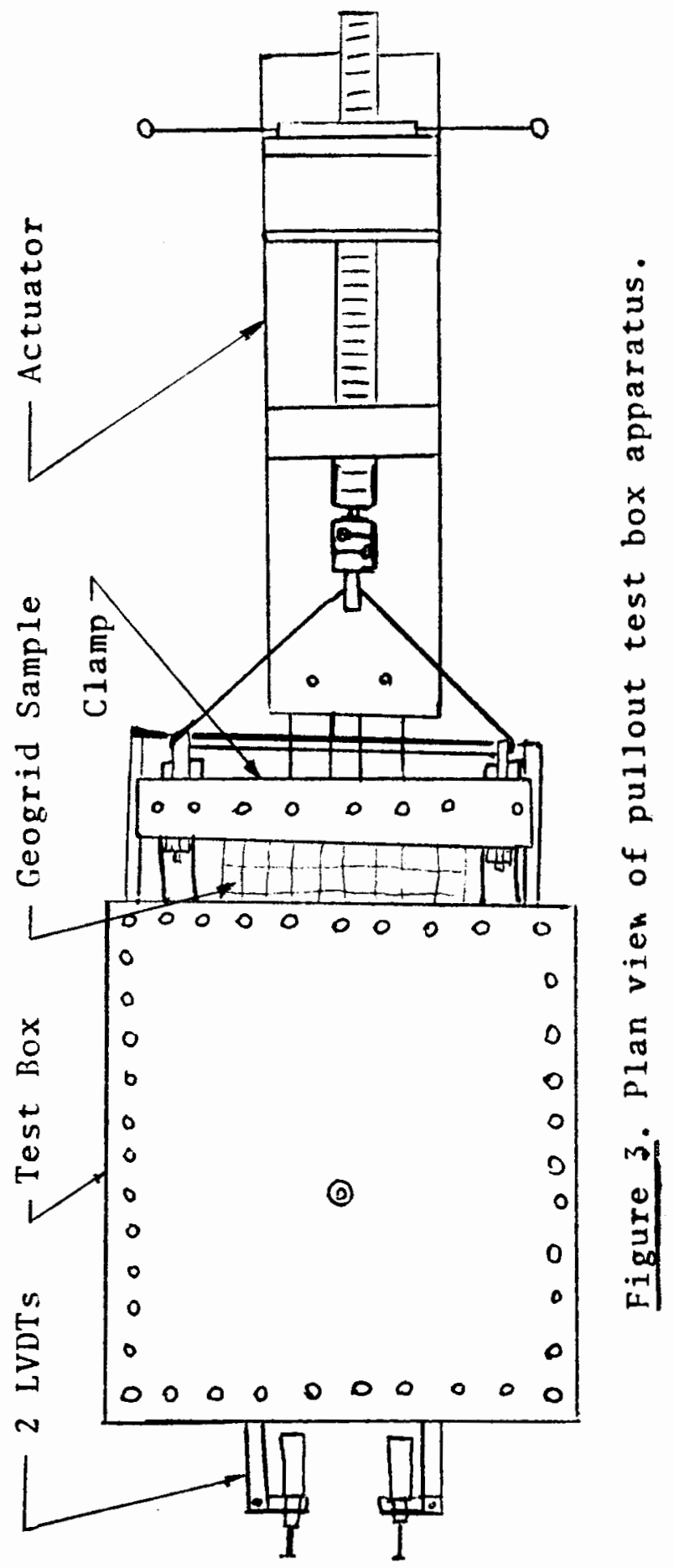


The inflatable membranes are formed by bolting $1 / 16$ " (2 $\mathrm{mm})$ sheet rubber and $3 / 32^{\prime \prime} \mathrm{X} 1 / 2^{\prime \prime}(2 \mathrm{~mm} \mathrm{X} 13 \mathrm{~mm})$ steel strips between the steel top and bottom plates and the ring of angles forming the top and bottom of the box. A sealant was placed between the rubber sheet and the steel plate. This forms an air tight compression seal between the rubber sheet and the steel plates. Automotive tire valve stems were placed in the top and bottom plates to inflate the membranes .

The box contains soil during the test, allowing different soil types, different geogrid types, and different normal pressures to be tested. The box was tapped with a hammer during deposition to densify the test soil or sand.

A $1 / 2 "(13 \mathrm{~mm})$ slot at the back of the box allows instrumentation to enter the box. Two linear variable displacement transducers, (LVDTs), were mounted at the back of the box. They were attached to the front and back of the embedded geogrid and displacements of these points were monitored during the pullout test.

A foam rubber guard placed across the open slot prevented escape of the test soil during the test. The front of the box contained a similar slot with foam. The geogrid sample passed through this slot to the clamping mechanism. The geogrid sample was bolted between two 18 inch $(.5 \mathrm{~m})$ long, 2 inch $(50 \mathrm{~mm})$ by 4 inch $(100 \mathrm{~mm})$ boards. These were all bolted between two 18 inch $(.5 \mathrm{~m})$ 
long 3 inch $(76 \mathrm{~mm})$ by $1 / 8$ inch $(3 \mathrm{~mm})$ steel plates.

Two hardened $1 / 2$ inch $(13 \mathrm{~mm})$ eye bolts pass through the 2 inch $(50 \mathrm{~mm})$ by 4 inch $(100 \mathrm{~mm})$ boards and were connected by a flexible cable to a single eye bolt in the load cell. The total pullout load was monitored at this point as the test progressed.

The load was applied manually by turning the handle of a soil sample extruder. The thrust bearing on the sample remover was reversed to apply a tension load and the end of the threaded shaft was drilled and tapped and an adaptor was made to connect it to the load cell.

An earth pressure cell was constructed to monitor the pressures within the soil. This instrument consisted of a 250 pound $(1.12 \mathrm{kN})$ capacity load button placed between two 4 square inch (2581 sq. $\mathrm{mm})$ aluminum plates $1 / 16$ inch $(1.6 \mathrm{~mm})$ thick. The plates were separated by thin strips of light foam and the load button was mounted in the center of the plates. The load could then be converted to a pressure. This instrument was calibrated by placing known weights on the instrument and converting this to a pressure by dividing by the area. The actual applied normal pressure was monitored using a pressure gauge on the input air line.

The wiring diagram for the apparatus is shown in Figure 4. The two LVDTs are powered by $a+/-15$ volt direct current power supply. They output a voltage of $+/-12$ volts DC. This was reduced to $+/-.2$ volts DC for input to the 


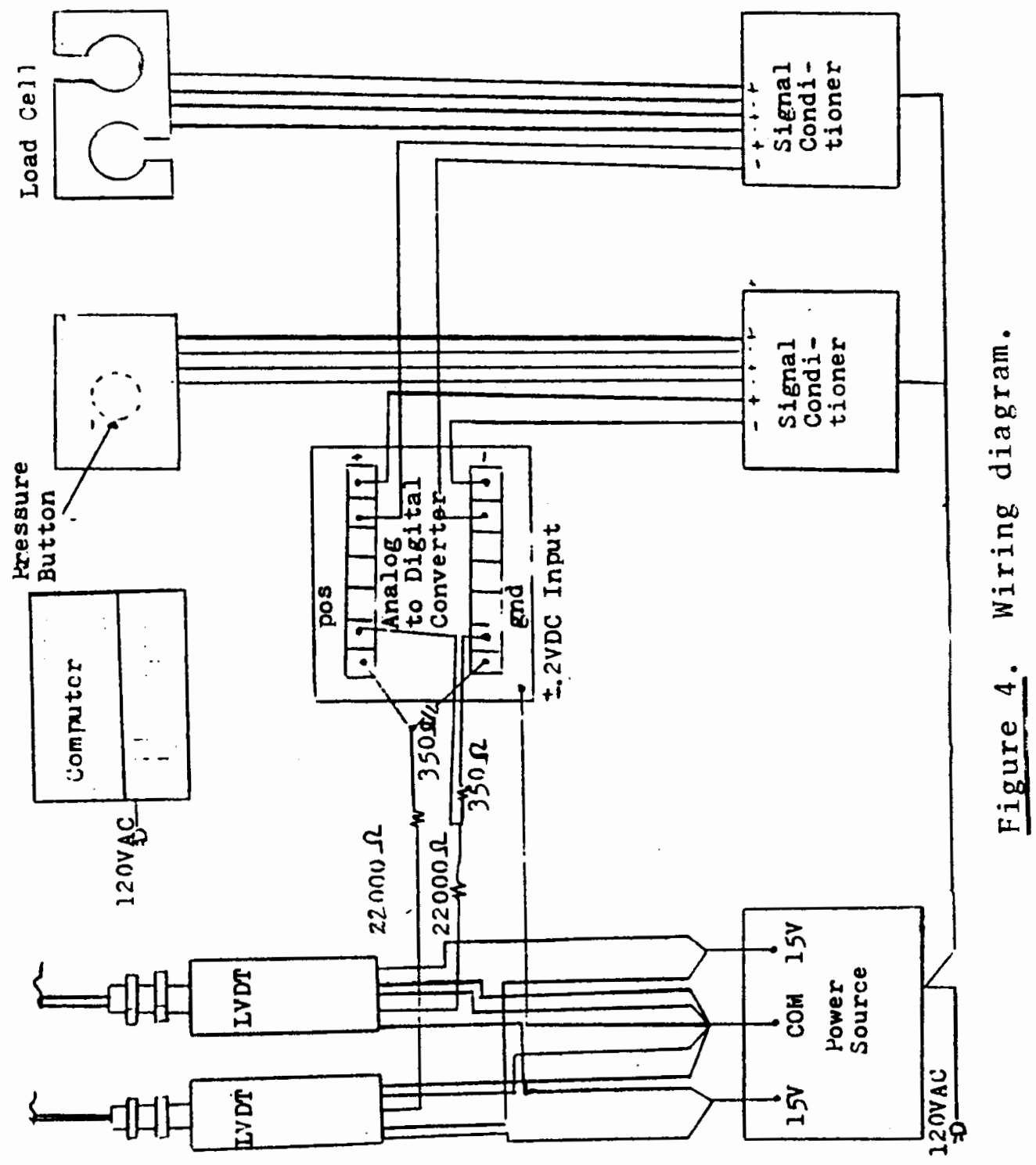


analog to digital converter by placing a 22,000 ohm resistor and a $350 \mathrm{ohm}$ resistor in series and measuring the voltage drop across the 350 ohm resistor. The load cell and earth pressure cell were powered by signal conditioners, and their outputs were scaled down by signal conditioners.

From the analog to digital converter, the test data was transferred to a 286 Supersport laptop computer. A program for electronic data acquisition (Boyer, 1990) was altered by $\mathrm{Mr}$. Bob Slyh to collect data once every second from four channels and write the information to a computer file. This information may be loaded into spreadsheet programs such as Lotus 123 or Quatro Pro for analysis and display. Load versus front displacement were plotted on the computer screen as the test was conducted.

Calibration of the LVDTs was done by plotting the output voltage against the actual displacement as measured by a dial gauge. A conversion factor was then determined. The LVDTs were manually set in their linear range using a digital voltmeter before each test.

Calibration of the 1000 and 5000 pound $(4.4 \mathrm{kN}$ and $22.2 \mathrm{kN}$ ) capacity load cells was achieved by constructing brackets to adapt the consolidometer to apply a tensile load. The lever arms were used to apply loads up to approximately $75 \%$ of the load cell capacity. The 5000 pound $(22.2 \mathrm{kN})$ capacity load cell was the only load cell used. A conversion factor was determined by plotting mil- 
livolts versus pounds of load. These graphs are shown in Appendix A.

\section{PULLOUT TEST RESULTS}

A homogeneous commercial density sand was used for all of the tests performed. The Unified Soil Classification for this sand was SP, (poorly graded sand). Sand densities were calculated to range from $97.6 \mathrm{lbs} / \mathrm{cu}$. ft. $(15.3 \mathrm{kN} / \mathrm{cu}$. m) to $99.0 \mathrm{lbs} / \mathrm{cu}$. ft. $(15.6 \mathrm{kN} / \mathrm{cu}$. m). Direct shear tests at $2 \mathrm{psi}, 5 \mathrm{psi}$, and $10 \mathrm{psi}(13.8 \mathrm{kN} / \mathrm{sq} . \mathrm{m}, 34.5 \mathrm{kN} / \mathrm{sq}$. $\mathrm{m}$, and $69.0 \mathrm{kN} / \mathrm{sq}$. m) showed the effective soil friction angle, $\varnothing$, to be 31.7 degrees, these test results are shown in Appendix B. Pullout tests were conducted with 2 psi. $5 \mathrm{psi}$, and $10 \mathrm{psi}(13.8 \mathrm{kN} / \mathrm{sq}, \mathrm{m}, 34.5 \mathrm{kN} / \mathrm{sq}, \mathrm{m}$, and $69.0 \mathrm{kN} / \mathrm{sq}$. m) normal pressures applied to the top and bottom of the sand sample. Normal stresses were monitored with an in line air pressure gauge and checked for accuracy using an earth pressure cell on several tests. Geogrids from three commercial manufacturers were available. Wellman Quline, Bay Mills, and Tenax geogrids were tested. Typical test results for each manufacturer's geogrid are shown in Figures 5,6 , and 7 .

The Tenax geogrids were an extruded polypropylene material with grid openings of 1.0 inch by 1.5 inches $(25 \mathrm{~mm}$ by $38 \mathrm{~mm}$ ) to 1 inch by 6 inches $(25 \mathrm{~mm}$ by $152 \mathrm{~mm}$ ). The Fortrac geogrids were polyester, coated with polyvinyl 


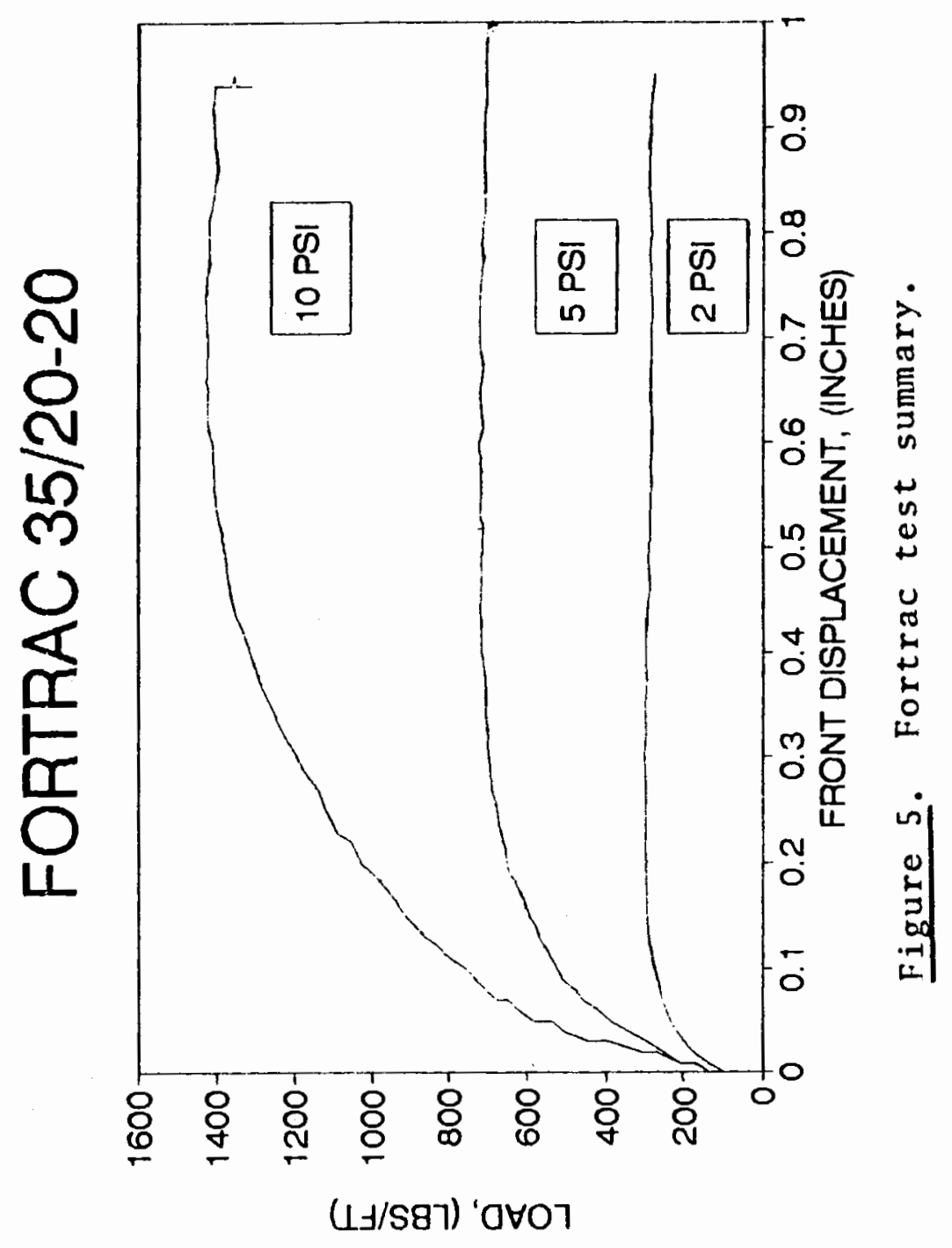




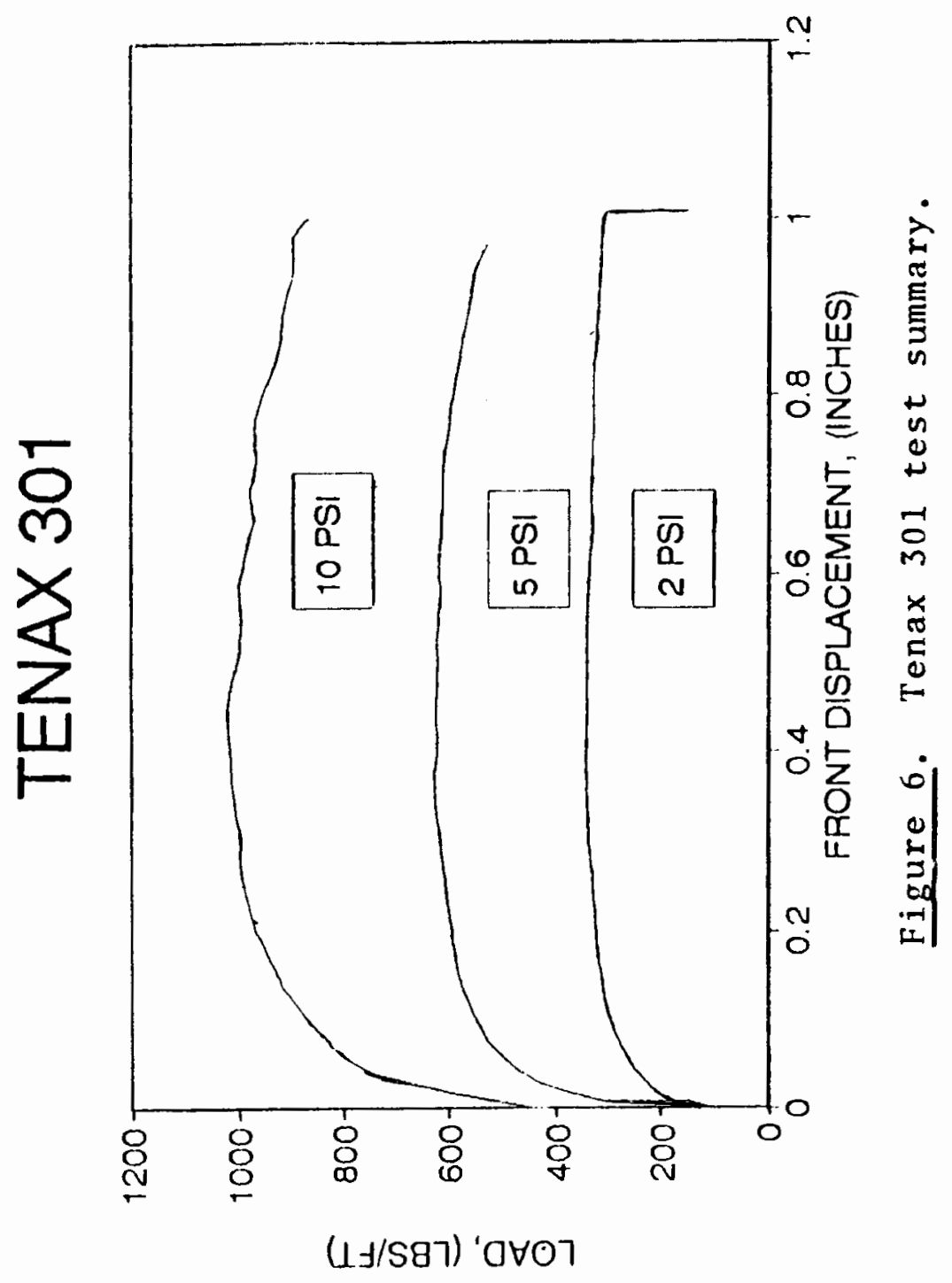




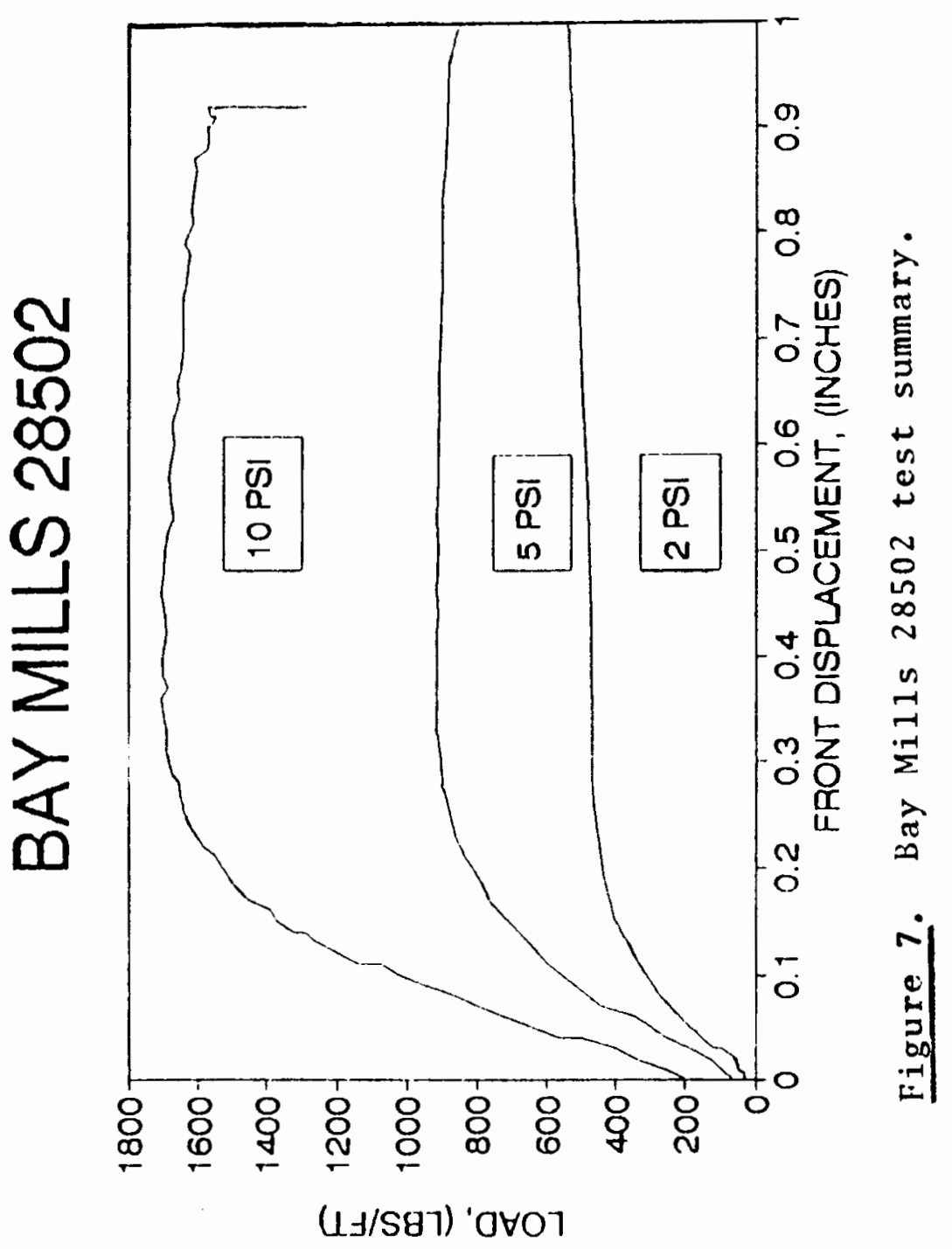


chloride and had a grid opening of .9 inches by .9 inches $(23 \mathrm{~mm}$ by $23 \mathrm{~mm})$. The Bay Mills geogrids were polyester, coated with butyl rubber and had a grid opening of .5 inches by .5 inches $(13 \mathrm{~mm}$ by $13 \mathrm{~mm})$. Pullout load results are shown per foot of width of geogrid normal to the pullout direction. The embedded samples were 1 foot $(.3 \mathrm{~m})$ wide and 1 foot $(.3 \mathrm{~m})$ long, unless otherwise specified.

Fortrac 35/20-20 from Wellman Quline showed significant joint damage throughout the sample when tested under 10 psi $(69.0 \mathrm{kN} / \mathrm{sq}$. m) normal pressure. Maximum pullout loads ranged from $1040 \mathrm{lbs} / \mathrm{ft}(15.2 \mathrm{kN} / \mathrm{m})$ to $1684 \mathrm{lbs} / \mathrm{ft}$ $(24.6 \mathrm{kN} / \mathrm{m})$. Average tests at $10 \mathrm{psi}(69.0 \mathrm{kN} / \mathrm{sq} . \mathrm{m})$ reached maximum pullout loads of approximately $1400 \mathrm{lbs} / \mathrm{ft}$ $(20.4 \mathrm{kN} / \mathrm{m})$.

The pullout test on Fortrac 35/20-20 at 5 psi $(34.5 \mathrm{kN} / \mathrm{sq}$. m) exhibited a maximum load of $722 \mathrm{lbs} / \mathrm{ft}$ $(10.5 \mathrm{kN} / \mathrm{m})$. There was no joint damage to the sample, but the transverse ribs were slightly distorted. The pullout test at $2 \mathrm{psi}(13.8 \mathrm{kN} / \mathrm{sq}$. m) had a maximum load of $299 \mathrm{lbs} / \mathrm{ft}(4.4 \mathrm{kN} / \mathrm{m})$. There was no joint damage and only minor deformation of the transverse ribs.

Tests on Bay Mills grid 28501 showed minor deformations of the transverse ribs and no joint damage at normal pressure applications of $5 \mathrm{psi}(34.5 \mathrm{kN} / \mathrm{sq}, \mathrm{m})$ and $10 \mathrm{psi}$ $(69.0 \mathrm{kN} / \mathrm{sq} . \mathrm{m})$. The pullout load was $1717 \mathrm{lbs} / \mathrm{ft}$ $(25.1 \mathrm{kN} / \mathrm{m})$ for the $10 \mathrm{psi}(69.0 \mathrm{kN} / \mathrm{sq} . \mathrm{m})$ normal stress 
test and $875 \mathrm{lbs} / \mathrm{ft}(12.8 \mathrm{kN} / \mathrm{m})$ for the $5 \mathrm{psi}$

$(34.5 \mathrm{kN} / \mathrm{sq}$. m) normal stress test. No deformation or joint damage was observed in the geogrid sample for the 2 psi

(13.8 kN/sq. m) normal stress test.

Bay Mills grid 28502 was tested at 2 psi, 5 psi, and $10 \mathrm{psi}(13.8 \mathrm{kN} / \mathrm{sq} \cdot \mathrm{m}, 34.5 \mathrm{kN} / \mathrm{sq} \cdot \mathrm{m}$, and $69.0 \mathrm{kN} / \mathrm{sq} \cdot \mathrm{m})$ with the double rib oriented transverse to the pullout direction. Slippage and joint failure were observed within the clamp, and a minimal amount of distortion of the geogrid was observed in the embedded grid when tested under 10 psi (69.0 kN/sq. m) normal pressure. The maximum pullout load reached $1705 \mathrm{lbs} / \mathrm{ft}(24.9 \mathrm{kN} / \mathrm{m})$.

One test was attempted with an applied normal pressure of $15 \mathrm{psi}(103.4 \mathrm{kN} / \mathrm{sq} . \mathrm{m})$, however, it was not possible to hold the geogrid sample in the clamping mechanism during the pullout test at this stress level. There were no visible signs of damage to the geogrid samples for the 2 psi $(13.8 \mathrm{kN} / \mathrm{sq} . \mathrm{m})$ and $5 \mathrm{psi}(34.5 \mathrm{kN} / \mathrm{sq}$. m) normal pressure tests.

Bay Mills grid 28502 was tested with a 10 psi applied normal pressure and with the double ribs oriented parallel to the pullout direction. The maximum pullout load was $1890 \mathrm{lbs} / \mathrm{ft}(27.6 \mathrm{kN} / \mathrm{m})$. This was $173 \mathrm{lbs} / \mathrm{ft}(2.5 \mathrm{kN} / \mathrm{m})$ more than with the double ribs oriented transverse to the pullout direction. The shape of the front and rear displacement versus load curves were very similar to each 
other for the two tests, and the difference in pullout load may have been due to a slight over pressurizing of the second test. An over pressurizing of 1.0 to $1.2 \mathrm{psi}$ (6.9 to $8.3 \mathrm{kN} / \mathrm{sq}$. m) could account for this difference. Therefore, only one test was conducted with the geogrid in this orientation. Sand grains were observed to adhere to all of the Bay Mills test specimens.

Three geogrid types from Tenax were tested under 2 psi $(13.8 \mathrm{kN} / \mathrm{sq} . \mathrm{m}), 5 \mathrm{psi}(34.5 \mathrm{kN} / \mathrm{sq} . \mathrm{m})$, and $10 \mathrm{psi}$ (69.0 kN/sq. m) normal pressures. Tenax grid type 201 was the first type tested. The $10 \mathrm{psi}(69.0 \mathrm{kN} / \mathrm{sq} . \mathrm{m})$ normal stress test had a maximum pullout load of $992 \mathrm{lbs} / \mathrm{ft}$, $(13.5 \mathrm{kN} / \mathrm{m})$ the 5 psi $(34.5 \mathrm{kN} / \mathrm{sq}$. m) normal stress test had a maximum pullout load of $594 \mathrm{lbs} / \mathrm{ft}(8.7 \mathrm{kN} / \mathrm{m})$. The $2 \mathrm{psi}$ $(13.8 \mathrm{kN} / \mathrm{sq}$. m) normal stress test had a maximum pullout load of $408 \mathrm{lbs} / \mathrm{ft}(6.0 \mathrm{kN} / \mathrm{m})$.

Tenax grid type 301 was tested under 2 psi, 5 psi and $10 \mathrm{psi}(13.8 \mathrm{kN} / \mathrm{sq} . \mathrm{m}, 34.5 \mathrm{kN} / \mathrm{sq} . \mathrm{m}$, and $69.0 \mathrm{kN} / \mathrm{sq}$. m) normal pressures. Maximum pullout loads were $346 \mathrm{lbs} / \mathrm{ft}(5.0 \mathrm{kN} / \mathrm{m}), 630 \mathrm{lbs} / \mathrm{ft}(9.2 \mathrm{kN} / \mathrm{m})$, and $1025 \mathrm{lbs} / \mathrm{ft}(15.0 \mathrm{kN} / \mathrm{m})$, respectively.

Maximum pullout loads for Tenax grid type 401 at 2 psi, $5 \mathrm{psi}$, and $10 \mathrm{psi}(13.8 \mathrm{kN} / \mathrm{sq} . \mathrm{m}, 34.5 \mathrm{kN} / \mathrm{sq} . \mathrm{m}$, and $69.0 \mathrm{kN} / \mathrm{sq}$. m) normal pressures were $291 \mathrm{lbs} / \mathrm{ft}$ $(4.2 \mathrm{kN} / \mathrm{m}), 644 \mathrm{lbs} / \mathrm{ft}(9.4 \mathrm{kN} / \mathrm{m})$, and $1058 \mathrm{lbs} / \mathrm{ft}$ $(15.4 \mathrm{kN} / \mathrm{m})$, respectively. No damage or distortions were 
observed in any of the Tenax geogrid test specimens.

The maximum pullout loads are summarized in Appendix C. Graphs of front displacement and rear displacement of the geogrid versus pullout loads are given in Appendix D.

Equivalent modulus values were calculated for each test. These values represent the equivalent interaction stiffness between each geogrid and the density sand. The equivalent modulus values were determined graphically from the front displacement versus load curves for each test. Equivalent modulus values are shown in Appendix $E$. They range from $12,000 \mathrm{lbs} / \mathrm{ft}(175.1 \mathrm{kN} / \mathrm{m})$ to $600,000 \mathrm{lbs} / \mathrm{ft}$ $(8755.8 \mathrm{kN} / \mathrm{m})$ and increase with increasing normal pressures.

Friction angles were determined for each geogrid by graphing the peak pullout loads against the applied normal pressures. These values are summarized in Appendix F. Bay Mills and Fortrac grids had a friction angle of over 45 degrees, while the Tenax grids had friction angles of 29 degrees to 36 degrees.

Initial tests were conducted with different pullout rates. Actuator speeds were varied from .04 in./minute ( $1 \mathrm{~mm} / \mathrm{minute}$ ) to approximately $.20 \mathrm{in.} / \mathrm{minute}$ ( $5 \mathrm{~mm} / \mathrm{minute}$ ) and it was found that the rate of pullout did not significantly affect the test data within this range. Therefore, constant pullout rates of approximately $.20 \mathrm{in.} / \mathrm{minute}(5 \mathrm{~mm} / \mathrm{minute})$ were used.

The embedment footprint area was varied with the 
Fortrac $35 / 20-20$ geogrid. Tests were run on 12 " by 12 " $(.3 \mathrm{~m}$ by $.3 \mathrm{~m}), 6^{\prime \prime}$ by $12^{\prime \prime}(.2 \mathrm{~m}$ by $.3 \mathrm{~m})$, and $6 "$ by $6 "$ $(.2 \mathrm{~m}$ by $.2 \mathrm{~m})$ embedded test specimens. A graph of the maximum pullout load versus embedded area showed a linear relationship and is shown in Appendix G.

Use of the earth pressure cell allowed pressures within the soil to be monitored before and during the pullout test. It was found that pressurizing the test box to the desired pressure did not allow the desired pressures to be achieved within the soil. It was necessary to disturb the test box by hitting it with a hammer as the test sand was deposited, and to over-pressurize the box, then depressurize the apparatus before beginning the pullout test. This procedure densified the sand and was found to give a more homogeneous stress distribution within the sand. Graphs of the earth pressure cell data against the front displacement of the geogrid are shown for each test in Appendix $\mathrm{H}$.

The earth pressure cell was placed at various locations in both horizontal and vertical orientations. By placing the earth pressure cell near the surface and at various depths in the center of the test box, it was found that the applied pressure was evenly distributed throughout the soil. Placement of the earth pressure cell near the corner of the box showed a loss of nearly $20 \%$ at a depth of 2 inches $(51 \mathrm{~mm})$. All except two tests showed a slight decrease in vertical earth pressure during the pullout test. These two 
exceptions were when the earth pressure cell was located 2 to 3 inches ( 51 to $76 \mathrm{~mm}$ ) below the sand surface and near the front corner of the test box.

Several tests were also conducted with the earth pressure cell placed vertically, flat against the front face of the test box. Appendix I shows the earth pressure cell data for both the $6^{\prime \prime}$ by $6 "(.2 \mathrm{~m}$ by $.2 \mathrm{~m})$ and $6 "$ by 12 " $(.2 \mathrm{~m}$ by $.3 \mathrm{~m})$ Fortrac $35 / 20-20$ tests at $10 \mathrm{psi}$ (69.0 kN/sq. m) applied normal pressure. The curves are shaped nearly identically, except that the longer 6" by 12 " $(.2 \mathrm{~m}$ by $.3 \mathrm{~m})$ sample test reaches a higher earth pressure. For all tests with the earth pressure cell placed in the vertical nosition against the front face of the test box, the pressure was essentially zero before the pullout test began. For the Fortrac grid $35 / 20-20$, the final value of the ratio of horizontal to vertical stress reached 0.7 . For the Tenax grids, the final ratio of horizontal to vertical stresses reached 0.35. Based on the applied normal pressures and the maximum pullout loads, a final horizontal to vertical stress ratio of approximately 1.0 was estimated for the Bay Mills geogrids 28501 and 28502 .

The earth pressure cell data versus front displacement graph for the Tenax grid \#401 with a normal pressure application of $10 \mathrm{psi}(69.0 \mathrm{kN} / \mathrm{sq} . \mathrm{m})$ shows a strong anomaly in the earth pressure cell data. This was speculated to be caused by the front transverse $r i b$ of the test sample 
passing out of the test box.

As the pullout test progresses, a wedge of higher stresses develop from the geogrid to the front face of the test box. This has also been shown to occur in the numerical model of the geogrid pullout test.

The numerical model, introduced in Chapter III, has also shown that shear stresses are highest at the rear of the geogrid sample. This accounts for the failure of the joints at the rear of the Fortrac $35 / 20-20 \mathrm{grid}$ specimens. It is expected that longer embedment lengths will minimize the possibility of joint failure in the soil.

The results of a relaxation test are shown in Appendix $\mathrm{J}$ with a $10 \mathrm{psi}(69.0 \mathrm{kN} / \mathrm{sq}$. m) normal pressure applied. The sample was loaded to $1207 \mathrm{lbs} / \mathrm{ft}(17.6 \mathrm{kN} / \mathrm{m})$ and allowed to stand for 48 hours. The load decayed to $919 \mathrm{lbs} / \mathrm{ft}$ $(13.4 \mathrm{kN} / \mathrm{m})$, a $23.9 \%$ decrease. The front of the geogrid moved 0.06 inches $(1.5 \mathrm{~mm})$ forward, while the rear of the grid did not move after the initial load was applied. All movement was from material straining. Uniform deformations in the transverse ribs were observed throughout the geogrid.

Earth pressure cell data showed a slight rise in pressure against the front face of the box after the initial load application. The pressure on the face of the box decayed slightly as the test progressed further. 


\section{SUMMARY OF GEOGRID PERFORMANCE}

A geogrid pullout test box was constructed and instrumented to collect displacement, load, and earth pressure data electronically. A series of 33 tests were performed on 6 different geogrid types at 3 different normal pressures.

Friction angles for the geogrid to soil interaction range from 29 degrees to 48 degrees. The equivalent modulus of the geogrid to soil interaction appears to depend on the geogrid type and the applied normal pressure.

Data from these tests have proven to be repeatable and support numerical work completed in this thesis. Based on the equation,

$$
a=\frac{\tan \delta^{\prime}}{\tan \Phi^{\prime}}
$$

the coefficient of interaction was determined to range from a low of .71 for the Tenax geogrids, to a high of 1.43 for the Bay Mills geogrids.

Damage to the geogrid samples was limited. The Fortrac geogrid samples experienced failures at the geogrid joints. The Bay Mills samples experienced minor deformations and failure within the clamping mechanism. This was not a problem with the geogrid. The Tenax samples did not show any damage due to pullout. The failure mechanism is shown in Figure 1 to be a passive failure of the soil. The maximum 
pullout load is a function of the soil type, the transverse rib height and the surface texture of the geogrid. Although the failure mechanism is not simple, it can be modelled as a shear failure between the geogrid and the soil. This is not an accurate representation of what really happens, however, it is an accurate representation of the geogrid's behavior on a global scale. 
CHAPTER I I I

\section{NUMERICAL EXPERIMENTS}

\section{INPUT MODEL SELECTION}

Geogrids have been model led in several ways. There are different assumptions for each method of modelling geogrids. Geogrids may be modelled as linear elastic bar elements, as elastic/plastic bar elements, or as bar elements with interface elements (Humphrey, 1986). Interface elements have been used by several researchers (Humphrey, 1986, and Hird et al. 1991). Elastic and elastic/plastic bar elements have also been used by several researchers (Humphrey, 1986, and Franks et al. 1988). A model similar to the model developed in this thesis was used, (Franks et al. 1988), to model reinforcement as bar elements in a dike. This model was developed in CON2D. This study was able to accurately model soil behavior, however, it did not attempt to model collapse.

Physical model tests (Andrawes and McGown, 1985) on plane strain dam models have shown that displacements reduce in the core of the dam and increase at the toe of the dam when the layered construction sequence is 
considered, as compared to a dam construction without a layered sequence. These tests were conducted in a $1 \mathrm{ft}$. $(.3 \mathrm{~m})$ wide test box with a $3.0 \mathrm{ft} .(.9 \mathrm{~m})$ high embankment. The foundation material was $1 \mathrm{ft} .(.3 \mathrm{~m})$ deep and $12.5 \mathrm{ft}$. $(3.8 \mathrm{~m})$ wide. The embankment was $6.6 \mathrm{ft} .(2.0 \mathrm{~m})$ wide and had 30 degree side slopes. Results of these tests were collected using photographic measurements, $x$-ray techniques, and stereo-photogrammetric techniques. These methods yielded very accurate displacement results. The corrected displacement results from this study did not match the displacement results for the dam model in this thesis because the displacement due to construction was modelled (Andrawes and McGown, 1985) while collapse was modelled in this thesis.

A numerical plane strain pullout simulation was developed to model the pullout of a geogrid from a soil box. The geogrid is modeled as one foot $(.3 \mathrm{~m})$ long and of unit, (one foot, .3 m), width. The geogrid is positioned 3.5 inches $(.1 \mathrm{~m})$ from the bottom of a 12 inch $(.3 \mathrm{~m})$ by 15 inch $(.4 \mathrm{~m})$ soil box. One foot $(.3 \mathrm{~m})$ of the geogrid is embedded within the soil.

The geogrid pullout test model and the collapsing earth embankment dam model were produced, and run, using two programs on a Sun computer system operating under Unix Operating System. The system was a Sparc station witha 375 megabyte hard drive. Execution times for the pullout 
model were approximately thirty minutes. Execution times for the collapsing dam model were approximately an hour and a half. The two programs were: PATRAN which is a graphical pre-processor and post-processor program used to produce the input models, and ABAQUS which is a general purpose finite element program with geomechanics features employed to calculate stresses, strains and displacements under geogrid pullout. PATRAN may also be used to graphically display the output displacements and stresses from ABAQUS by the use of a translator program. These two programs were chosen because they are compatible with each other, and have the ability to model geomechanics with interface capabilities.

\section{INPUT DATA SUMMARY}

Several element definitions were used to model the soil, geogrid, and slide 1 ine interface. For the soil, 143 quadrilateral elements were used and is defined by four nodes. Stresses and strains are linearly interpolated across the element. These elements model a solid section of unit thickness, the complete Finite Element Model, (FEM), mesh is shown in Figure 8 .

For the geogrid, thirteen two-node bar elements were employed. This is a two-dimensional bar element of unit thickness and is defined by two nodes. Stresses and strains are determined by linear interpolation. Twelve 


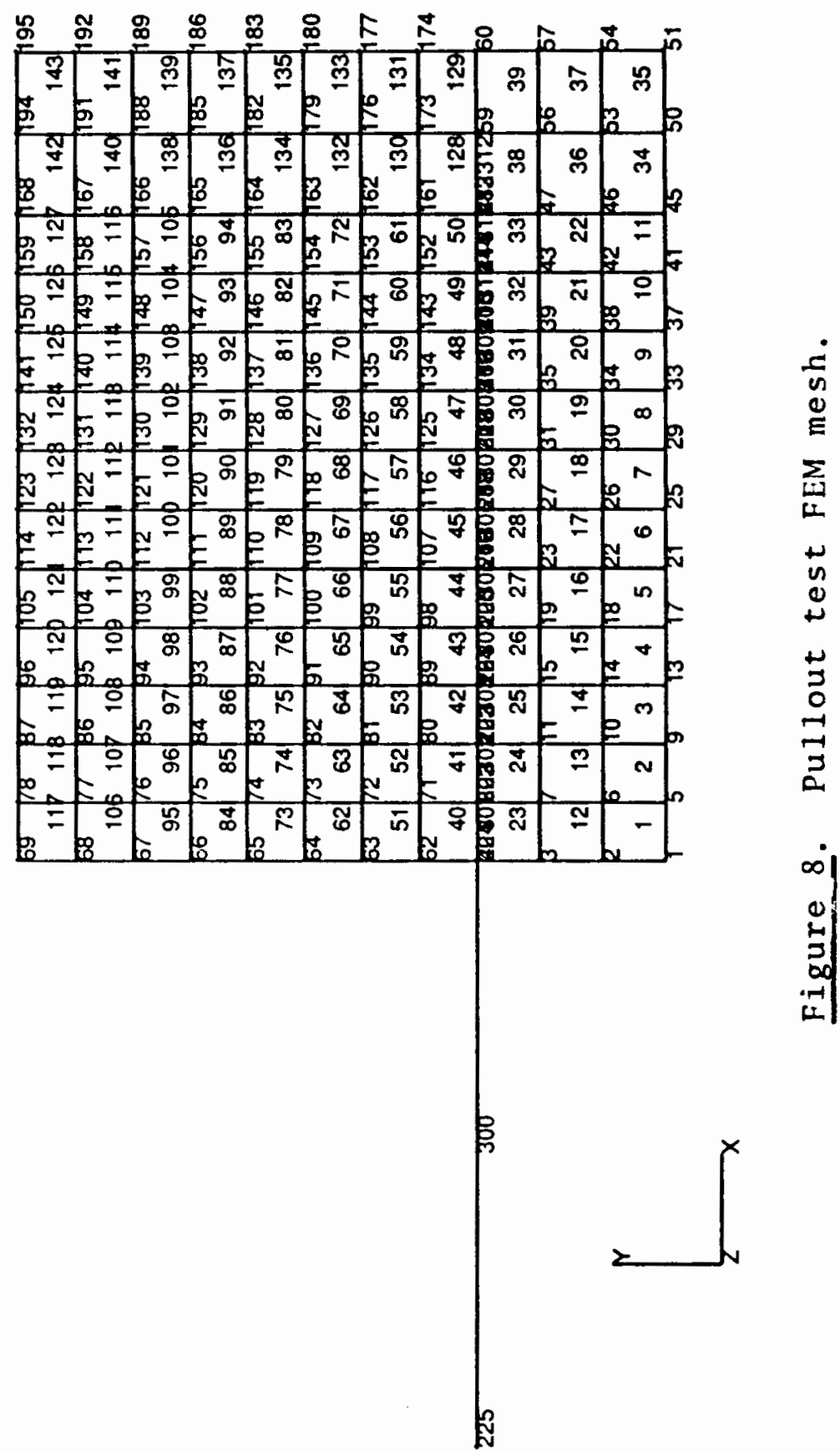


were embedded within the soil and one was defined outside of the soil model. Slide line elements were used to model the sliding interface between the geogrid and the soil. These elements were defined by the same nodes as the geogrid bar elements. This was the only practical way that a geogrid could be modelled in ABAQUS in a two dimensional model. The preceding group of 24 slide line elements were defined as interface elements of unit thickness, width, or cross-sectional area. These elements were modelled between the twelve bar elements and the soil elements.

The frictional characteristics of the interface were defined by three parameters. The first parameter was the friction coefficient, $\bar{\mu}$, ranging from zero to infinity. A value of .37 was assumed to closely model the soil and geogrid interaction. The second parameter is the stiffness in stick, Ks, (G). 10,000 pounds per square foot was assumed for this model. The final parameter is the equivalent shear stress limit, $\bar{\tau}$. This may be calculated from the equation,

$$
\bar{\tau}=\sqrt{\tau_{1}^{2}+\tau_{2}^{2}}
$$

where $\tau_{1}$ and $\tau_{2}$ are shear stress components. Figure 9 represents the use of these parameters in the interface element constitutive model. A value of 800 pounds per square foot was assumed to closely model the physical test soil used. 


\section{INTERFACE PARAMETERS}

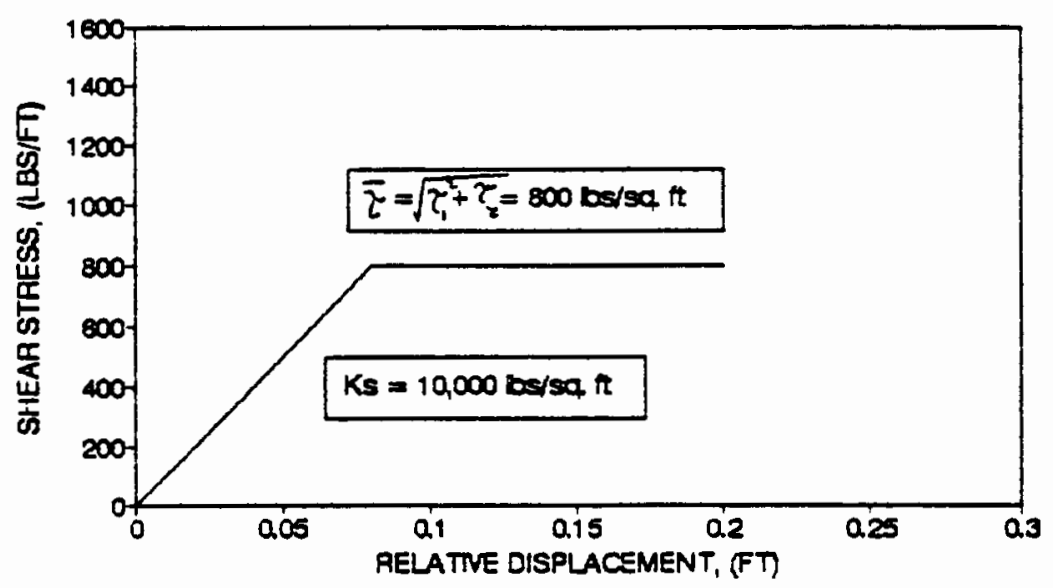

Figure 9. Interface parameters. 
A slide line was defined along which the interface elements will allow sliding to occur. For the slide line along the top of the geogrid, the slide line is defined by the soil nodes just above the geogrid nodes, but at the same coordinates. For the slide line below the geogrid, the slide line is defined by the soil nodes below the geogrid nodes and at the same coordinates. The slide line was made up of linear segments because first order elements made up the soil model. When second order elements make up the model, the slide line may be made up of parabolic segments. Nodes were defined in sets. 220 nodes were used. The soil and geogrid elements were defined as material names and properties in element sets.

The geogrid bar elements were modeled as having an elastic/plastic stress-strain relationship. Two parameters were used to define these properties; a Young's Modulus, E, of $32,500 \mathrm{lbs} / \mathrm{ft} . / \mathrm{ft} .(1556.2 \mathrm{kN} / \mathrm{m} / \mathrm{m})$ and a Poisson's Ratio, $\downarrow$, of .45 were selected from manufacturer's data. The plastic yielding of the geogrid was defined by two parameters, stress and strain. Stress was specified as plastic strain increased.

The pullout of the geogrid was done in steps. Each step was subdivided as needed, by the computer into several increments. The default value was 10 . Fifty was specified. The maximum number of iterations in an increment was specified as 25. The default value is six. 
Numerical subdivision was suppressed, except when convergence was not achieved in the maximum number of allowable iterations. These changes were made because the model was both nonlinear, and an interface problem. Body force loads were applied over the first step.

During the non-linear pullout of the geogrid, the solution at the siart of each increment was extrapolated to begin the nonlinear equation solution for the next increment. A distributed load was used to create the load applied by the soil weight throughout the soil elements. A property identification was specified, and given a body force loading. The unit weight was the final parameter used to specify the distributed load. A value of $99 \mathrm{lbs} / \mathrm{cu}$. ft. $(15.6 \mathrm{kN} / \mathrm{cu}$. m) was used based on the density sand used for the actual mechanical pullout tests.

The boundary conditions for the soil model used to $f i x$ the soil nodes in the $x$ or $y$ direction were set to simulate a rigid box. The nodes at the "front" and "rear" of the box were fixed in the $x$ direction, while the nodes along the bottom of the test box were fixed in the $y$ direction. This model is shown in Figure 8.

The boundary conditions were modified in the steps following the first step. By specifying a node, direction, and displacement, ABAQUS "pulled" the geogrid out, by moving the specified node on the end of the bar element in the specified direction by the specified displacement. 
In the displacement steps, an additional non-linear geometry specification was made to aid in convergence of the model solution.

A tolerance of 1 was used in the first step as the body forces were applied. The tolerance was increased to 100 due to the difficulty in reaching a convergent solution in the second step. This was the tolerance allowed in the stress values for convergence to occur. Normal stresses were applied as overburden pressures across the top row of soil elements.

When defining the slide line, a node was defined outside of the mesh to define where the geogrid is sliding to. When defining the geogrid, it was necessary to connect the interior end of the geogrid to the soil elements. This was done because two distinct models cannot be modeled together. The final element, number 312 , of the geogrid was modeled with a very low modulus of elasticity and a low Poisson's Ratio so that its strength did not significantly affect the results of the pullout test.

\section{OUTPUT DATA SUMMARY}

A total of four models were simulated. The first model used an elastic soil and an elastic geogrid. The second model used an elastic soil and an elastic/plastic geogrid. A Young's Modulus of $400,000 \mathrm{lbs} / \mathrm{sq}$. $\mathrm{ft}$. ( $19152 \mathrm{kN} / \mathrm{sq} . \mathrm{m})$ and a Poisson's Ratio of .33 were used for 
these elastic soil models. The third model consisted of a Von Mises (elastic/plastic) soil, and an elastic/plastic geogrid. The fourth and $f$ inal model used a Drucker-Prager soil model and an elastic/plastic geogrid model. These models were simulated with no applied overburden pressures, except for that due to the soil in the test box above the geogrid. More complete numerical and constitutive descriptions of these models follow.

\section{Mode 1}

The first model used an elastic soil and an elastic geogrid model. Plots for the first principal stresses showed that the highest soil stresses occur as a wedge at the front of the geogrid. Maximum soil displacements occur at the front and above the geogrid.

Stress versus strain plots for elements 301, 305, and 311 act elasticly. Load versus displacement graphs show that the loads and displacements are low in element 301 , higher in element 305 , and approach infinity in element 311. This model appeared to "lock" and was unable to run to completion due to its elastic properties. Displacement contour plots and first principal stress plots are shown in Appendix $K$ with load versus displacement graphs and load versus strain graphs. A plot of the front displacement versus pullout load is shown in Figure 10. 


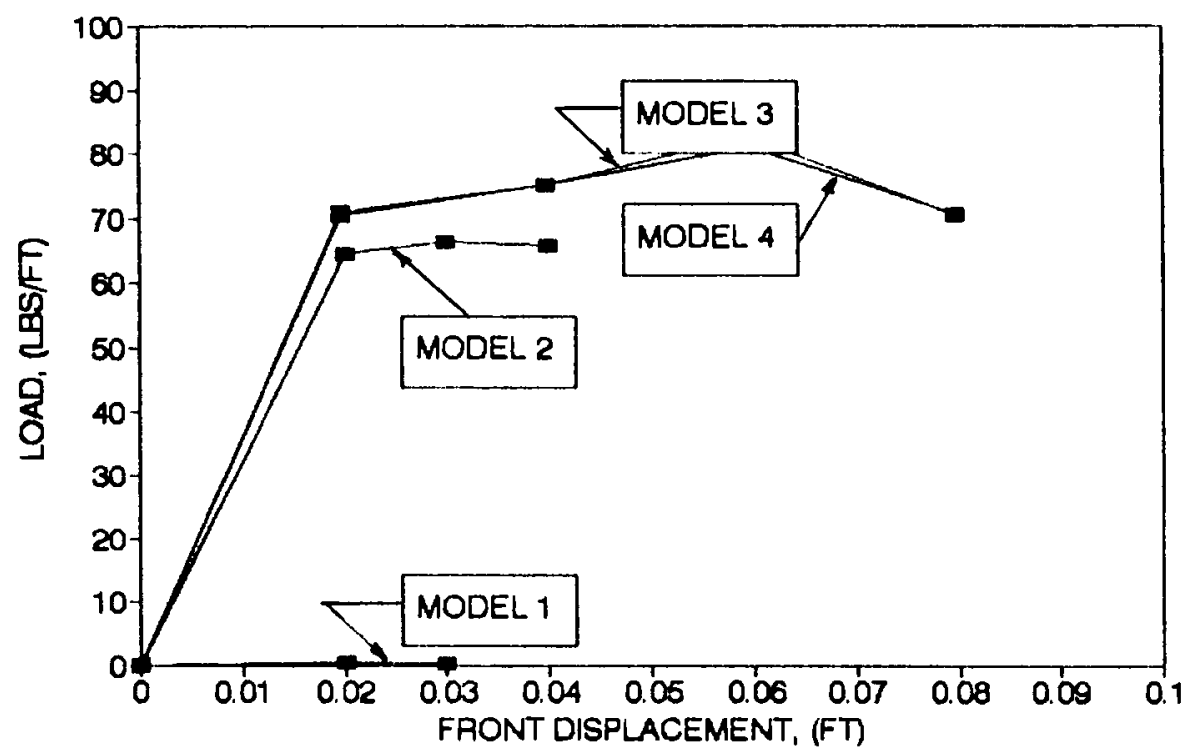

Figure 10. Pullout model output. 
$\underline{\text { Model }} \underline{2}$

The second model consists of an elastic soil and an elastic/plastic geogrid. The shear stress plots show that the highest shear stresses occurred at the end of the interior end of the geogrid in the soil. Maximum displacements occurred above the interior end of the geogrid and increase along the geogrid as pullout occurs.

Stress versus strain graphs for elements 301, 305, and 311 show the elements remain within the elastic portion of their properties.

Load versus displacement graphs show that the maximum stress (load) is $66.5 \mathrm{lbs} .(295.8 \mathrm{~N})$ in element 301 and decreases as displacement increases. The shape of these curves is the same for all elements along the geogrid, but the magnitude of the stresses decrease.

ABAQUS had difficulty converging during the final step and was unable to run to completion. The initial stresses, strains, and displacements are very reasonable. Displacement contours, first principal stress contours, load versus displacement, and load versus strain graphs for this model are shown in Appendix L. A plot of front displacement versus pullout load is shown in Figure 10.

Model $\underline{3}$

The third model uses a Von Mises (elastic/plastic) soil and an elastic/plastic geogrid. Maximum shear 
stresses in the soil were concentrated behind the interior end of the geogrid. Maximum total soil displacements occur above the interior end of the geogrid and also increase along the geogrid. Stress versus strain plots along the geogrid show the geogrid elements remain in their elastic region.

Load versus displacement graphs for elements 301,305 , and 311 show a leveling off of stress, then an increase in stress before finally decreasing as displacement increases. This may be due to the loose tolerance on the load, however, using a tighter tolerance on the load results in ABAQUS being unable to reach a convergent solution.

A Young's Modulus value of $400,000 \mathrm{lbs} / \mathrm{sq}$. f $\mathrm{t}$. $(19,152 \mathrm{kN} / \mathrm{sq}$. m) was used for this soil model and a Poisson's Ratio of .33 was used with a value of 0.0 for the plastic strain. Output from this model is shown in Appendix M. A plot of front displacement versus pullout load is shown in Figure 10.

\section{Model 4}

The final model was the Drucker-Prager model. This soil model is used to simulate a sand or granular soil. This is the model that was finally expanded for use in the dam model. The Drucker-Prager soil properties were defined by the following parameters. A value of 40 degrees was used for the material friction angle, $\beta$. The ratio of flow 
stresses in triaxial tension to flow stresses in triaxial compression, $K$, was specified as .7695 , and the dilation angle, $\psi$, in the p-t plane was specified as 0 degrees. These parameters were calculated to closely represent the soil under consideration by Mr. Robert Slyh.

Maximum shear stresses for this model were behind the interior end of the geogrid and also are higher along the edge of the geogrid. Maximum displacements were above the interior end of the geogrid and were also high along the geogrid and in the vicinity of the interior end of the geogrid.

Stress versus strain plots for this mesh showed that the elements remain in their elastic region and the load versus displacement graphs show a leveling off of the stress, then an increase to $82.9 \mathrm{lbs} .(368.7 \mathrm{~N})$, before decreasing as displacement increases. Plots for elements 305 and 311 were identical to the plots for element 301 , except that the magnitudes of the loads and displacements were less. Total displacement contours, first principal stress contours, load versus displacement graphs, and load versus strain graphs are shown in Appendix $N$. The input data file for this model is shown in Appendix 0 . A plot of front displacement versus load is shown in Figure 10 .

By adjusting the frictional coefficient, this model was changed to match mechanical pullout test results at $2 \mathrm{psi}(13.8 \mathrm{kN} / \mathrm{sq} \cdot \mathrm{m}), 5 \mathrm{psi}(34.5 \mathrm{kN} / \mathrm{sq} \cdot \mathrm{m})$, and $10 \mathrm{psi}$ 
(69.0 kN/sq. m) normal stress applications. The results of these computer models matched the results of the mechanical pullout tests to within $10 \%$ of the actual pullout loads. The results of these models are shown in Appendix $P$.

Shear values on the interface varied from approximately $15 \mathrm{lbs} / \mathrm{sq}$. ft. to $34 \mathrm{lbs} / \mathrm{sq}$. ft. $(718.2 \mathrm{~N} / \mathrm{sq}$. m to $1627.9 \mathrm{kN} / \mathrm{sq}$. m), with the lesser values at the front of the geogrid. Accepting the Mohr-Coulomb relationship, $\tau=c+$ otan $\phi$, peak shear at failure is calculated to be,

$$
\begin{aligned}
\tau & =c+\sigma \tan \phi \\
\tau & =0+85(.4) \\
\tau & =34 \mathrm{lbs} / \mathrm{sq} \cdot \mathrm{ft} \cdot(1.6 \mathrm{kN} / \mathrm{sq} \cdot \mathrm{m})
\end{aligned}
$$

Where the normal stress, $\sigma$, is equal to the overburden, $85 \mathrm{lbs} / \mathrm{s}_{1} . \mathrm{ft} .(4.1 \mathrm{kN} / \mathrm{sq} . \mathrm{m})$. This agrees well with the maximum values along the geogrid.

The lesser values of shear occur at the front of the geogrid because of the boundary effects of the rigid front face of the box model. Compressive stresses within the soil in this area are also increased due to the rigid boundary effects. This agrees very well with the results of another researcher (Johnston, 1985). Johnston concluded that as the geogrid was pulled out, the soil arched over the front of the geogrid. This reduced the normal stresses on the geogrid. The final result was a lower pullout resistance with a rigid face than with a flexible face. 
Additional studies (Hornbeck, 1982) found that using a flexible face resulted in lower pullout resistances than the rigid face. These results appear to be inconsistent, however, numerical results obtained in this study strongly support Johnston's findings. It has not been possible to accurately evaluate this phenomenon by conventional techniques such as the Mohr-Coulomb limit equilibrium approach. 


\section{CHAPTER IV}

\section{GEOGRID/SOIL INTERACTION MODELLING}

\section{CONSTITUTIVE ASSUMPTIONS FOR GEOGRIDS}

There are several ways to model reinforcement within a soil mass and each has a different set of assumptions associated with it. Reinforcement may be modelled as a linear elastic bar element, it may be modelled as an elastic/plastic bar element, or it may be modelled with interface elements to represent the shearing interface between the soil and the reinforcement (Humphrey, 1986). Interface elements have been used in other studies of reinforced earth embankments also (Hird et al. 1991). Bar elements were also used as reinforcement in a dike (Franks et al. 1988). This model was developed in CON2D and was able to accurately model soil behavior, however, it did not model collapse.

The important assumption associated with the use of a linear elastic element is that the typical working stresses in the reinforcement are less than the material's yield strength. If the working stresses are expected to be higher than the yield strength, an elastic/plastic bar element may be used to model the reinforcement. The use of 
interface elements to model the shearing stresses between the reinforcement and the soil assumes that slip occurs. The soil/geogrid friction angles are typically higher than the soil friction angle. Therefore, shear failure within the soil will likely occur before any relative movement or shear failure between the geogrid and soil occurs. It may then be assumed that there is no slip of the geogrid relative to the soil and the linear elastic or the elastic/plastic model may be used to adequately represent the reinforcement. Bar elements will carry any tensional stresses within the soil model. Theses elements may carry tensional stresses only and have a small flexural stiffness. Soil elements should be defined to carry compressional stresses only.

Another technique for modelling reinforcement within a soil involves changing the soil properties so that the soil can carry tension stresses and will therefore behave as if it contains reinforcement.

\section{IMPLEMENTATION}

Although the friction angles for different types of geogrids vary for a given soil type, direct shear tests on the test soil will give a good estimate of the frictional characteristics of a geogrid loaded in the soil. The maximum pullout load for any given geogrid appears to be a function of the normal stress, the soil type, the surface 
texture of the geogrid, the height of the ribs transverse to the direction of loading, and the number of ribs transverse to the direction of loading. The variation of soil to geogrid bond stress will directly arfect the maximum pullout load and the interaction coefficient, as given in equation 1 .

Data from the direct shear tests on the test soil may be used to numerically estimate how a geogrid will behave in a physical pullout test. This data will be an estimate. because an increase in the number of transverse $r i b s$ or an increase in the thickness of the transverse ribs will also increase the pullout resistance.

Modulus values from physical pullout tests model the interaction of the geogrid with the soil. These values are calculated from the load versus displacement curves for each geogrid sample under various normal stresses. Because these values represent the actual interaction of the geogrid and the soil, these are the "equivalent modulus" values that should be used when modelling reinforcement in a soil structure.

\section{RESULTS}

The final computer model of a geogrid pullout test used in this investigation used elastic/plastic bar elements to model the geogrid and interface elements to allow slip to occur as the geogrid was pulled out. For this 
model, modulus and stress/strain data were taken from manufacturer's data.

A dam and foundation model was developed to model collapse with temperature dependent nodes. The model contained 354 soil elements and 405 geogrid elements in the dam and foundation. The FEM mesh is given in Figure 11. The FEM mesh with body force initial stresses from PATRAN is given in Figure 12. It was assumed that no relative slip would occur between the geogrid and the soil. Therefore, no interface elements were used. An elastic/plastic bar element was used to represent the geogrid. A Von Mises (elastic/plastic) soil model was used to represent the dam and foundation. The soil modulus was lowered by an order of magnitude as the temperature dependent nodes were subjected to a temperature change. The model was a two dimensional model.

ABAQUS was unable to model the soil elements without a tensile capacity, therefore, an excessively high modulus was given to the bar elements. This allowed the tensile stresses to be carried by the bar elements, while minimal tensile stresses were induced in the soil elements. The Drucker-Prager soil model will model soil without a tensile capacity, however it cannot function with temperature dependent nodes, which were used to simulate soil collapse.

To accurately model geogrids in an earth embankment dam and foundation, an elastic/plastic bar element should 


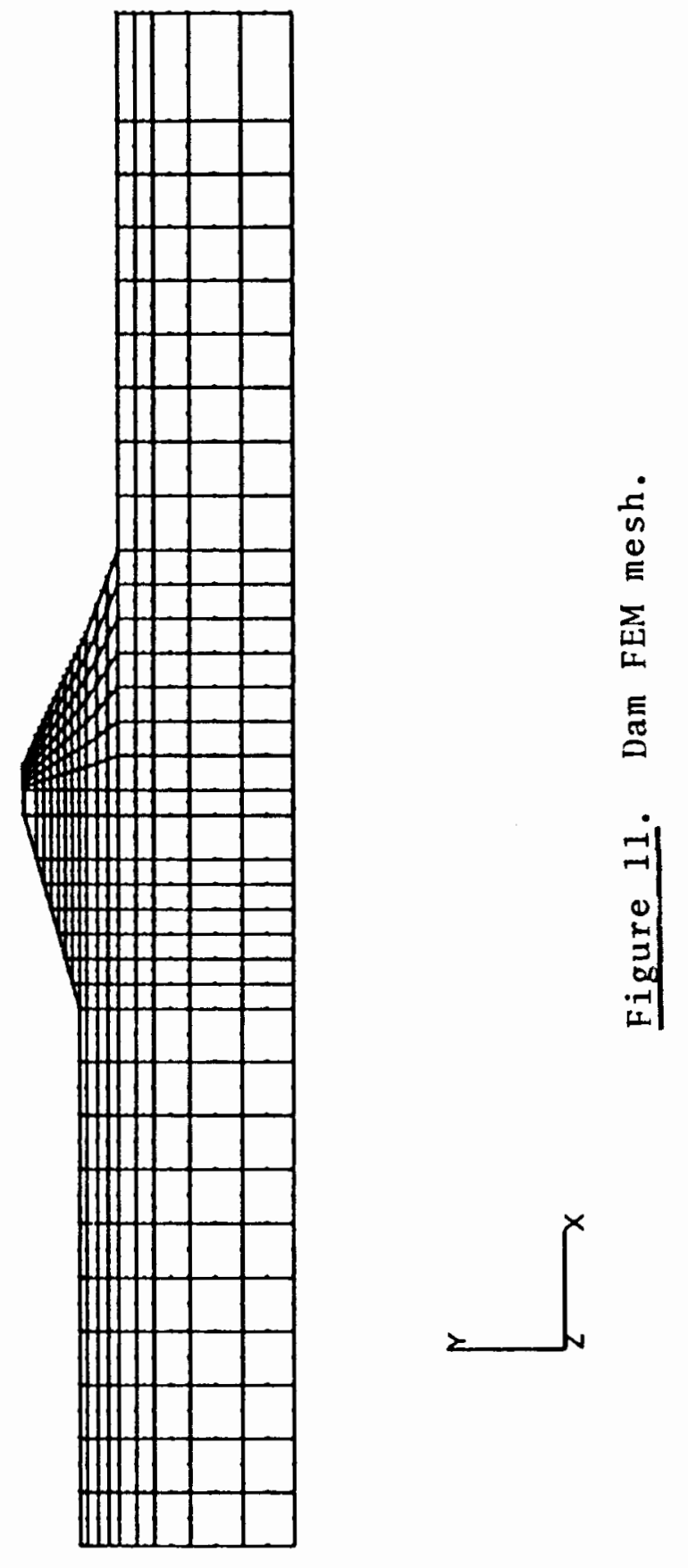




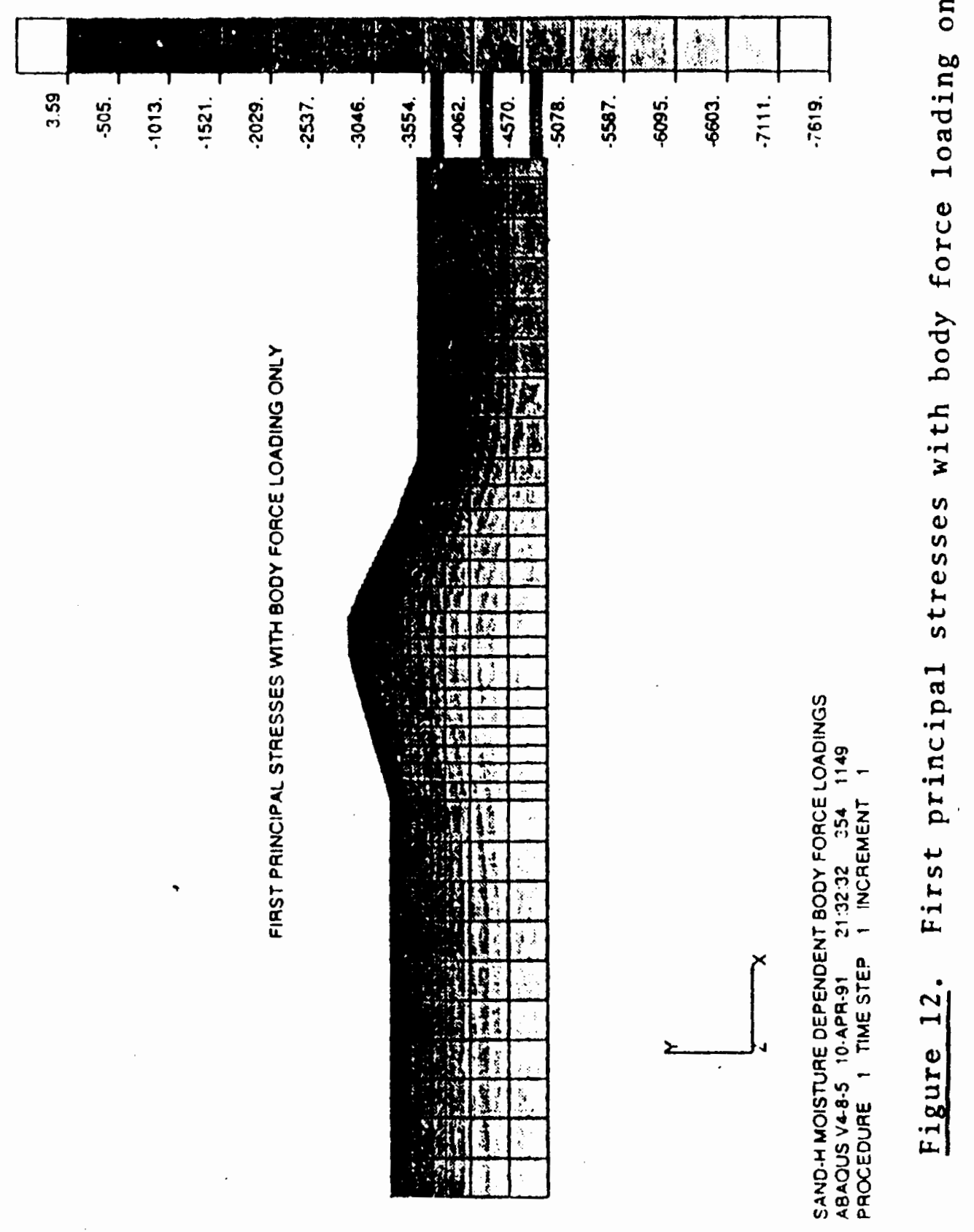


be used with equivalent modulus values obtained from physical pullout tests. Stress/strain data may be obtained from wide width tensile tests. It is also necessary to specify the soil elements as no tension elements. ABAQUS was unable to do this. Thus, the soil properties were equal in compression and tension. Since the soil was stiffer in compression, (and hence, tension), than the true geogrid stiffness, the portion of tensile stresses carried by the bar elements was relatively small. The tensile stresses in the soil were reduced by approximately $5 \%$ to $25 \%$. Contours of horizontal stresses and total displacements are shown in Figures 13 and 14 for a collapsed model with no reinforcement. Cracks were not modelled, however, tensile stresses did develop in the upstream and downstream slopes of the structure. This is where the most severe longitudinal cracks have appeared in the structures built on collapsible soils. Contours of horizontal stresses and total displacements are shown in Figures 15 and 16 for a collapsed model with geogrid reinforcement. The modulus value used for the geogrid was $32,500 \mathrm{lbs} / \mathrm{ft} . / \mathrm{ft} .(1556.1 \mathrm{kN} / \mathrm{m} / \mathrm{m})$, which is not excessively stiff. This is why the maximum tensile stress decreased by only $2.2 \%$. Total displacements remained nearly unchanged. 


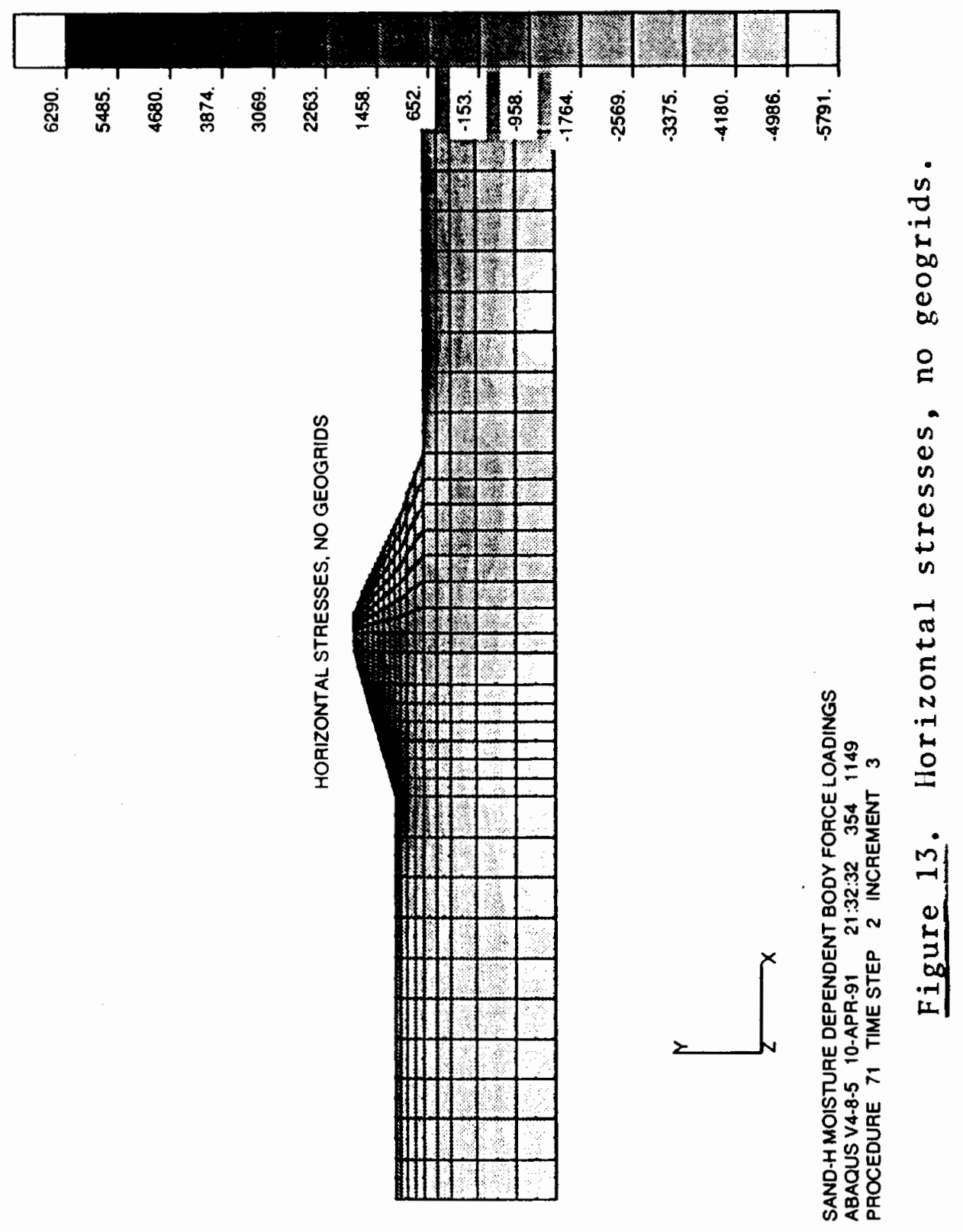




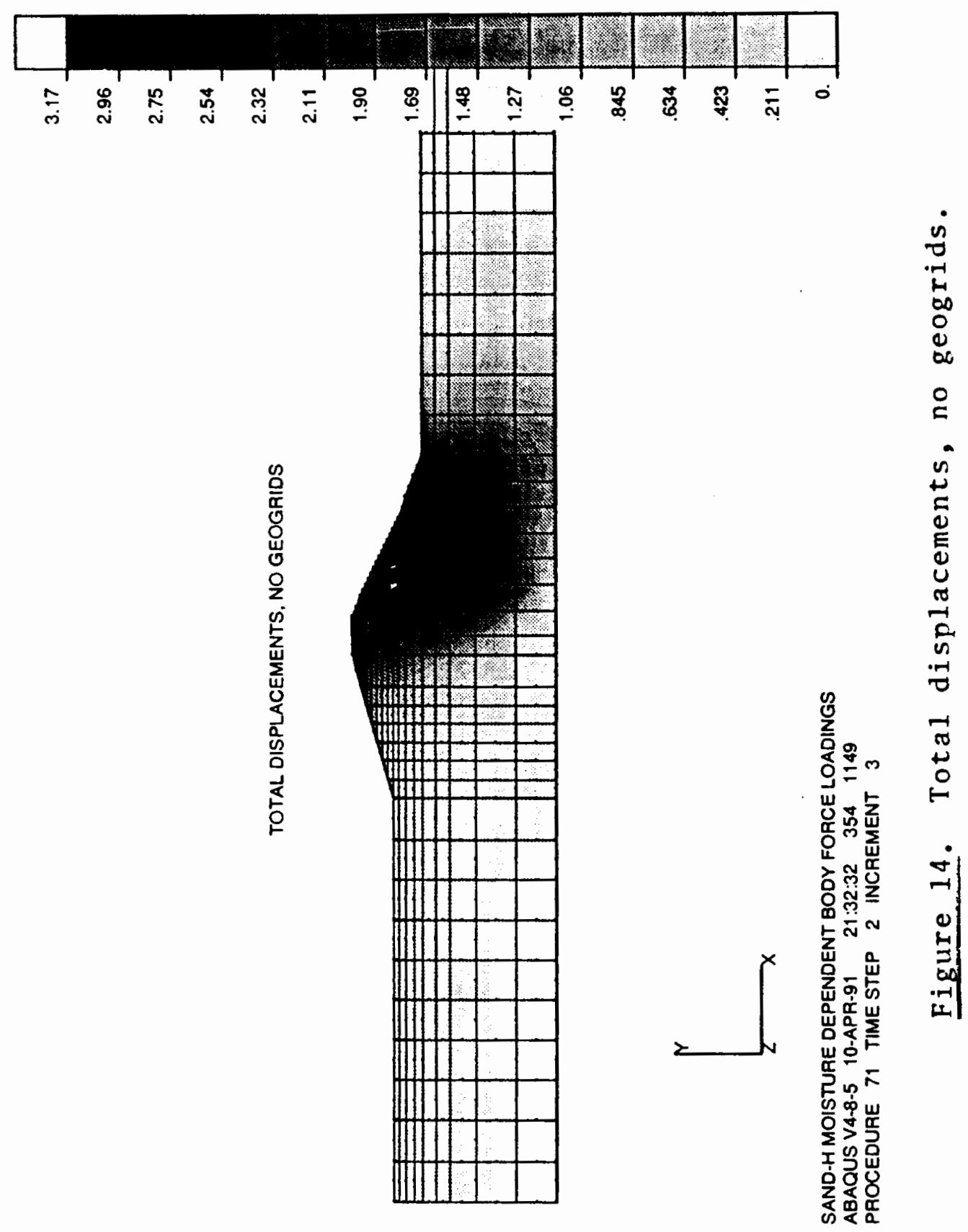




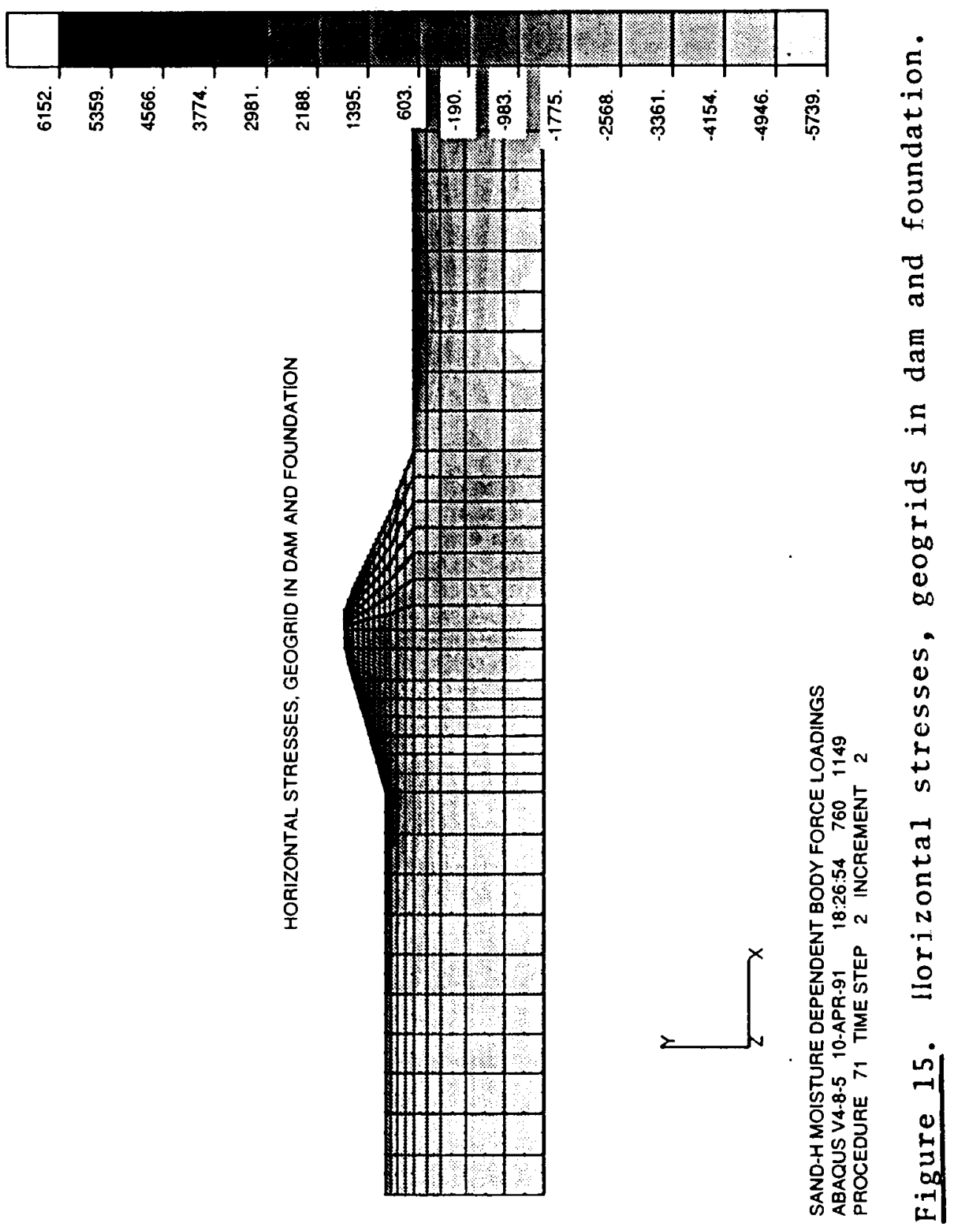




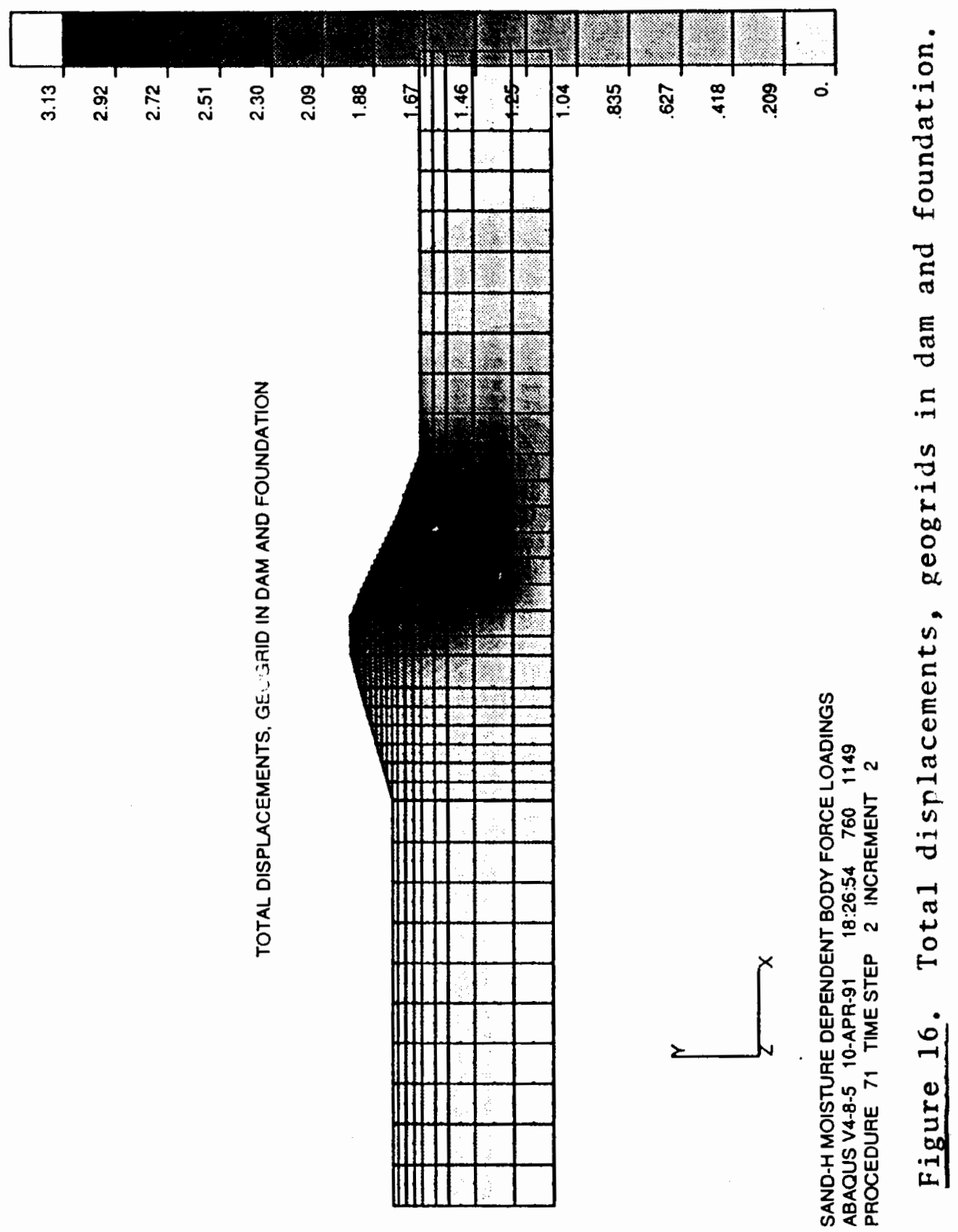




\section{CHAPTER V}

\section{OTHER REMEDIAL OPTIONS}

At the present time, the application of geogrids is the only remedial measure which has been numerically modelled as a possible solution to the cracking and collapse problem in earth embankment dams. There are, however, several other possible alternatives which are presented here. It is important to discuss these options because several are simpler and less expensive than the use of geogrids, and may be as effective, or more effective, at preventing or reducing collapse and cracking damage. In addition, the likely success of any procedure may be enhanced when used in combination with another technique.

\section{GEOMATRIX}

One possible option is the use of Geomatrix. This is a three-dimensional web material produced from a non-woven, polyester fabric. It is currently used for earth and slope reinforcement, as well as for erosion control (Jagielski, 1991). This material may be placed in the dam or foundation and will likely behave similar to a geogrid. The "honeycomb" shape of the Geomatrix material contains the soil material. This may be modelled numerically in a 
manner similar to the modelling of geogrids.

\section{SOIL GROUTING}

Grouting is another option that may be used to stabilize the area. This will reduce settlements and therefore reduce cracking. Grouting is defined as "the injection of pumpable materials into a soil or rock formation to change the physical characteristics of the formation," (GKN Hayward Baker, 1986). There are four basic types of grouting: slurry grouting, compaction grouting, chemical grouting, and jet grouting.

Slurry grouting is "the intrusion under pressure of flowable particulate grouts into open cracks, voids, and expanded fractures," (GKN Hayward Baker, 1986). The grout used consists of cement, bentonite clay, sand, and water. Slurry grouting has been used successfully to treat rock foundations for dams (GKN Hayward Baker, 1986).

Chemical grouting may be used for structural strength or water control. Structural chemical grouting is "the permeation of sands with fluid grouts to produce sandstonelike masses to carry loads," (GKN Hayward Baker, 1986). Water control chemical grouting is "the permeation of sands with fluid grouts to completely fill voids to stop water flow," (GKN Hayward Baker, 1986). Sodium silicates, acrylates, and polyurethanes are used as chemical grouts. Both structural and water control chemical grouting 
are possible solutions to the collapse problem of earth embankment dams. Recent work under contract at Brigham Young University (Rollins and Rogers, 1990) has produced excellent results with collapsible soil settlement reduction by using a $2 \%$ sodium silicate mixture. Sodium silicate combines with the salts in the soil to form a gel. This gel will cure in approximately one month. The cost of sodium silicate is approximately $\$ 90$ per 55 gallon (208 liter) drum.

Compaction grouting is "the injection under high pressures of a very stiff, 'zero slump' mortar grout to displace and compact soils in place," (GKN Hayward Baker, 1986). The grout is a silty sand, cement, water mixture and it is placed with $1000 \mathrm{psi}(6895 \mathrm{kN} / \mathrm{sq}$. m) forced feed piston pumps. Compaction grouting is used primarily to control settlements.

Jet grouting is a variation of the grouting methods discussed previously. Jet grouting is "the use of high pressure liquid jets to make geometric cuts is soils, removing or mixing the soil with a grout that occupies the resulting shape. The jet material can be either water or grout," (GKN Hayward Baker, 1986). Cement slurry, cement/sand mortars or chemical grouts may be used. Jet grouting may be used in the construction of cut-off walls. Grouting techniques may be easily modelled numerically by increasing the stiffness characteristics of the soil to 
the stiffness of the grouted soil.

\section{ENERGY INPUT TECHNOLOGIES}

Dynamic compaction is the dropping of 10 ton to 50 ton (89.0 to $444.8 \mathrm{kN}$ ) weights from heights of 50 feet to 150 feet $(15.2 \mathrm{~m}$ to $45.7 \mathrm{~m})$ in a pattern of from 7 feet by 7 feet $(2.1 \mathrm{~m}$ by $2.1 \mathrm{~m})$ to 25 feet by 25 feet $(7.6 \mathrm{~m}$ by $7.6 \mathrm{~m})$. This method of compaction works well in silty sands and excellent in sands.

Excellent results were also reported (Rollins and Rogers, 1990) when employing dynamic compaction on collapsible soils. It was found that displacement becomes insignificant after dropping a four ton $(35.6 \mathrm{kN})$ weight seven times from 80 feet $(24.4 \mathrm{~m})$. Collapse settlement also becomes very small.

Vibro-compaction is "the rearrangement of particles into a denser configuration by the use of powerful depth vibrators," (GKN Hayward Baker, 1986). Vibro-compaction is used to reduce foundation settlements.

Vibro-replacement may be used to place stone columns. A hole is predrilled through the zone where settlement will occur and into a lower stable zone. The stone column is then formed by vibrating and feeding the material to the bottom of the borehole. Replacement and compaction repairs may be easily modelled using numerical techniques by changing the constitutive soil parameters to an appropri- 
ately stiffer state.

Soil nailing is a new procedure which has recently been used to stabilize embankments. The procedure involves firing $9.8 \mathrm{ft}$. ( $3 \mathrm{~m})$ long nails into the soil at $620 \mathrm{mi} . / \mathrm{hr}(1000 \mathrm{~km} / \mathrm{hr})$. Ryan International holds the rights to this machine ("Nailed Up", 1990). This procedure has recently been used successfully to stabilize a soft embankment in the United Kingdom near a British Rail line. Soil nailing may be modelled numerically as reinforcement, similar to the method used to model geogrids. Sumitomo Electric Industries of Japan has developed a rubber inflatable dam. These dams have been used for flood control, irrigation, and tidal control. The construction of the dam with synthetic chloroprene rubber has resulted in a durable product that is resistant to the atmosphere, and abrasion. The dams are inflated with air or water. They rest on and are anchored to a concrete base slab (Sumitomo Electric Industries, 1990). Their best application may be as a temporary measure during dam reconstruction. Inflatable rubber dams are flexible and have been proven to operate without problems. Differential settlement due to collapse would not likely be a problem, because this option would likely only be employed for a relatively short period of time while the dam is under construction. Therefore, it would not be necessary to model this option numerically. 
These options may be feasible, however, they are likely cost prohibitive, given the size of SCS's dams. The remaining options appear to be simpler and less expensive than those presented thus far.

\section{OTHER GEO-PRODUCTS}

The use of geomembranes has been examined by Susanne Leckband of SCS. Placement of the geomembrane on the upstream slope of the dam would prevent moisture from entering the dam and its foundation, and thus prevent collapse from occurring. The geomembranes may also need to be place on the downstream side of the dam to prevent water from entering the dam from sources other than floods (Leckband, 19'4).

The use of an impermeable geomembrane will also keep the dam and foundation at their initial moisture contents and prevent further drying of the structure. This remedial option may be modelled by creating a layer which will not allow the cause of collapse to begin its propagation through the dam and foundation. Numerically, the temperature change which causes collapse would begin farther away from the structure.

\section{RECOMPACTION}

An option which SCS has pursued is the excavation, replacement, and recompaction of the dam and its foundation. 
This has not been successful. Cracks have reappeared in the replaced and recompacted sections of the repaired dams. Another possible option is the construction of a saturation trench on the upstream side of the dam. This would allow the dam and foundation to become saturated and collapse. The intent of the saturation trench is to trigger all of the collapse, then, backfill the cracks and regrade the embankment slopes.

SCS has also attempted to allow the dam and foundation to collapse, and then to backfill and regrade the embankment slopes. This does not stop the damage from occurring again, nor does it ensure that the structure is safe. Further analysis is recommended to determine if the structure is indeed safe. This may be the most economically feasible option. As stated earlier, this may be numerically modelled be increasing the soil's strength and stiffness parameters.

A final option, which uses the same principle as the use of geomembranes, is the use of bentonite as a "seal". The bentonite may be spread and disked into the top layer of soil on the upstream side of the dam. This will significantly reduce the permeability of the top six to twelve inches (.2 $\mathrm{m}$ to $.3 \mathrm{~m}$ ) of soil upstream of the dam. Any water retained by the structure could then be released before the moisture front permeated the top soil layer and triggered a collapse in the dam or foundation. This 
alternative is simple and relatively inexpensive as compared to the others discussed previously. The use of a bentonite seal may be modelled numerically in a manner similar to the modeling of the geomembrane. A layer which would not allow the cause of collapse to begin would be modelled where the bentonite would be placed.

\section{THE OPTIMUM SCENARIO}

The options summarized in this chapter may be used alone or in various combinations to achieve the desired effects. The most economically feasible alternative for preventing collapse and cracking from occurring is likely to be the use of bentonite to reduce the permeability of the upper soil layer to maintain the structure and foundation soils at their initial moisture content. The other option which shows considerable promise is the construction of a saturation trench upstream of the structure to allow as much of the possible collapse to occur within a relatively short period of $t$ ime and to regrade the structure's slopes after collapse and cracking are completed. Geogrids would not likely be used in combination with these options. 
CHAPTER VI

\section{CONCLUSIONS AND RECOMMENDATIONS}

Based on the analysis of the pullout test results from other researchers and from this thesis, several conclusions may be made concerning the physical pullout testing procedure and the numerical modelling of geogrids as reinforcement.

\section{PHYSICAL TESTING CONCLUSIONS}

To achieve consistent, repeatable test results, a homogeneous test soil or sand should be used. The test soil should be densified to eliminate any arching of the material over the geogrid test sample and to reduce stress losses due to side friction within the test box. This may be done by disturbing the test box or by over-pressurizing the test box before the pullout test begins. The applied normal stress should be monitored with a pressure gauge, and the normal stress should be monitored within the test soil. Test data should be collected electronically to provide accurate data throughout the test.

Normal stresses should be applied from both above and below the test sample. By applying the stress in this manner and densifying the test soil, a more homogeneous 
stress distribution may be achieved within the test soil.

Pullout test boxes have been constructed by several

researchers and have varied considerably in size. Although there are no ASTM standards for geogrid pullout testing, recommended testing procedures are currently being developed (Geosynthetic Research Institute, 1990). In general, the test box should be large enough to eliminate any boundary effects which may influence the test data. This will depend on the type of soil and the type of geogrid being tested.

Based on the results of the pullout tests performed, the amount of pullout resistance a particular geogrid may offer appears to be a function of the soil it is embedded in, the number of embedded ribs transverse to the loading direction, the thickness of the transverse ribs, the type of material the geogrid is made of, and the surface texture of the geogrid. A minimum of seven or eight transverse ribs should be embedded in the soil to obtain an accurate indication of the pullout resistance for the geogrid.

\section{NUMERICAL TESTING CONCLUSIONS}

Based on the physical test results and work performed by other researchers (Bergado et al, 1986), the theoretical failure mechanism appears to be a passive bearing capacity failure. This may be modelled globally as a shear failure between the soil and the geogrid by using interface 
elements. This greatly simplifies the modelling procedure without significantly affecting the accuracy of the results.

\section{MODELLING RECOMMENLATIONS}

Based on the analysis of the numerical model of the geogrid pullout tesi, and the physical pullout tests, the following recommendations may be made for numerical input into a dam model containing reinforcement.

1) Assume that no relative slip occurs between the reinforcement and the soil.

2) Use the "equivalent interaction modulus" from the geogrid/soil interaction modulus for the geogrid modulus as defined on page 28 in Chapter II.

3) Use wide width tensile test data for the plastic strain properties of the geogrid.

4) Use a no tension constitutive model to model the soil.

These assumptions and recommendations further simplify the modelling of reinforcement within a soil mass without introducing any significant error. This also demonstrates how physical test results may be incorporated into numerical models.

RECOMMENDED AREAS FOR FUTURE STUDY

Based on the results of this study, the following 
areas are recommended for further investigation:

1) Evaluate more completely the shearing and failure mechanisms of the soil in a geogrid pullout test box during a pullout test.

2) Evaluate the use of reinforcement in an earth embankment structure model using no tension soil elements and proper "equivalent interaction modulus" values.

3) Develop a constitutive soil model that will allow a no tension specification. This is currently in progress at Portland State University.

4) The development of a DOS based Finite Element program which can simulate collapse of foundation soils is also currently being researched in conjunction with the cor titutive soil model mentioned above, at Portland State University, and should be pursued in the future.

5) The use of electronic data acquisition has been limited in Geotechnical testing and should be incorporated into the testing program whenever possible.

6) Pullout tests should be performed on various soil types so that the behavior of geogrids and the effects of different soils may be evaluated and better understood. 


\section{REFERENCES}

Andrawes, Kamal Z, and Alan McGown. "StereoPhotogrammetric Measurements of the Kinematics Within Plane Strain Model of Reinforced Embankments" in Developments in Soil Mechanics and Foundation Engineering: Volume 1. Ed. P. K. Banerjee, and R. Butterfield. New York: Elsevier Applied Science Publishers, 1985 .

Arrington, Ralph; Stearns, Charles; Monville, Paul; and Nelson, Robert; Department of Agriculture. ( 8 June 1979). Report of Investigation of Structural Deficiency: Graveyard Wash Dam. Soil Conservation Service. Stafford, Arizona.

"Blow-Up Dams." Construction Today August 1990: 14.

Bove, John; Westinghouse Environmental and Geotechnical Services, Incorporated. Technical Test Results. 16 October 1989.

Boyer, Marcella. Consolidation Testing With Data Aquisition Units. Portland State University: 1990.

Burgado, D. T.; Bukkanasuta, A.; and Balasubramaniam, A. S . "Laboratory Pull-Out Tests Using Bamboo and Polymer Geogrids Including a Case Study." Geotextiles and Geomembranes. Ed. T. S. Ingold. England: Elsevier Science Publishers Ltd., 1987: 153-159.

Deal, Clifford; United States Department of Agriculture. (July 1986) Engineering Geologic Investigation Report on Sand-H Debris Basin. Soil Conservation Service. Portland, Oregon.

Dembicki, Eugeniusz, and Jermolowicz, Piotr. "Soil-GeoTextile Interaction." Geotextiles and Geomembranes Ed. T. S. Ingold. England: Elsevier Science Publishers Ltd., 1991: 249-268.

Eichler, Fred; Westinghouse Environmental and Geotechnical Services, Incorporated. Technical Test Results. 5 October 1990 . 
Fannin, Jonathan. "Research on Geosynthetics at the University of British Columbia." Geotechnical News. March 1991: 42-45.

Franks, Duncan, Collins, Fowler, Peters, and Schaefer. "Use of Reinforcement at Mohicanville Dike No. 2." Proceedings: Second International Conference on Case Histories in Geotechnical Engineering. St. Louis. June 1988: 977-983.

Geosynthetic Research Institute. Proposed GRI Standard. 4 th Draft. 8 July 1990.

GKN Hayward Baker Incorporated. Ground Modification Seminar. Ventura: GKN Hayward Baker, 1986.

Hate Geotextiles. (1990). Fortrac. Technical Test Results.

Hird, C. C., I. C. Pyrah, and D. Russell. "Finite Element Analysis of the Collapse of Reinforced Embankments on Soft Ground." Geotechnique. March 1991: 633-640.

Hornbeck, D. E. (1982). "Laboratory Modeling of Reinforced Earth." Thesis presented to Georgia Tech Universiy, Atlanta, Georgia, in partial fulfillment of the requirements for the degree of Doctor or Philosophy.

Humphrey, Dana Norman. (1986). Design of Reinforced Embankments. Indiana. Purdue University.

Ingold, Terrance S. "Laboratory Pull-out Testing of Grid Reinforcements in Sand." Geotechnical Testing Journal. Volume 6, Number 3, (September, 1983): 101-111.

Ingold, T. S. and Miller, K. S. (1988). Geotextiles Handbook. London: Thomas Telford.

Jagielski, Kevin. "Erosion-Control Market Takes Hold." Geotechnical Fabrics Report. March 1991: 14-15.

Johnston, R. S. (1985). "Pull-out Testing of Tensar Geogrids." Thesis presented to the University of California, at Davis, California, in partial fulfillment of the requirement for the degree of Master of Science in Civil Engineering. 
Juran, I.; Knochenmus, G.; Acar, Y. B.; and Arman, A. (1988). "Pull-Out Response of Geotextile and Geogrids (Synthesis of Available Experimental Data)." R. D. Holtz (Ed.), Geosynthetics for Soil Improvement. (pp. 92-111) New York: American Society of Civil Engineers.

Leckband, Susanne; United States Department of Agriculture. (April 1982) Magma Dam Repair Alternatives. Soil Conservation Service. Pheonix, Arizona.

Leckband, Susanne; United States Department of Agriculture. (May 1984). A Barrier to Cracks in Dry Earth Embankment Dams. Soil Conservation Service. Pheonix, Arizona.

"Nailed-Up." Construction Today August 1990: 14.

Rollins, Kyle M., and G. Wayne Rogers. "Mitigation Measures for Small Structures on Collapsible Alluvial Soils." Submitted to ASCE Geotechnical Journal (1990).

STS Consultants Ltd. Consulting Engineers. Geogrid Evaluation Report. 18 April 1989.

Sumitomo Electric, (1990). Inflatible Rubber Gate. Sumigate. Los Angeles. 
APPENDIX A

CALIBRATION CURVES 


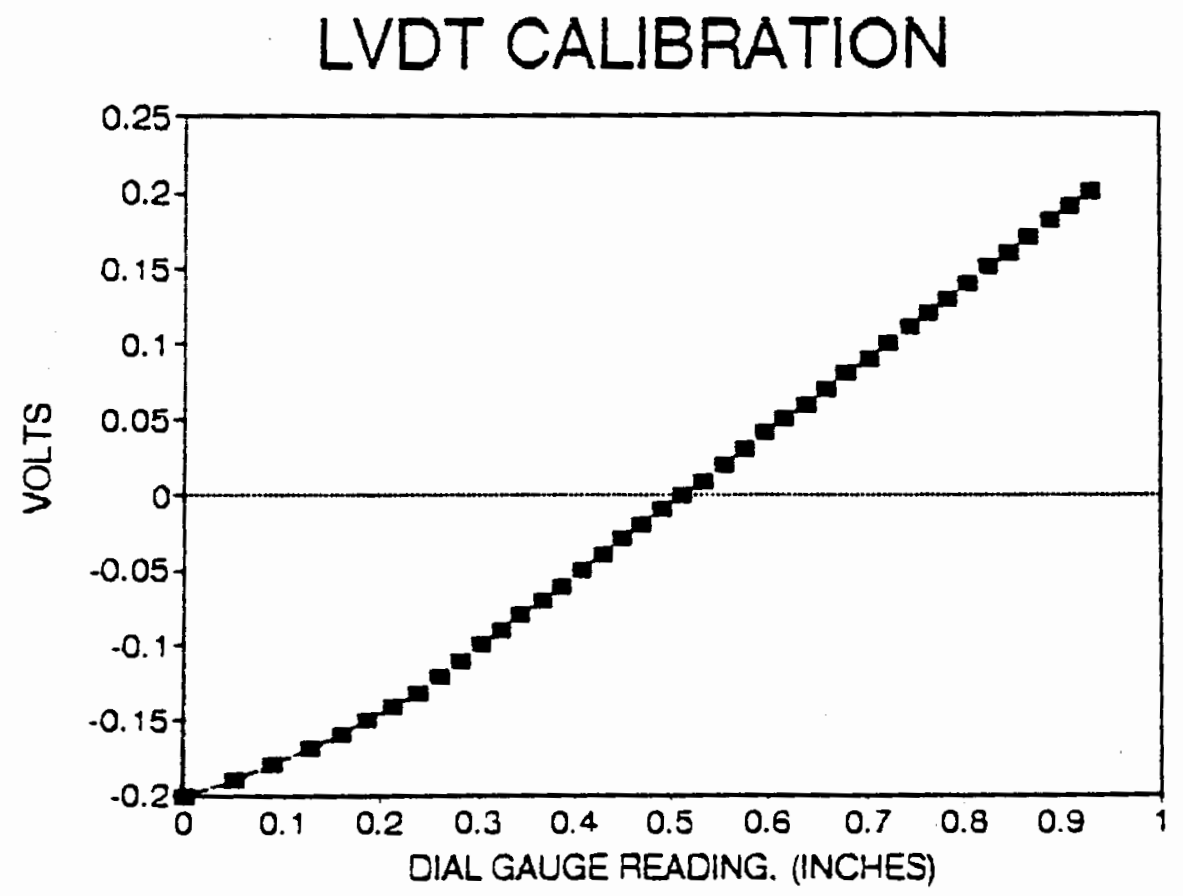




\section{POUND LOAD CELL CALIBRATION}

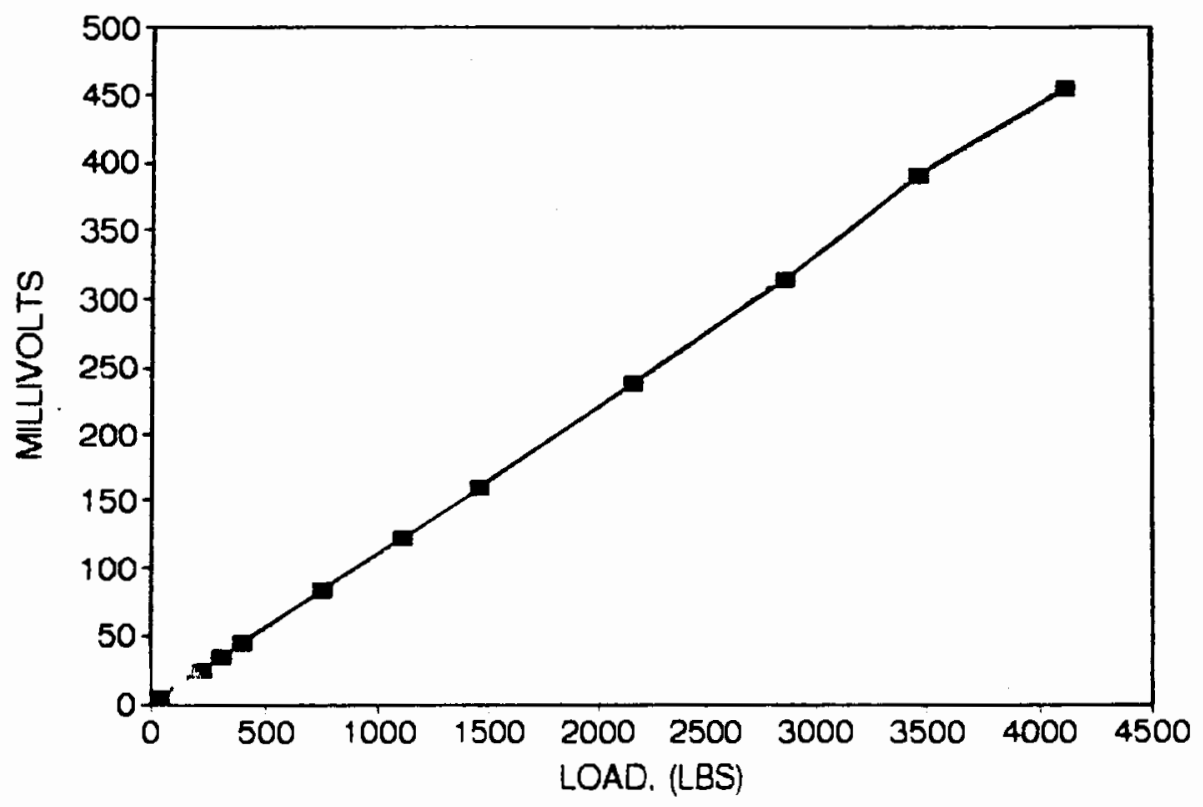


APPENDIX B

DENSITY AND DIRECT SHEAR DATA 
DENSITY CALCULATIONS:

TEST 1

Container \#107

$$
\begin{array}{lr}
\text { Sample + Container Wt. } & 137.9 \mathrm{~g} \\
\text { Container Wt. } & 13.5 \mathrm{~g} \\
\text { Container Volume } & 79.5 \mathrm{ml} \\
y=(\mathrm{S} . \mathrm{G} .)\left(\gamma_{w}\right) & (137.9 \mathrm{~g}-13.5 \mathrm{~g})\left(62.4 \mathrm{lbs} / \mathrm{ft}^{3}\right) \\
y=\frac{\left(79.5 \mathrm{~cm}^{3}\right)}{} \\
y=97.6 \mathrm{lbs} / \mathrm{ft}^{3}
\end{array}
$$

Container $\# 501$

$$
\begin{array}{lr}
\text { Sample + Container Wt. } & 141.8 \mathrm{~g} \\
\text { Container Wt. } & 14.7 \mathrm{~g} \\
\text { Container Volume } & 80.0 \mathrm{ml} \\
\gamma=(\mathrm{S} . \mathrm{G} .)\left(\gamma_{\omega}\right) & (141.8 \mathrm{~g}-14.7 \mathrm{~g})\left(62.4 \mathrm{lbs} / \mathrm{ft}^{3}\right) \\
\gamma=\frac{\left(80 \mathrm{~cm}^{3}\right)}{\gamma=99.0 \mathrm{lbs} / \mathrm{ft}^{3}}
\end{array}
$$




\section{TEST 2}

$$
\begin{aligned}
& \text { Container \#107 } \\
& \text { Sample + Container Wt. 139.4g } \\
& \text { Container Wt. } 13.5 \mathrm{~g} \\
& \text { Container Volume } \quad 79.5 \mathrm{ml} \\
& \gamma=(S . G .)\left(\gamma_{.}\right) \\
& \gamma=\frac{(139.4 \mathrm{~g}-13.5 \mathrm{~g})\left(62.4 \mathrm{lbs} / \mathrm{ft}^{3}\right)}{\left(79.5 \mathrm{~cm}^{3}\right)} \\
& \gamma=98.8 \mathrm{lbs} / \mathrm{ft}^{3}
\end{aligned}
$$

Container \#501

$$
\begin{array}{lr}
\text { Sample + Container Wt. } & 141.8 \mathrm{~g} \\
\text { Container Wt. } & 14.7 \mathrm{~g} \\
\text { Container Volume } & 80.0 \mathrm{ml} \\
y=(\mathrm{S} . \mathrm{G} .)\left(\gamma_{\mathrm{w}}\right) & \\
y=\frac{(141.8 \mathrm{~g}-14.7 \mathrm{~g})\left(62.4 \mathrm{lbs} / \mathrm{ft}^{3}\right)}{\left(80.0 \mathrm{~cm}^{3}\right)} \\
\varnothing=99.0 \mathrm{lbs} / \mathrm{ft}^{3}
\end{array}
$$




\section{DIRECT SHEAR}

$$
\begin{aligned}
\text { Soil friction angle } & =\tan ^{-1}\left(\frac{33-6}{10(4.38)}\right) \\
& =\tan ^{-1} .6 i 6 \\
& =31.7^{\circ}
\end{aligned}
$$




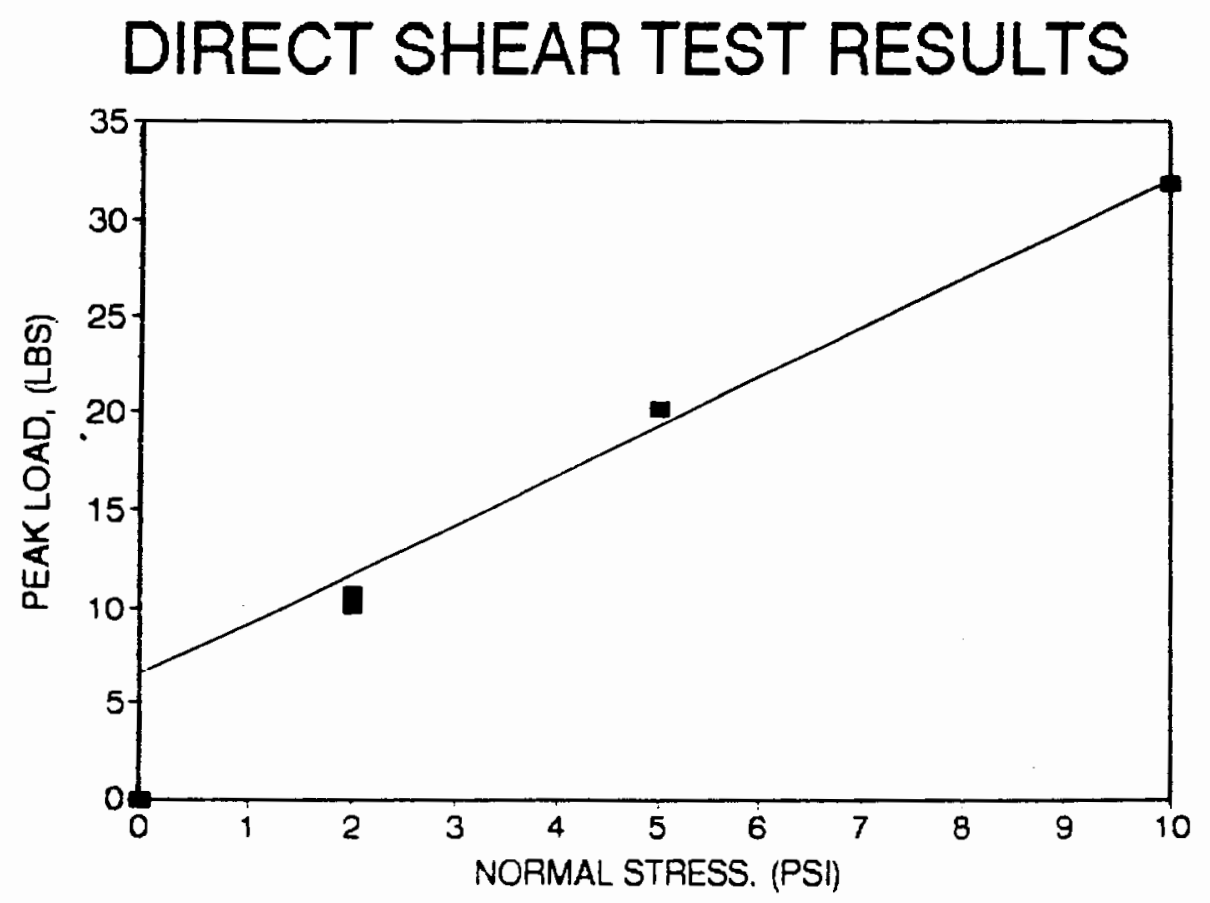




\section{DIRECT SHEAR TEST \\ 2 PSI NORMAL STRESS}

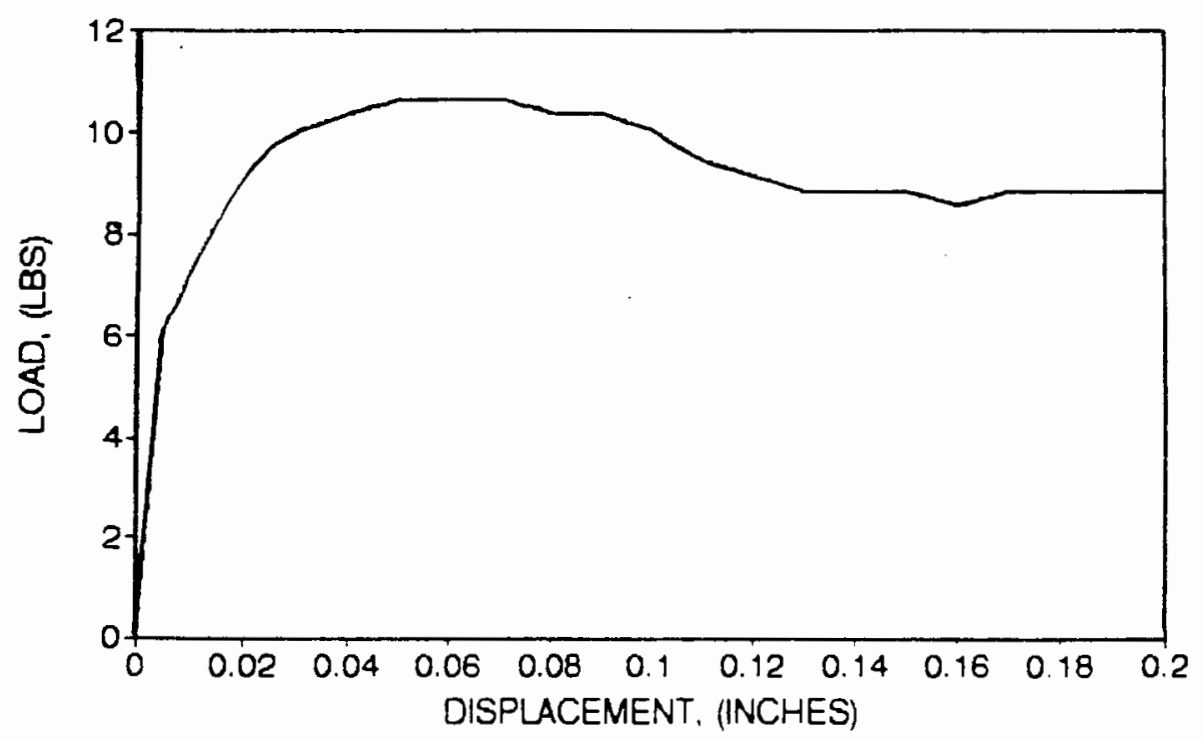




\section{DIRECT SHEAR TEST 2 PSI NORMAL STRESS}

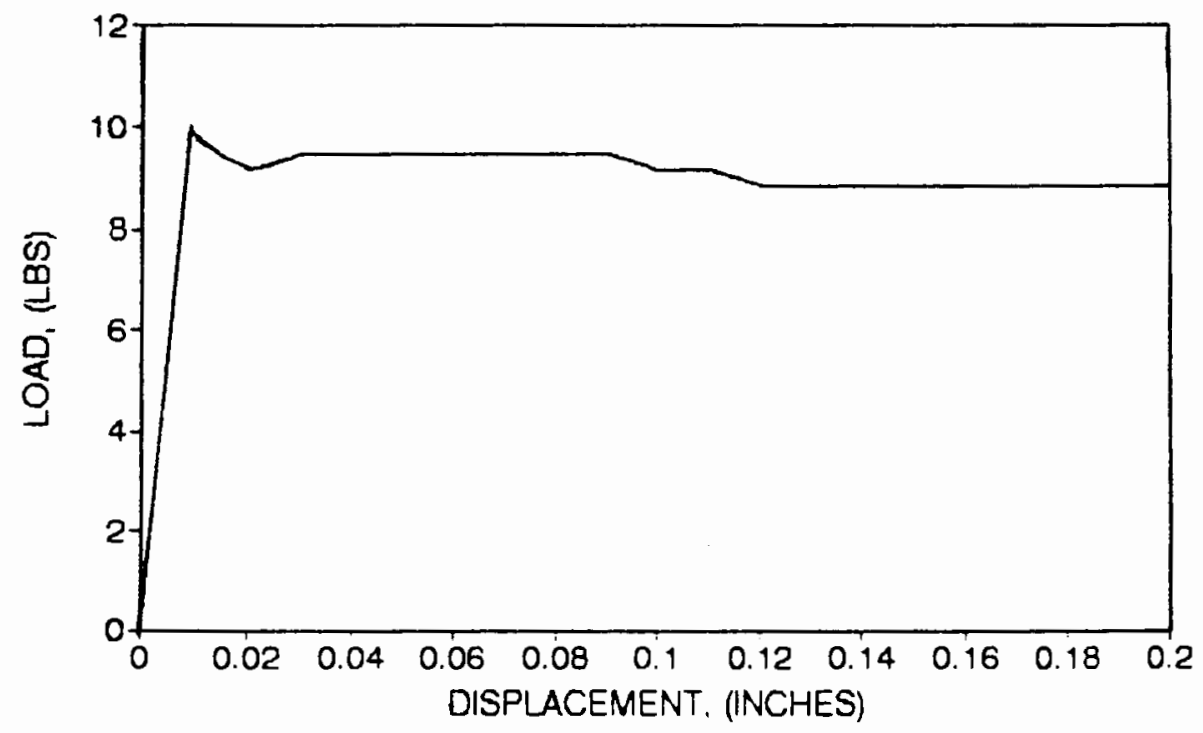


DIRECT SHEAR TEST

5 PSI NORMAL STRESS

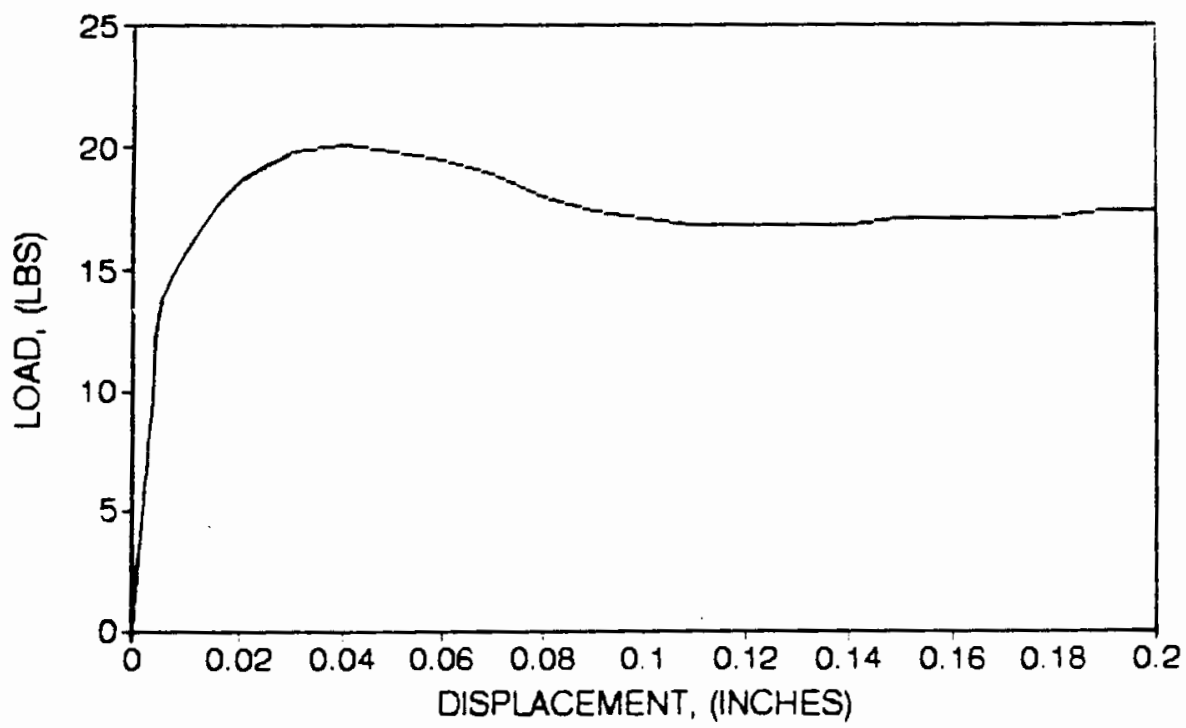




\section{DIRECT SHEAR TEST}

5 PSI NORMAL STRESS

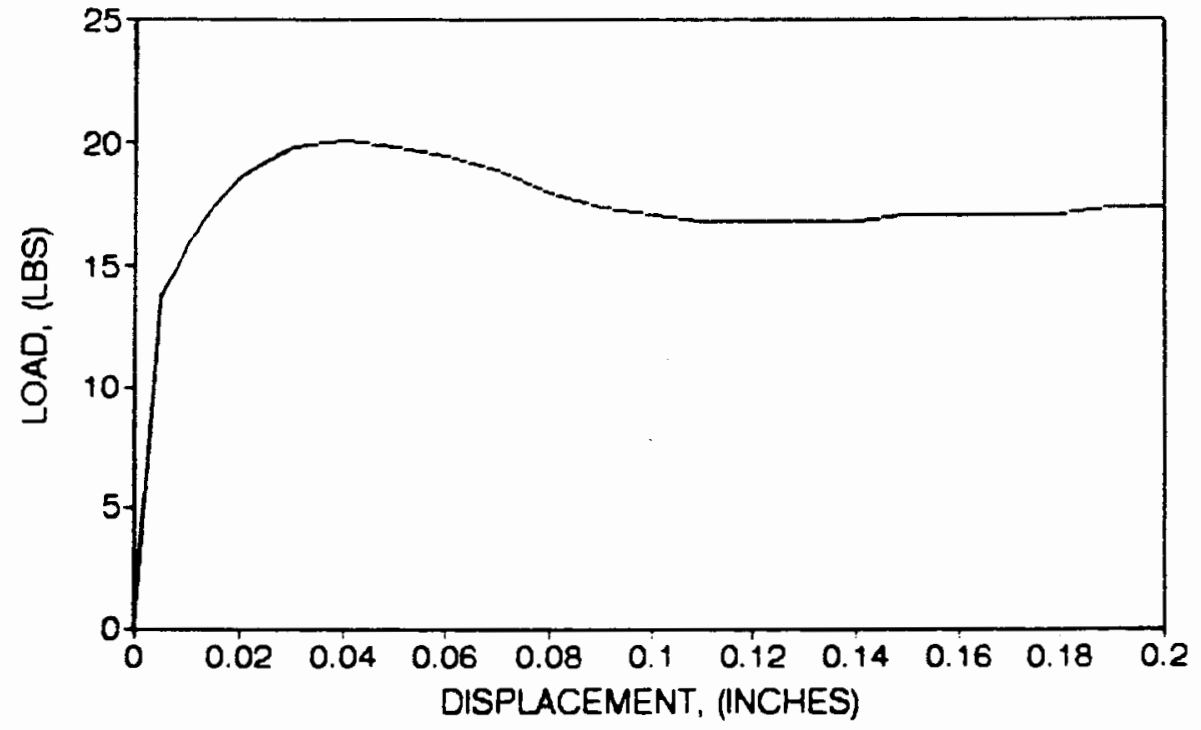




\section{DIRECT SHEAR TEST}

5 PSI NORMAL STRESS

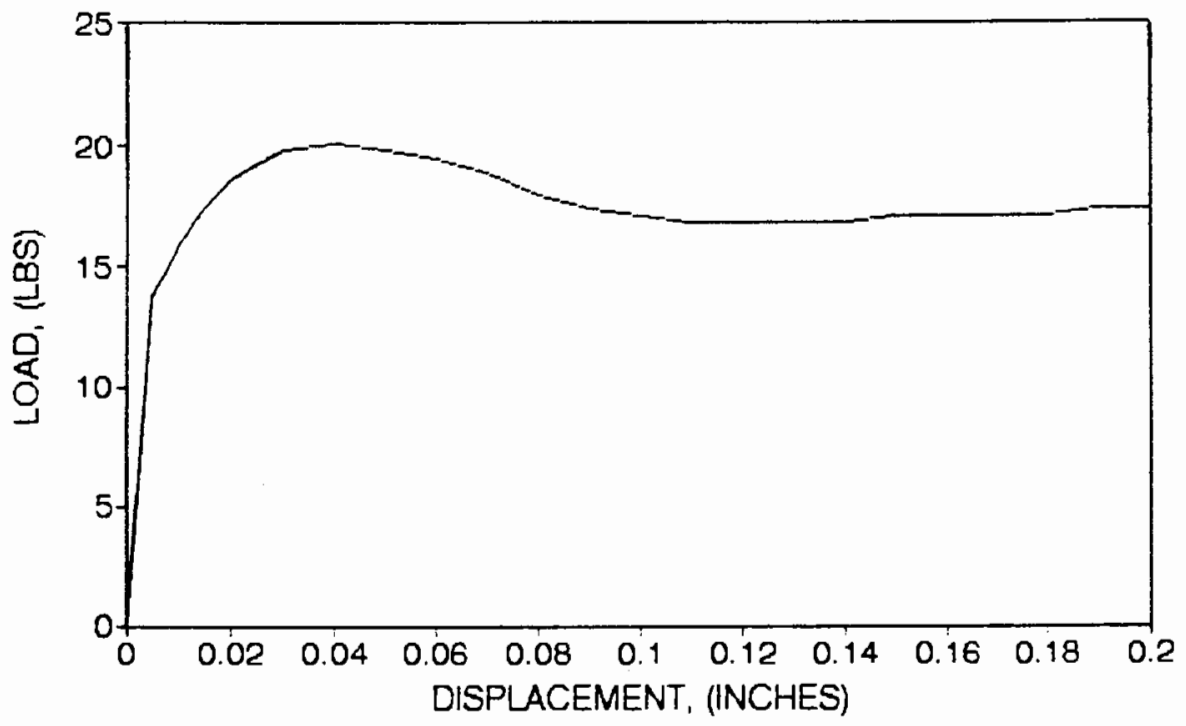




\section{DIRECT SHEAR TEST} 10 PSI NORMAL STRESS

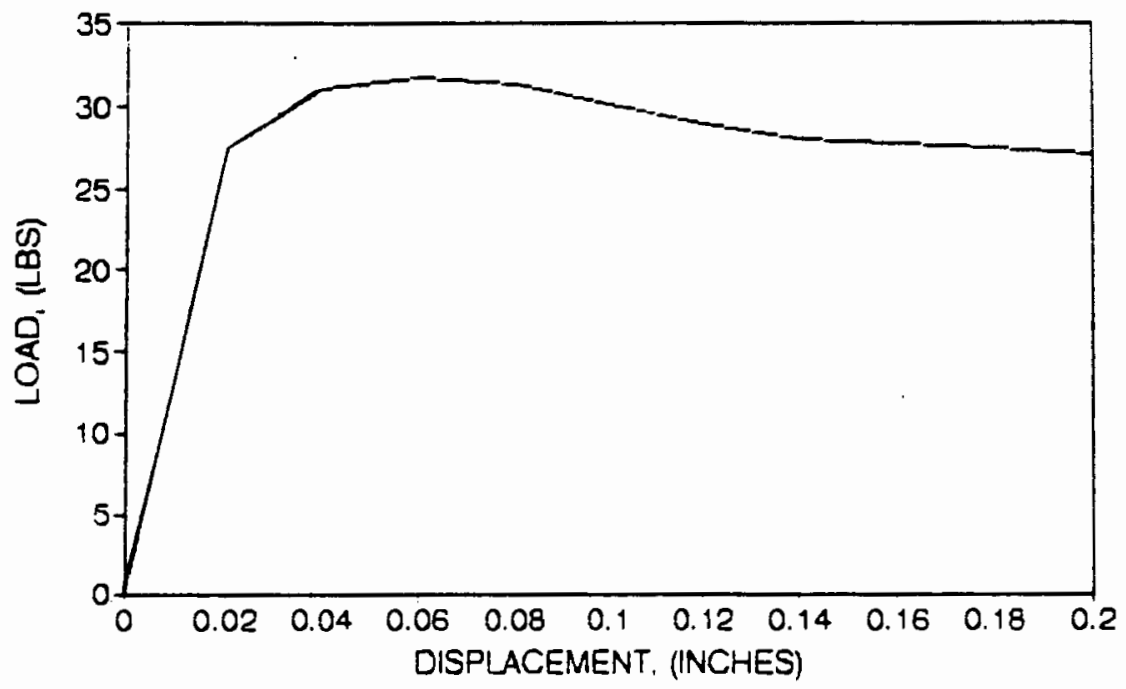


DIRECT SHEAR TEST 10 PSI NORMAL STRESS

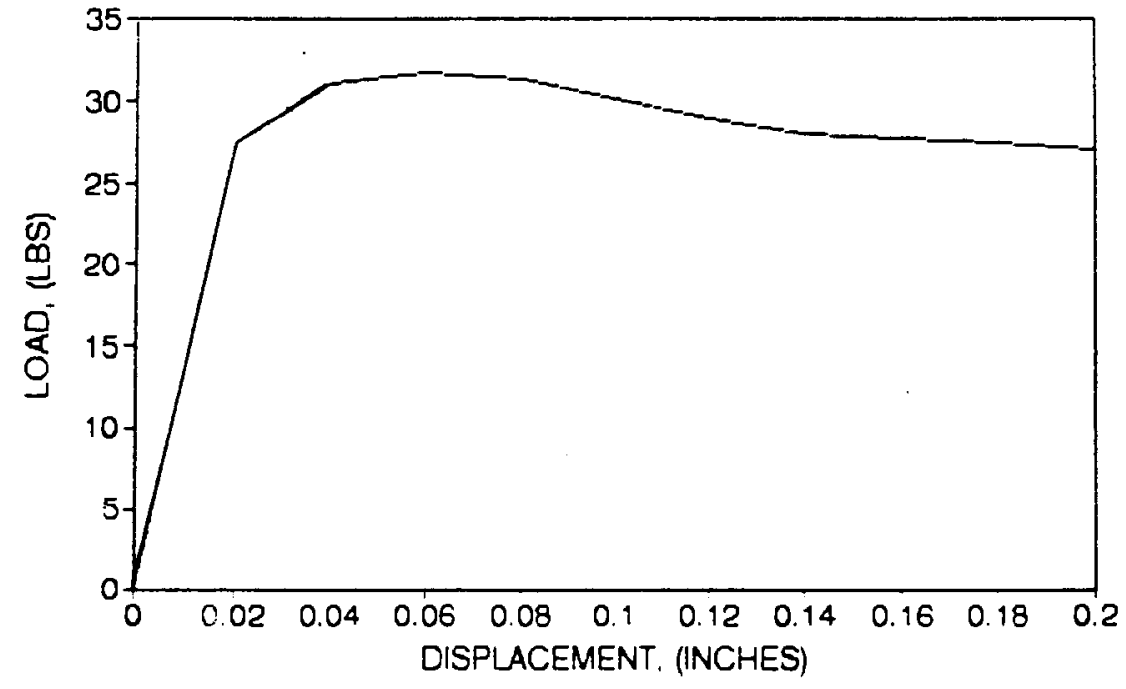


APPENDIX $\mathrm{C}$

MAXIMUM PULLOUT LOADS 
MAXIMUM PULLOUT LOAD, (LBS/FT)

2 PSI

FORTRAC $35 / 20-20$
TENAX 201

TENAX 301

TENAX 401
5 PSI

1499
1041
1684
1414
1459
1242
1428

722

299

\author{
408
}

594

346

10 PSI

1499

992

1074

1025

630

1058

644

291 
2 PSI

BAY MILLS 28501

BAY MILLS $28502(w)$
423

536

5 PSI

10 PSI

1717

875

1543

1705

916

BAY MILLS 28502 (s) 
APPENDIX D

LOAD VS. DISPLACEMENT GRAPHS 
FORTRAC 35/20-20

SAMPLE WIDTH $=12 "$

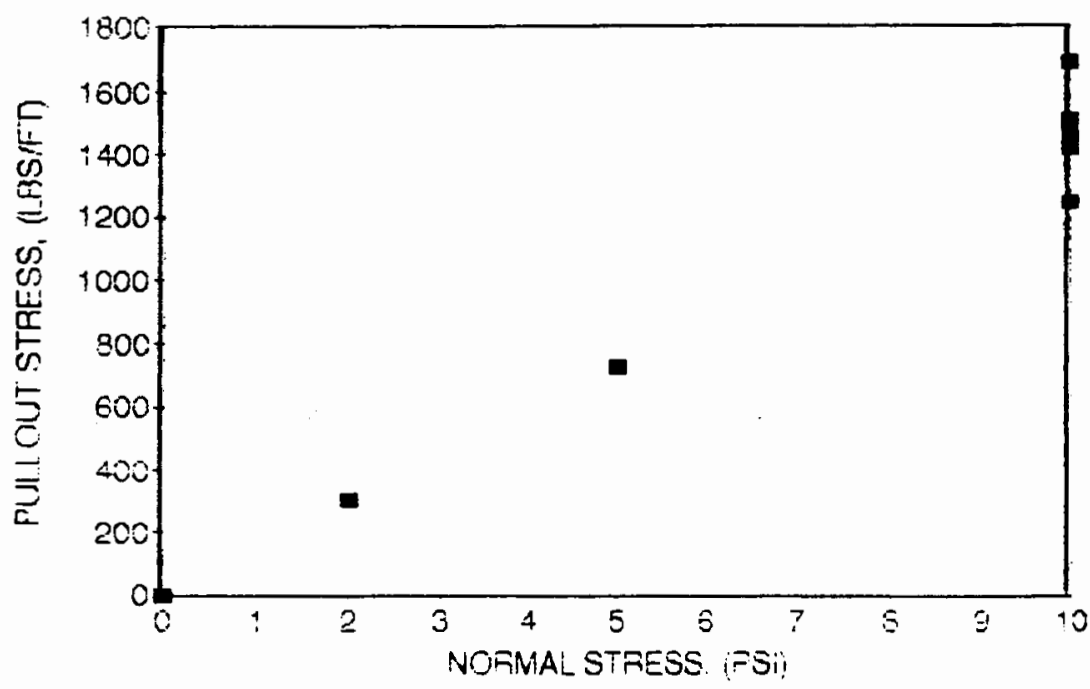


FORTRAC 35/20-20

2 PSI NORMAL STRESS, SAMPLE WIDTH $12^{\prime \prime}$

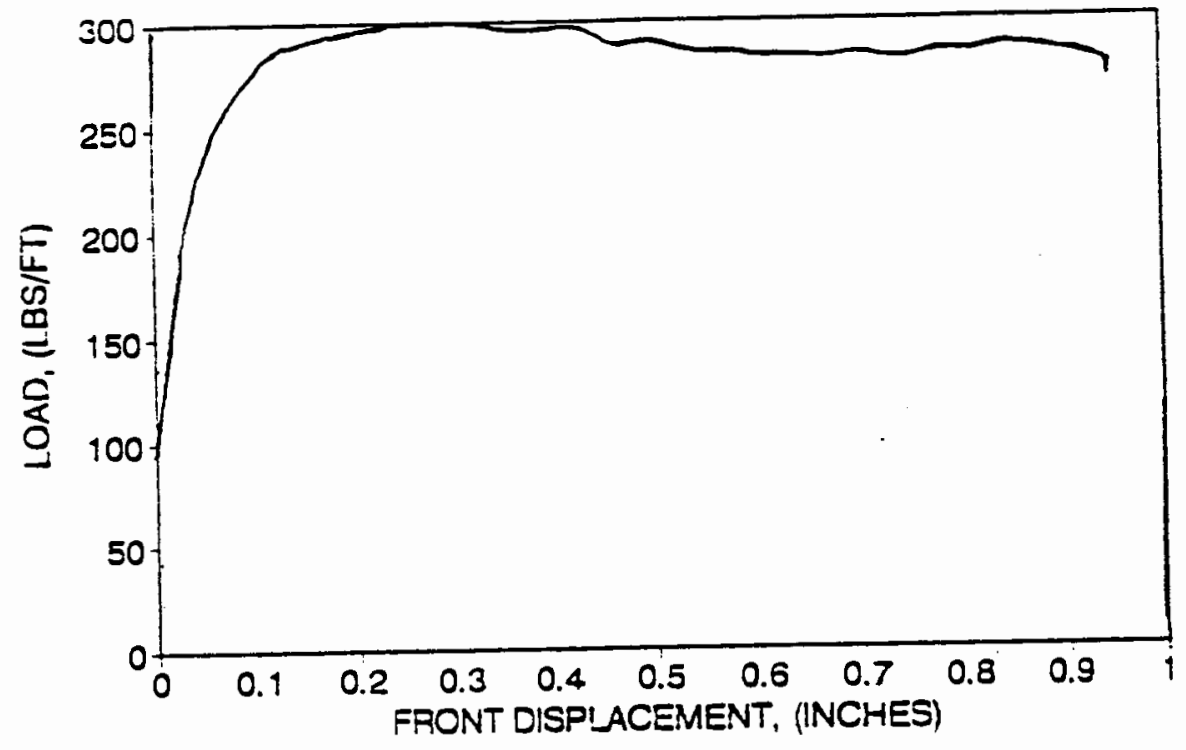

FORTRAC 35/20-20

2 PSI NORMAL STRESS, SAMPLE WIDTH $12^{n}$

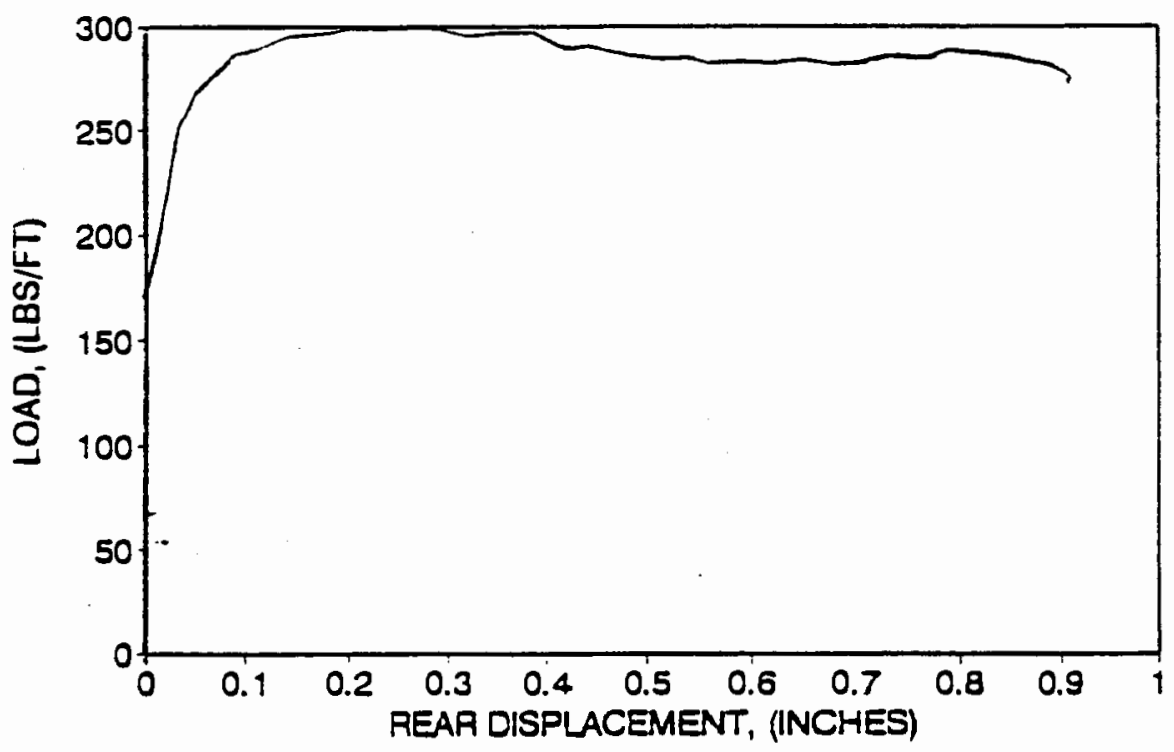


FORTRAC 35/20-20

5 PSI NORMAL STRESS, SAMPLE WIDTH 12"

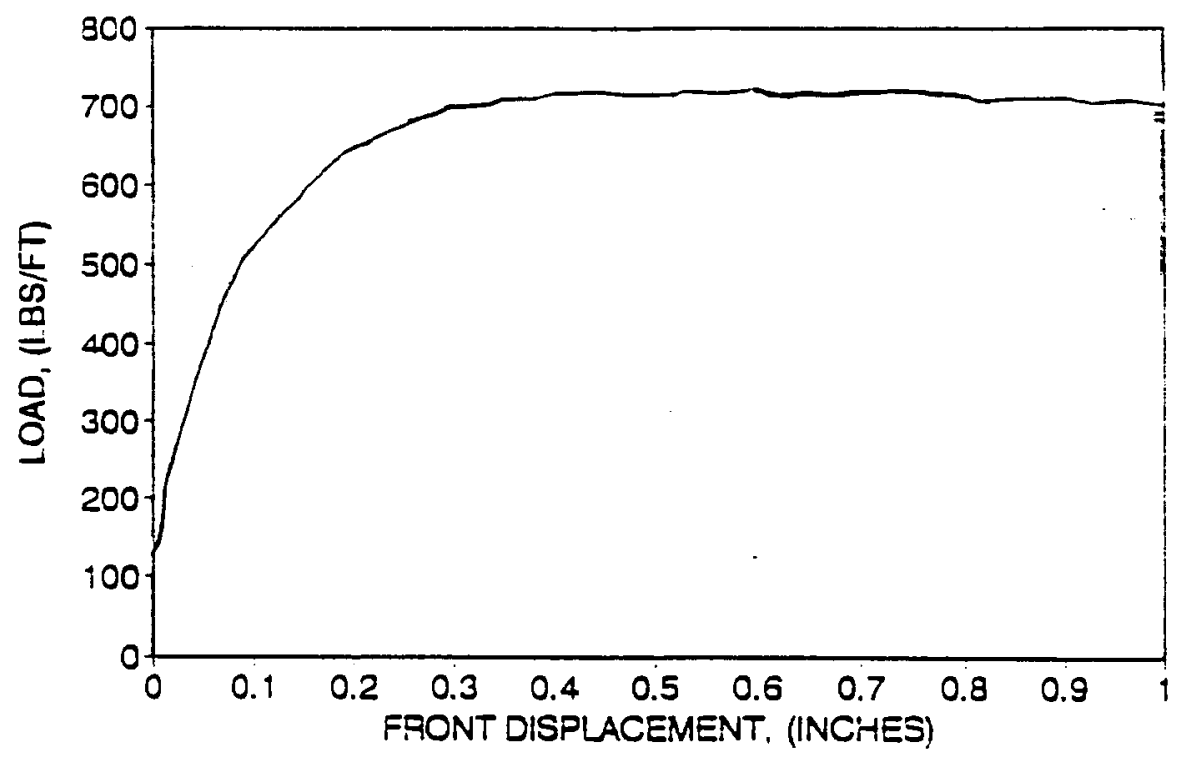

FORTRAC 35/20-20

5 PSI NORMAL STRESS, SAMPLE WIDTH 12"

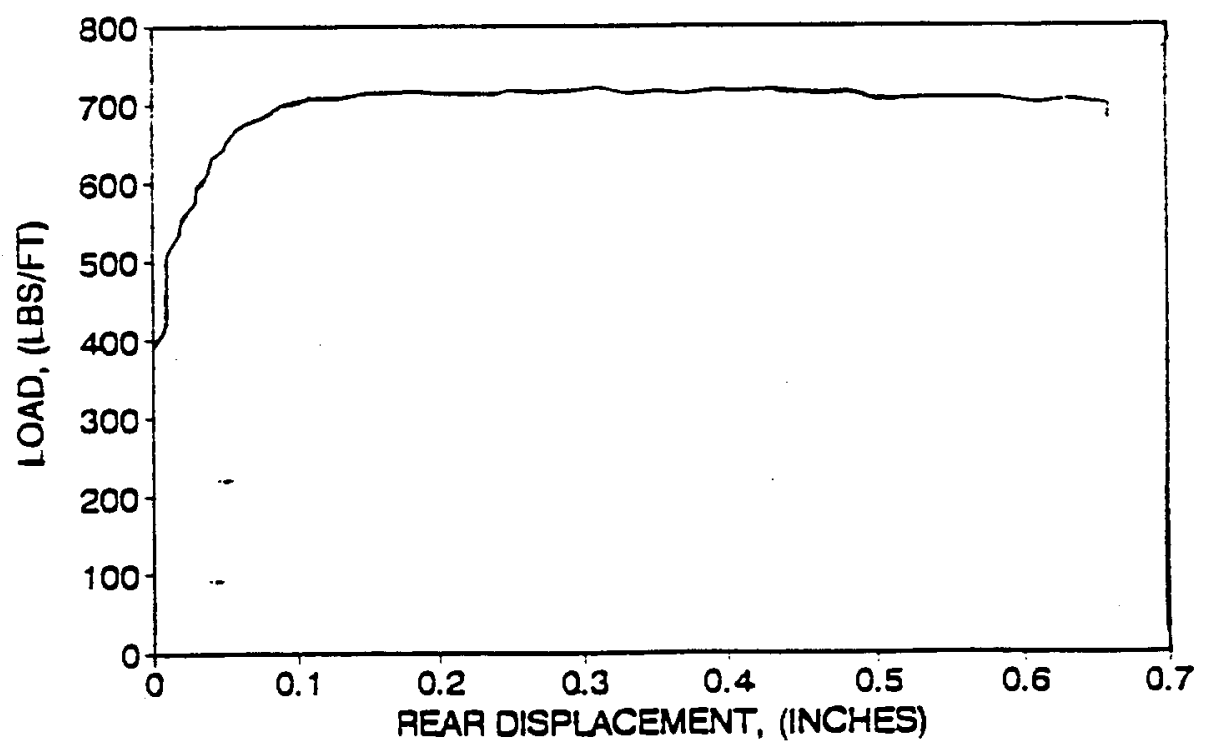


FORTRAC 35/20-20

10 PSI NORMAL STRESS, SAMPLE WIDTH $12^{\prime \prime}$

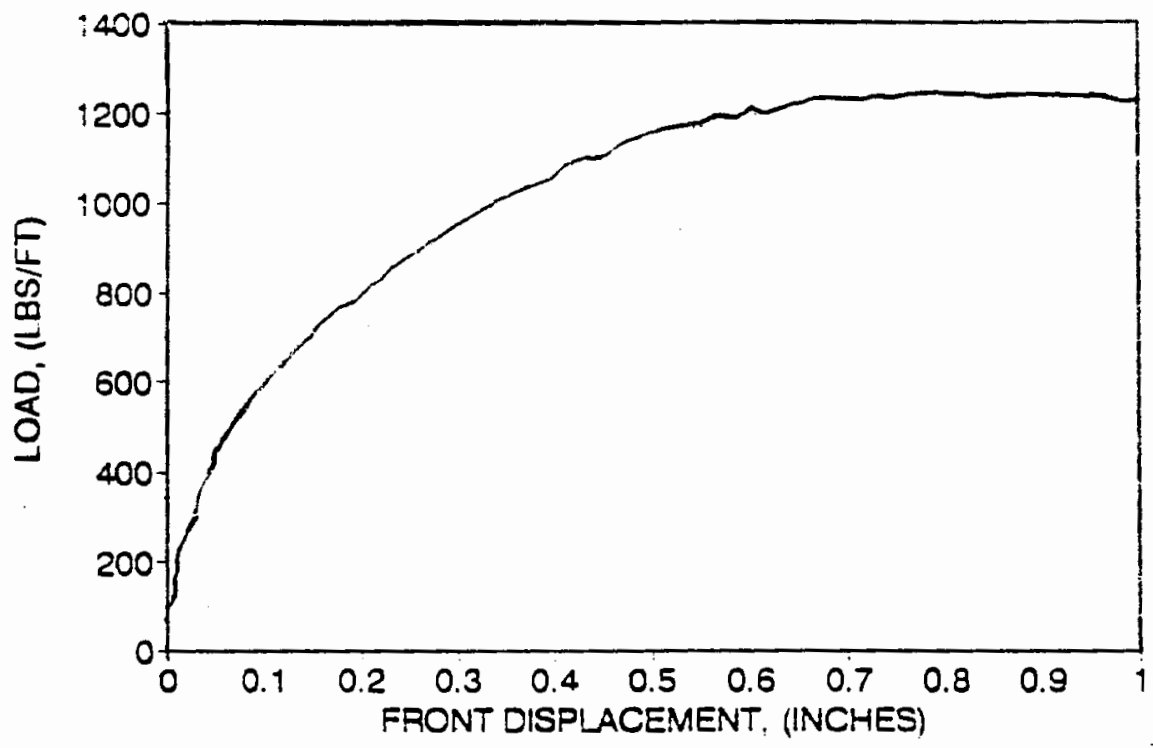

FORTRAC 35/20-20

10 PSI NORMAL STRESS, SAMPLE WIDTH $12^{\prime \prime}$

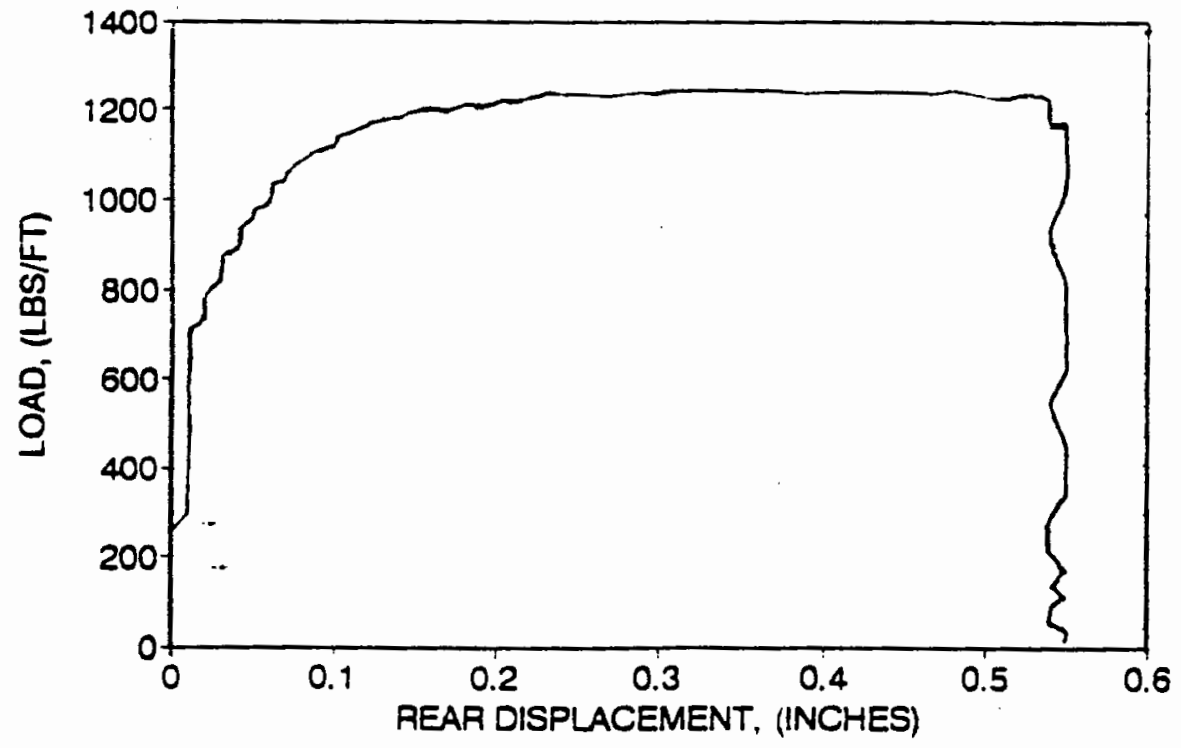


FORTRAC 35/20-20

10 PSI NORMAL STRESS, SAMPLE WIDTH $12^{\prime \prime}$

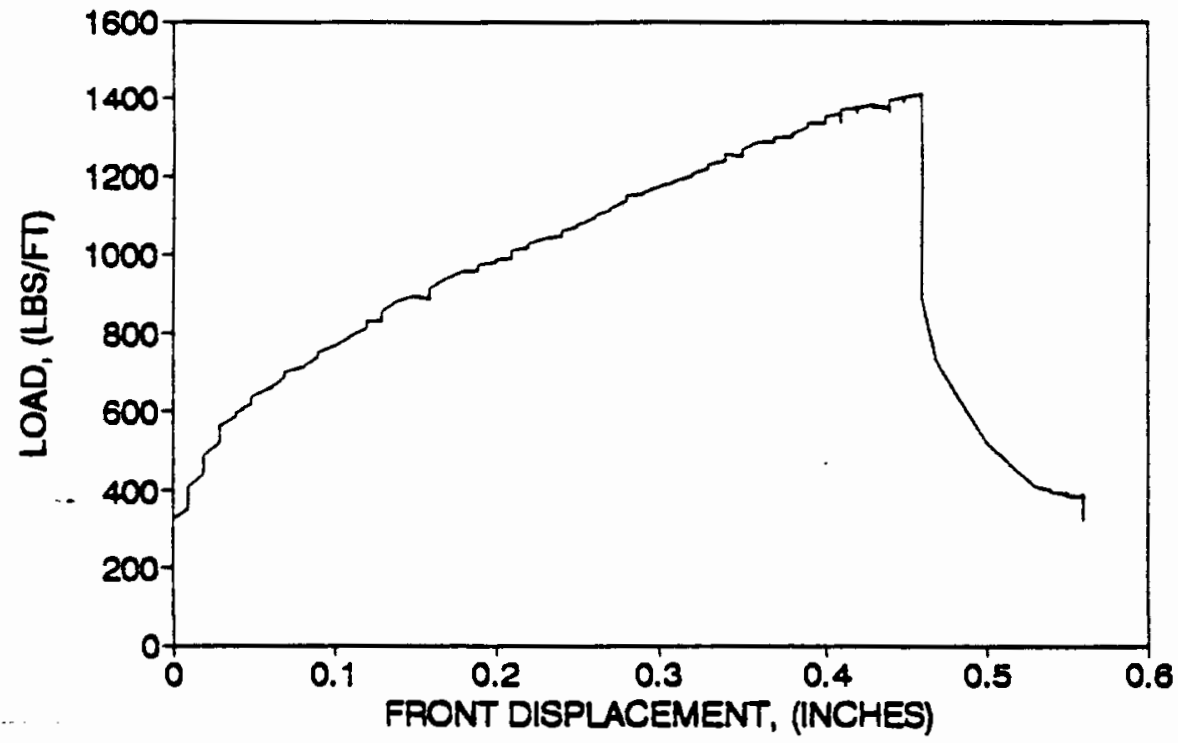

FORTRAC 35/20-20

10 PSI NORMAL STRESS, SAMPLE WIDTH $12^{\circ}$

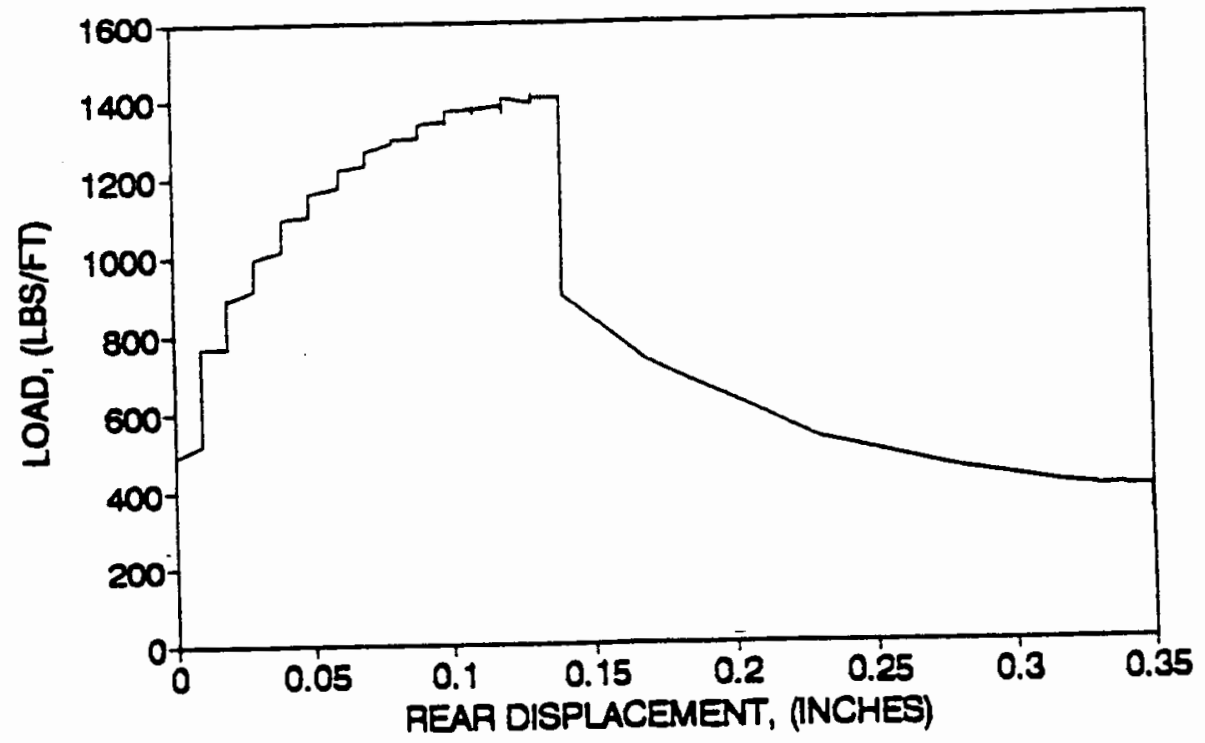


FORTRAC 35/20-20

10 PSI NORMAL STFESS. SAMPLE WICTH' $12^{\prime \prime}$

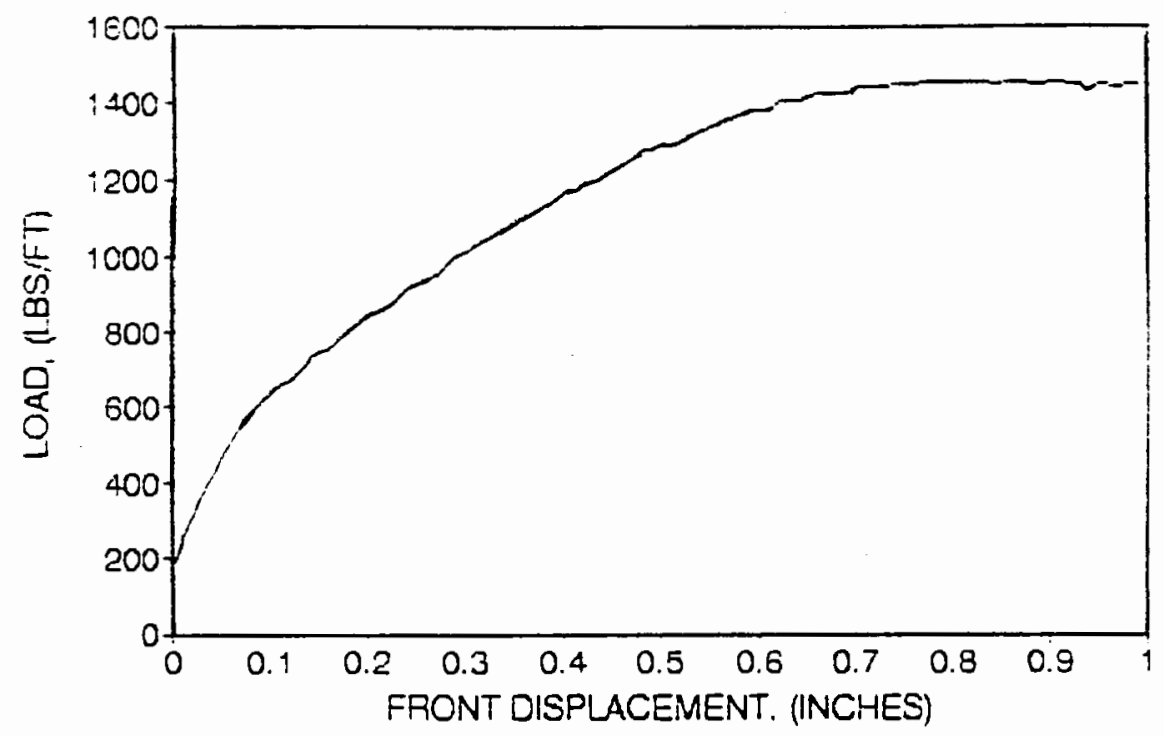

FORTRAC 35/20-20

10 PSI NORMAL STRESS. SAMPLE WIDTH $12^{\prime \prime}$

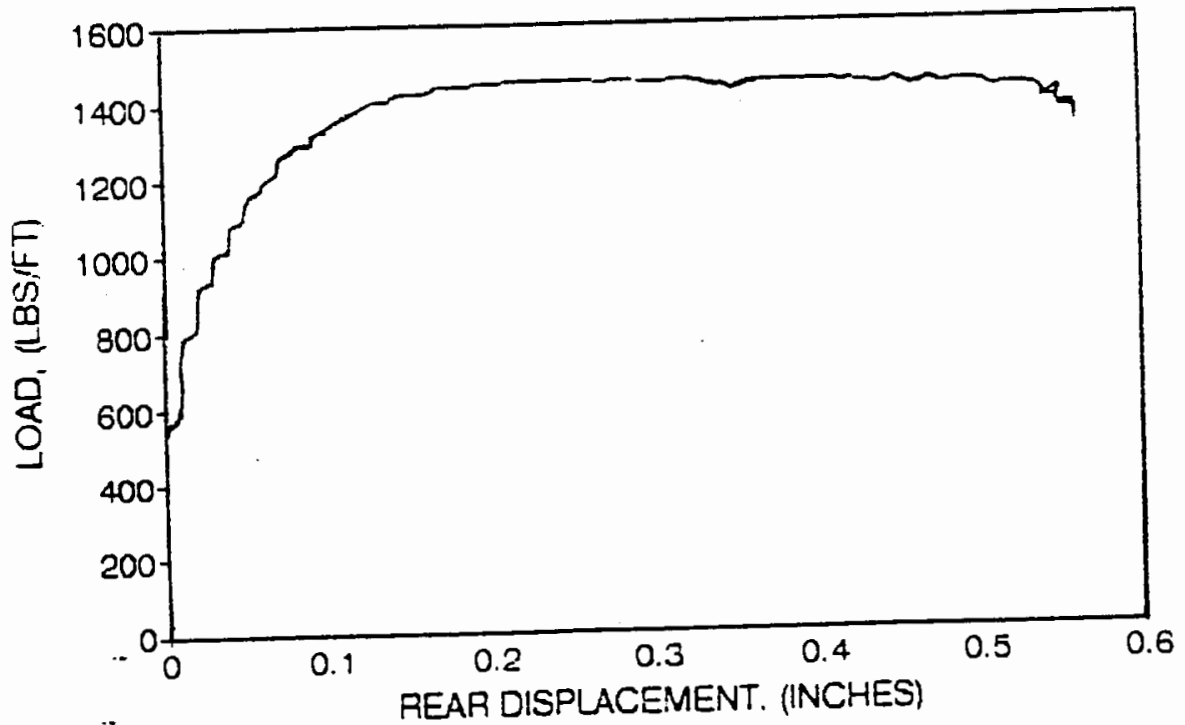




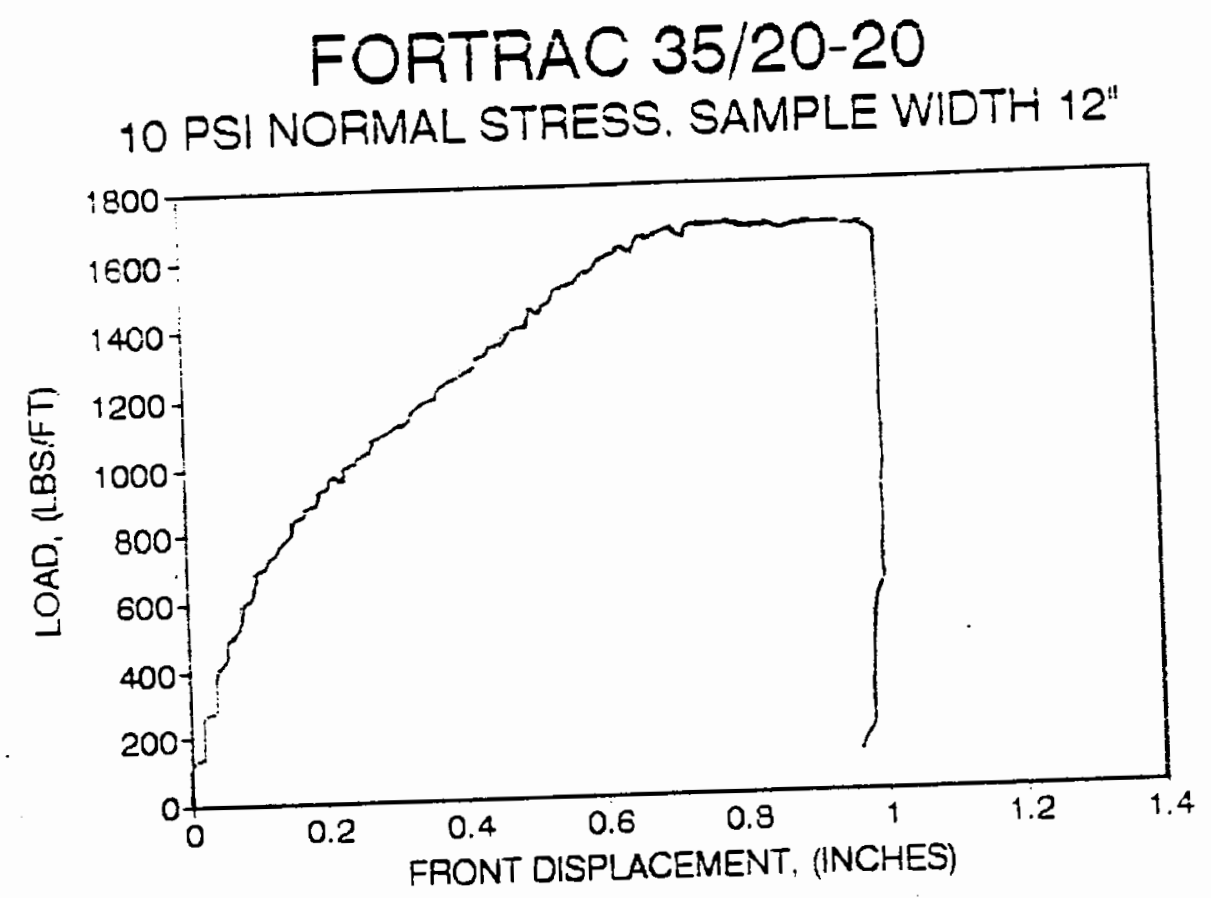

FORTRAC 35/20-20

10 PSI NORMAL STRESS. SAMPLE WIDTH $12^{\prime \prime}$

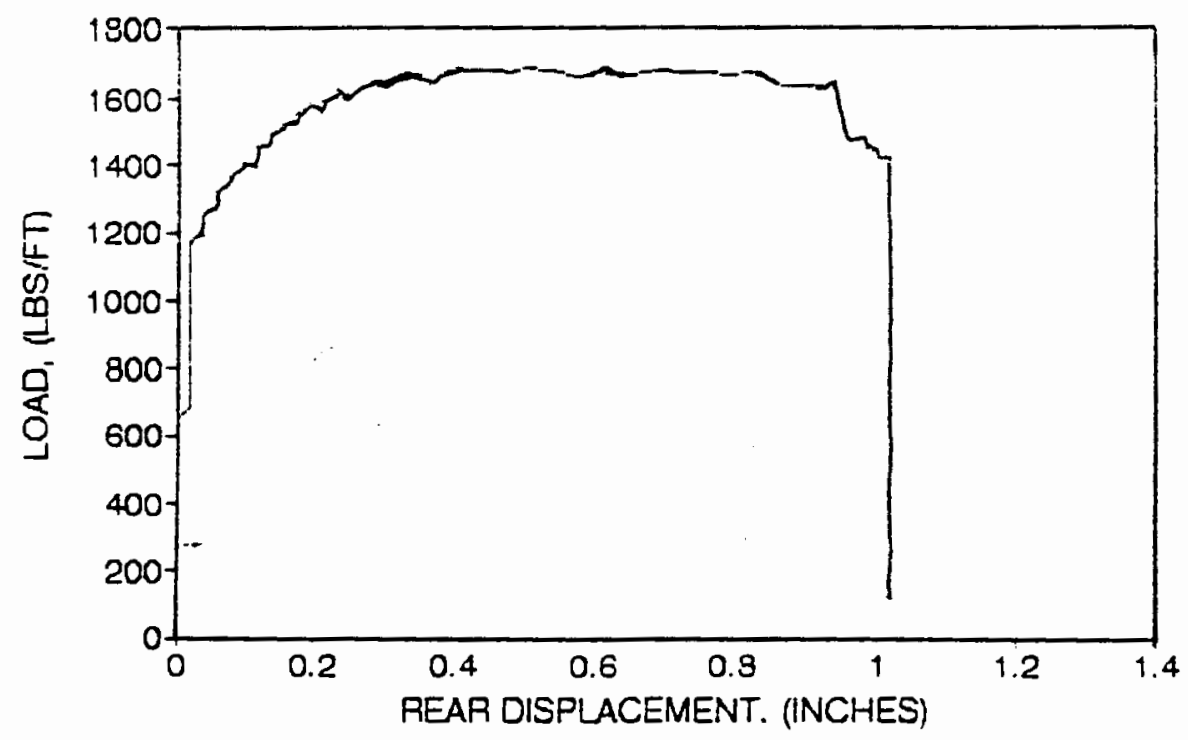




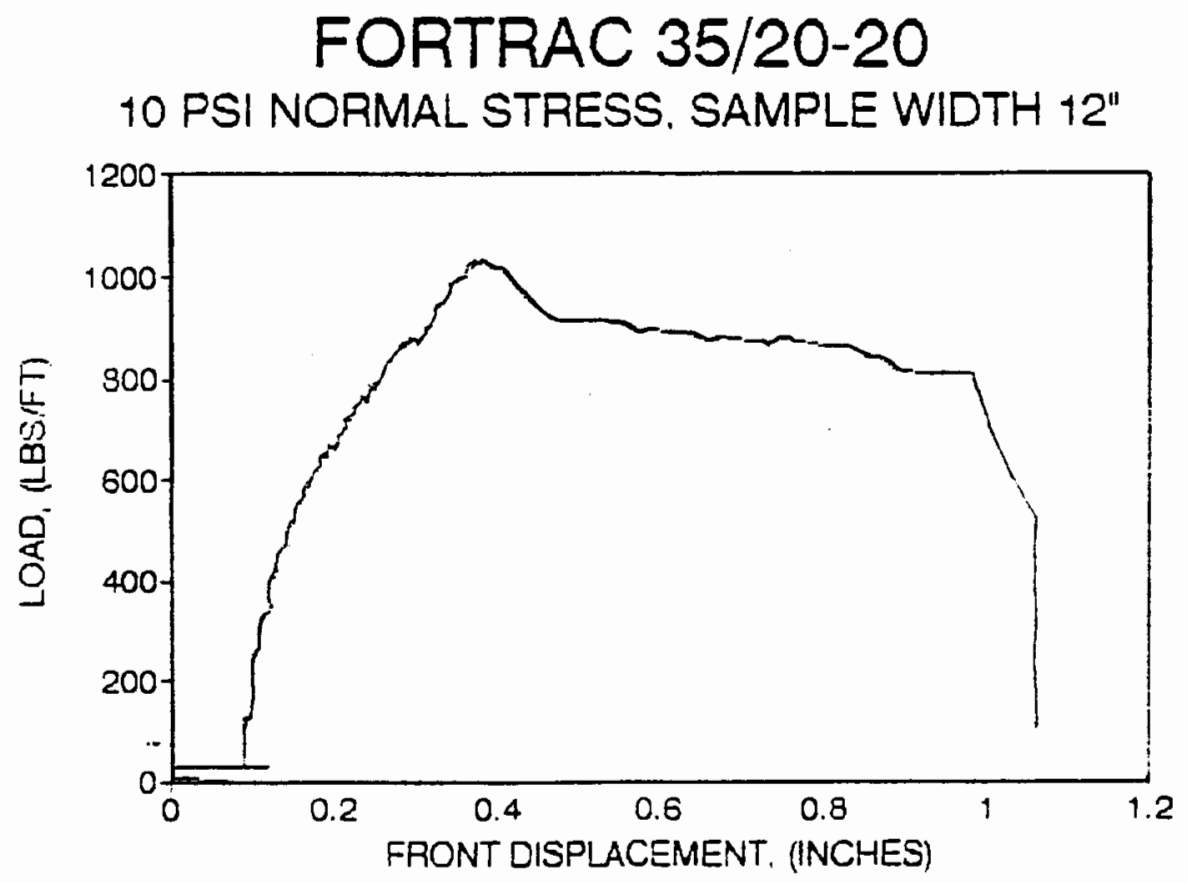

FORTRAC 35/20-20

10 PSI NORMAL STRESS. SAMPLE WIDTH $12^{\prime \prime}$

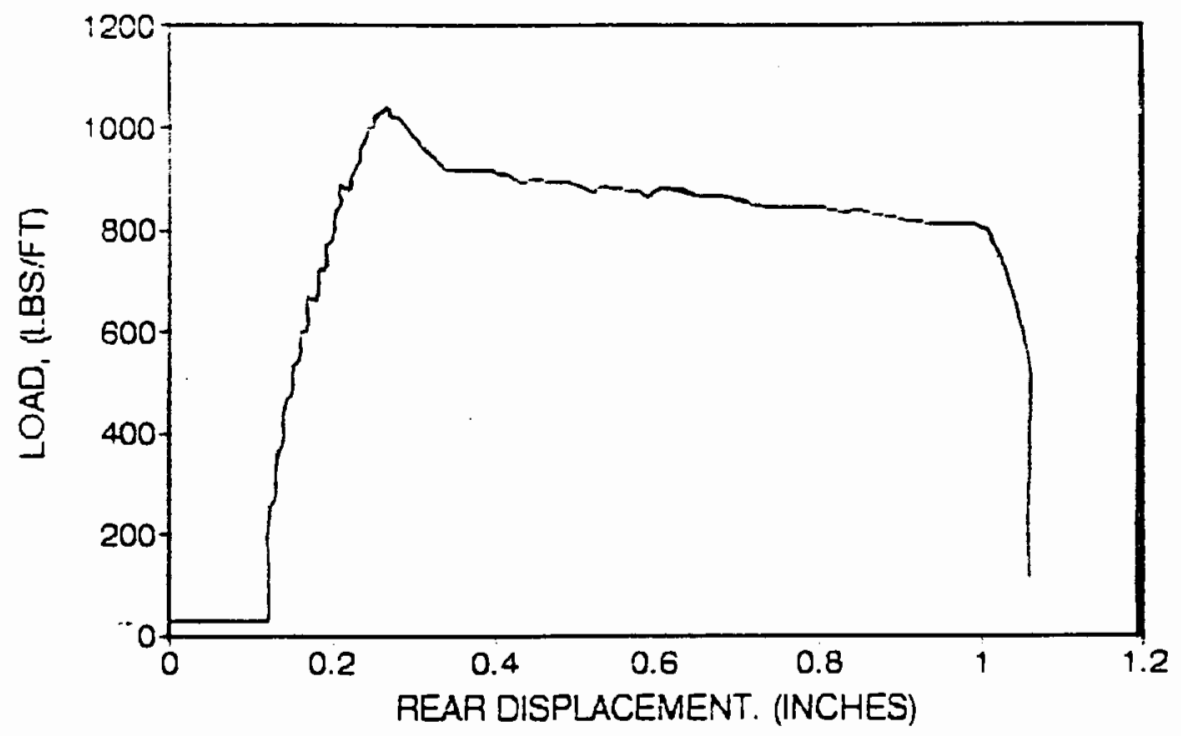


FORTRAC 35/20-20

to PSI NORMAL STRESS. SAMPLE WIDTH $12 "$

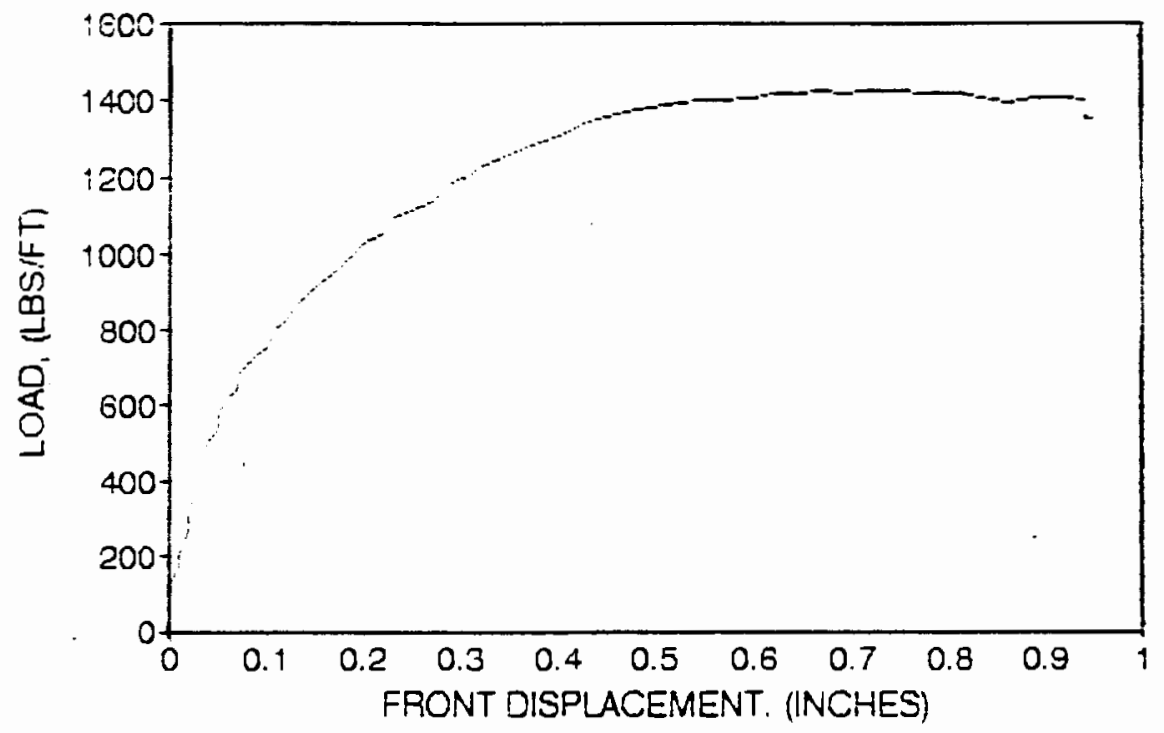

FORTRAC 35/20-20

10 PSI NORMAL STRESS. SAMPLE WIDTH $12^{\prime \prime}$

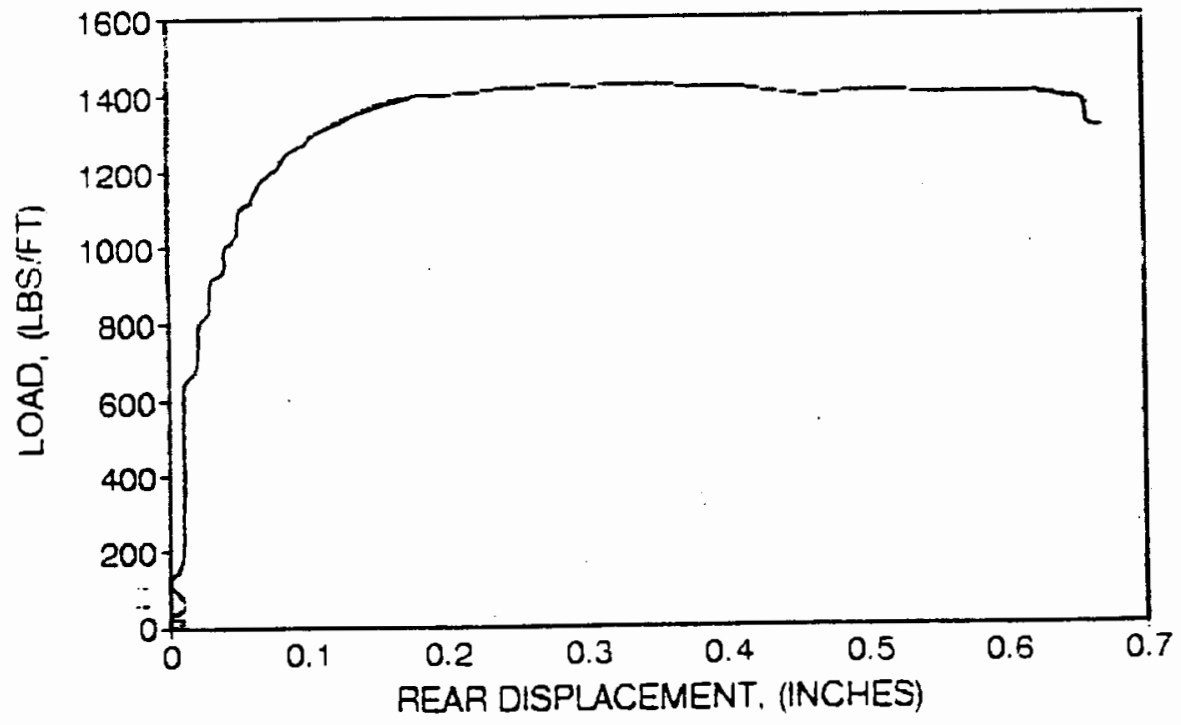




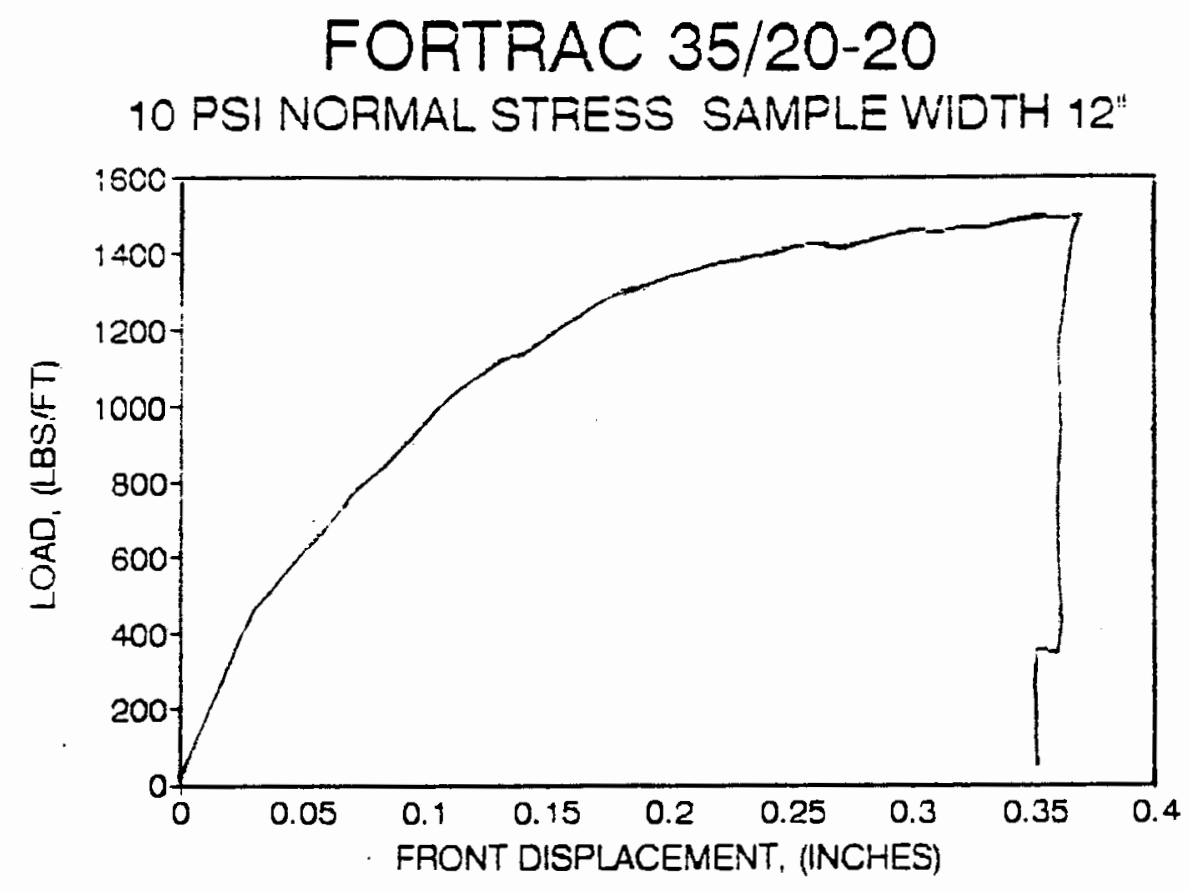

FORTRAC 35/20-20

10 PSI NORMAL STRESS. SAMPLE WIDTH $12^{\prime \prime}$

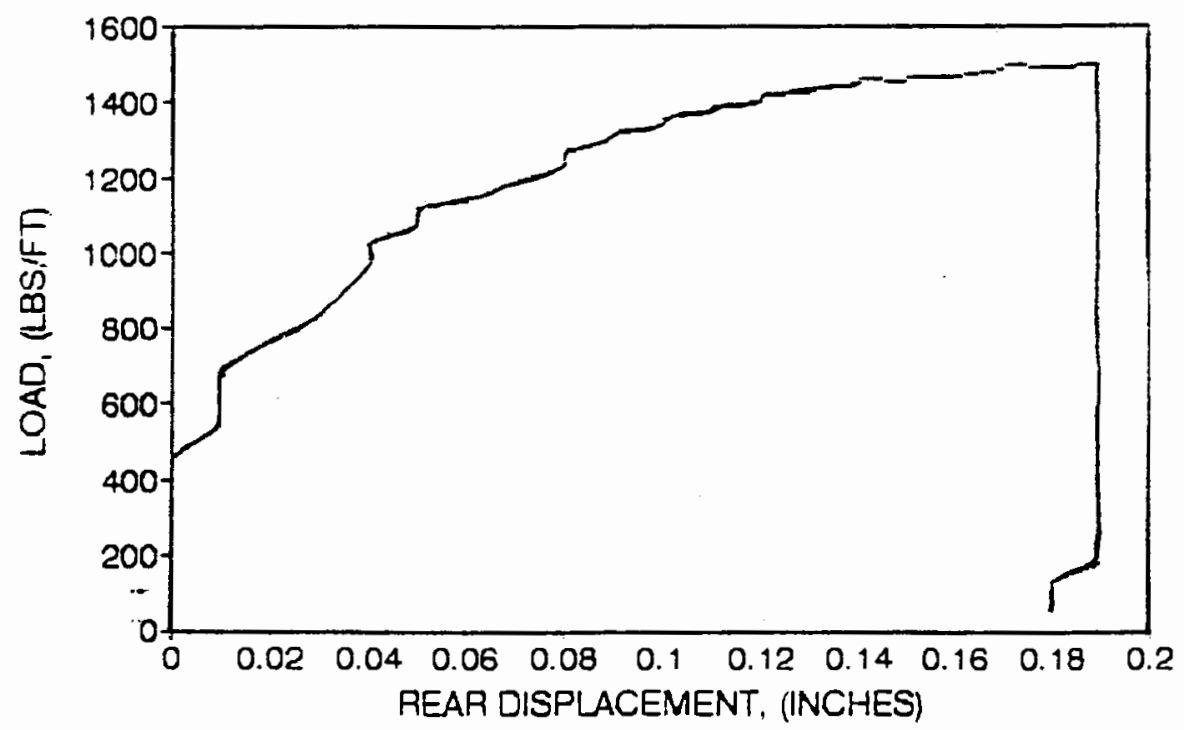



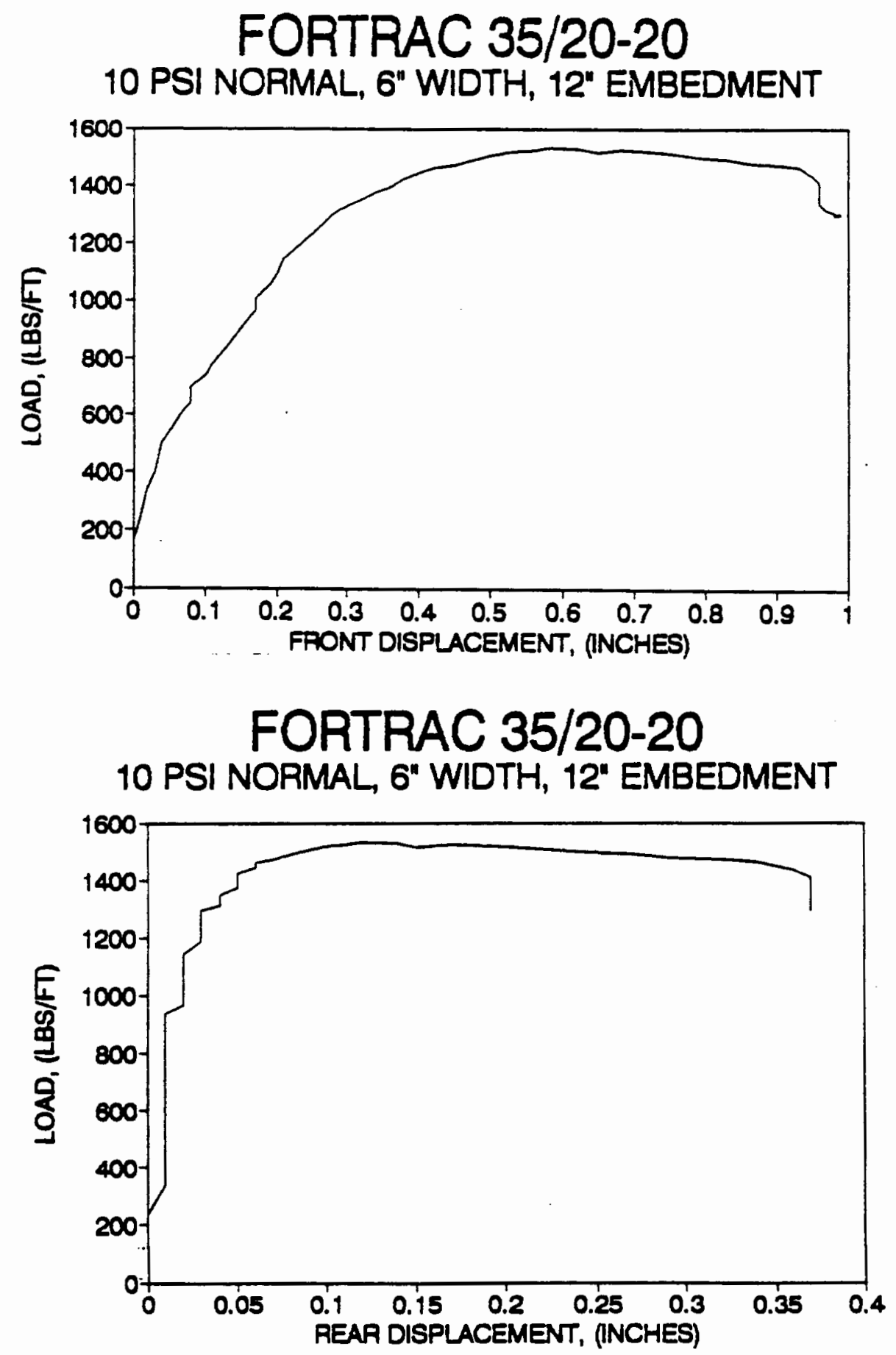

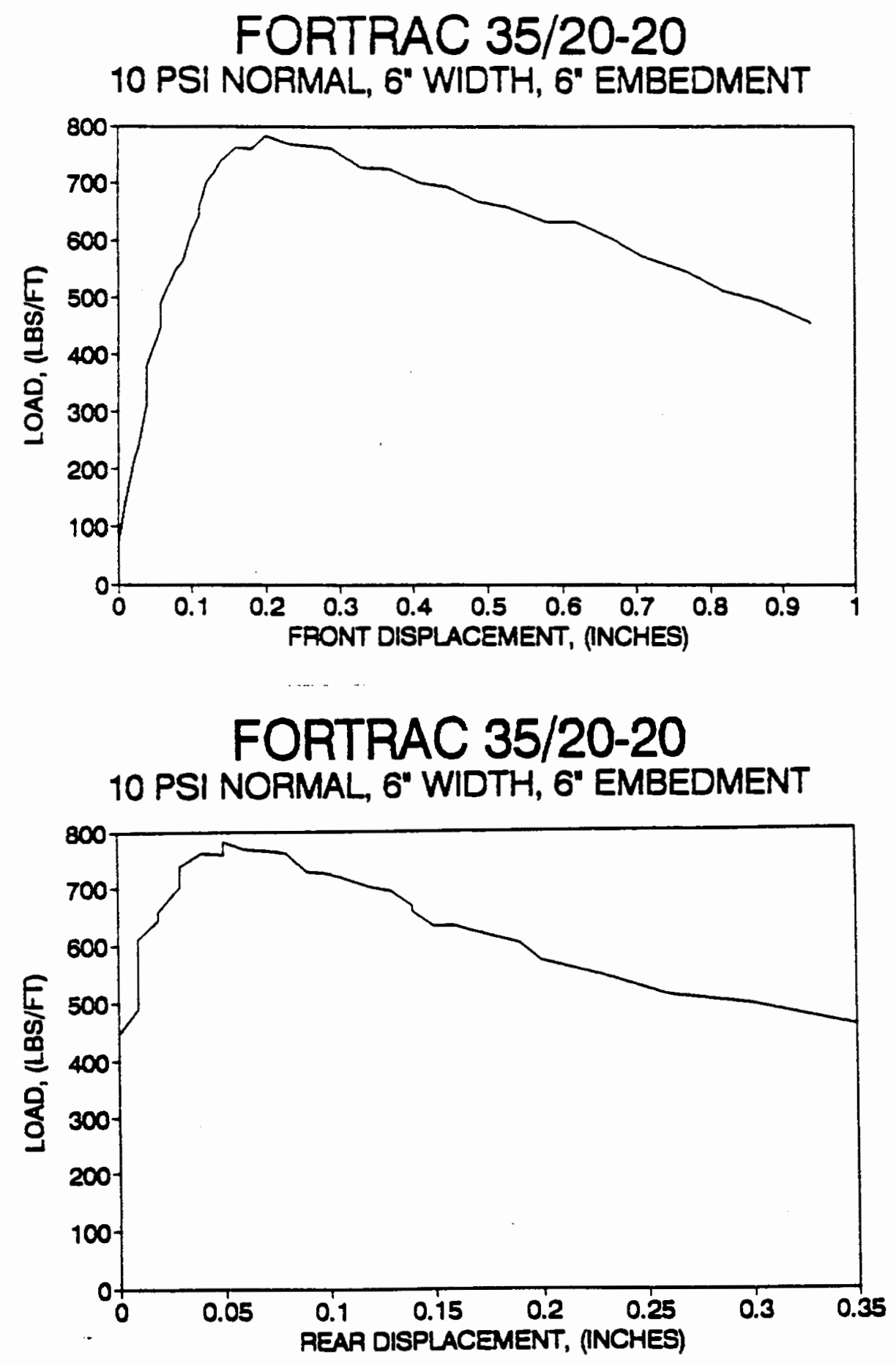
FORTRAC 35/20-20

10 PSI NORMAL STRESS. RELAXATION TEST

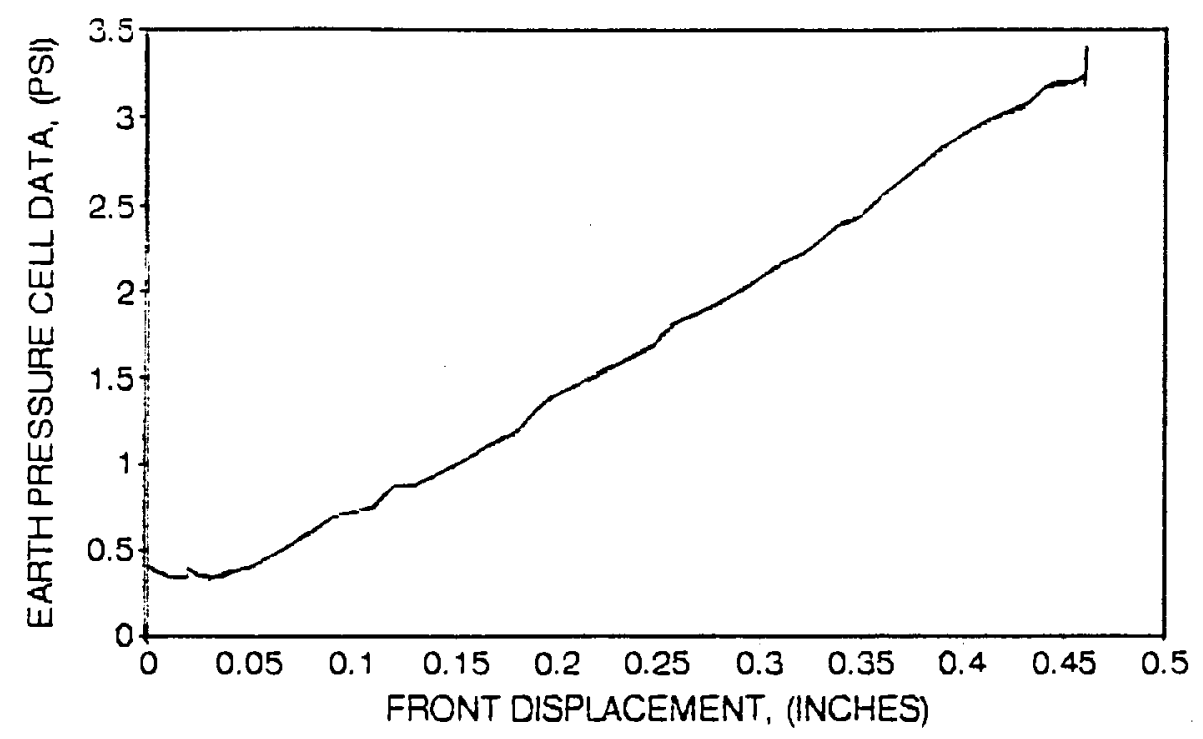

FORTRAC 35/20-20 10 PSI NORMAL STRESS. RELAXATION TEST

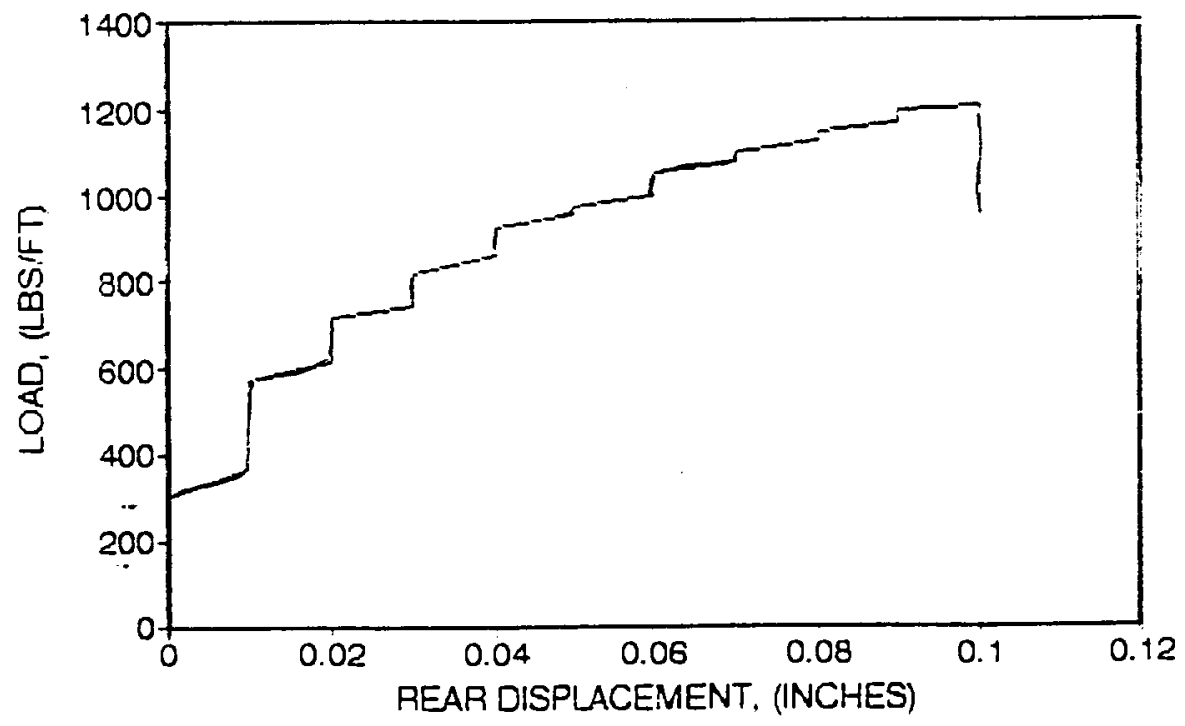


BAY MILLS 28501 SAMPLE WIDTH $=12^{\prime \prime}$

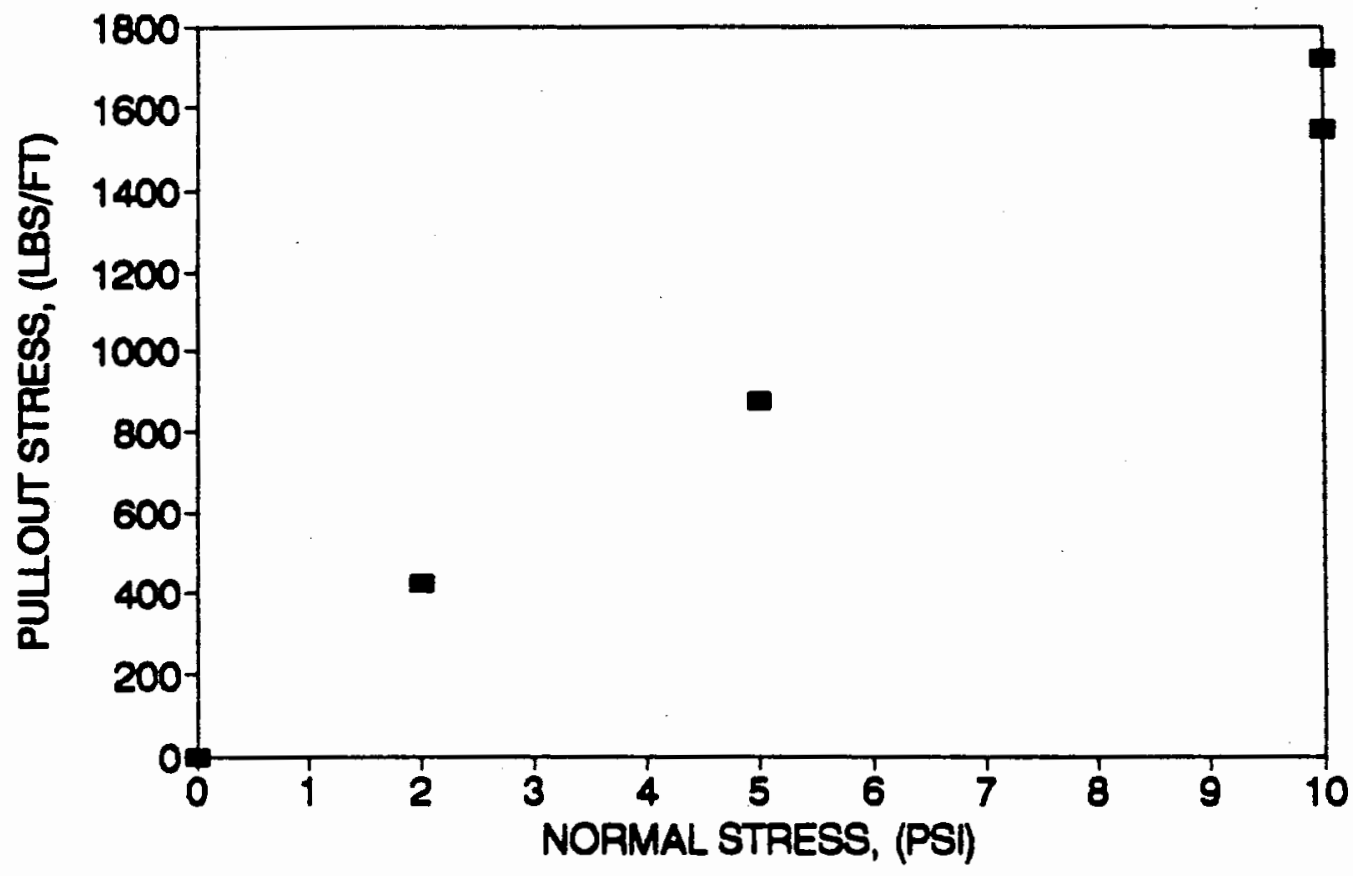


BAY MILLS 28501

2 PSI NORMAL STRESS, SAMPLE WIDTH 12"

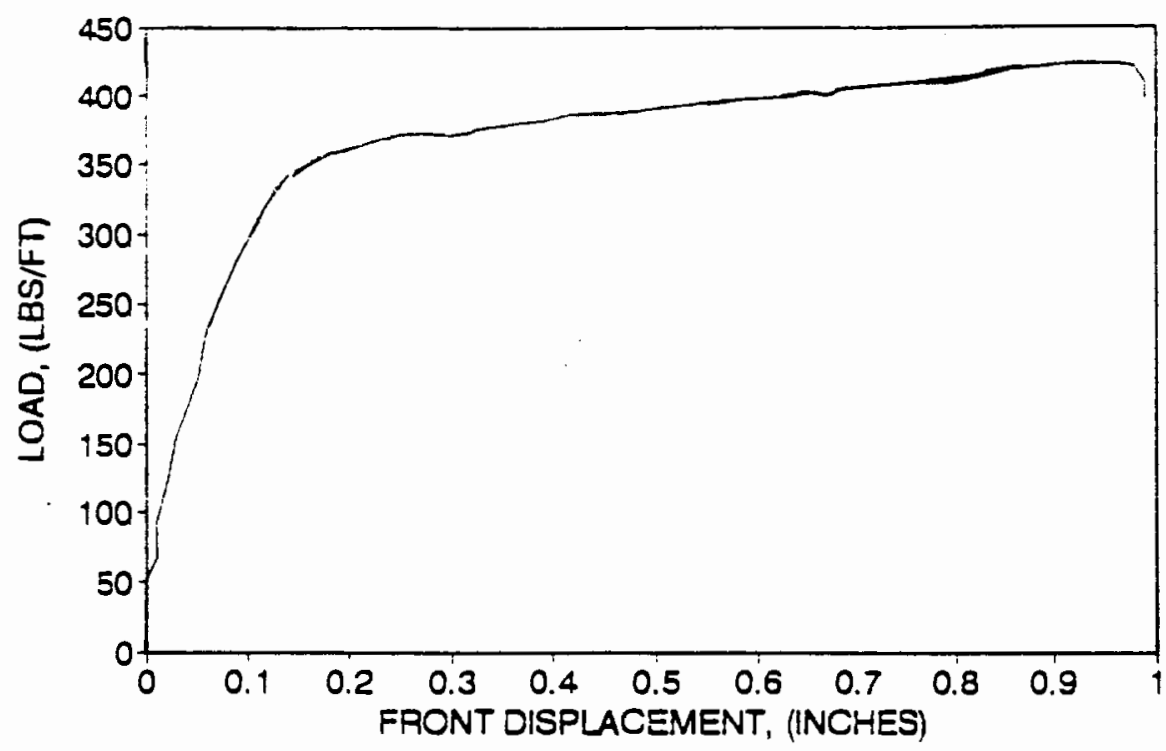

BAY MILLS 28501

2 PSI NORMAL STRESS, SAMPLE WIDTH 12"

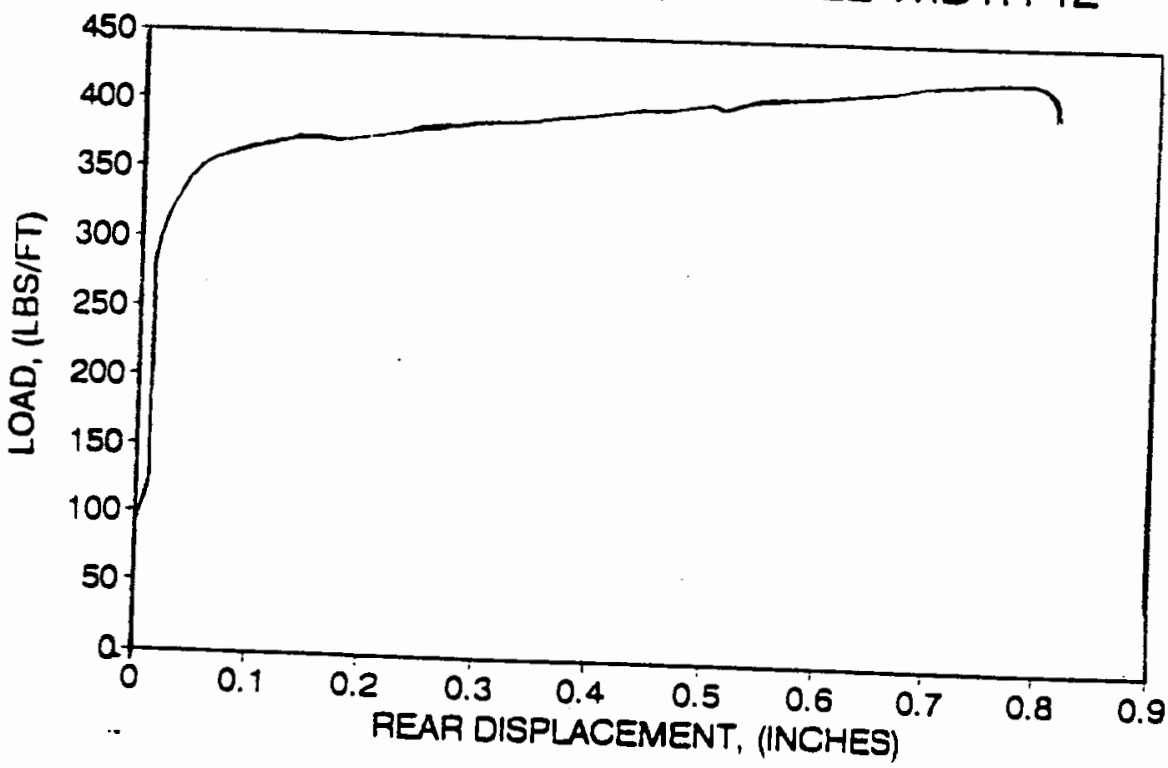



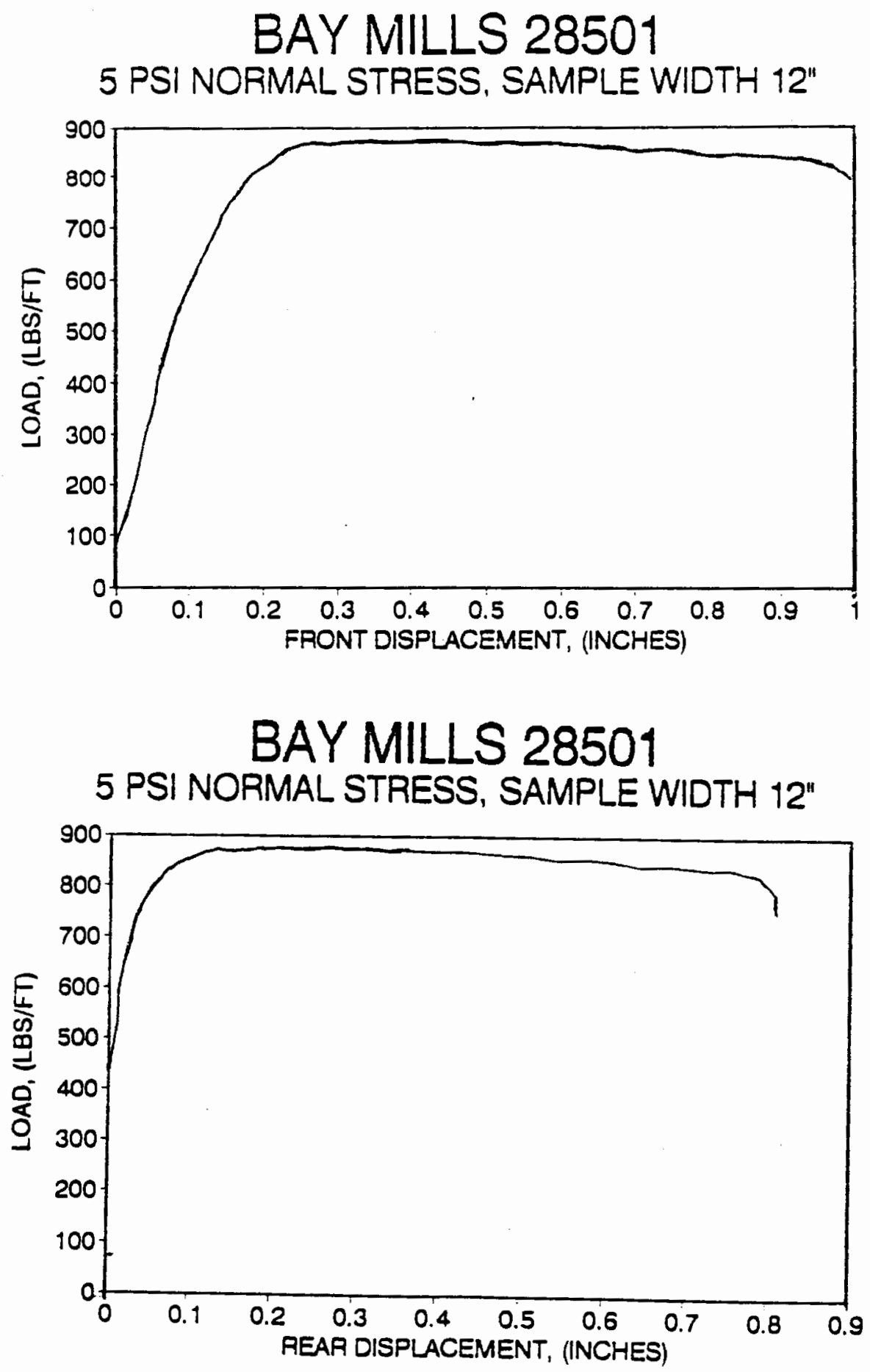
BAY MILLS 28501

10 PSI NORMAL STRESS. SAMPLE WIDTH 12"

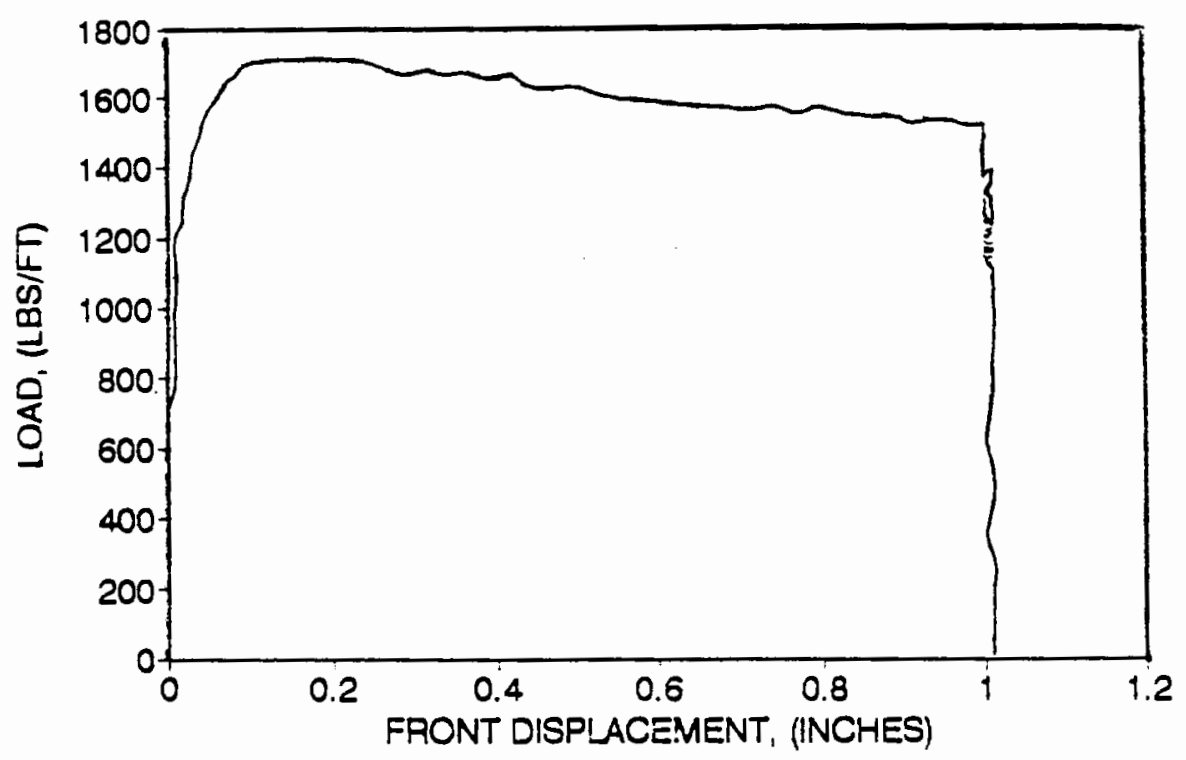

BAY MILLS 28501

10 PSI NORMAL STRESS, SAMPLE WIDTH 12"

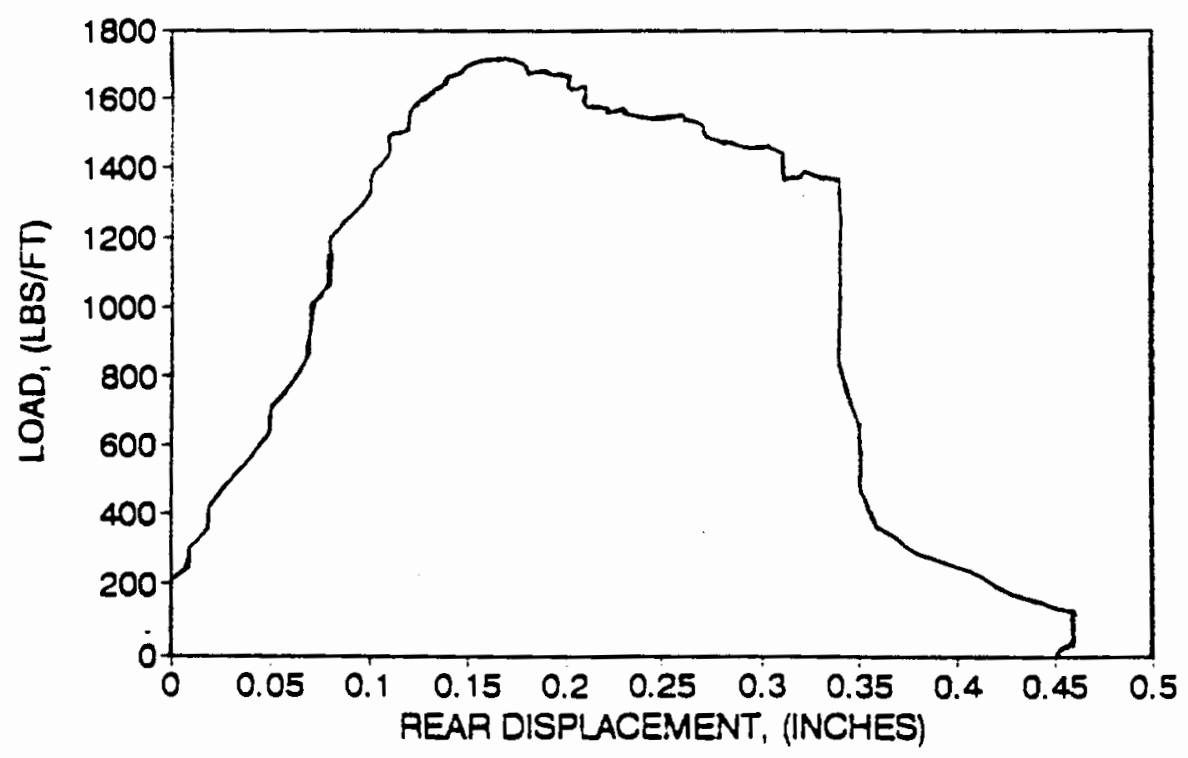


BAY MILLS 28502 (w) SAMPLE WIDTH $=12^{\prime \prime}$

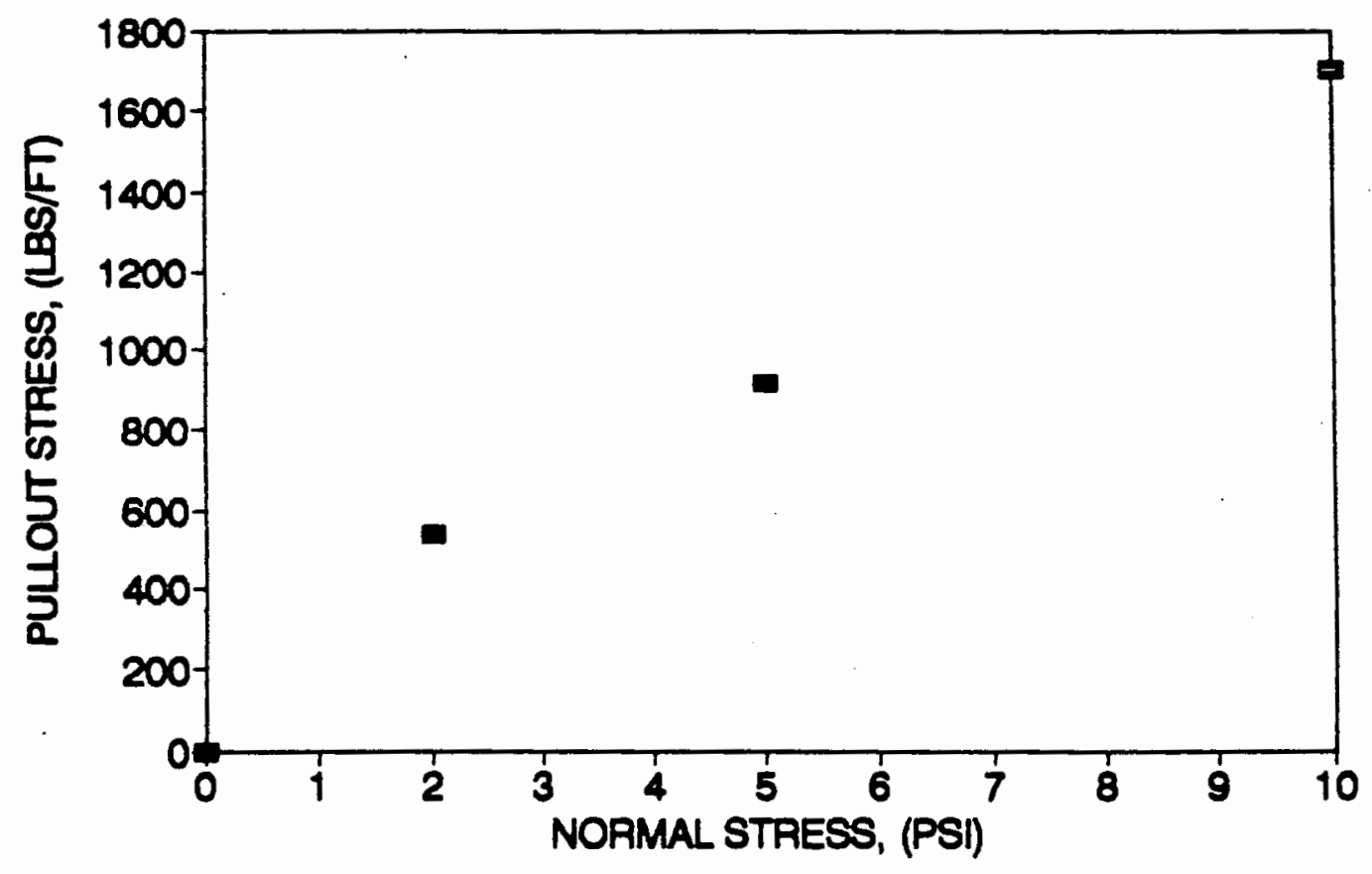



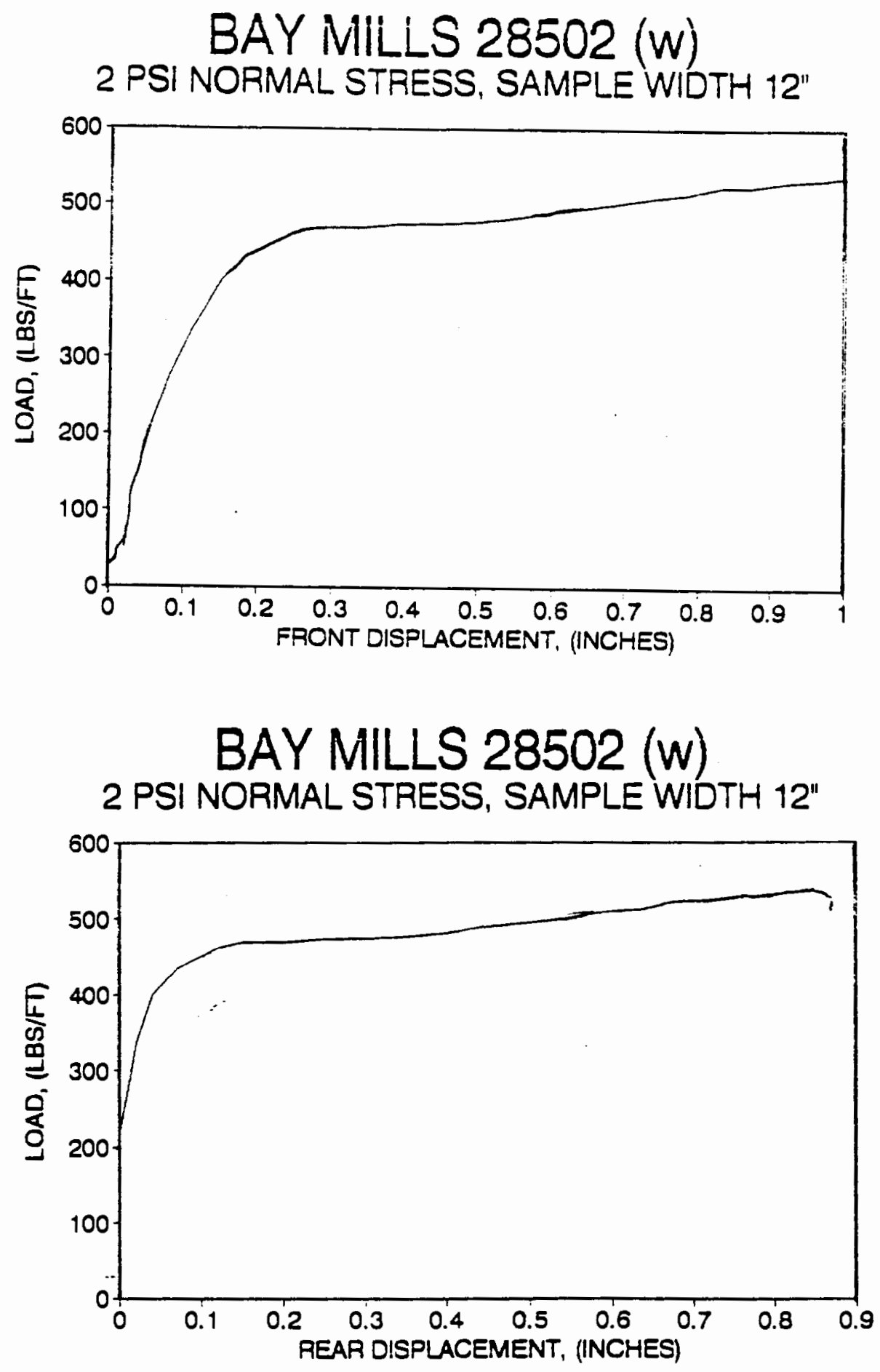

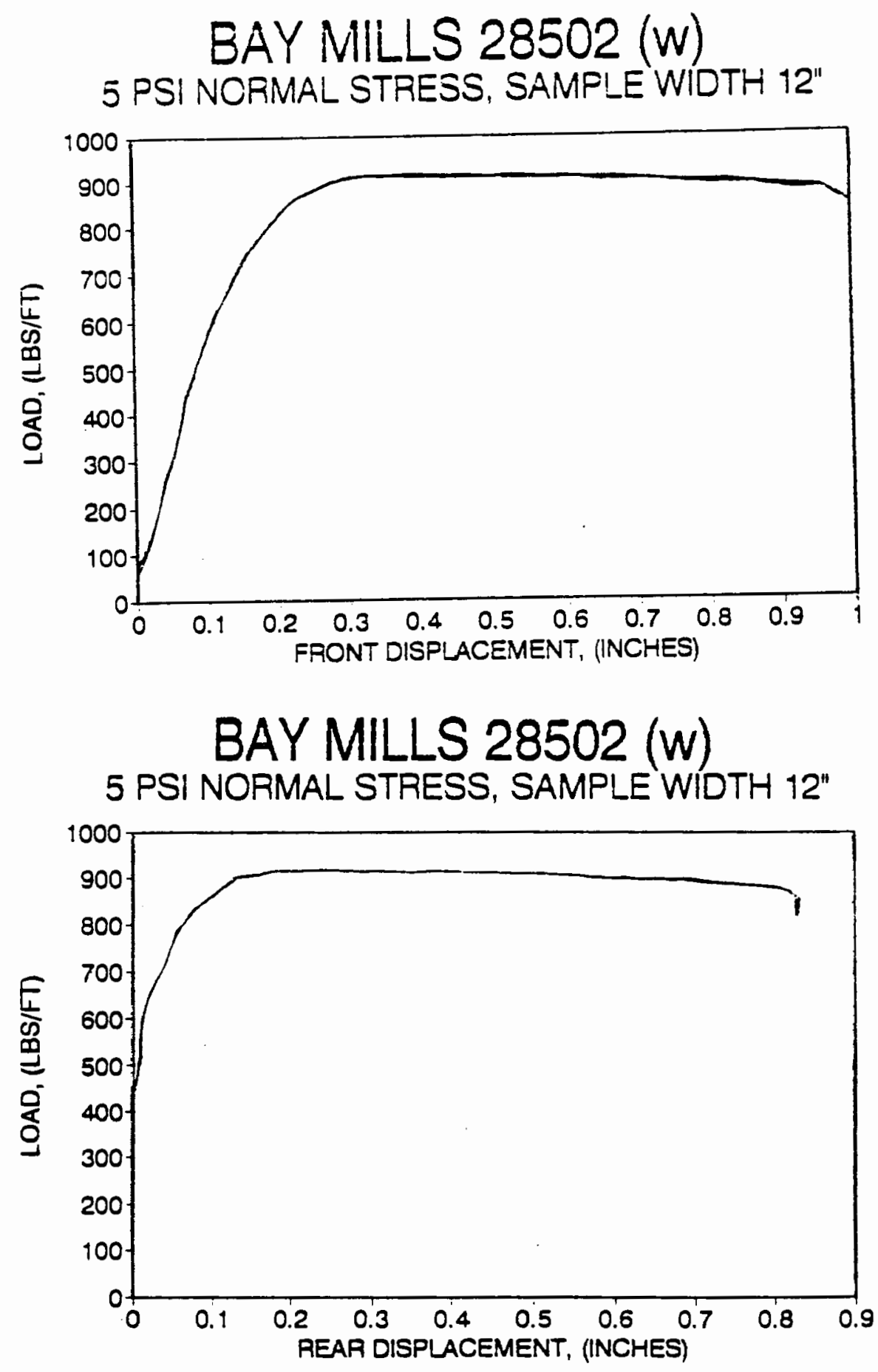

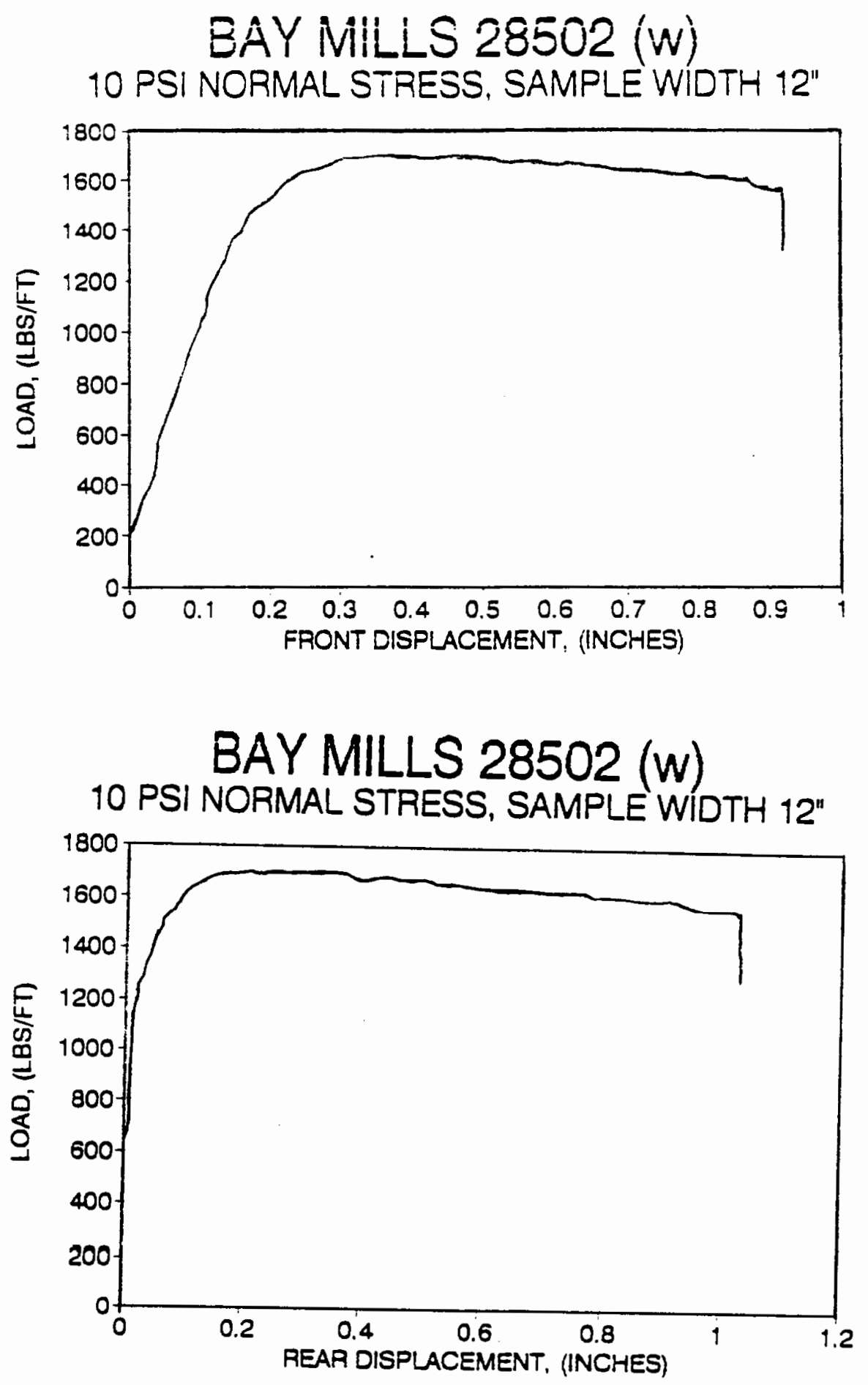
BAY MiLLS 28502 (W)

15 PSI NOFMAL STRESS. SAMPLE WIDTH $12^{\prime \prime}$

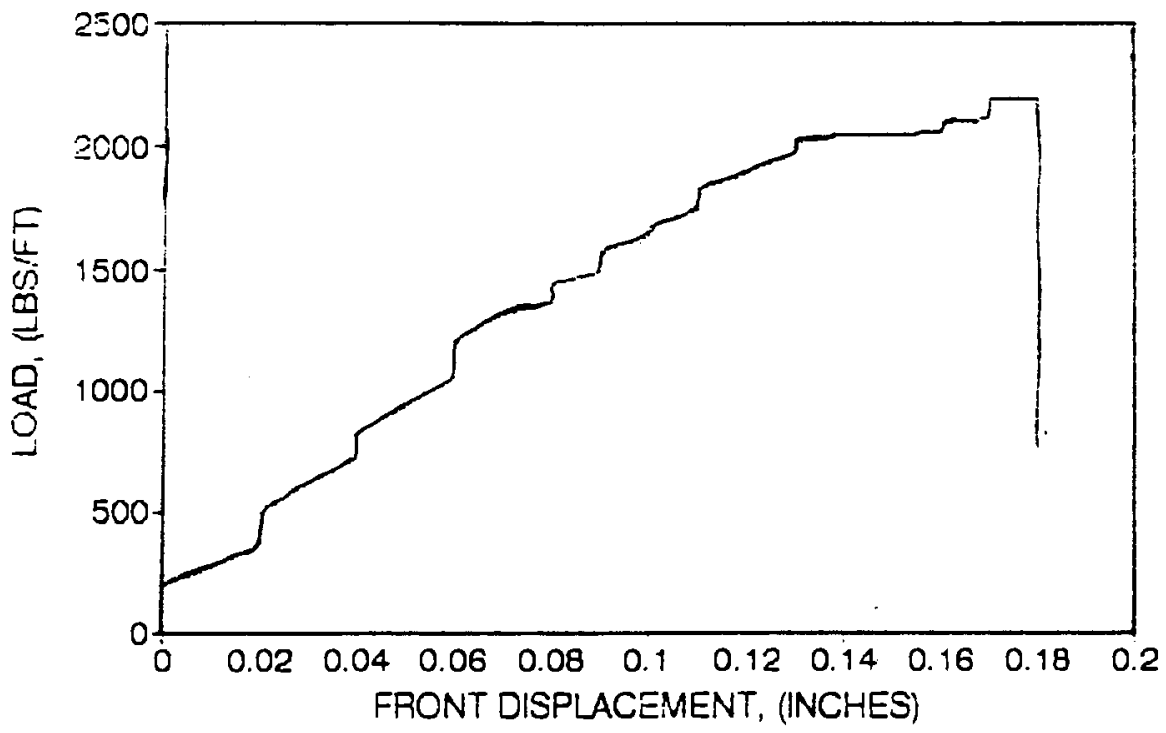

BAY MILLS 28502 (w)

15 PSI NORMAL STRESS. SAMPLE WIDTH $12^{\prime \prime}$

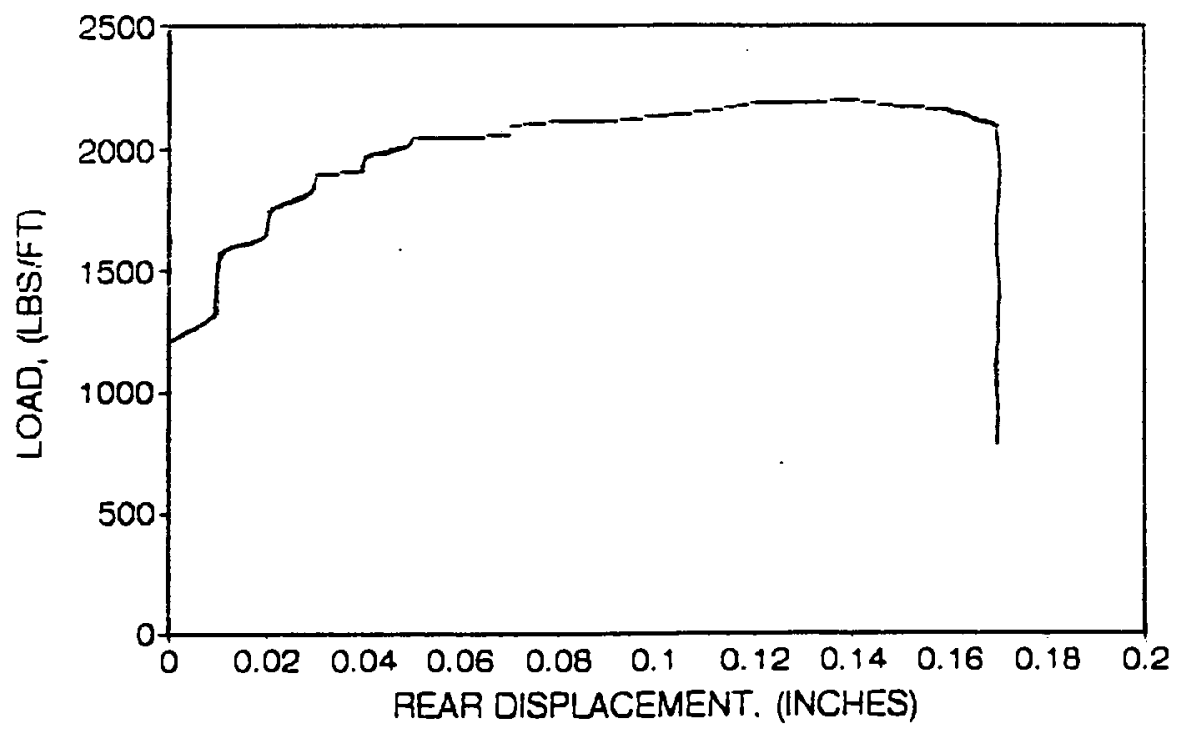


BAY MIiLLS 28502 (s)

10 FSI NORMAL STRESS. SAMPLE WIDTH $12^{\prime \prime}$

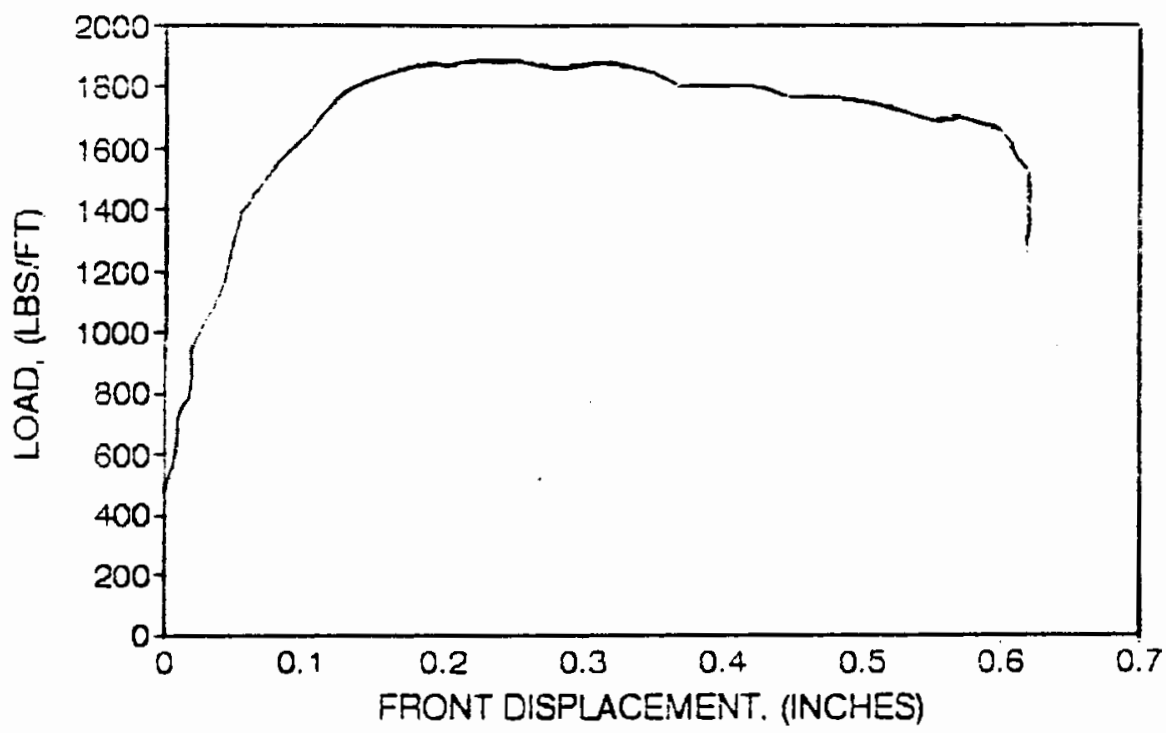

BAY MILLS 28502 (s)

10 PSI NORMAL STRESS. SAMPLE WIDTH' $12^{\prime \prime}$

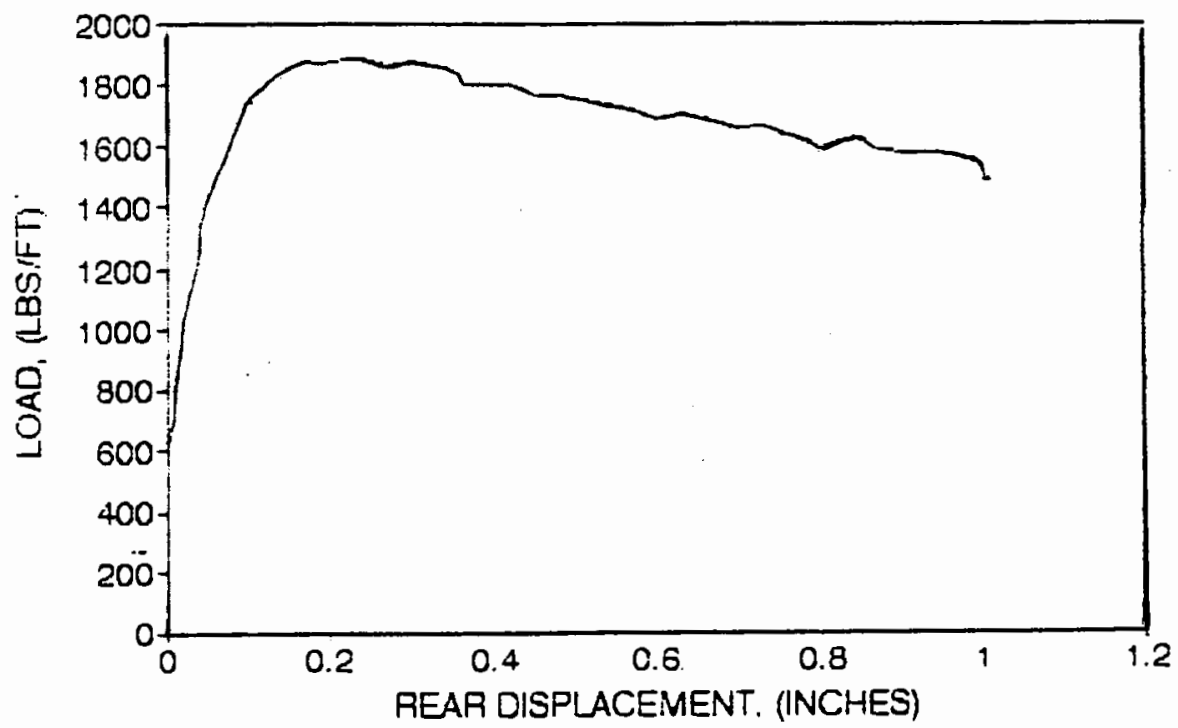




\section{TENAX 201 \\ SAMPLE WIDTH $=12$}

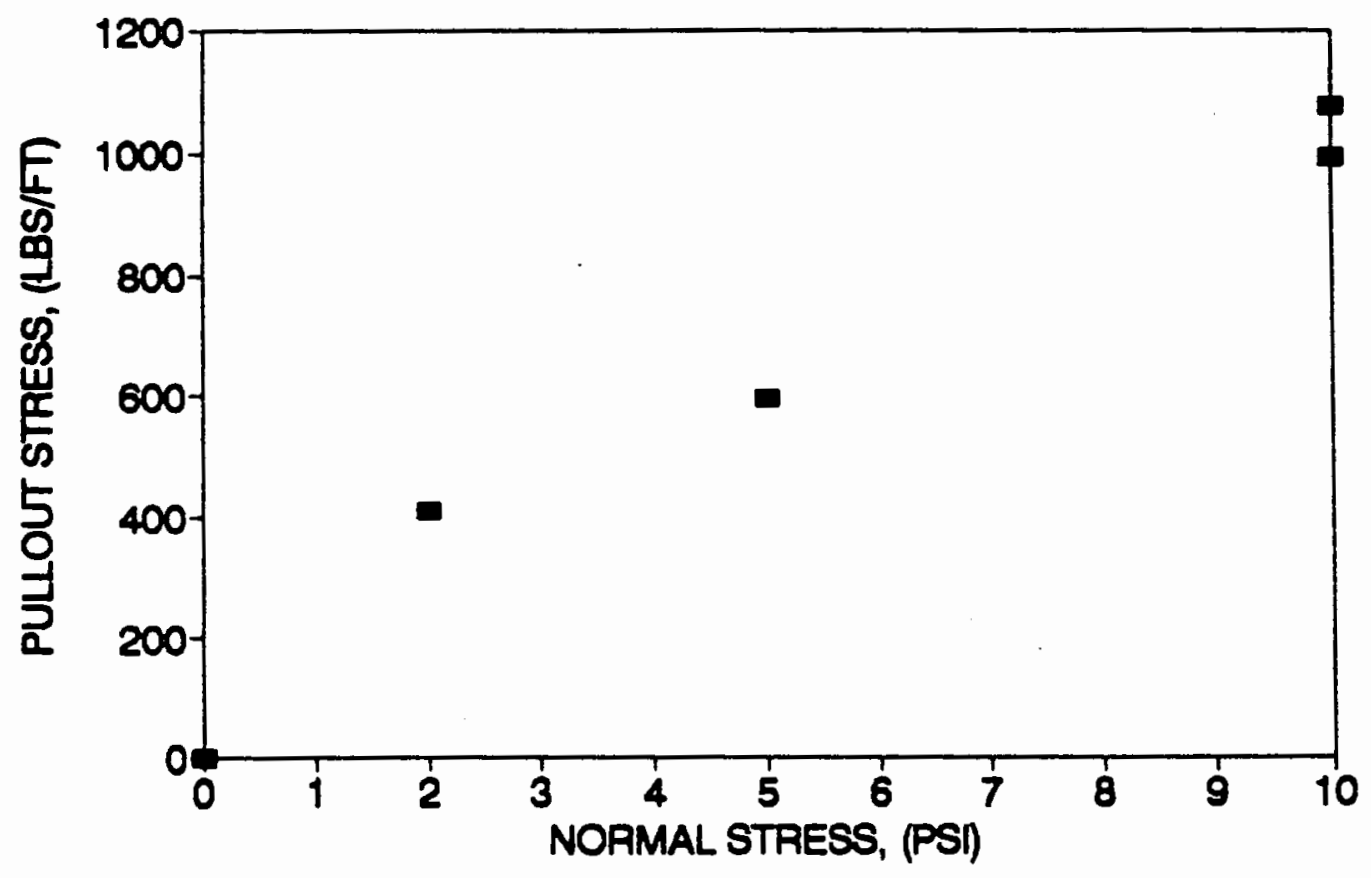



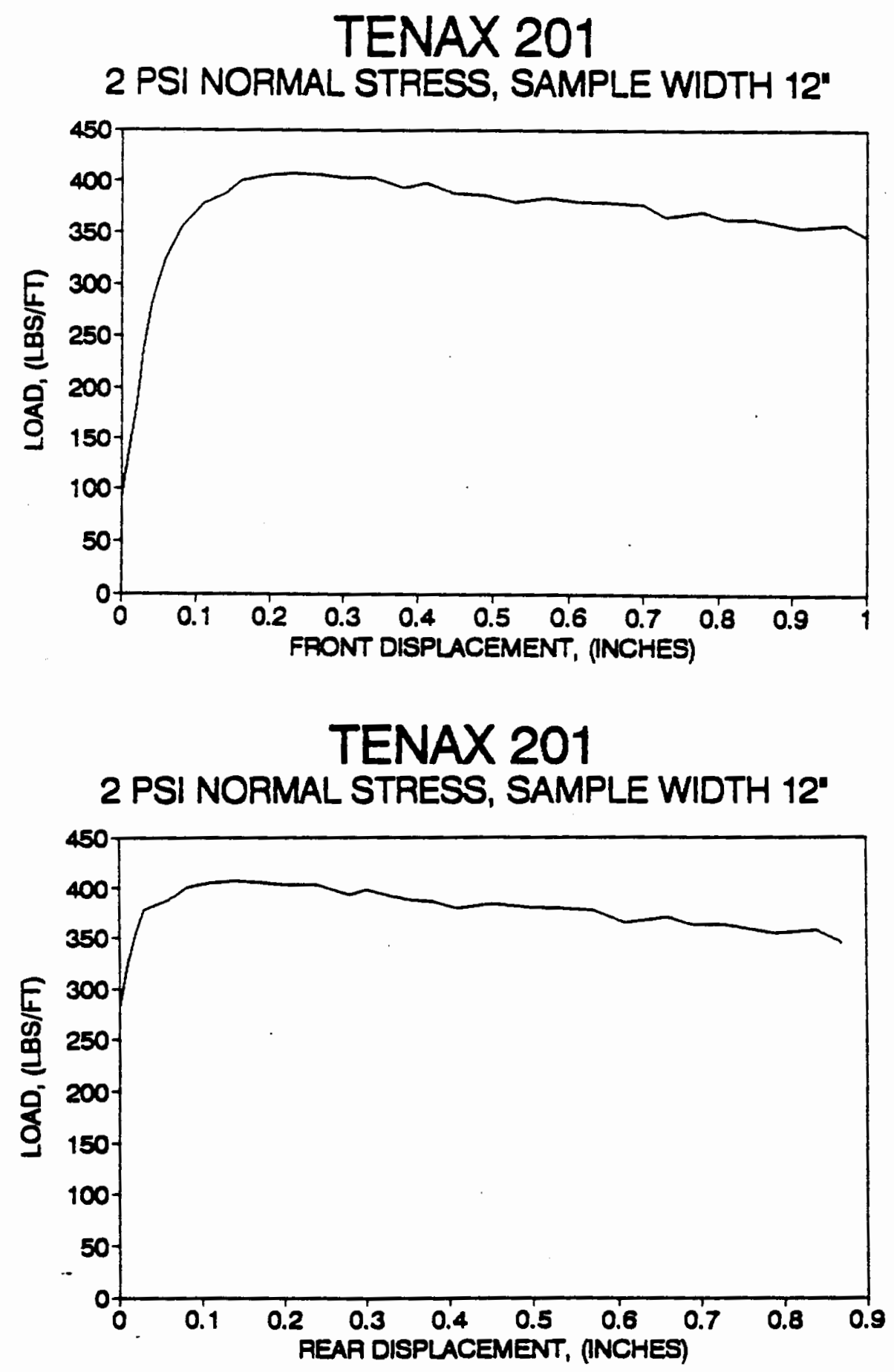


\section{TENAX 201}

5 PSI NORMAL STRESS, SAMPLE WIDTH 12"

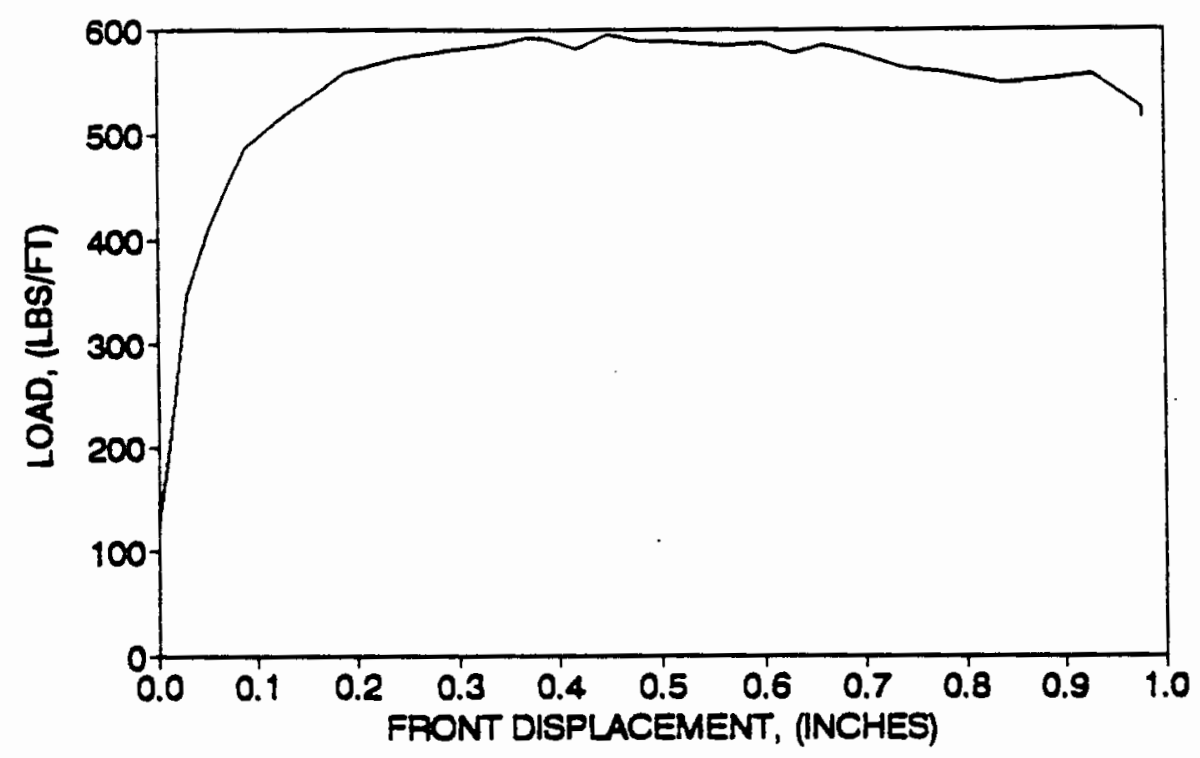

TENAX 201

$\because$ PSI NORMAL STRESS, SAMPLE WIDTH 12"

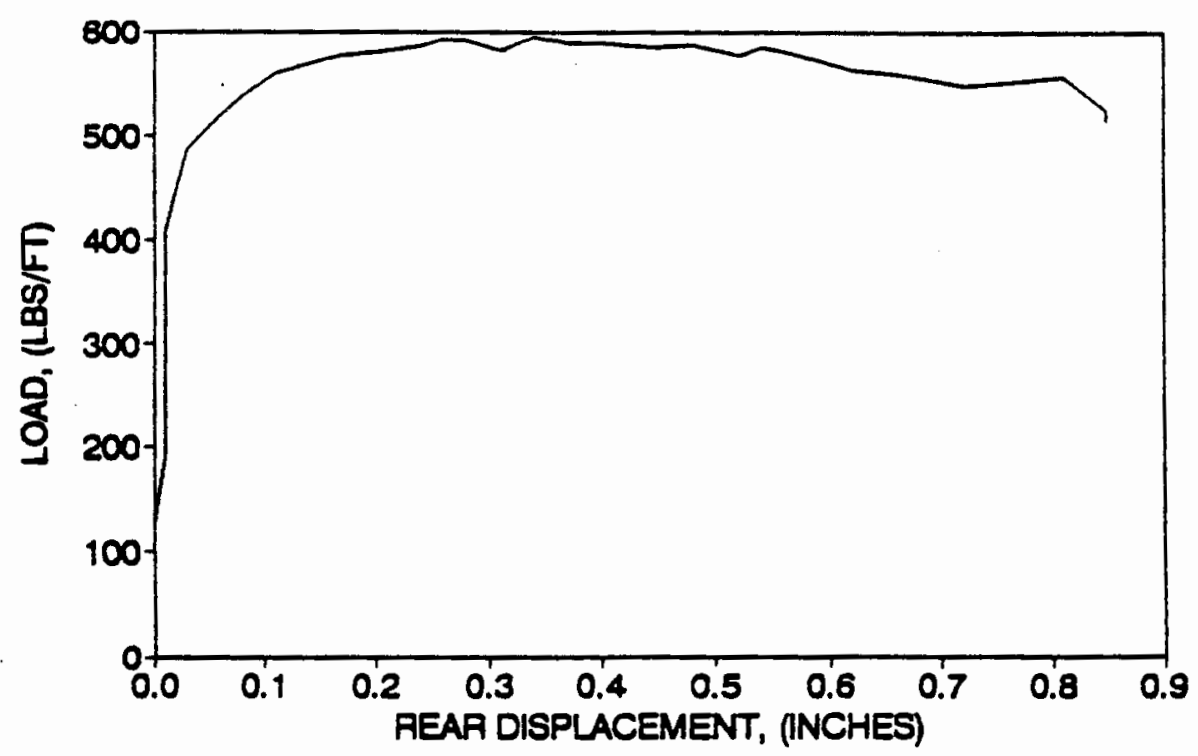



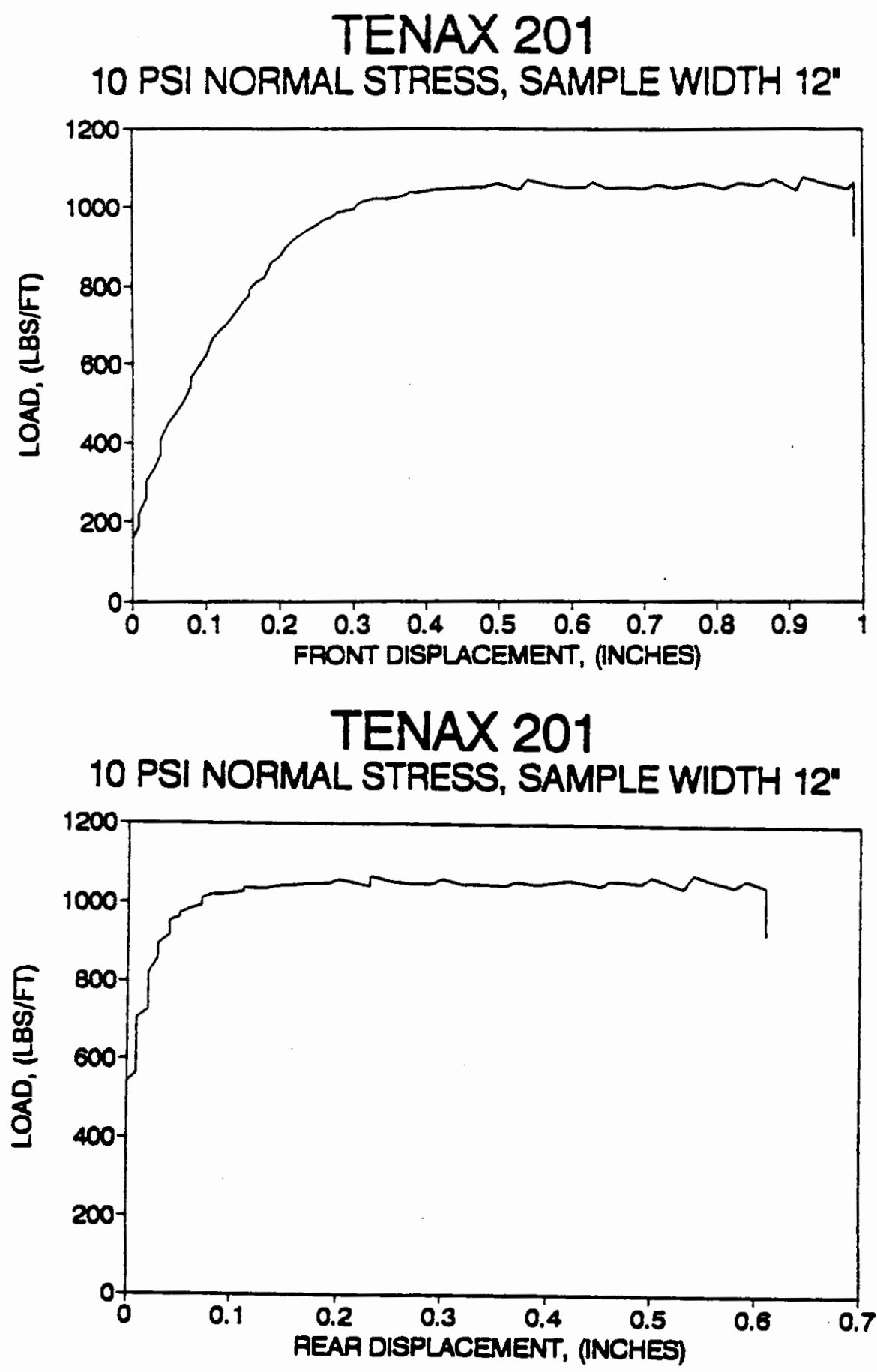


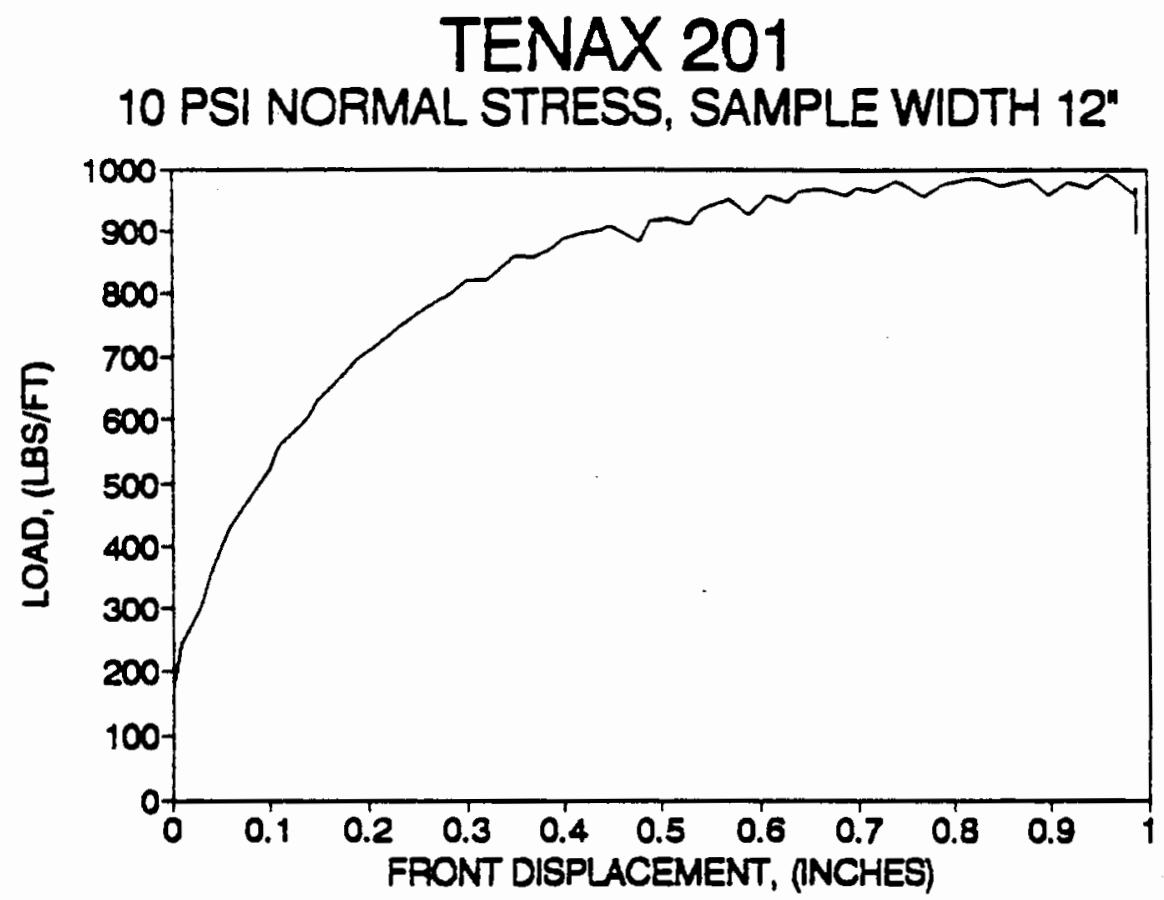

\section{TENAX 201}

10 PSI NORMAL STRESS, SAMPLE WIDTH 12"

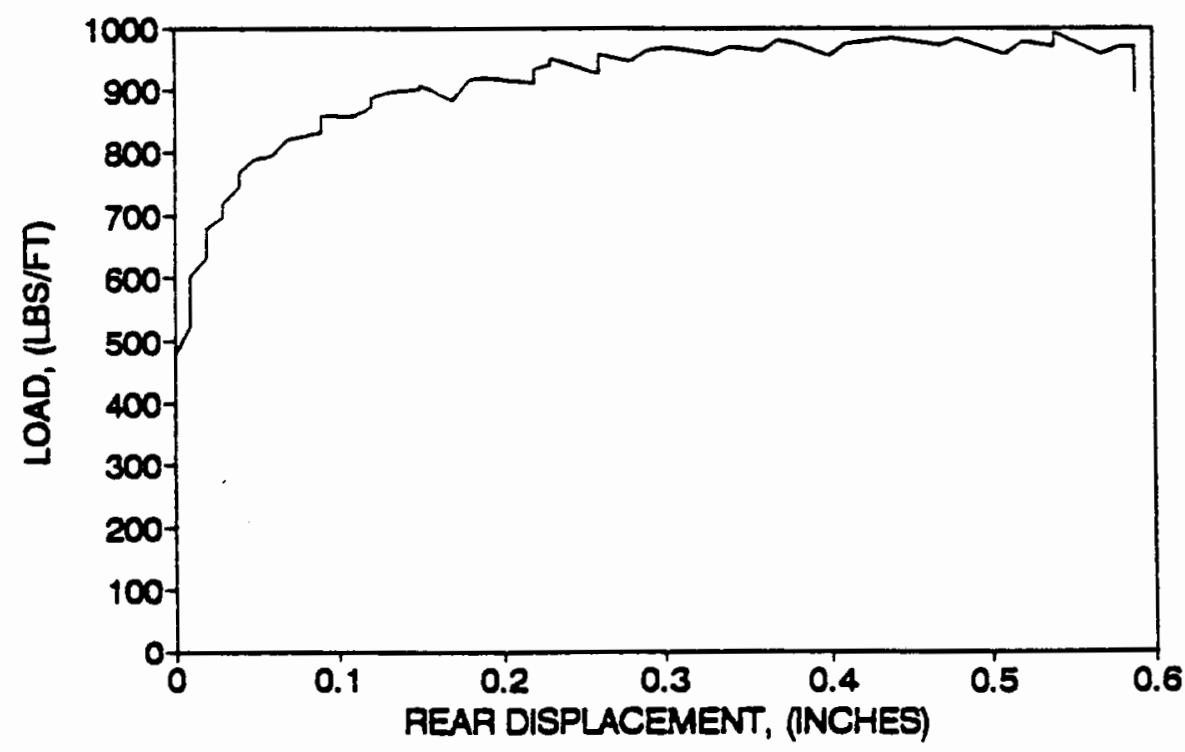




\section{TENAX 301 \\ SAMPLE WIDTH $=12^{\prime \prime}$}

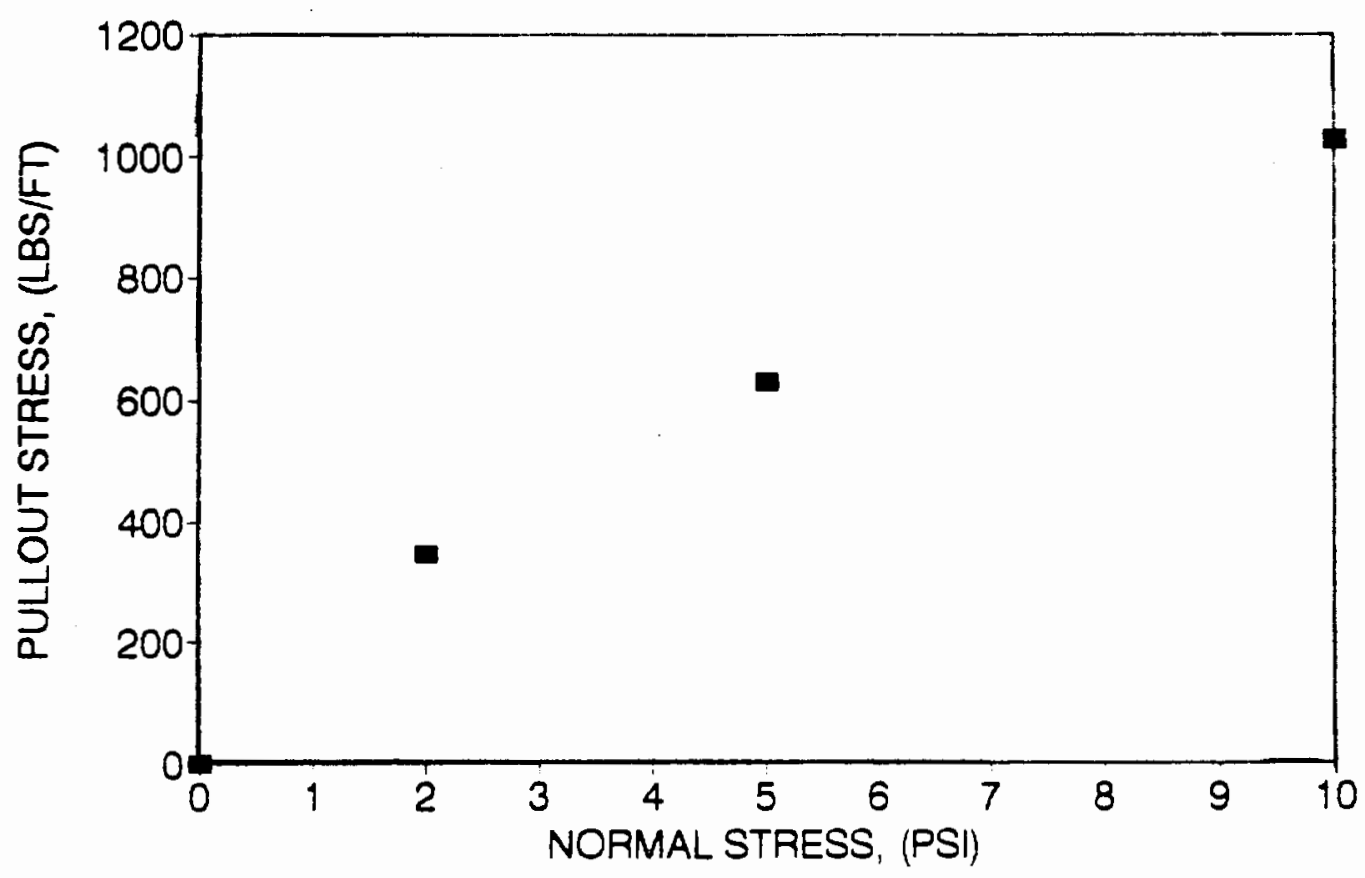




\section{TENAX 301}

2 PSI NORMAL STRESS. SAMPLE WIDTH $12 "$

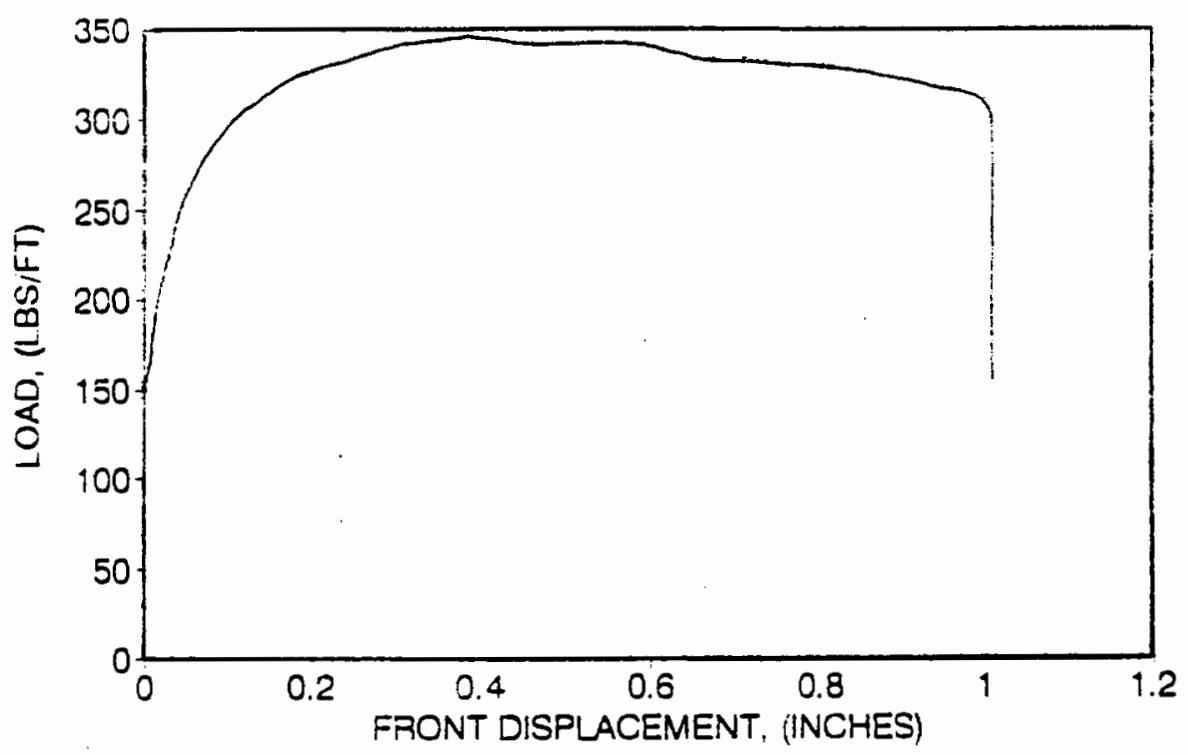

TENAX 301

2 PSI NORMAL STRESS. SAMPLE WIDTH 12"

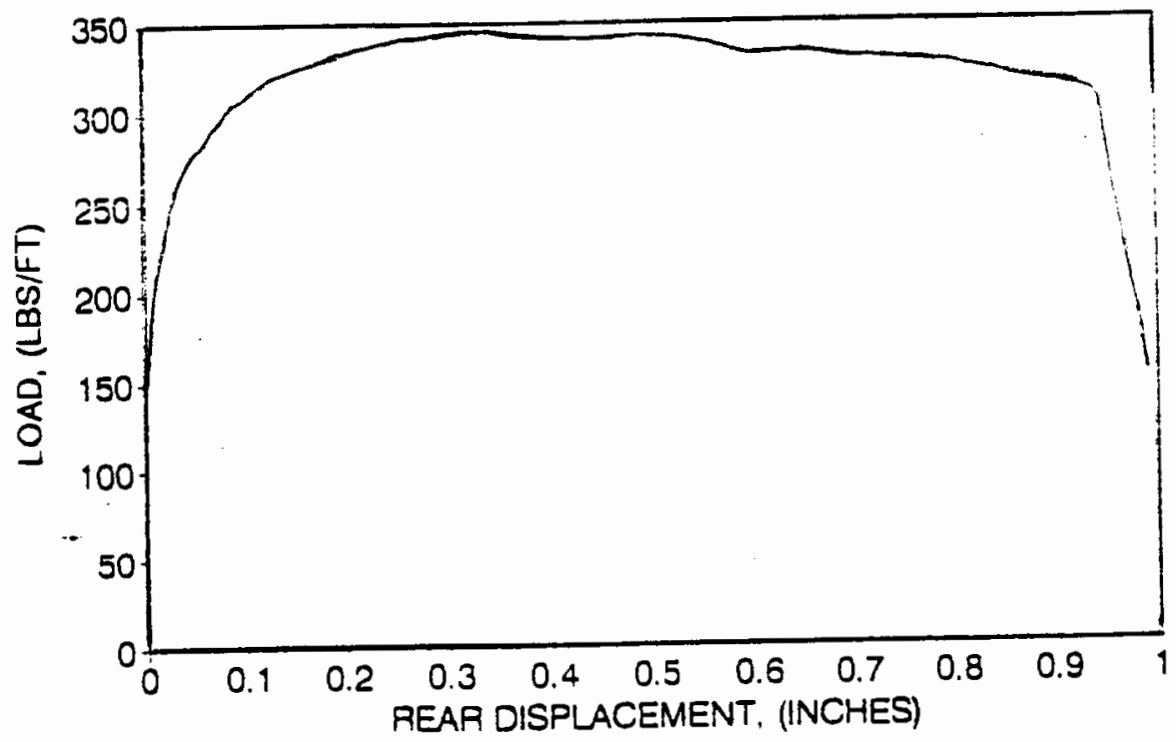


TENAX 301

5 PSI NORMAL STRESS. SAMPLE WICTH $12^{\prime \prime}$

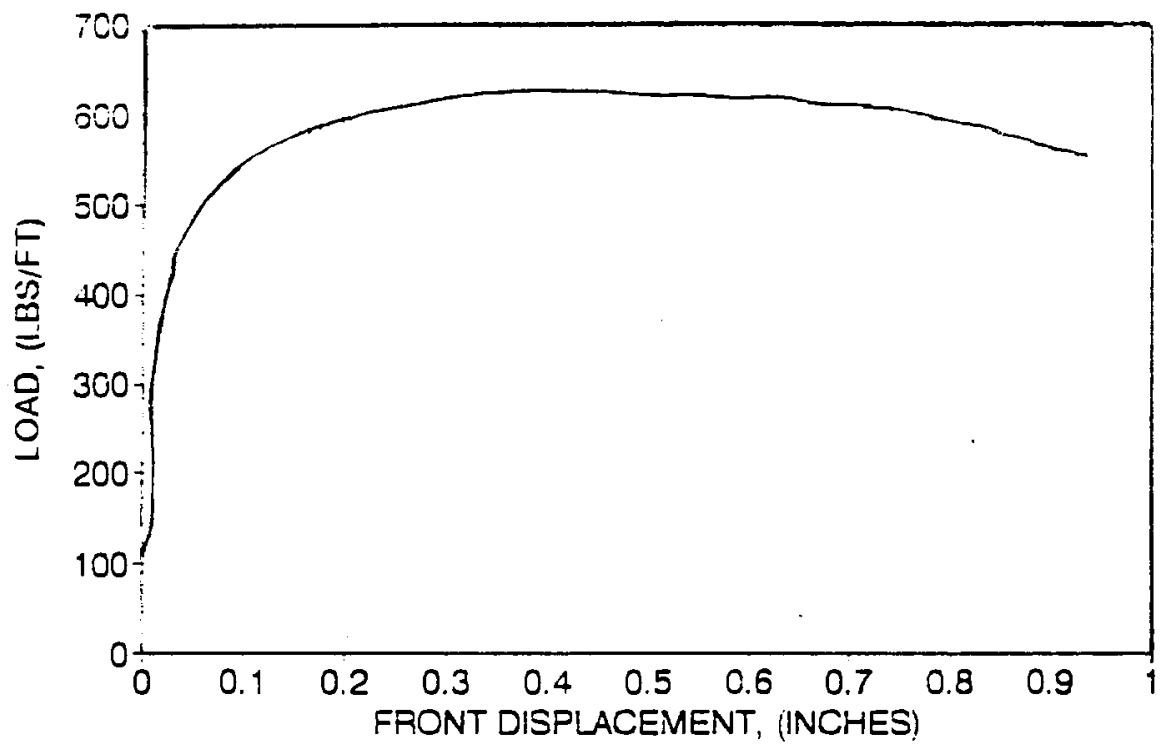

\section{TENAX 301}

5 PSI NORMAL STRESS. SAMPLE WIDTH 12"

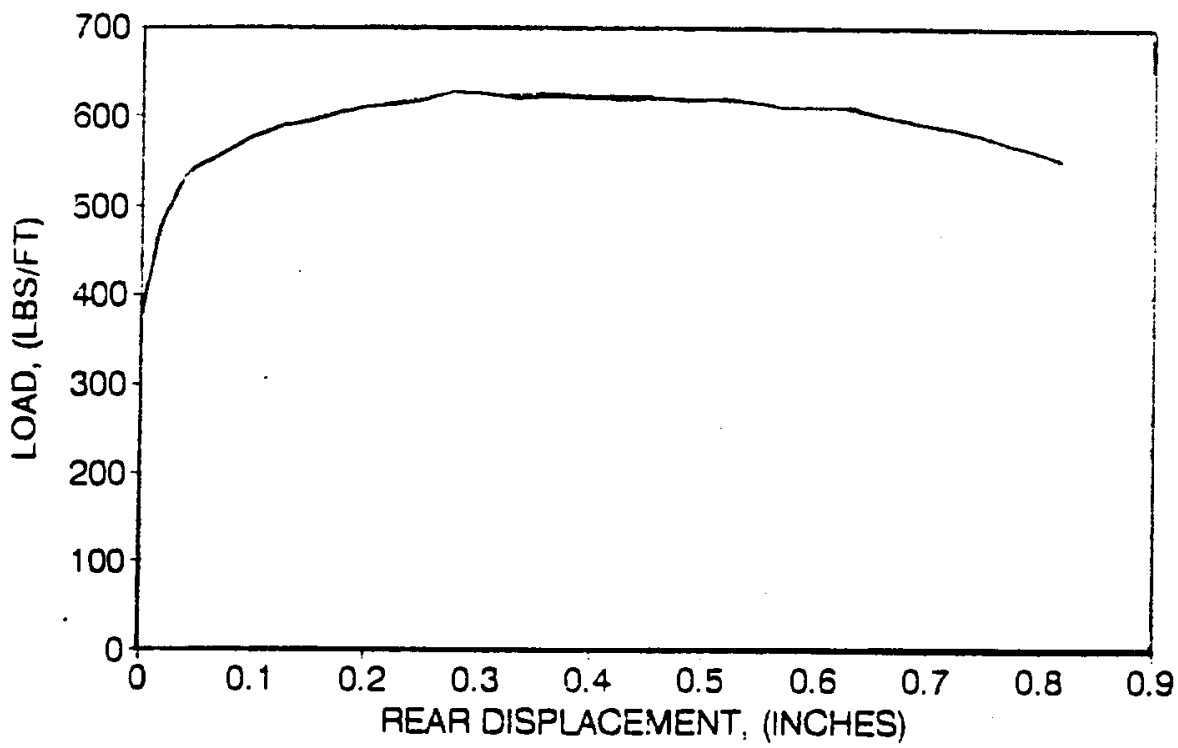



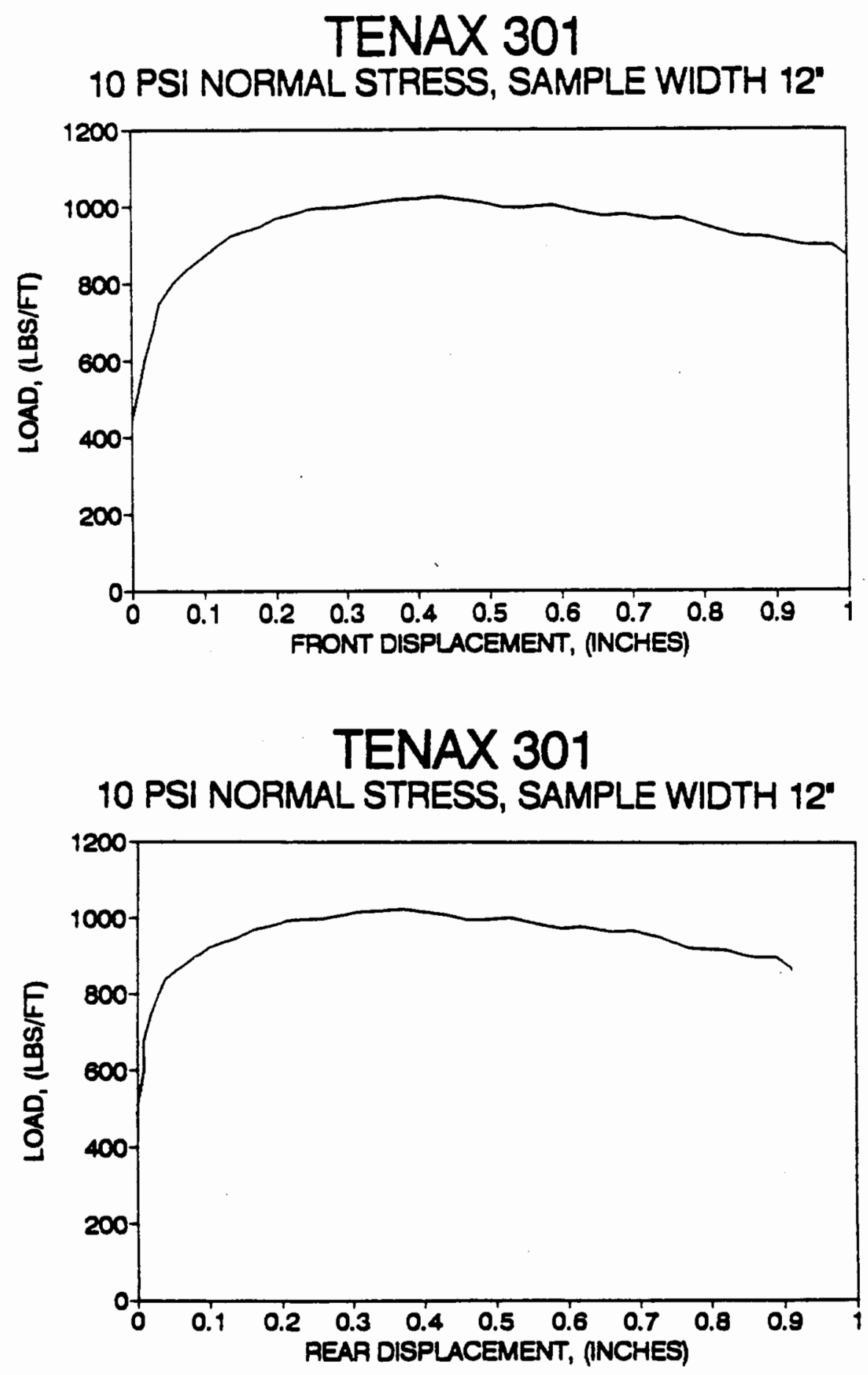


\section{TENAX 401 \\ SAMPLE WIDTH $=12^{\prime \prime}$}

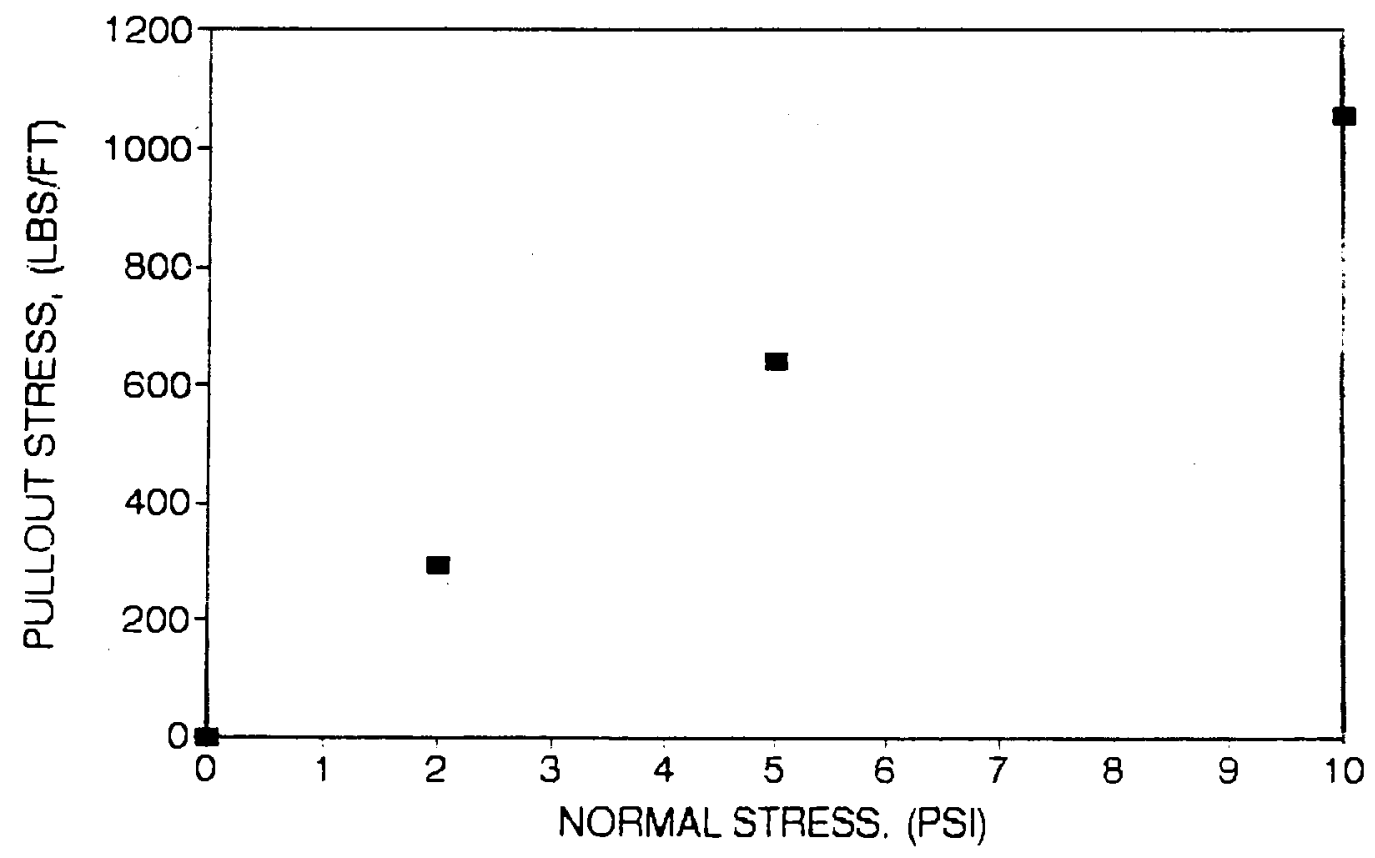




\section{TENAX 401}

2 PSI NOFMAL STRESS. SAMVLE WIOTH $12^{\prime \prime}$
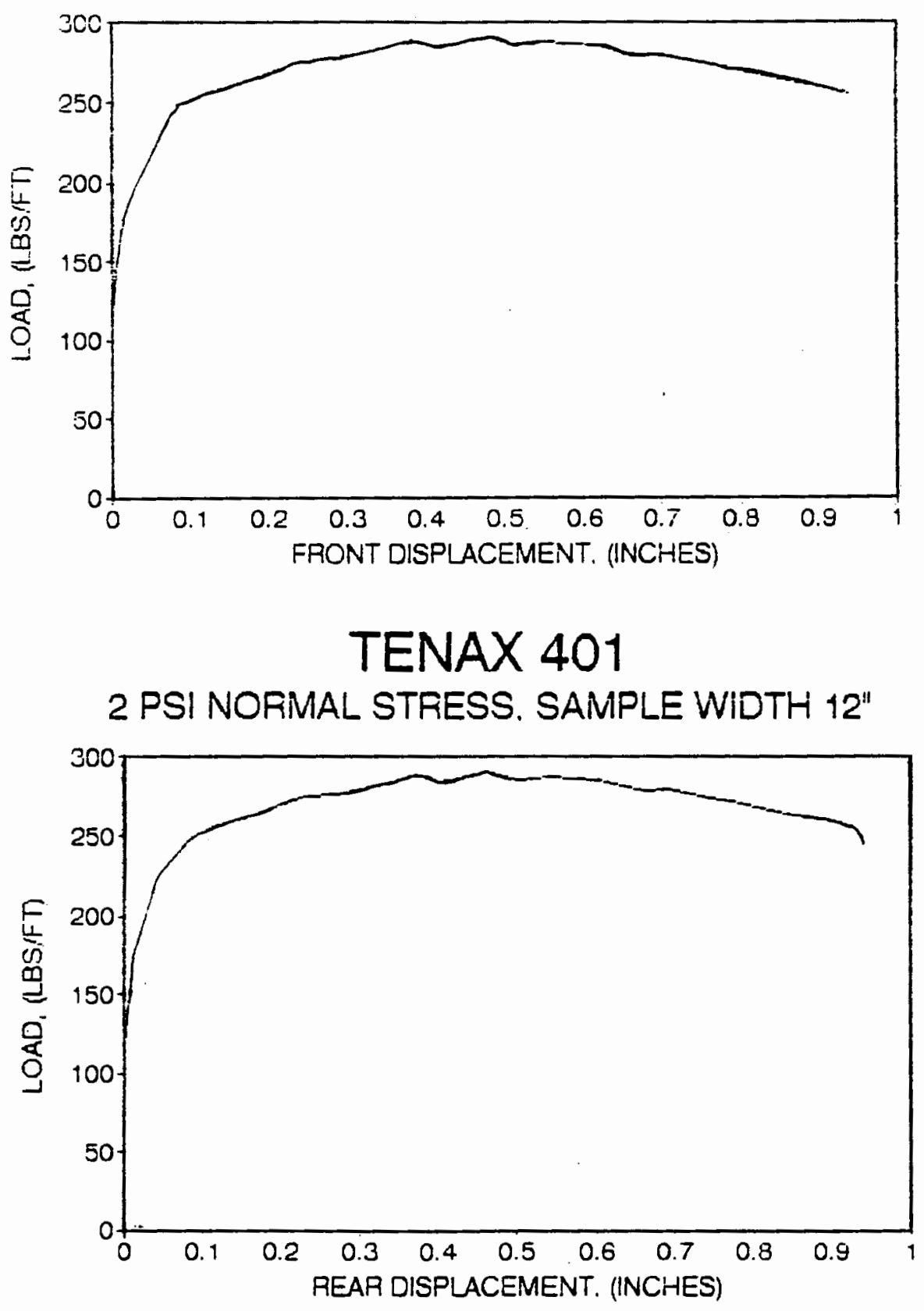
TENAX 401

5 PSI NORMAL STRESS. SAMPLE WIOTH $12^{\prime \prime}$

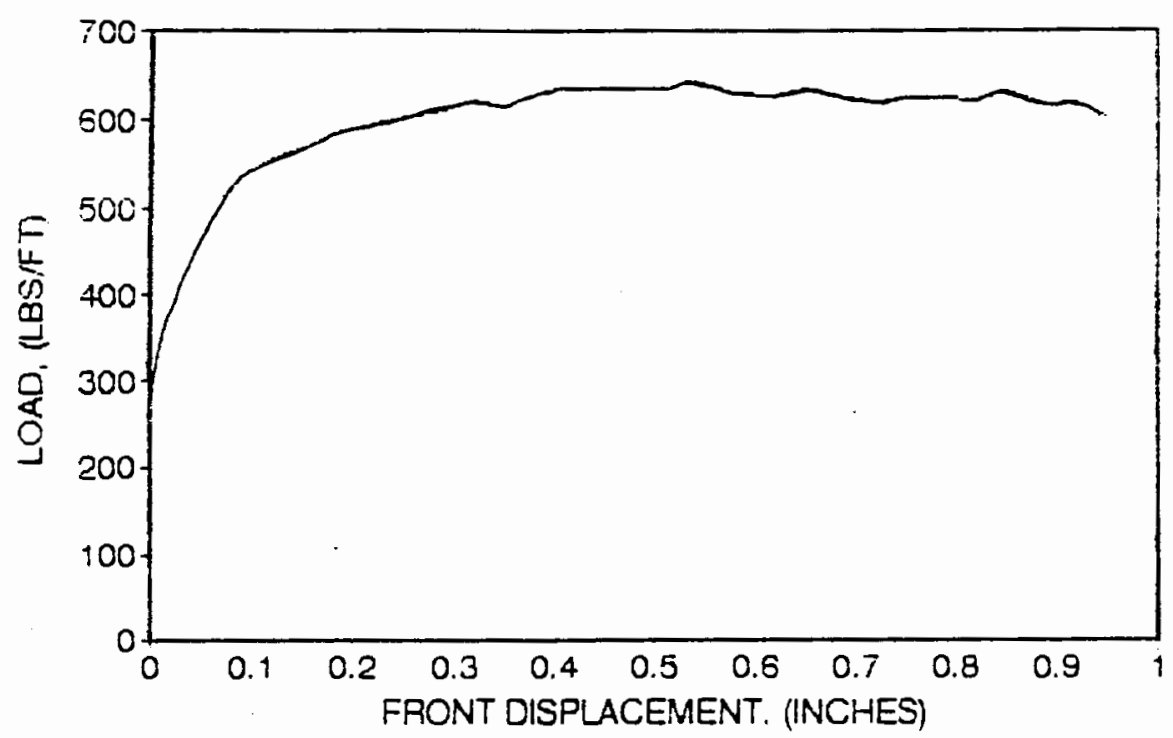

\section{TENAX 401}

5 PSI NORMAL STRESS, SAMPLE WIDTH $12^{\prime \prime}$

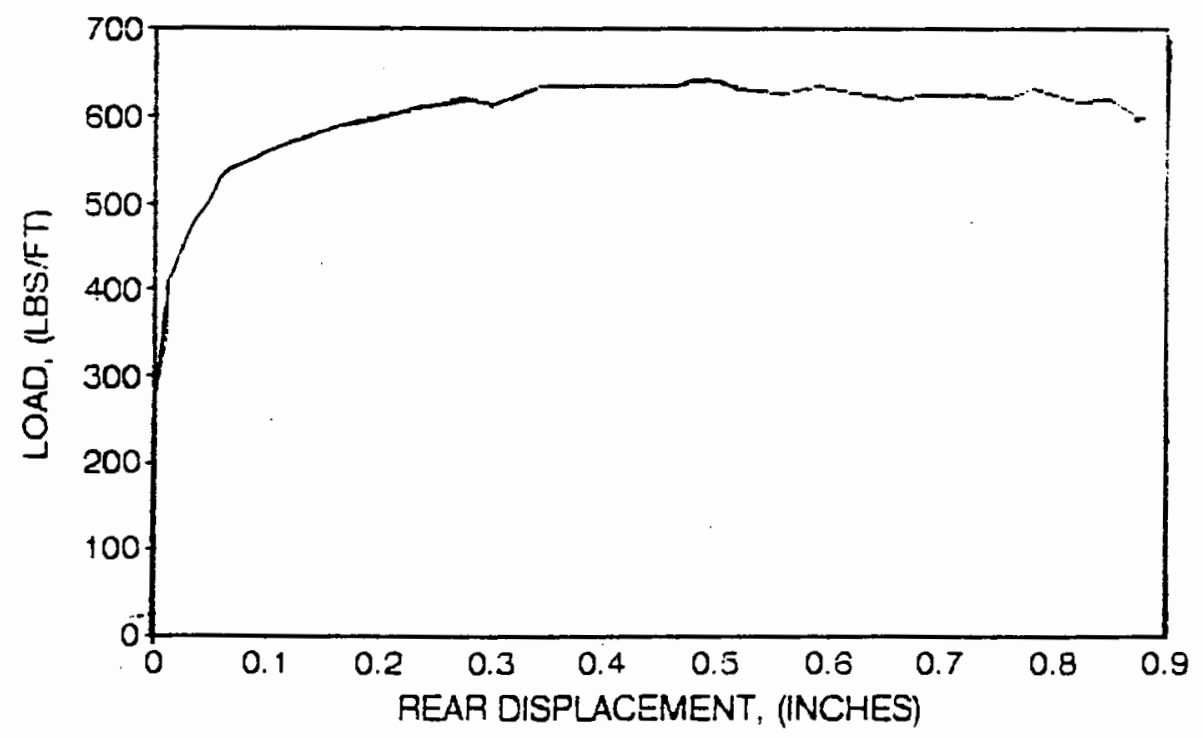




\section{TENAX 401}

10 FSI NORMAL STRESS. SAMIFLE WIOTH $12^{\prime \prime}$

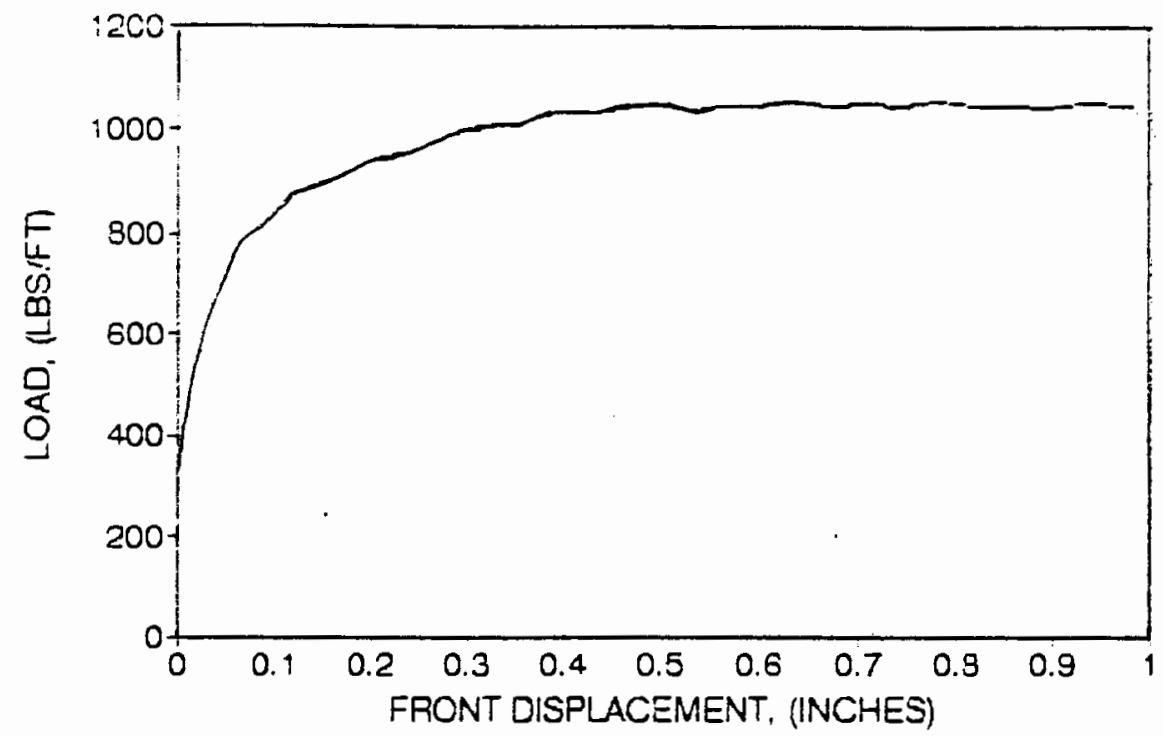

TENAX 401

10 PSI NORMAL STRESS. SAMPLE WIDTH $12 "$

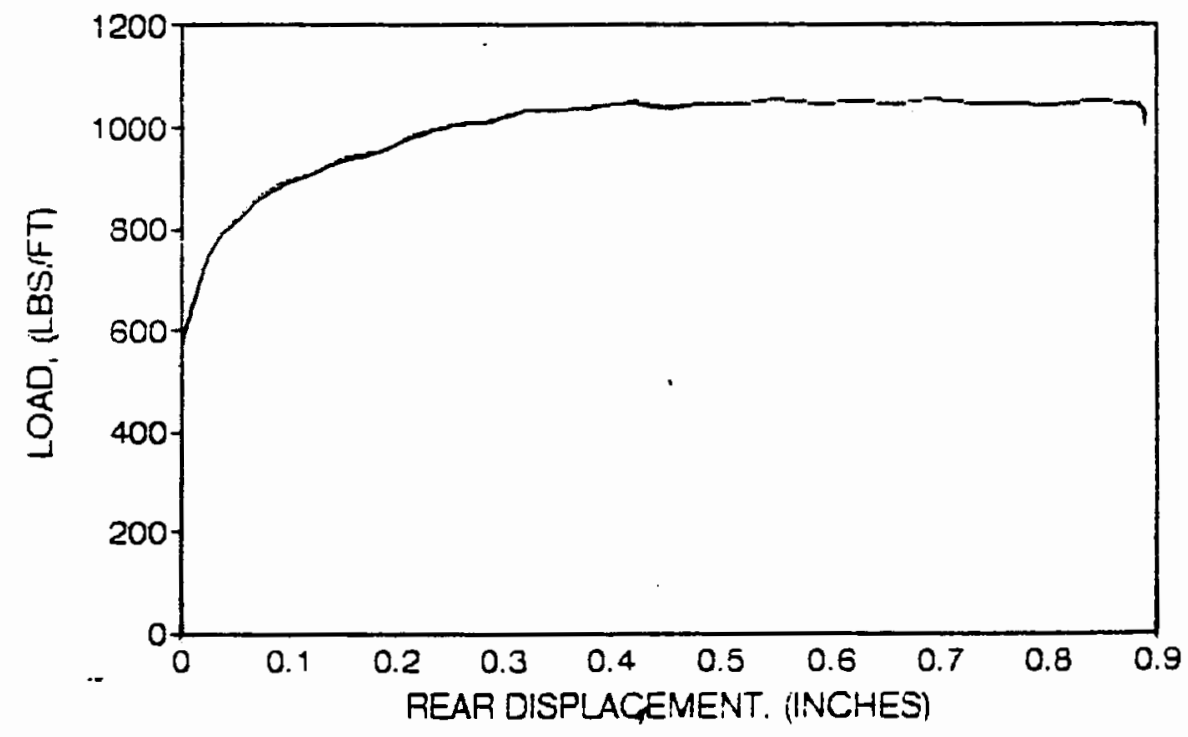


APPENDIX E

EQUIVALENT MODULUS VALUES 
EQUIVALENT MODULI, (LBS/FT)

2 PSI

FORTRAC $35 / 20-20$
5 PSI

10 PSI

180,000

109,000

133,000

102,000

59,000

65,000

157,000

49,000

32,000

TENAX 201

TENAX 301

54,000

98,000

120,000

144,000

154,000

29,000

TENAX 401
84,000

50,000

12,000 
2 PSI

BAY MILLS 28501

30,000
BAY MILLS $28502(w)$
23,000

5 PSI

10 PSI

600,000

61,000

BAY MILLS 28502 (s)
114,000

102,000

57,000
23,000

132,000 
APPENDIX F

GEOGRID FRICTION ANGLES 
GEOGRID FRICIION ANGLES

FORTRAC

$$
\delta=\tan ^{-1}\left(\frac{1450}{1440}\right)=45.2^{\circ}
$$

BAY MILLS 28501

$$
\delta=\tan ^{-1}\left(\frac{1700-100}{1440}\right)=48.0^{\circ}
$$

BAY MILLS 28502

$$
\delta=\tan ^{-1}\left(\frac{1700-200}{1440}\right)=46.2=
$$

TENAX 201

$$
\delta=\tan ^{-1}\left(\frac{1020-220}{1440}\right)=29.1^{\circ}
$$

TENAX 301

$$
\delta=\tan ^{-1}\left(\frac{1025-190}{1440}\right)=30.1^{\circ}
$$

TENAX 401

$$
\delta=\tan ^{-1}\left(\begin{array}{c}
1150-100 \\
1440
\end{array}\right)=36.1^{\circ}
$$


APPENDIX G

MAXIMUM PULLOUT LOAD VS. EMBEDDED AREA GRAPHS 


\section{FORTRAC 35/20-20 10 PSI NORMAL STRESS}

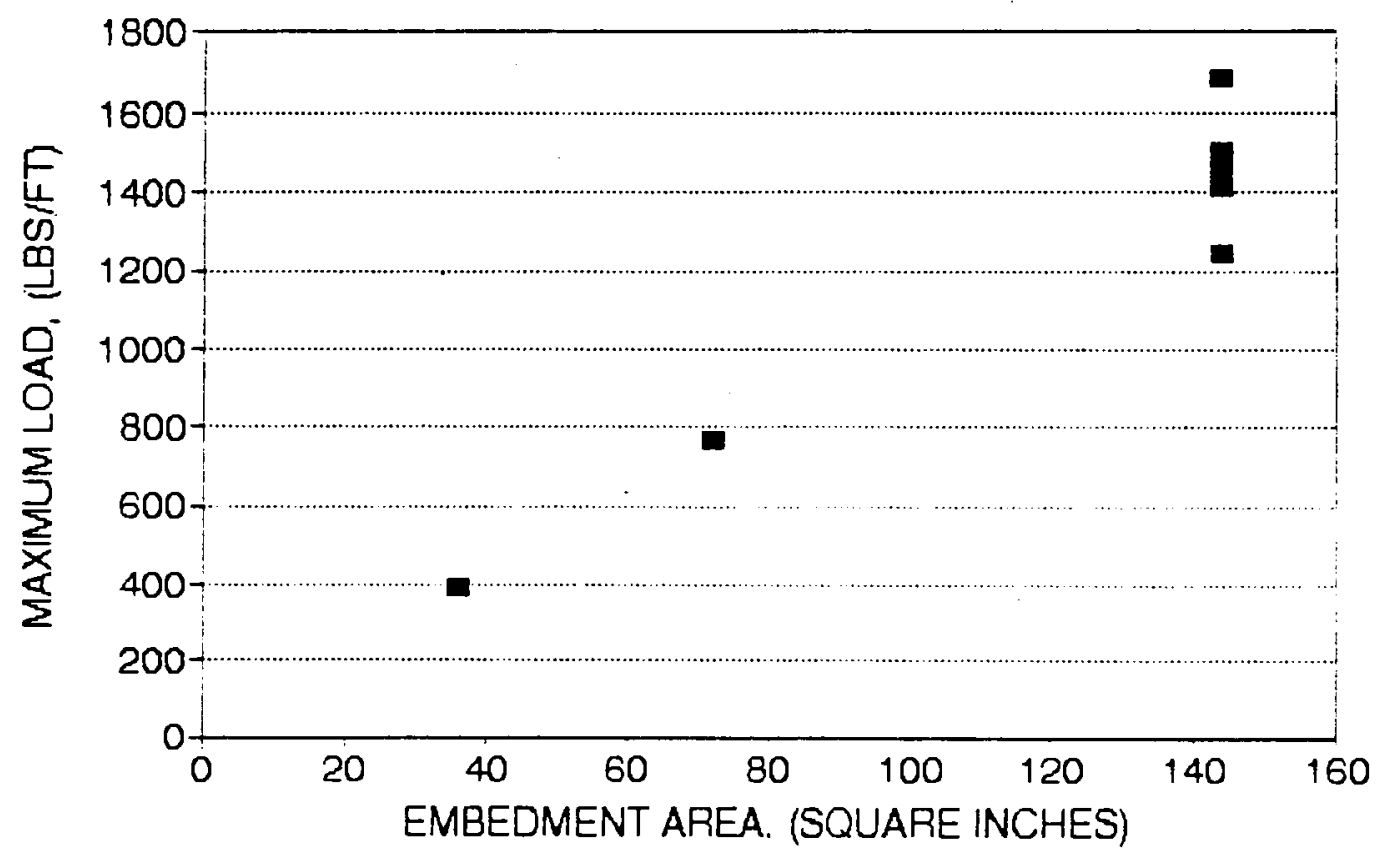


FORTRAC 35/20-20 10 PSI NORMAL STRESS

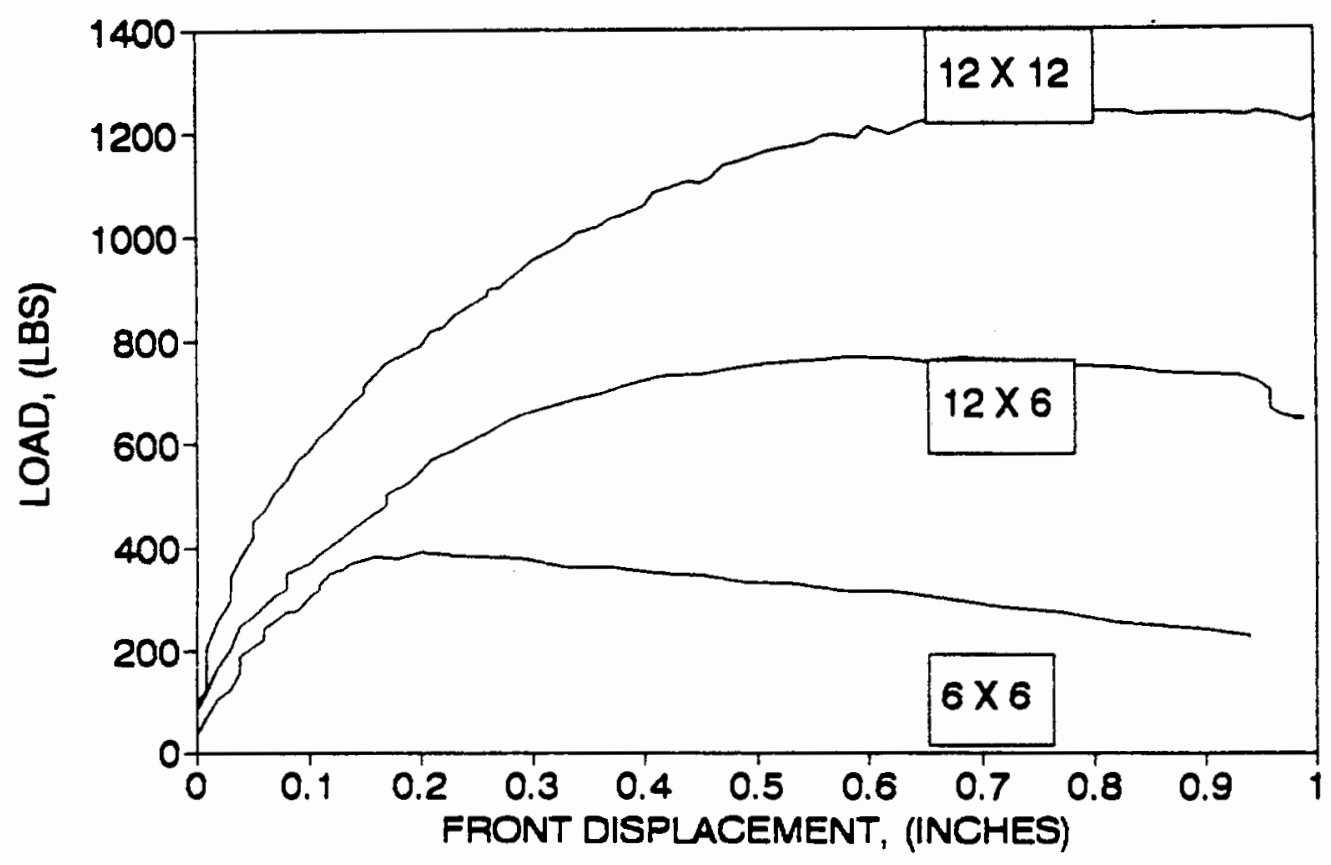



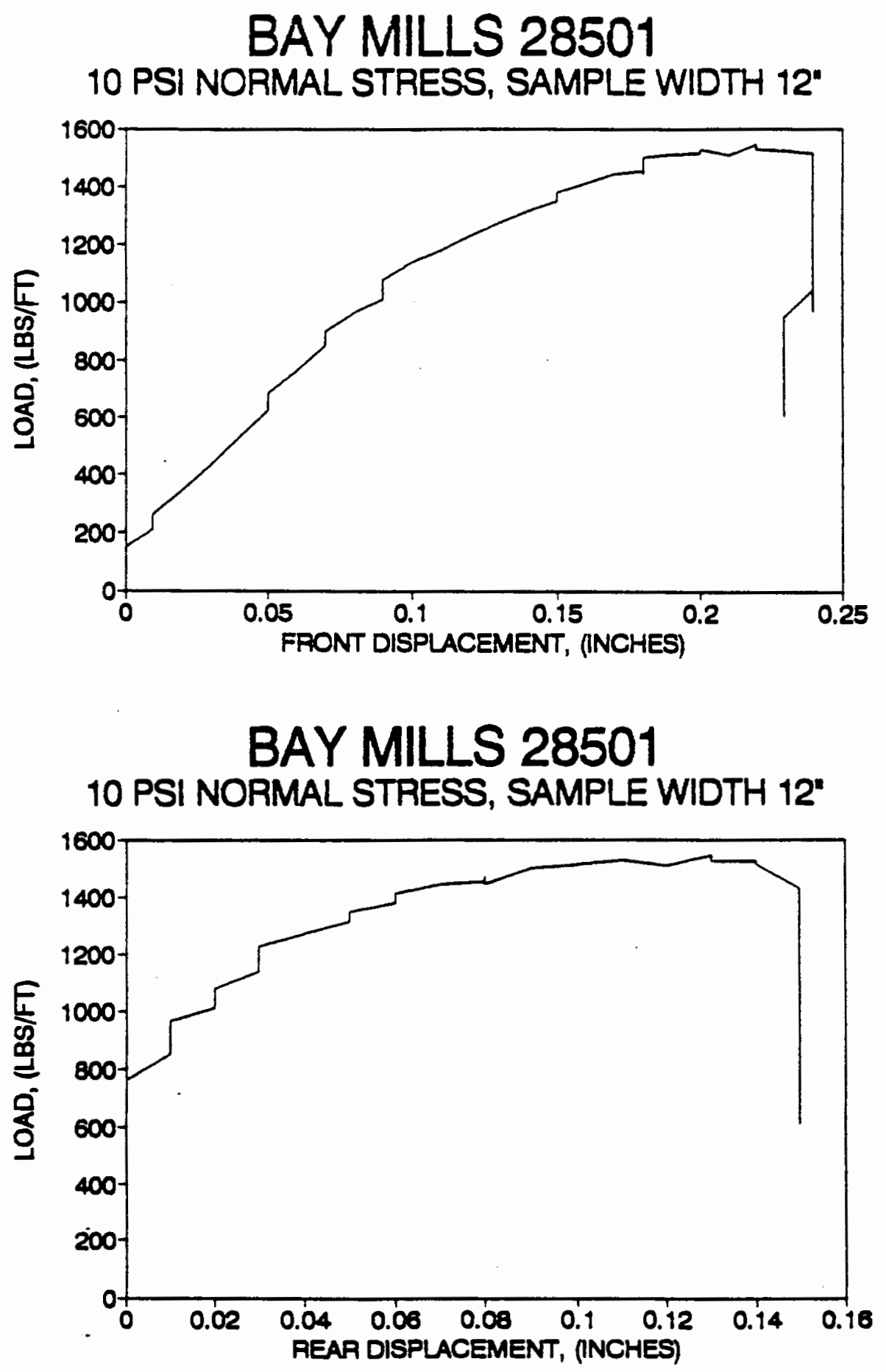
APPENDIX H

EARTH PRESSURE CELL DATA 


\section{FORTRAC 35/20-20 \\ 2 PSI NORMAL STRESS. EPC $-7 "$ CTR VERT}

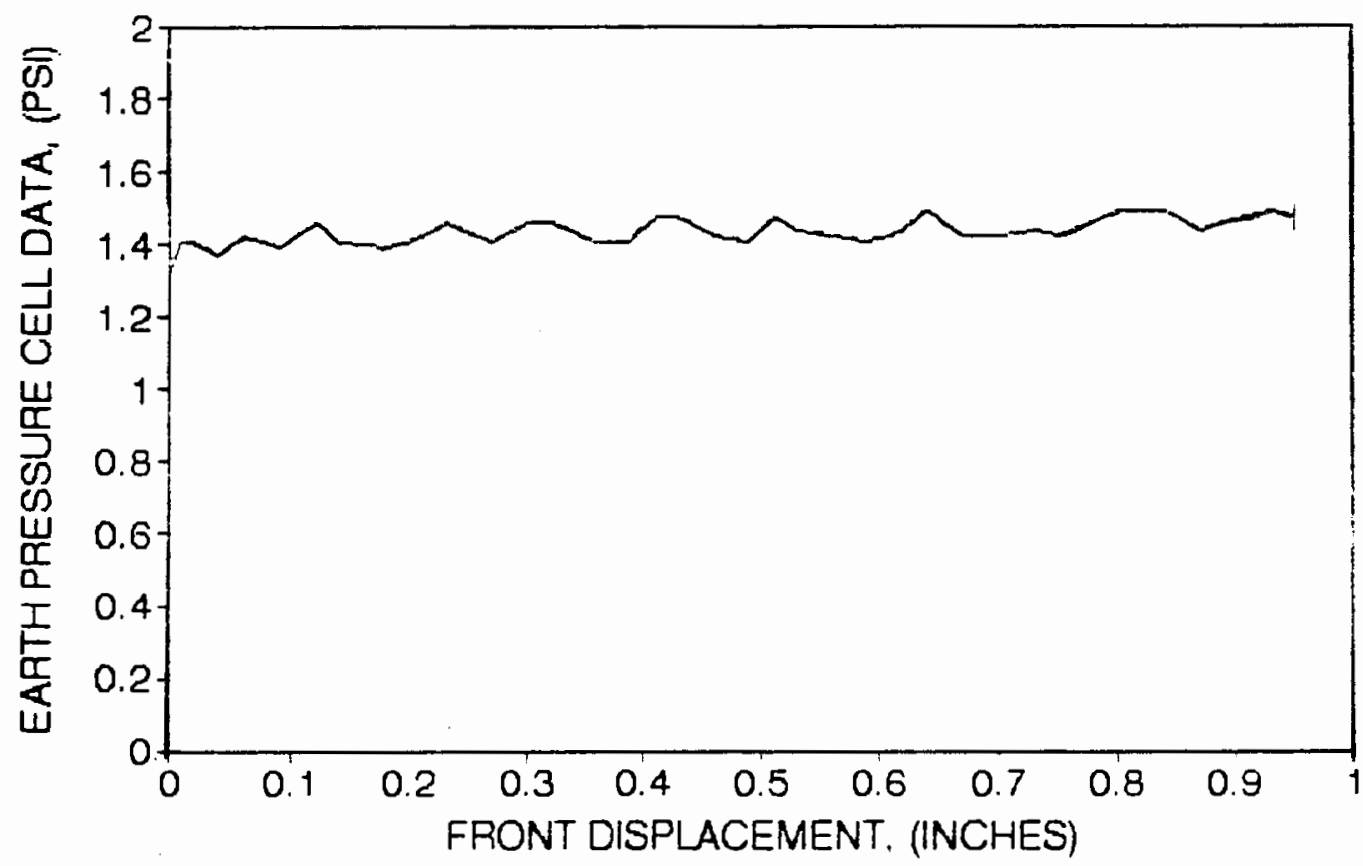


FORTRAC 35/20-20

5 PSI NORMAL STRESS, EPC $-7^{\mathrm{A}}$ FRNT VERT

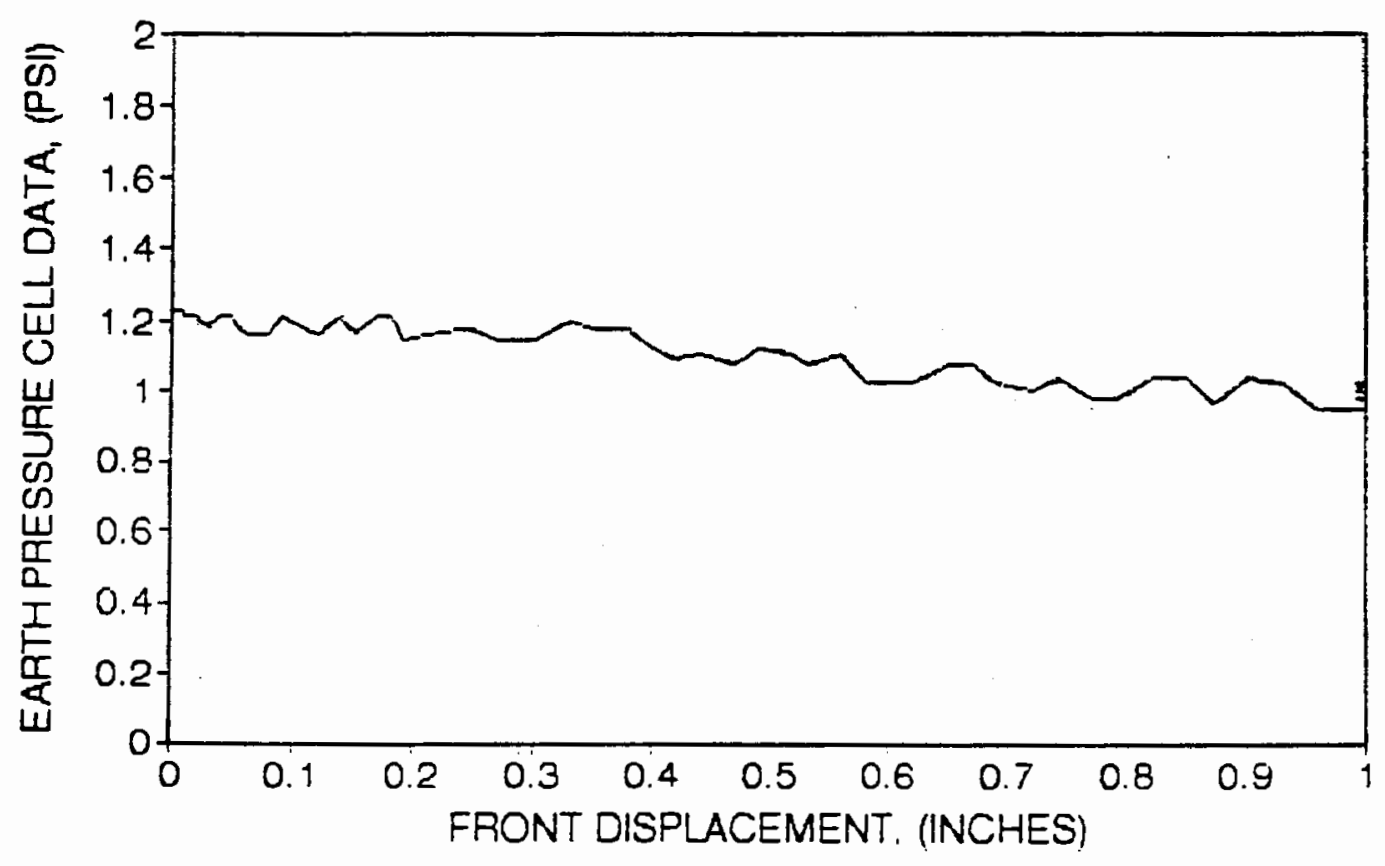


FORTRAC 35/20-20 10 PSI NORMAL STRESS

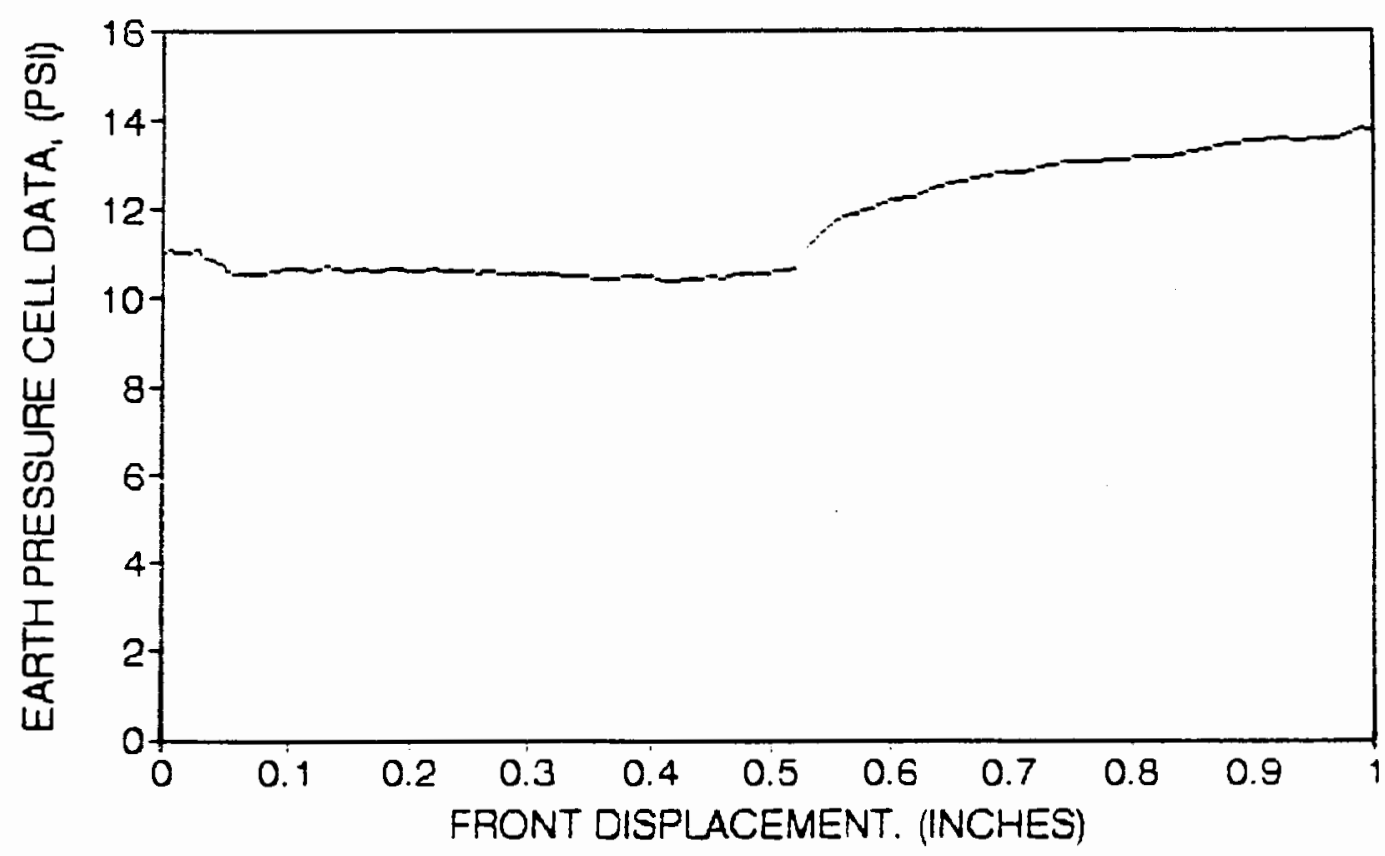


FORTRAC 35/20-20 10 PSI NORMAL STRESS

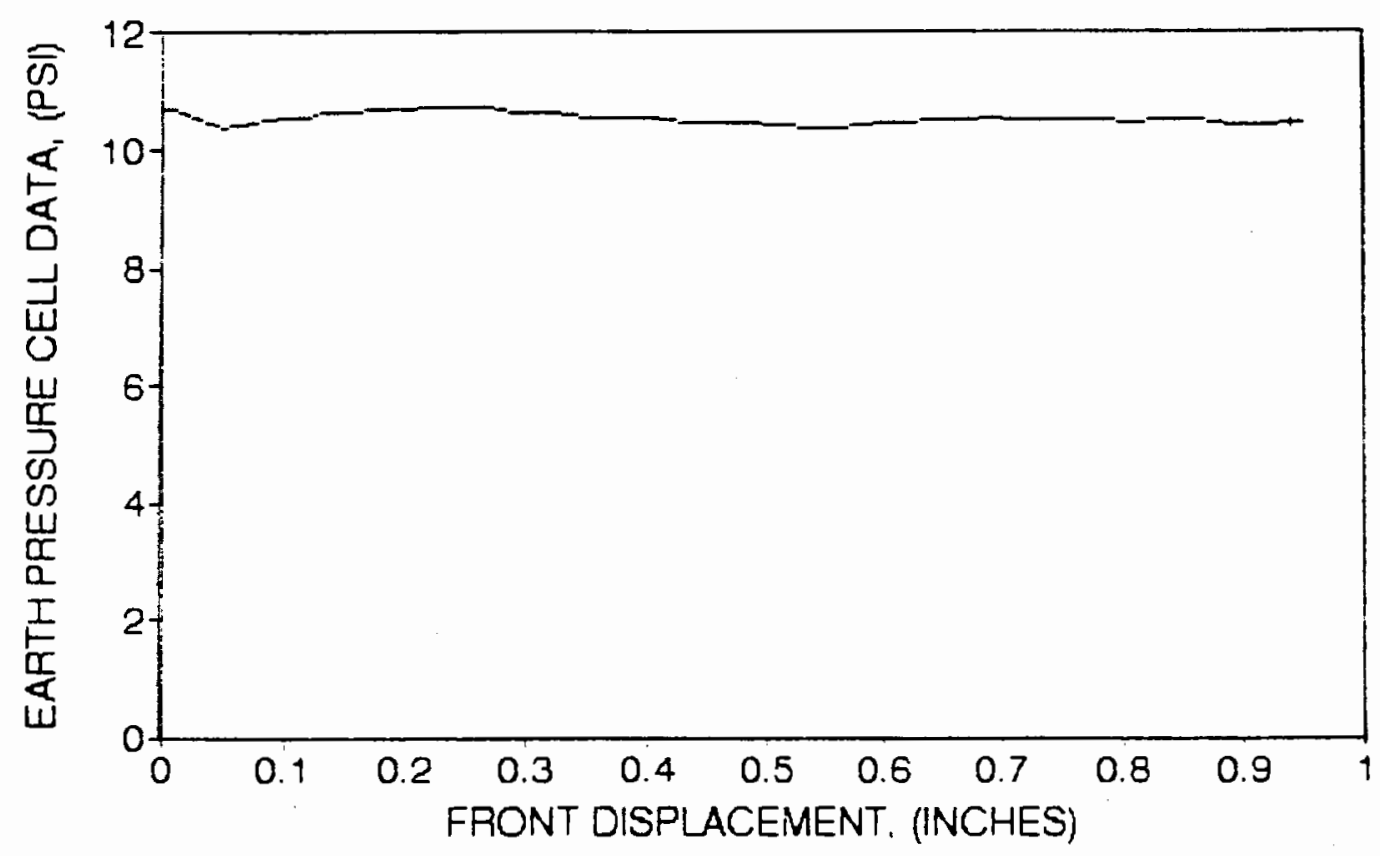


FORTRAC 35/20-20

10 PSI NORMAL STRESS. EPC AT SURFACE

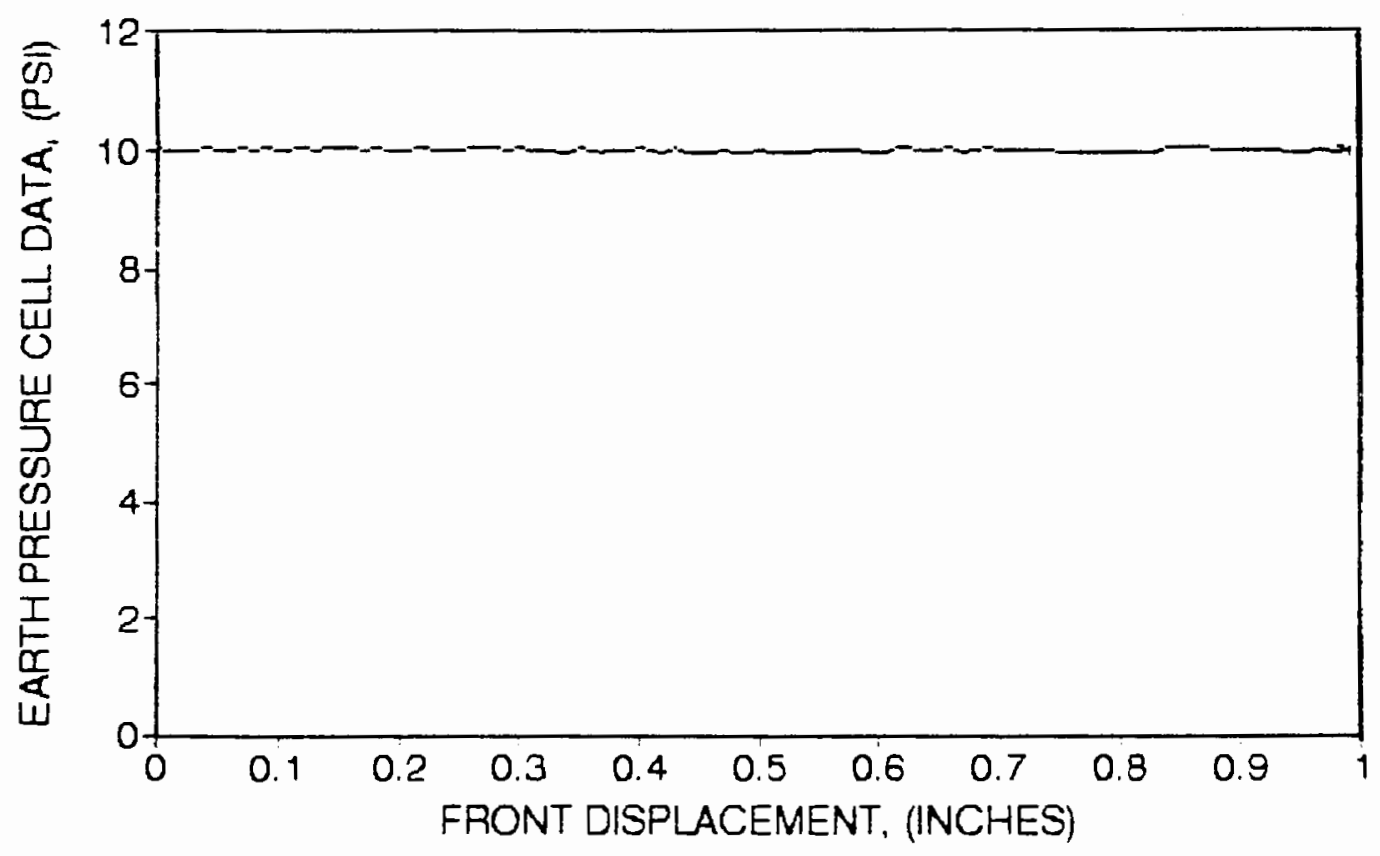


FORTRAC 35/20-20 10 PSI NORMAL, 6"W, 12"E. EPC FRNT VERT

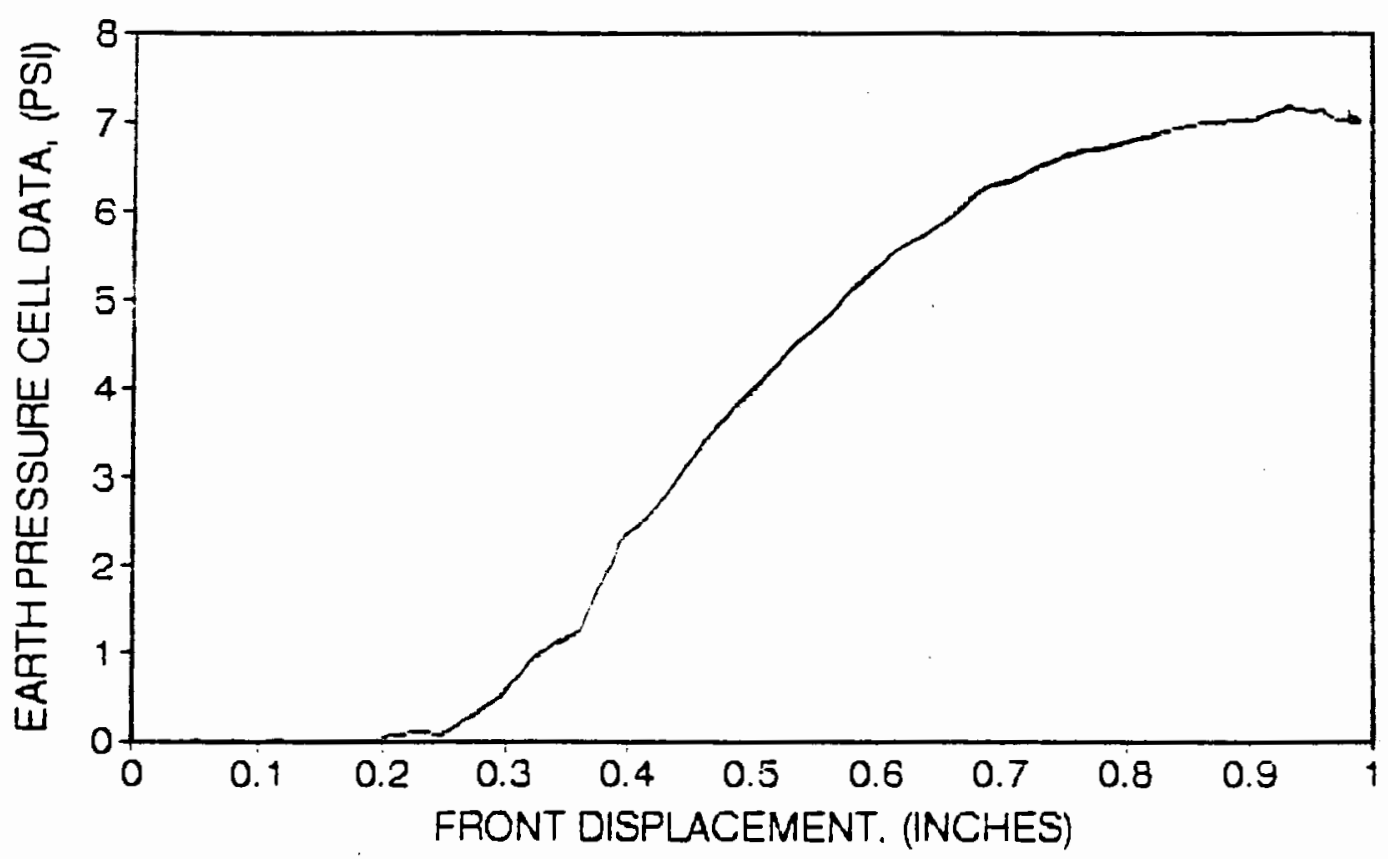


FORTRAC 35/20-20

10 PSI NORMAL, 6"W. 6"E. EPC FRNT VERT

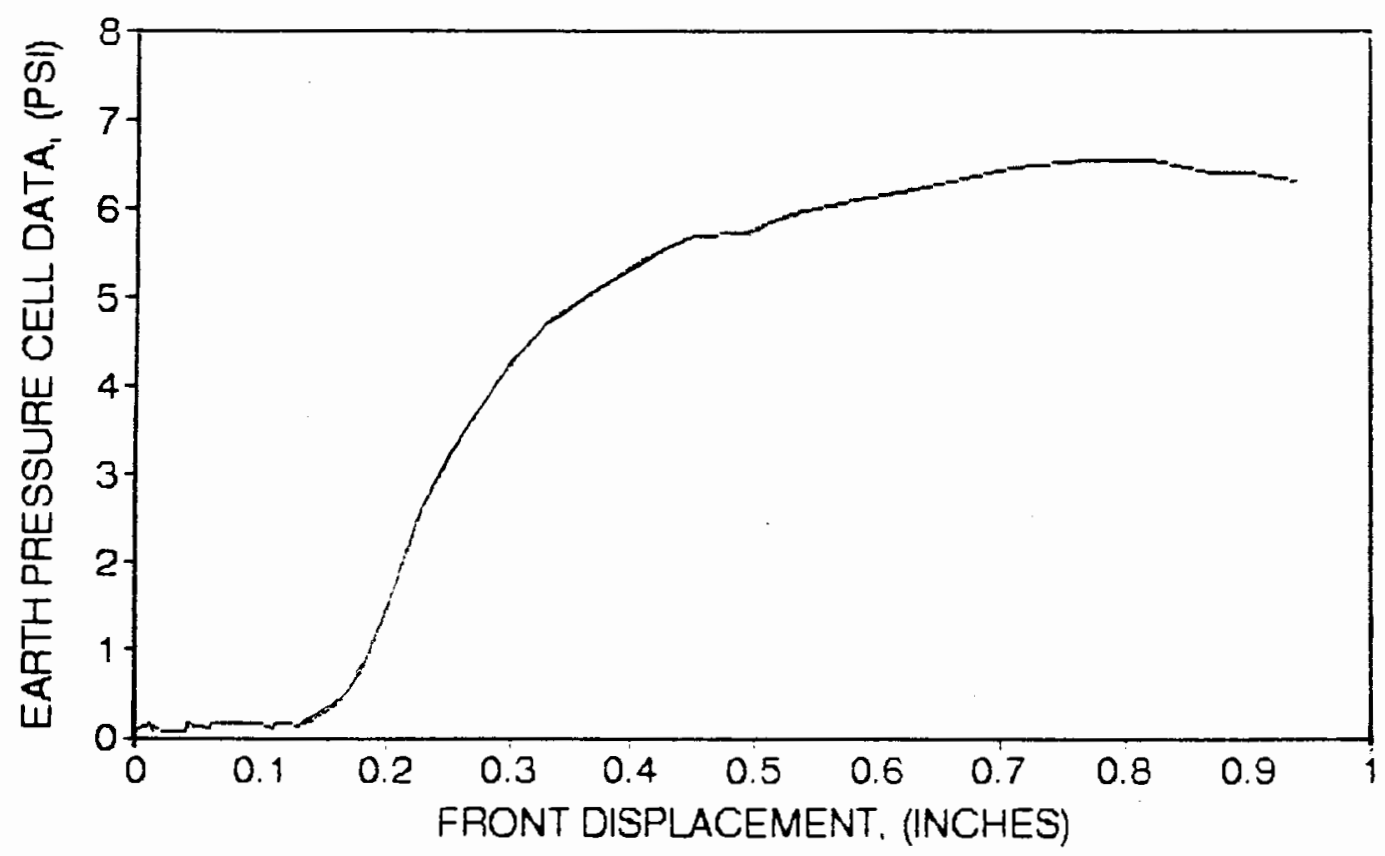




\section{BAY MILLS 28501 \\ 2 PSI NORMAL STRESS. EPC -5" CTR HORIZ}

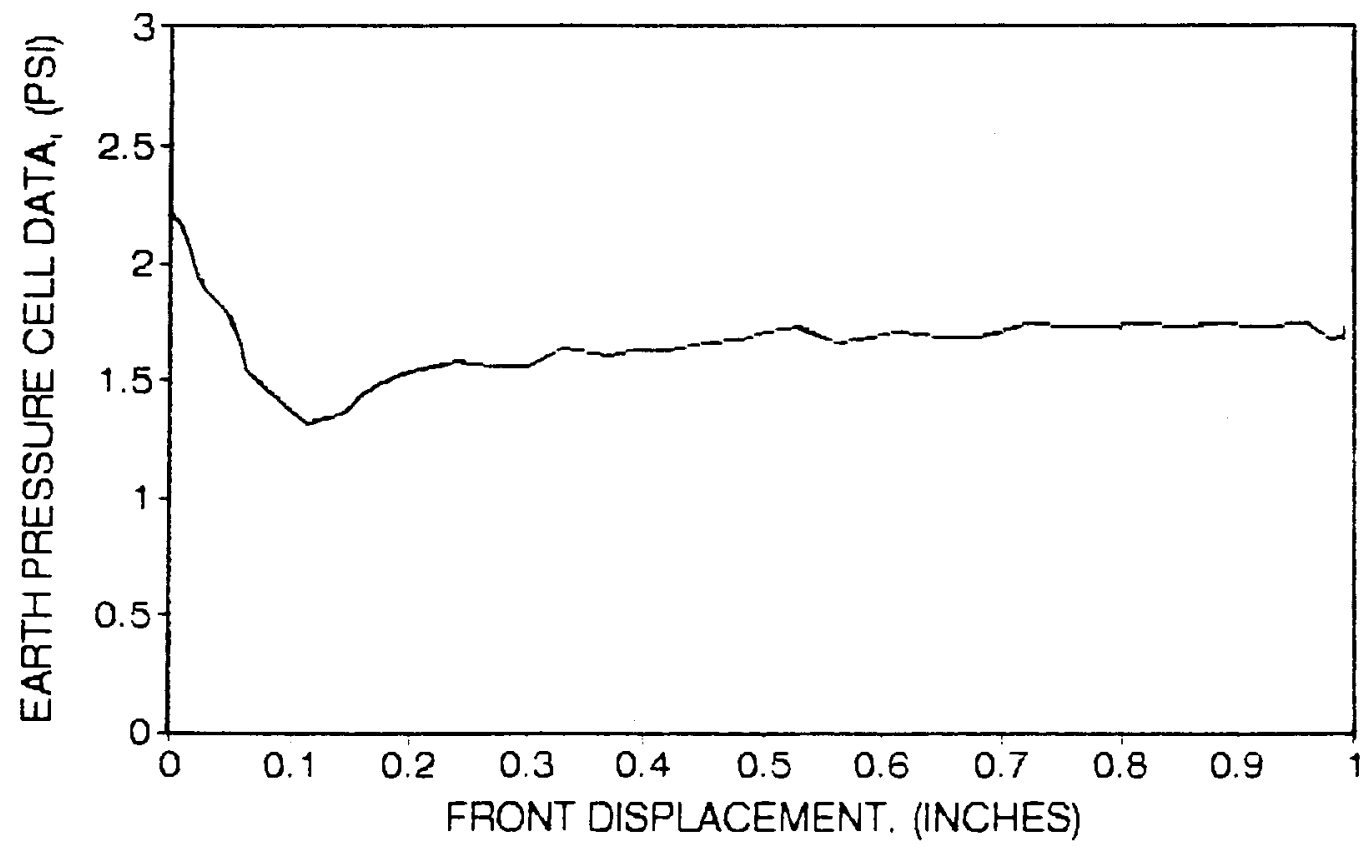




\section{BAY MILLS 28501 \\ 5 PSI NORMAL STRESS. EPC -2" FRNT CTR}

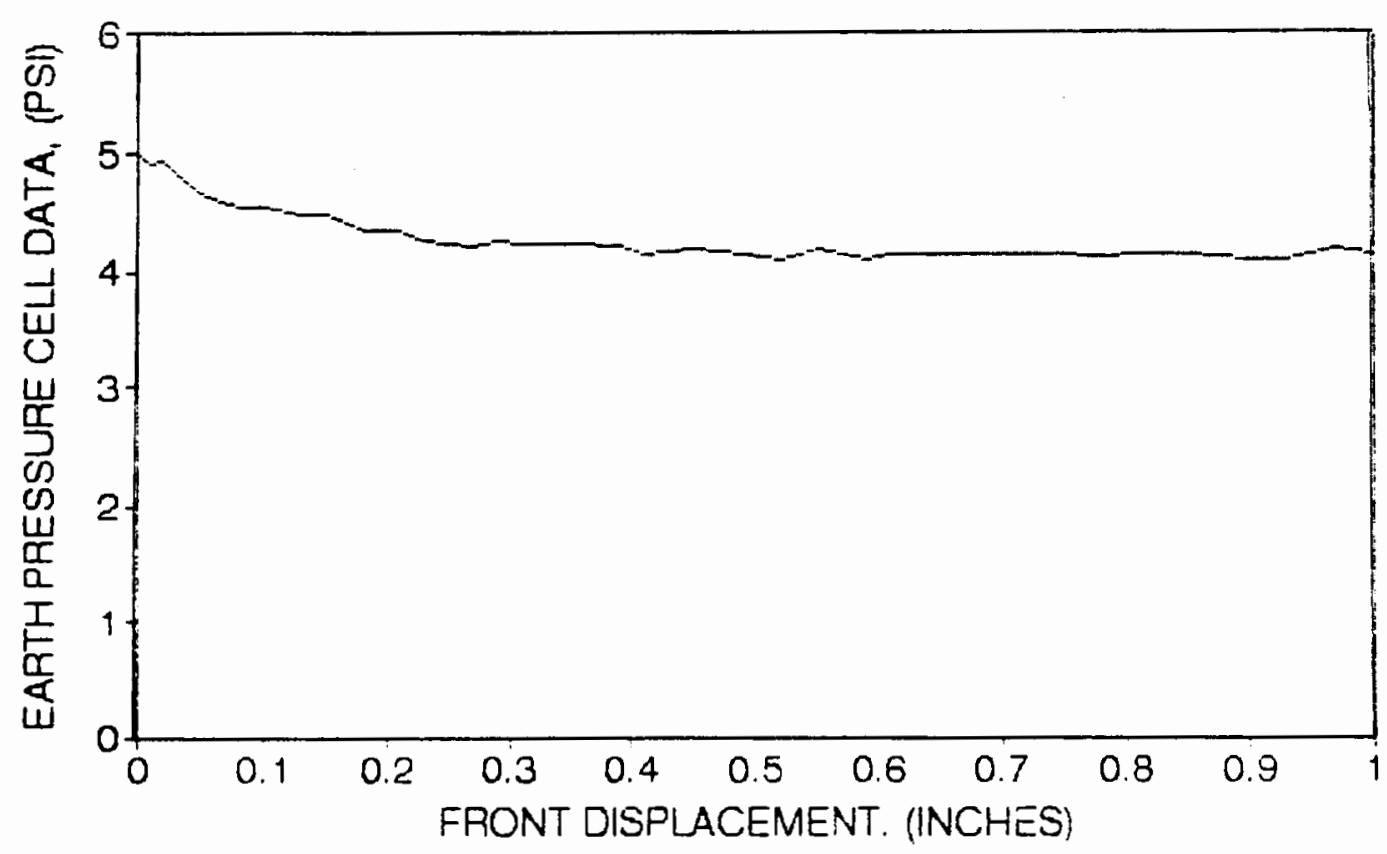




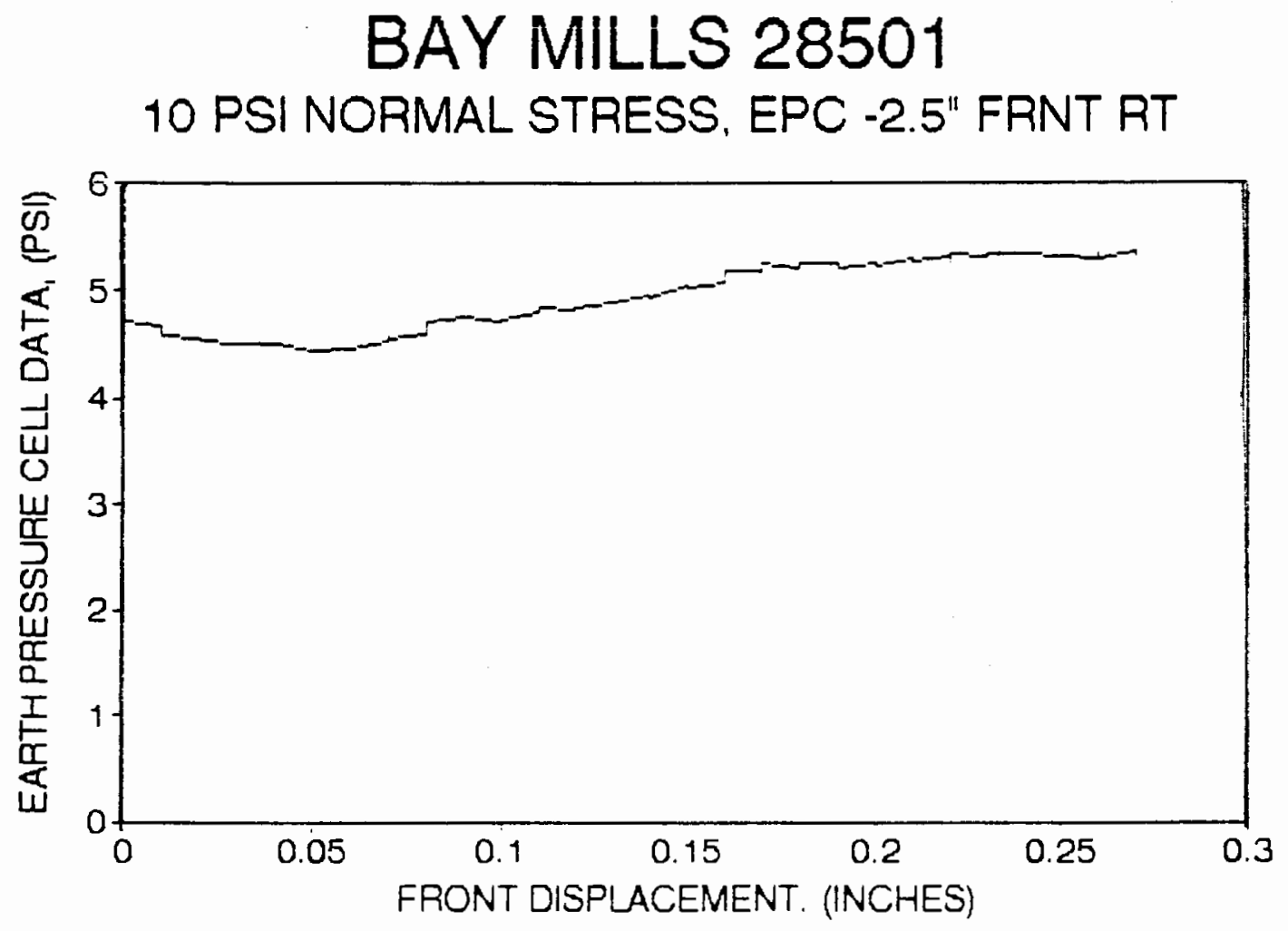




\section{BAY MILLS 28501 \\ 10 PSI NORMAL STRESS. EPC -4" FRNT VERT}

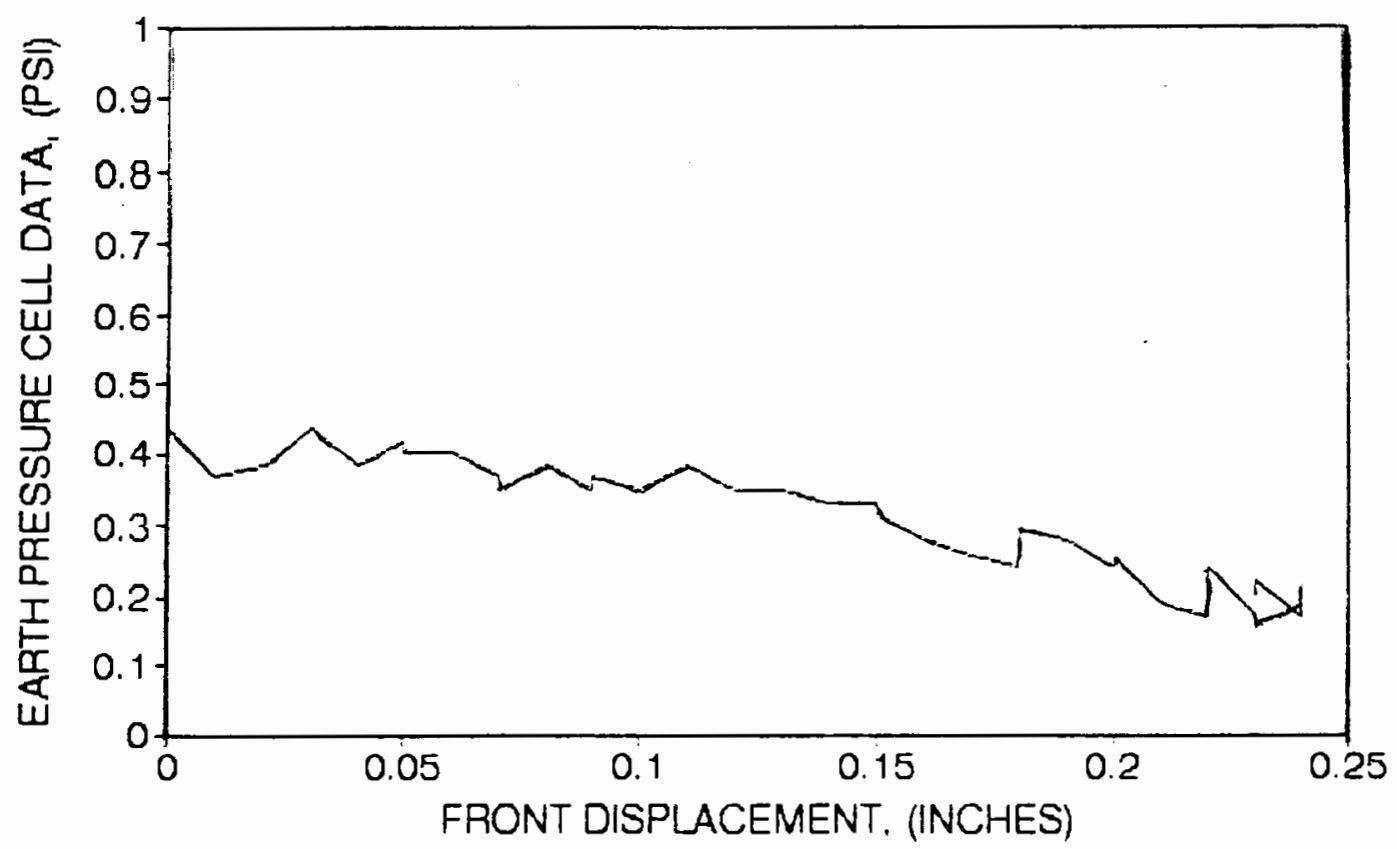




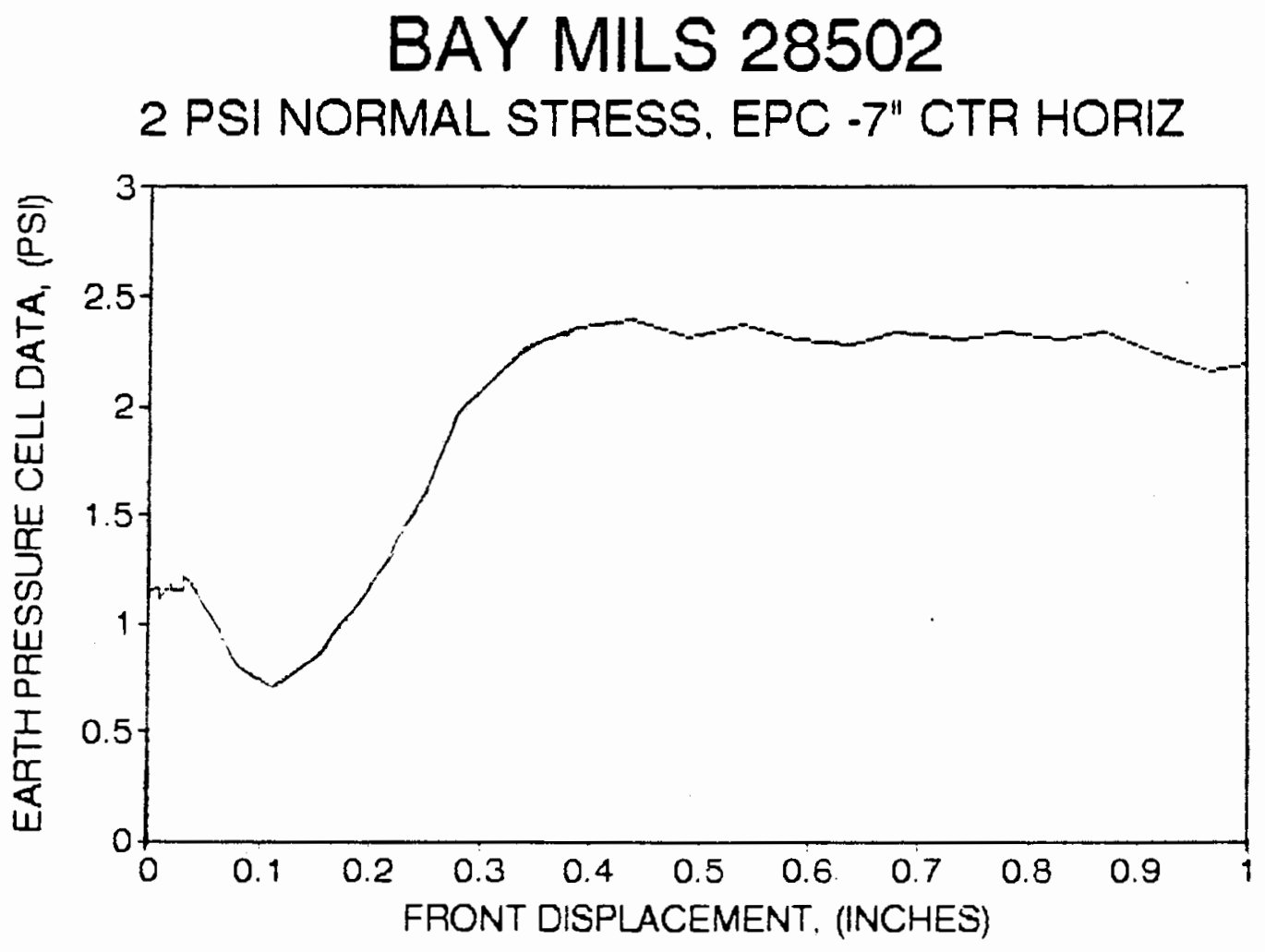




\section{BAY MILLS 28502}

5 PSI NORMAL STRESS. EPC -7" CTR HORIZ

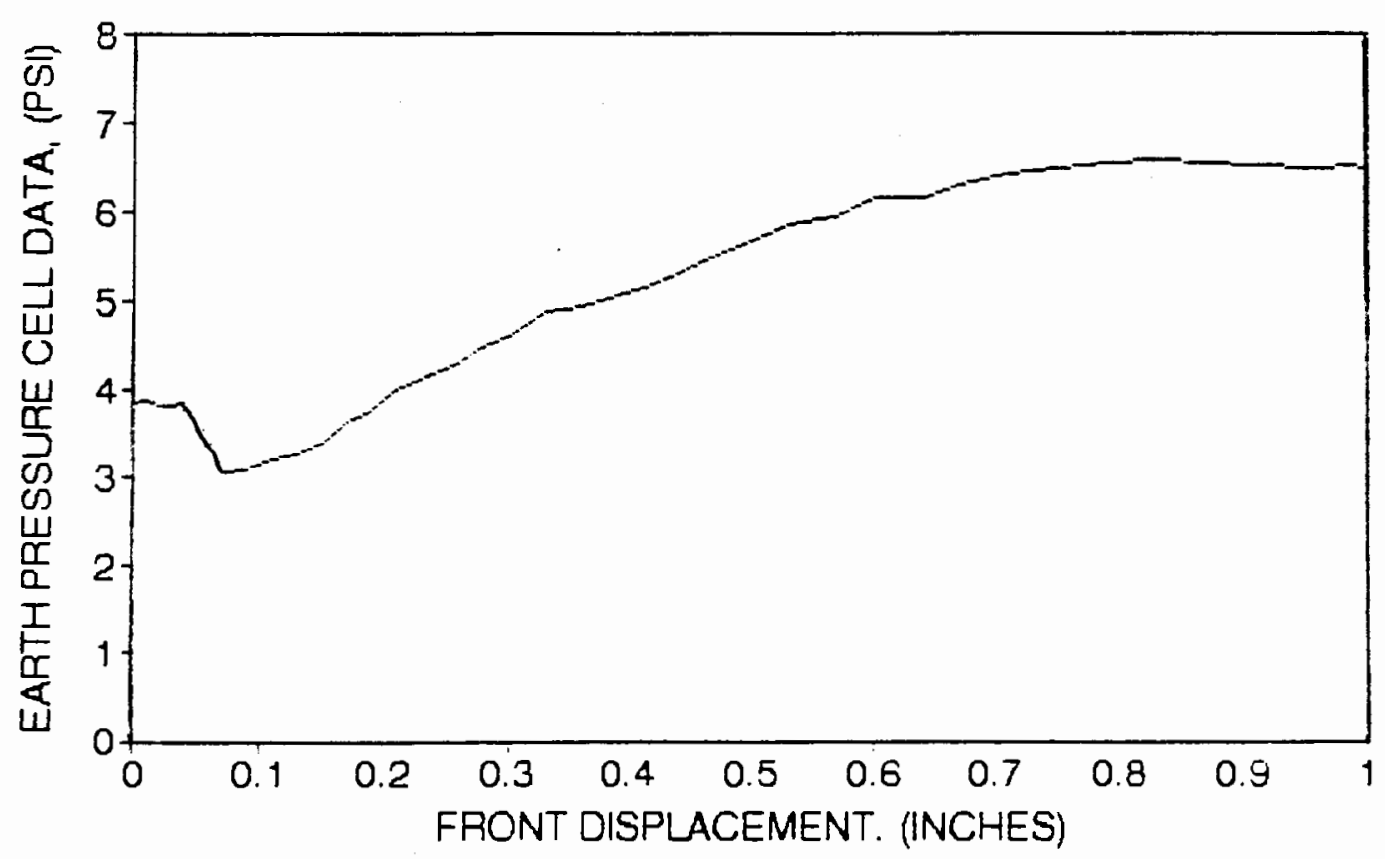




\section{BAY MILLS 28502}

10 PSI NORMAL STRESS. EPC -2" FRONT RT

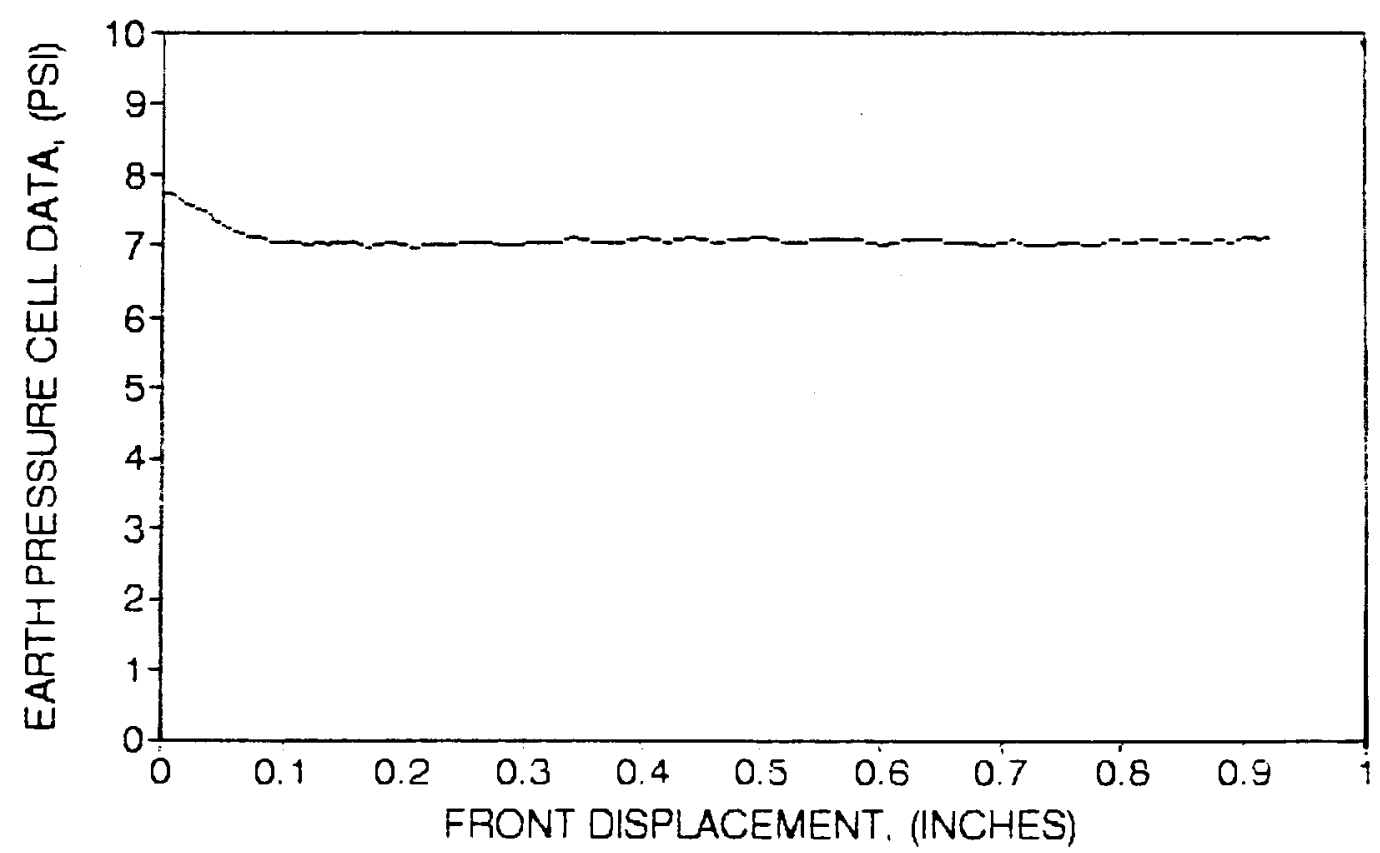


BAY MILLS 28502 (w)

15 PSI NORMAL STRESS. EPC -1.5 " CTR HOR

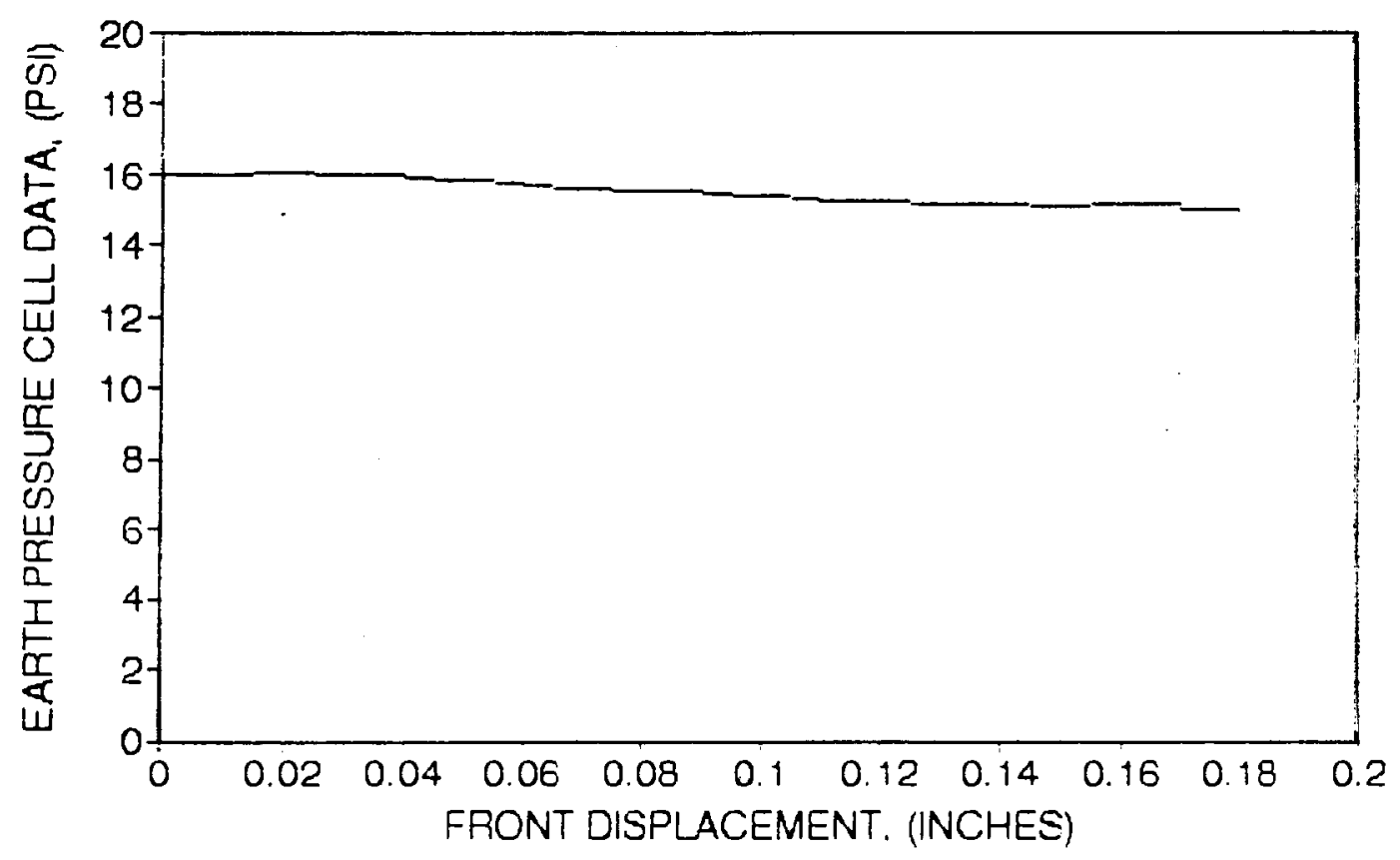


BAY MILLS 28502 (s)

10 PSI NORMAL STRESS, EPC -2" FRONT RT

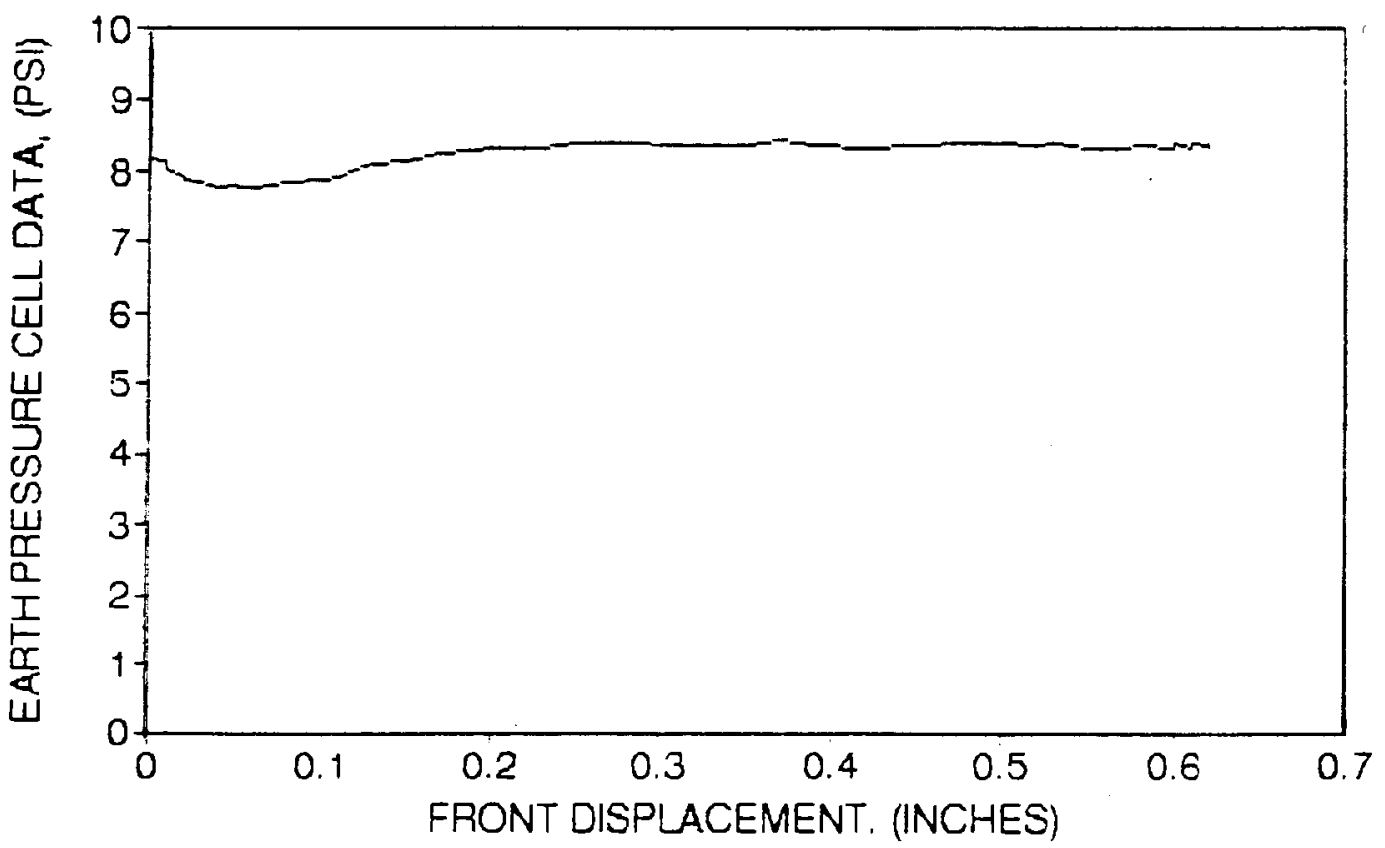


TENAX 201 2 PSI NORMAL STRESS. EPC - 1 " CENTER

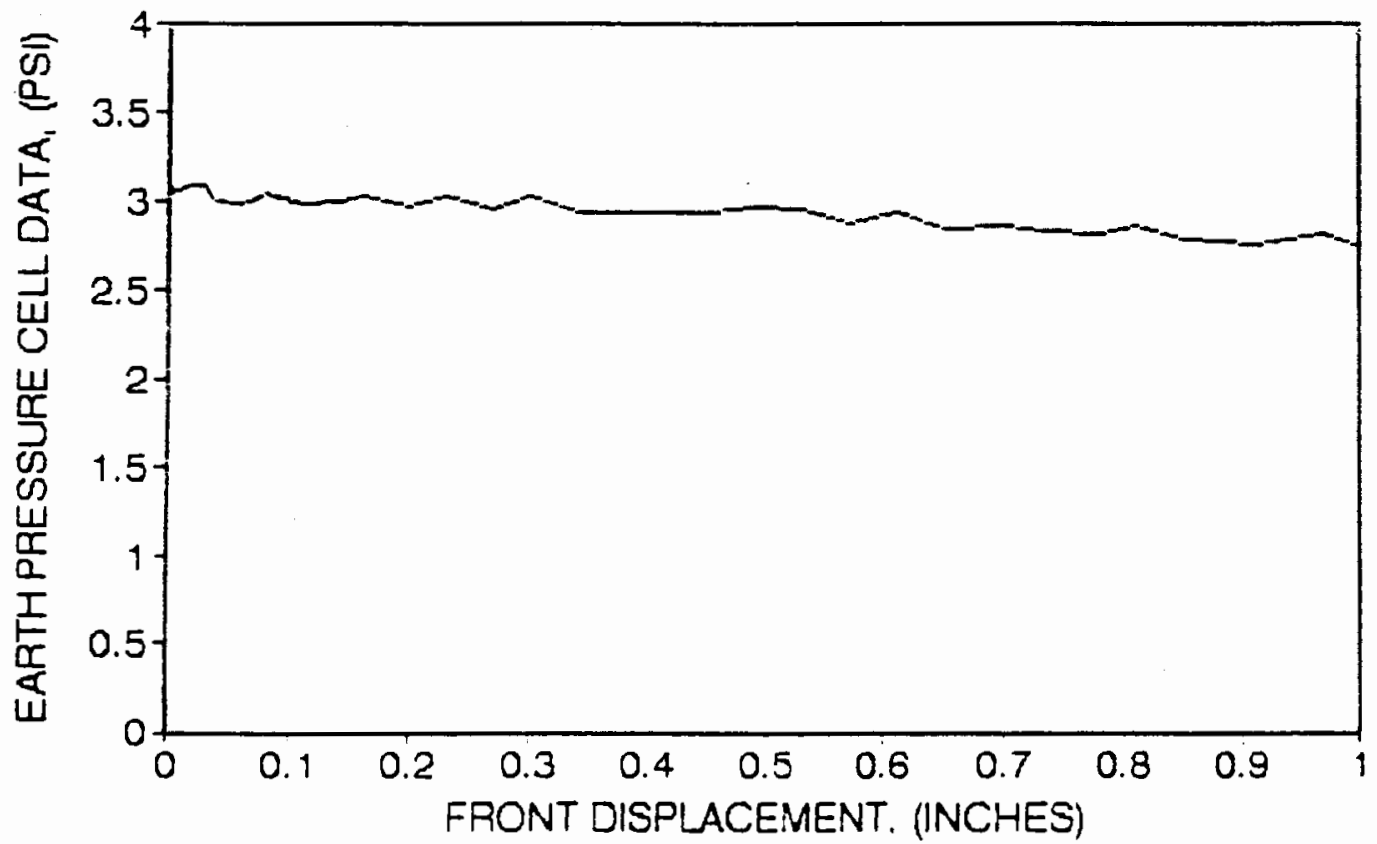




\section{TENAX 201}

5 PSI NORMAL STRESS, EPC TOP CENTER

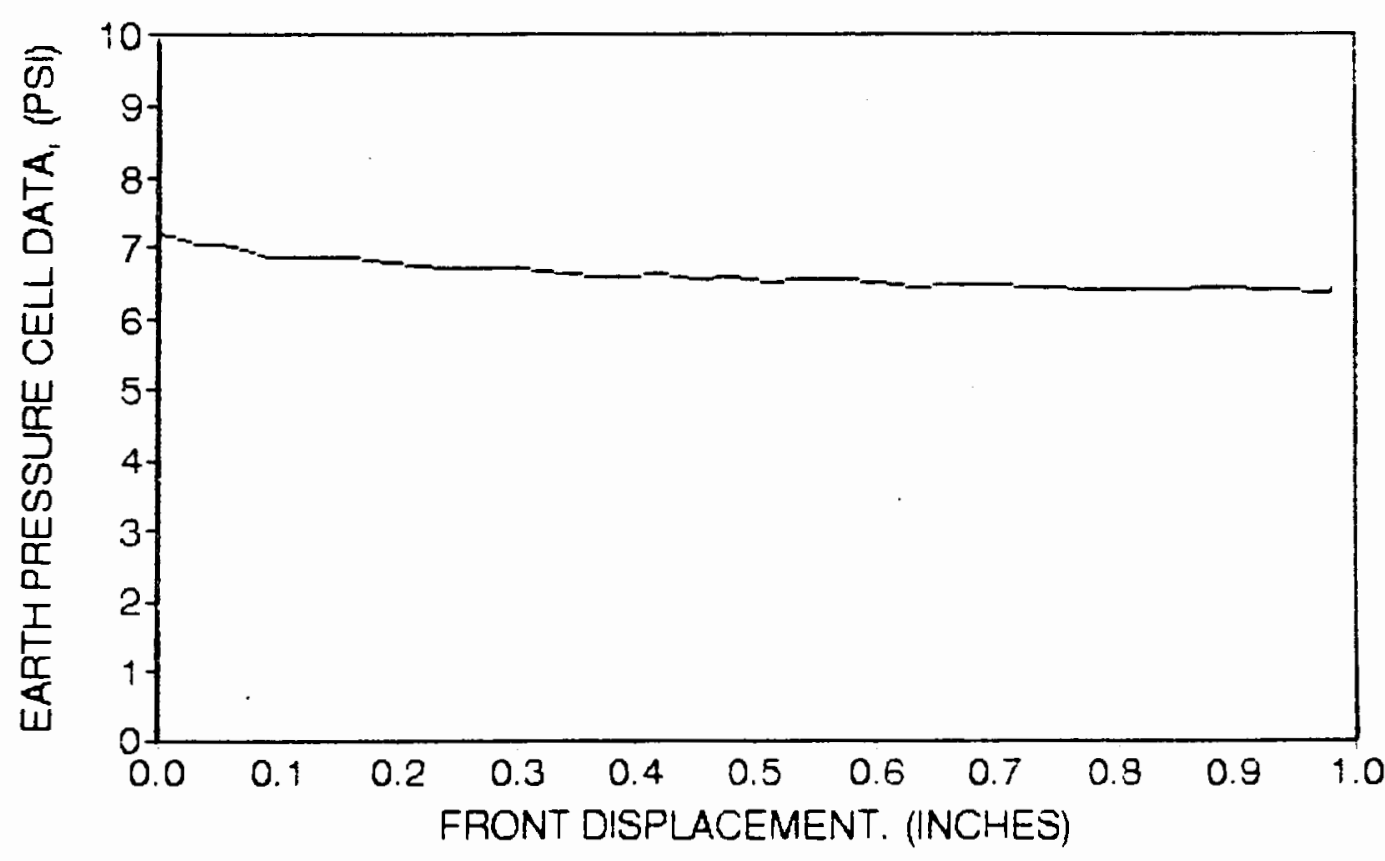


TENAX 201

10 PSI NORMAL STRESS. EPC -7.5" CENTER

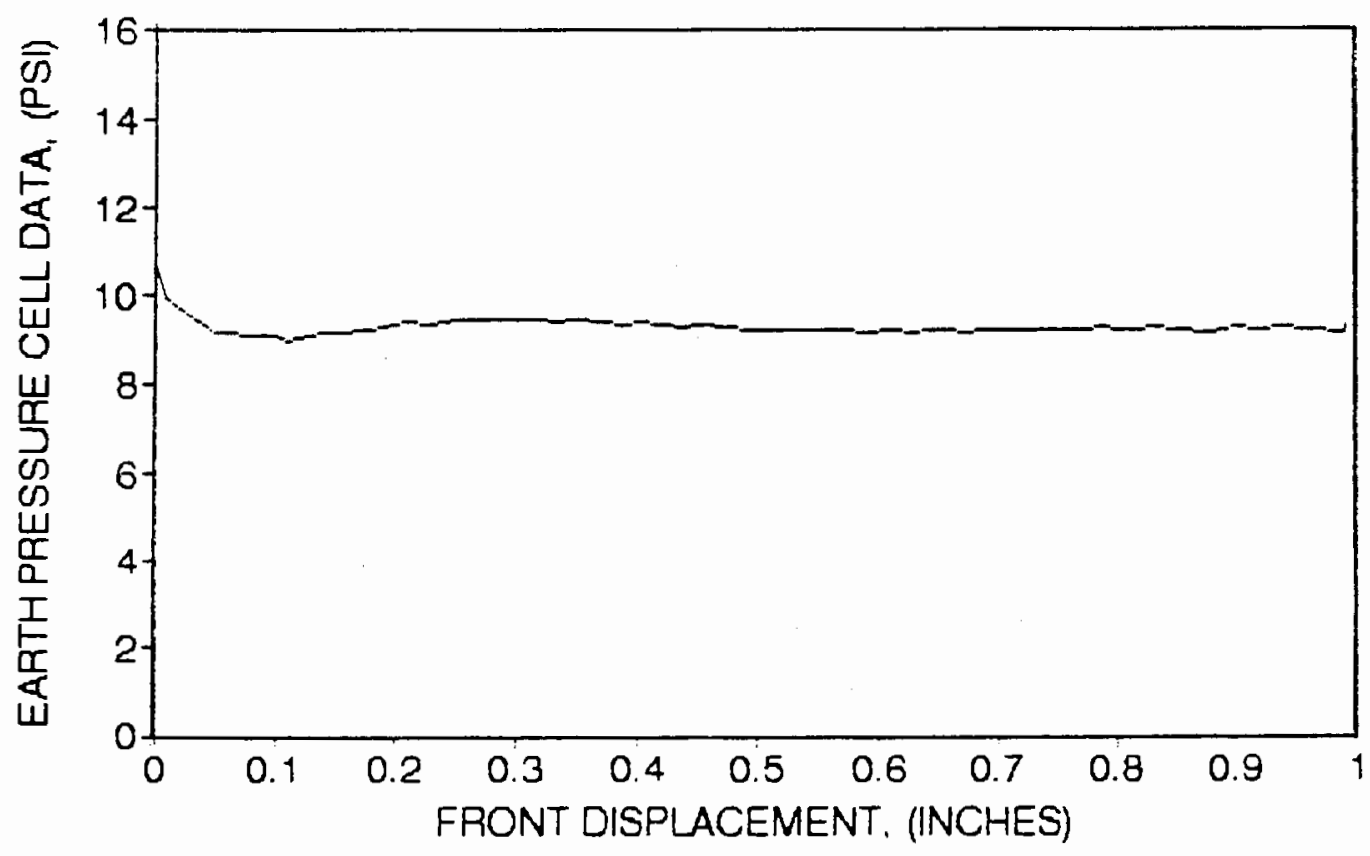


TENAX 201

10 PSI NORMAL STRESS, EPC - $7 "$ " CENTER

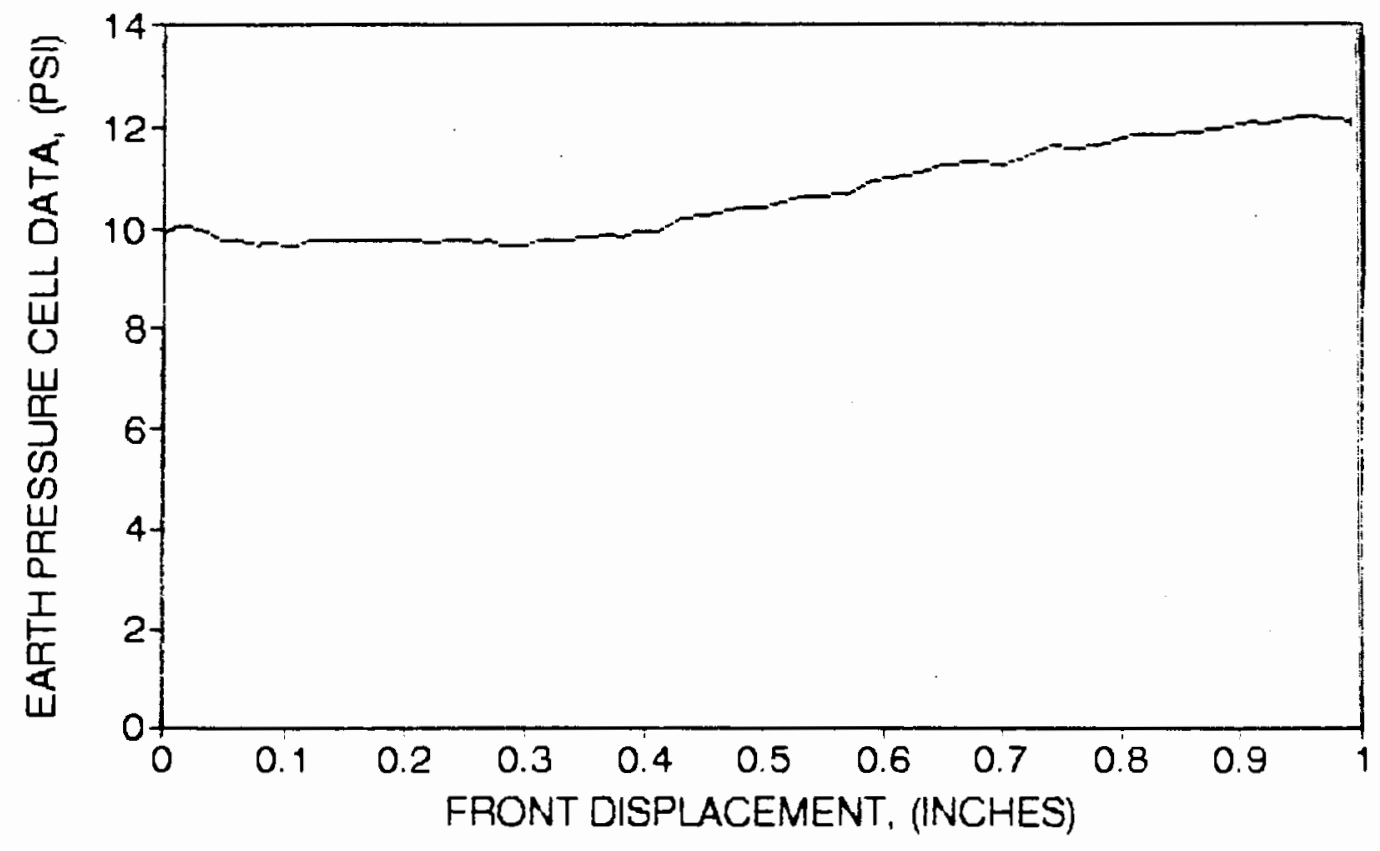


TENAX 301

2 PSI NORMAL STRESS, EPC -7" CTR HORIZ

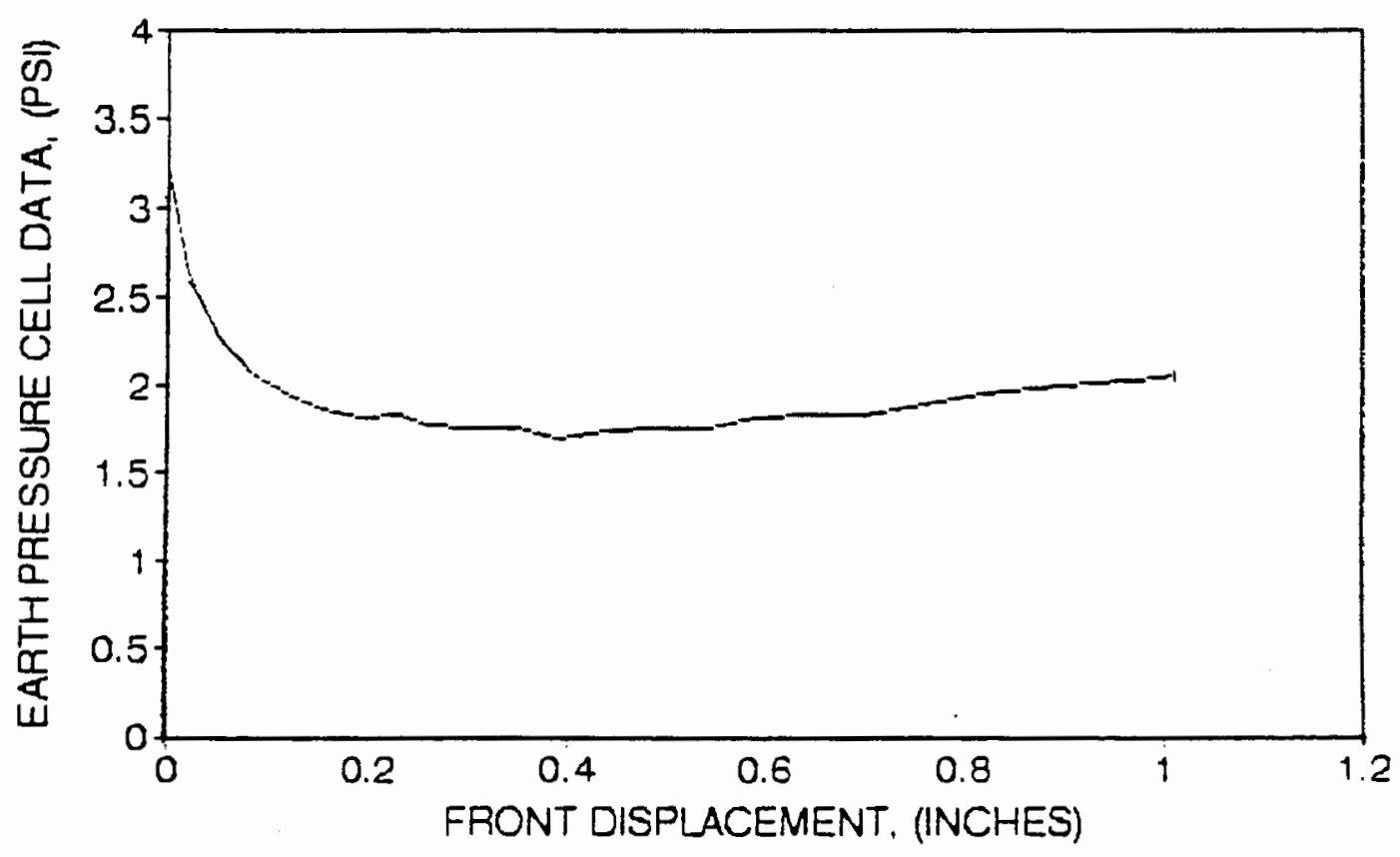


TENAX 301

5 PSI NORMAL STRESS, EPC $-1.5^{\prime \prime}$ CENTER

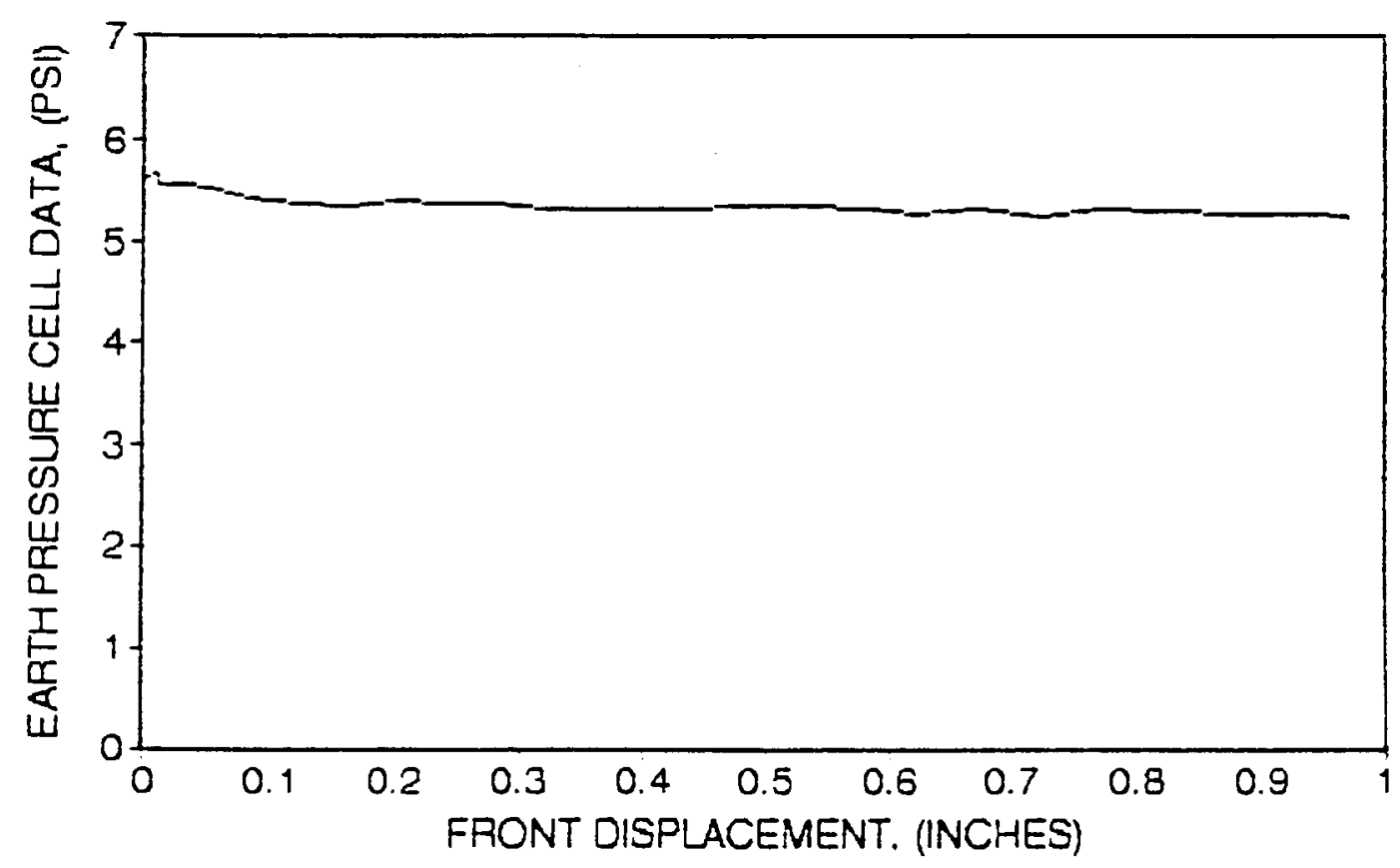


TENAX 301

10 PSI NORMAL STRESS. EPC -1" CENTER

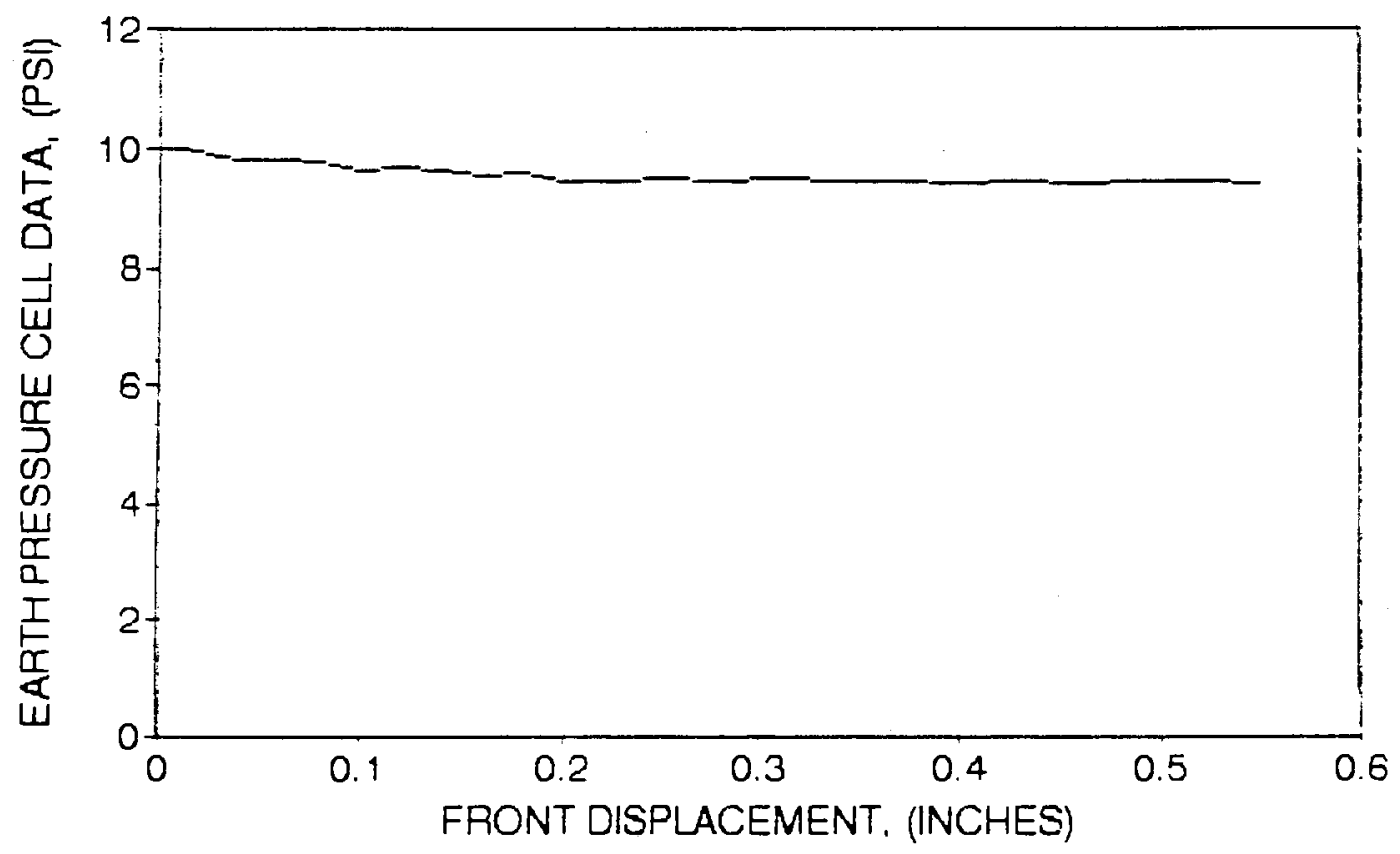


TENAX 401

2 PSI NORMAL STRESS. EPC -1" CTR HORIZ

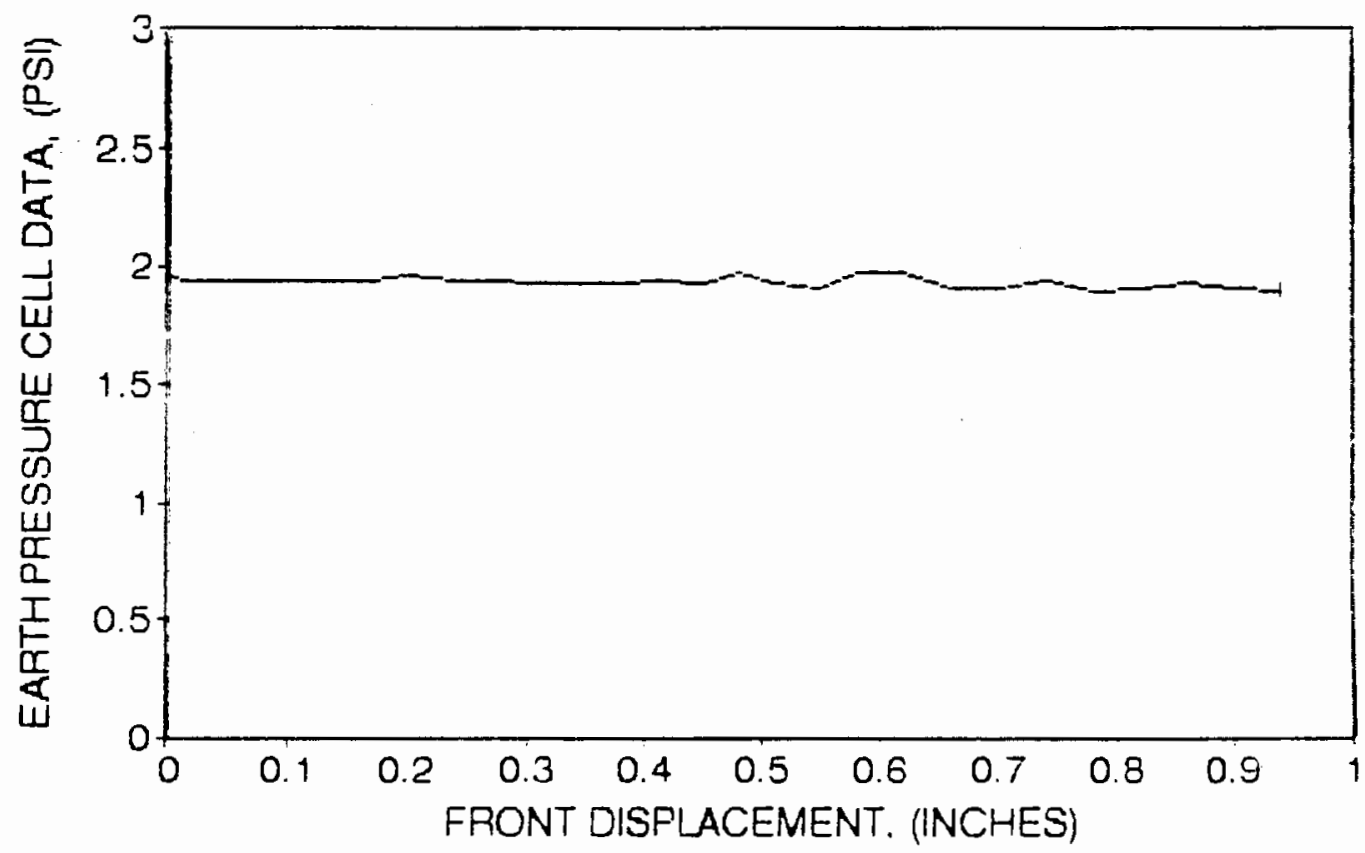


TENAX 401

5 PSI NORMAL STRESS. EPC -7 " CTR HORIZ

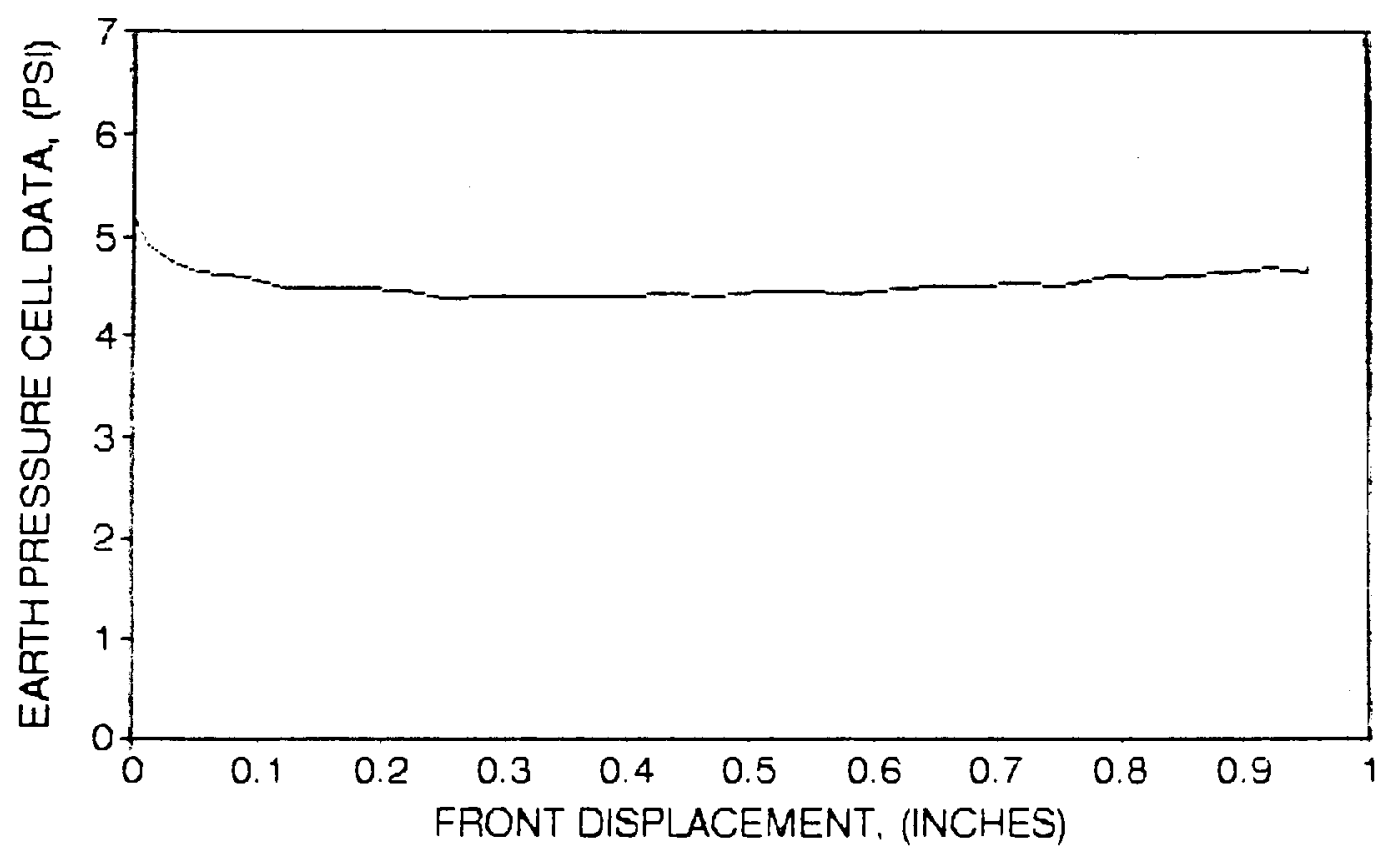


TENAX 401

10 PSI NORMAL STRESS. EPC -8" CTR VERT

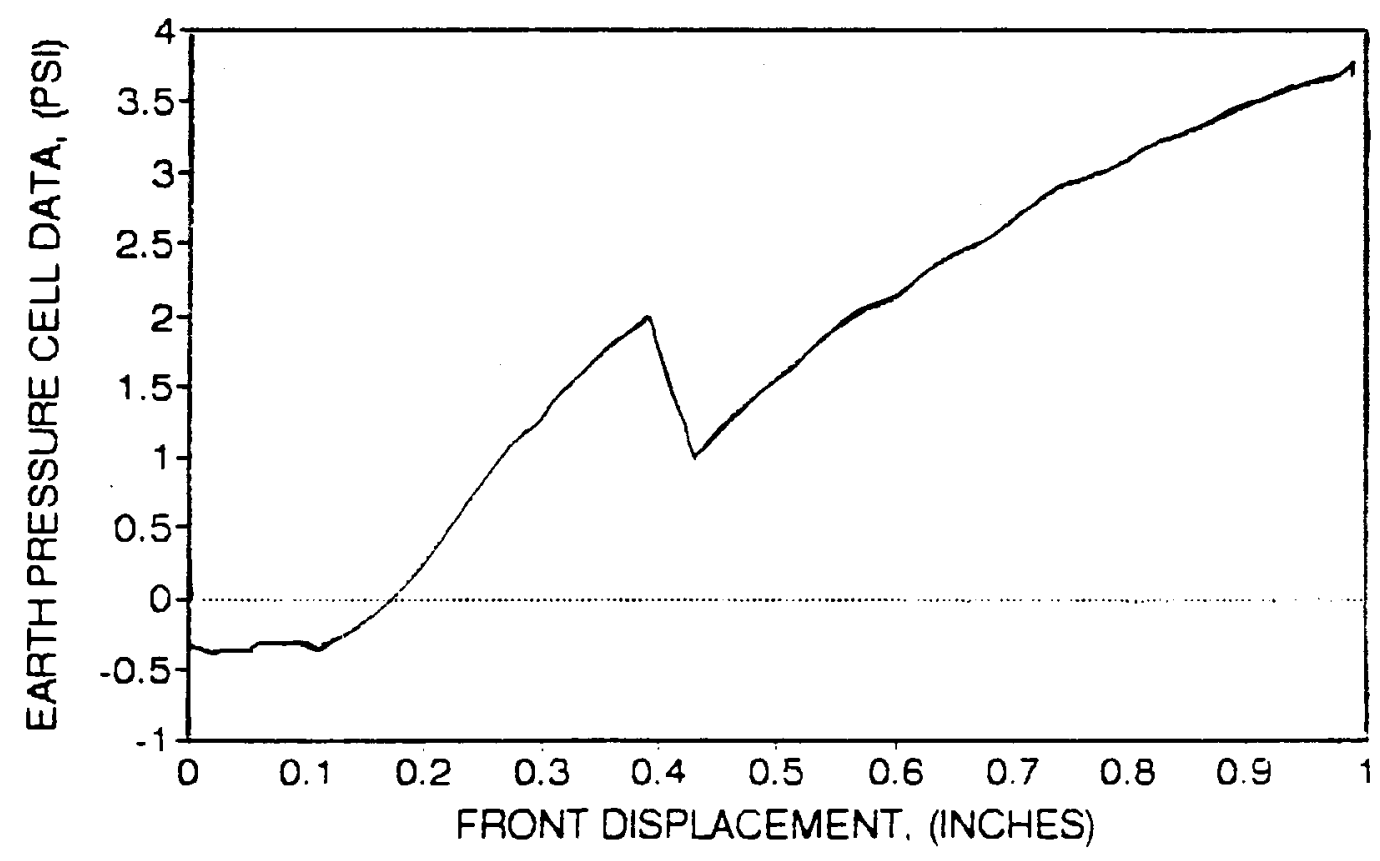


APPENDIX I

EARTH PRESSURE CELL DATA

FOR 6" 6 "6" AND 6" 6 " $12 "$ TEST SPECIMENS 


\section{FORTRAC 35/20-20 10 PSI NORMAL STRESS. EPC -7" FRNT VERT}

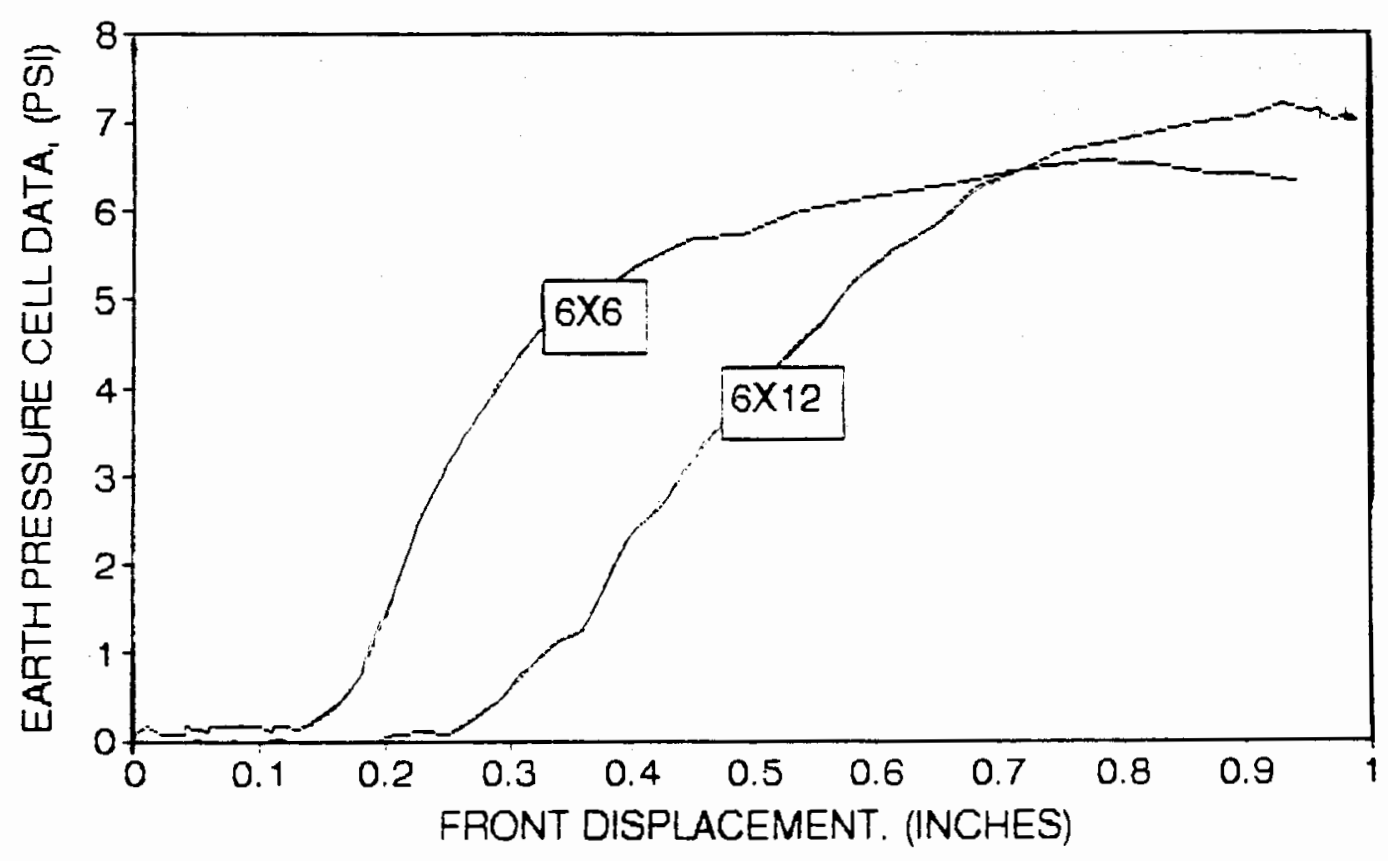


APPENDIX $J$

RELAXATION TEST DATA 
FORTRAC 35/20-20 10 PSI NORMAL STRESS. RELAXATION TEST

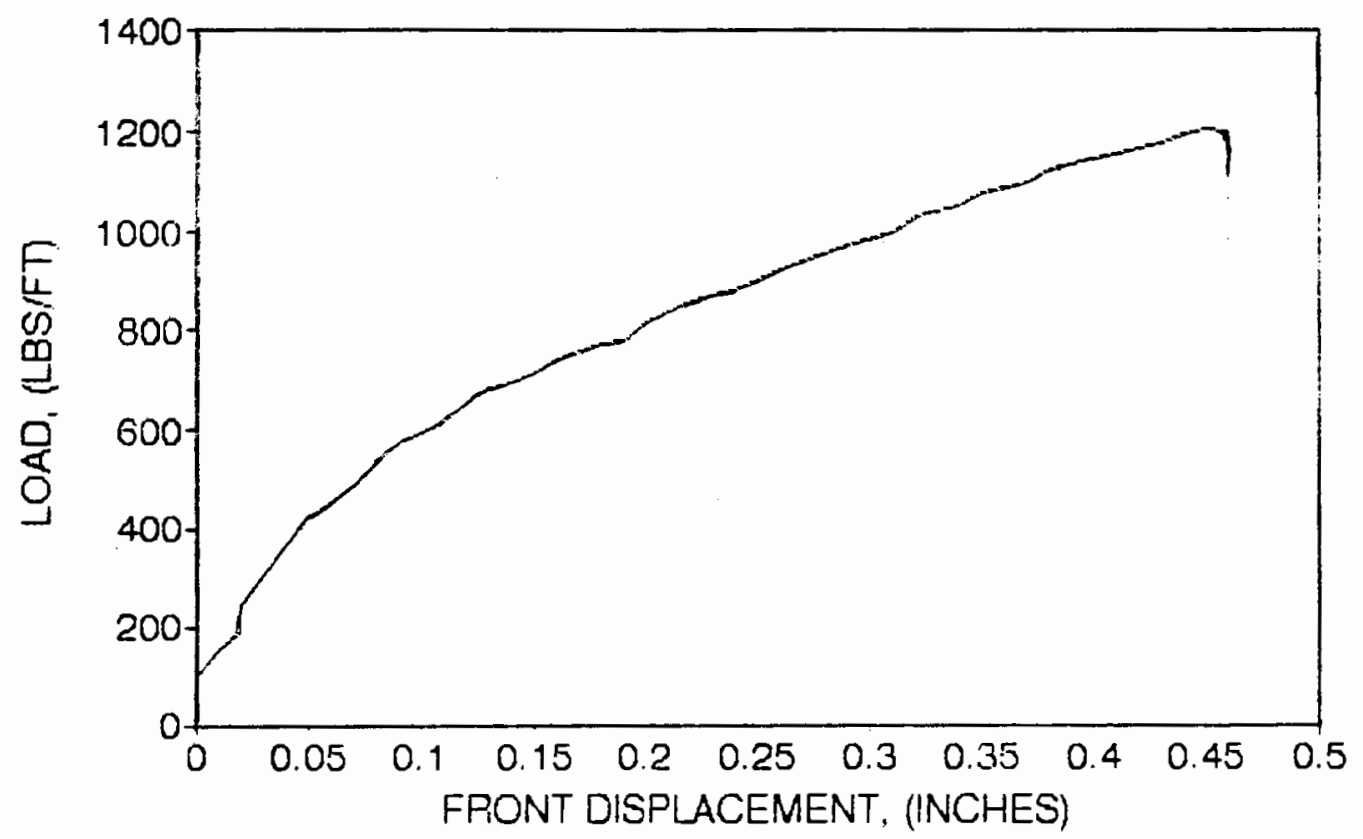




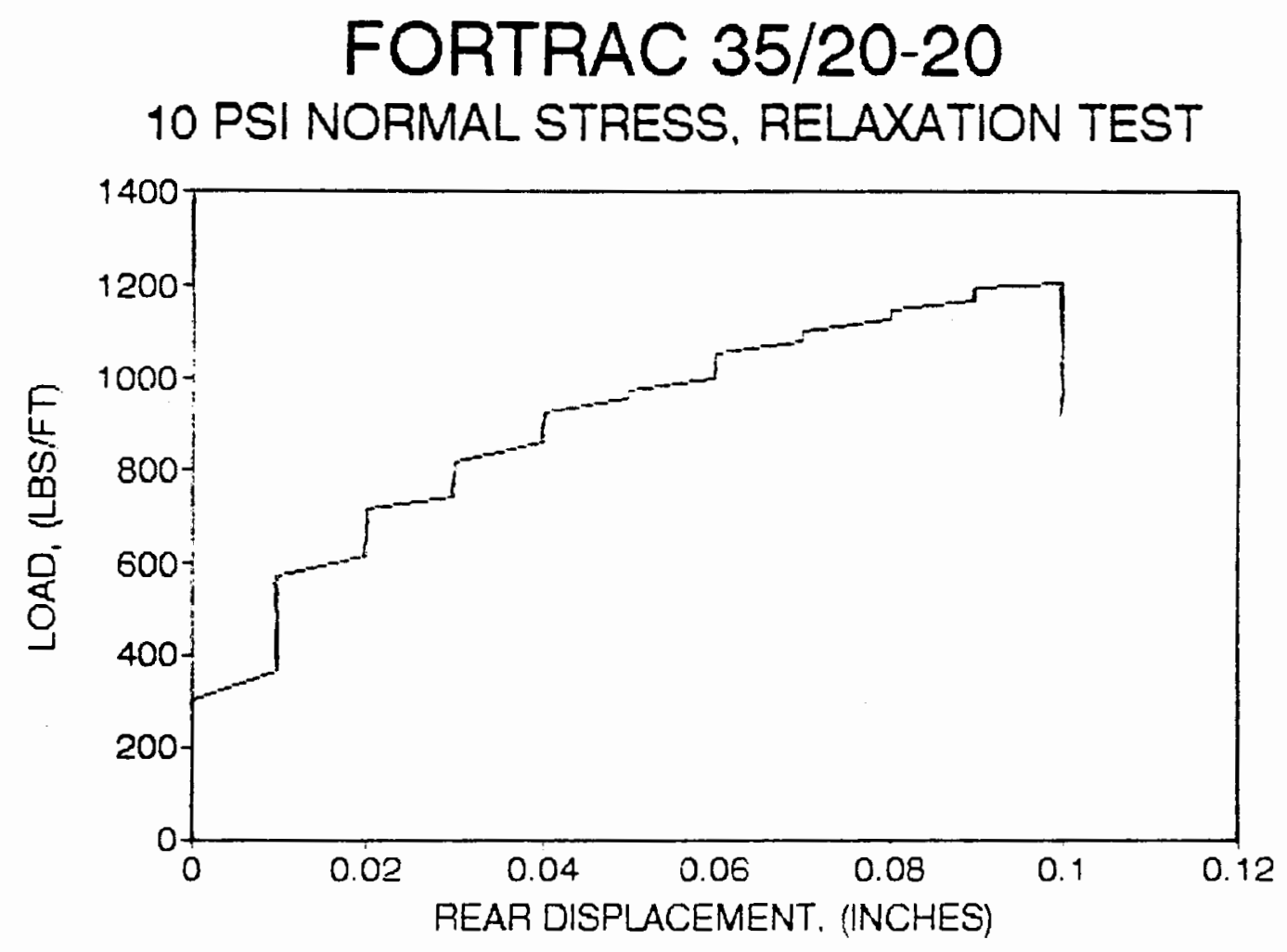


FORTRAC 35/20-20

10 PSI NORMAL STRESS, RELAXATION TEST

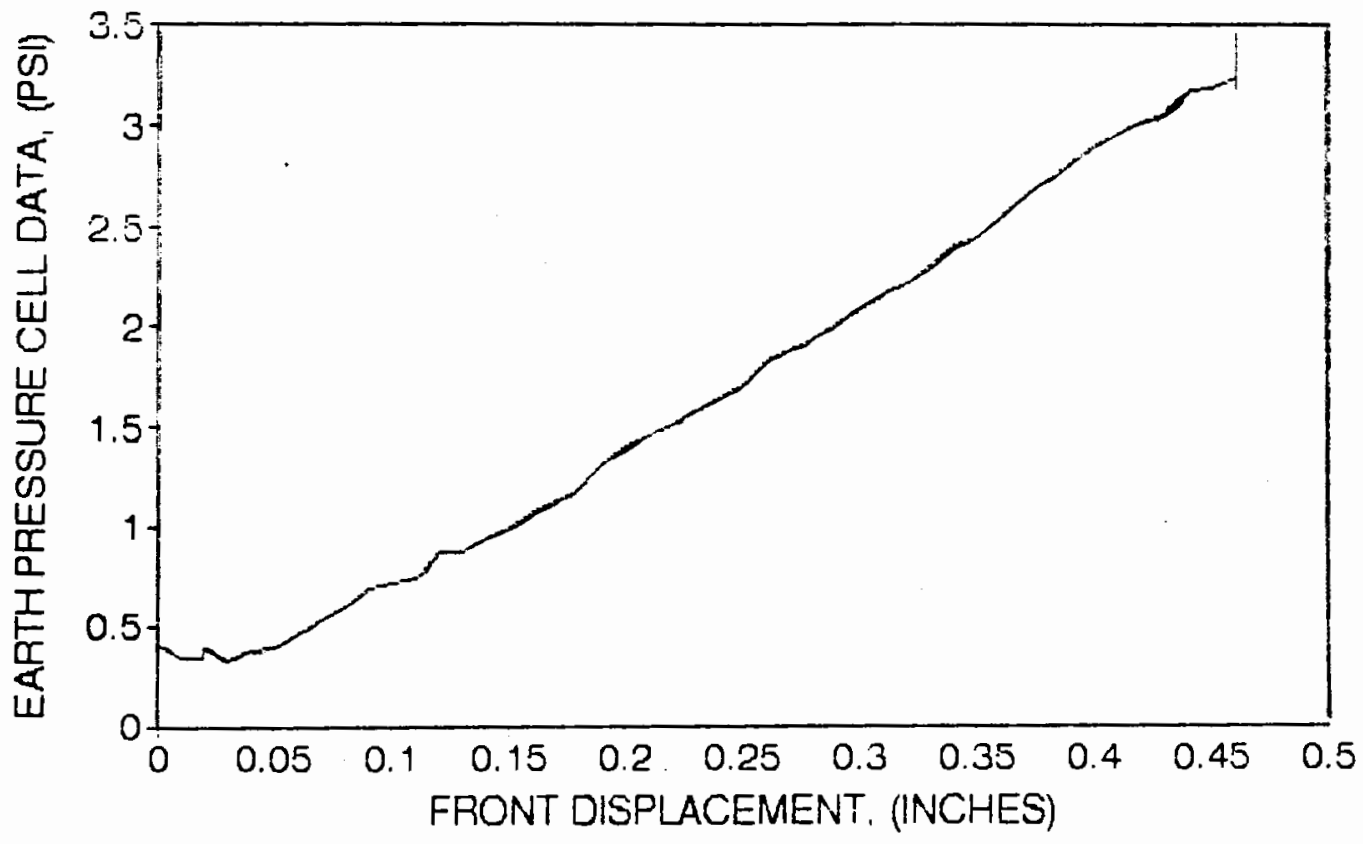


APPENDIX K

COMPUTER MODEL NUMBER ONE 
TEST2 1 OUT. DAT

PULTEST21. INP

ELASTIC SOIL

ELASTIC GRID

ELEMENT 301

(NODE 4)

STP

STRESS ( 11 ) STRAIN (E11) DISPLACEMENT (U1)

1 i 1

$-2.4024 \mathrm{E}-4$

$7.3921 E-9$

$2.6427 \mathrm{E}-7$

2 i 4

$5.4435 \mathrm{E}-1$

$1.6749 \mathrm{E}-5$

$2.0 \mathrm{E}-2$

3 i 1

$2.6586 \mathrm{E}-1$

8. $1803 E-6$

$3 \cdot O E-2$

ELEMENT 305

(NODE 20)

STP

1 i 1

2 i 4

3 i 1

$3.4322 E-2$

$7.0769 \mathrm{E}-3$

$2.4493 \mathrm{E}+0$
STRESS ( 111$)$ STRAIN (E11)

2. $1775 \mathrm{E}-7$

$7.5364 \mathrm{E}-5$

$1.0560 E-6$
DISPLACEMENT (U1)

$2.2713 \mathrm{E}-7$

$6.3247 E-2$

6. $3406 \mathrm{E}-2$ 
ELEMENT 311

(NODE 44)

STP

STRESS (S11) STRAIN (E11)

DISPLACEMENT (U1)

1 i 1

$2.0776 \mathrm{E}-4$

$6.3928 \mathrm{E}-9$

$2.0189 \mathrm{E}-7$

2 i 4

2. $4435 E+0$

$7.5186 E-5$

$6.3676 \mathrm{E}-2$

3 i 1

$2.8744 \mathrm{E}+0$

$8.8442 \mathrm{E}-5$

$6.3420 \mathrm{E}-2$ 


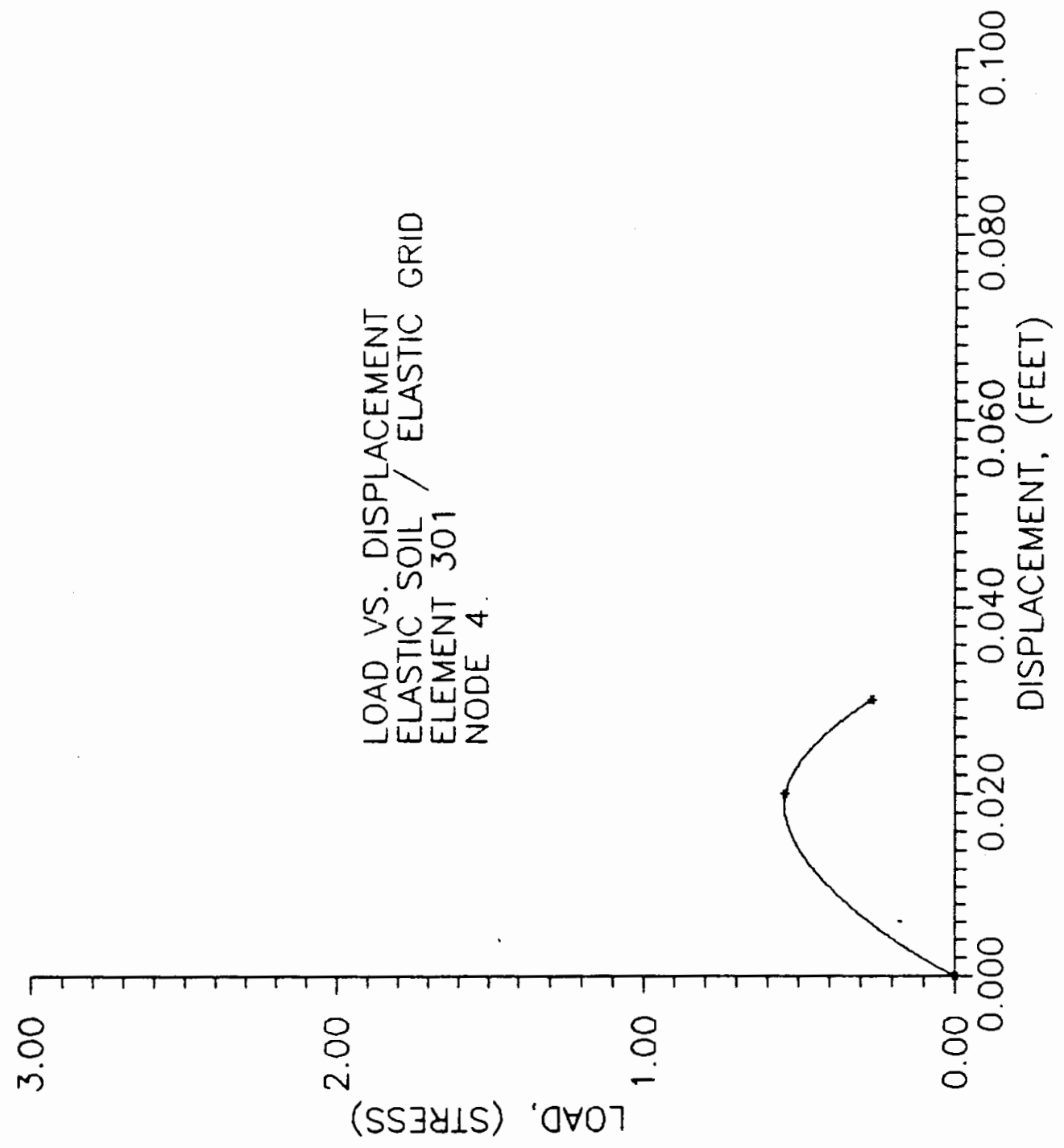




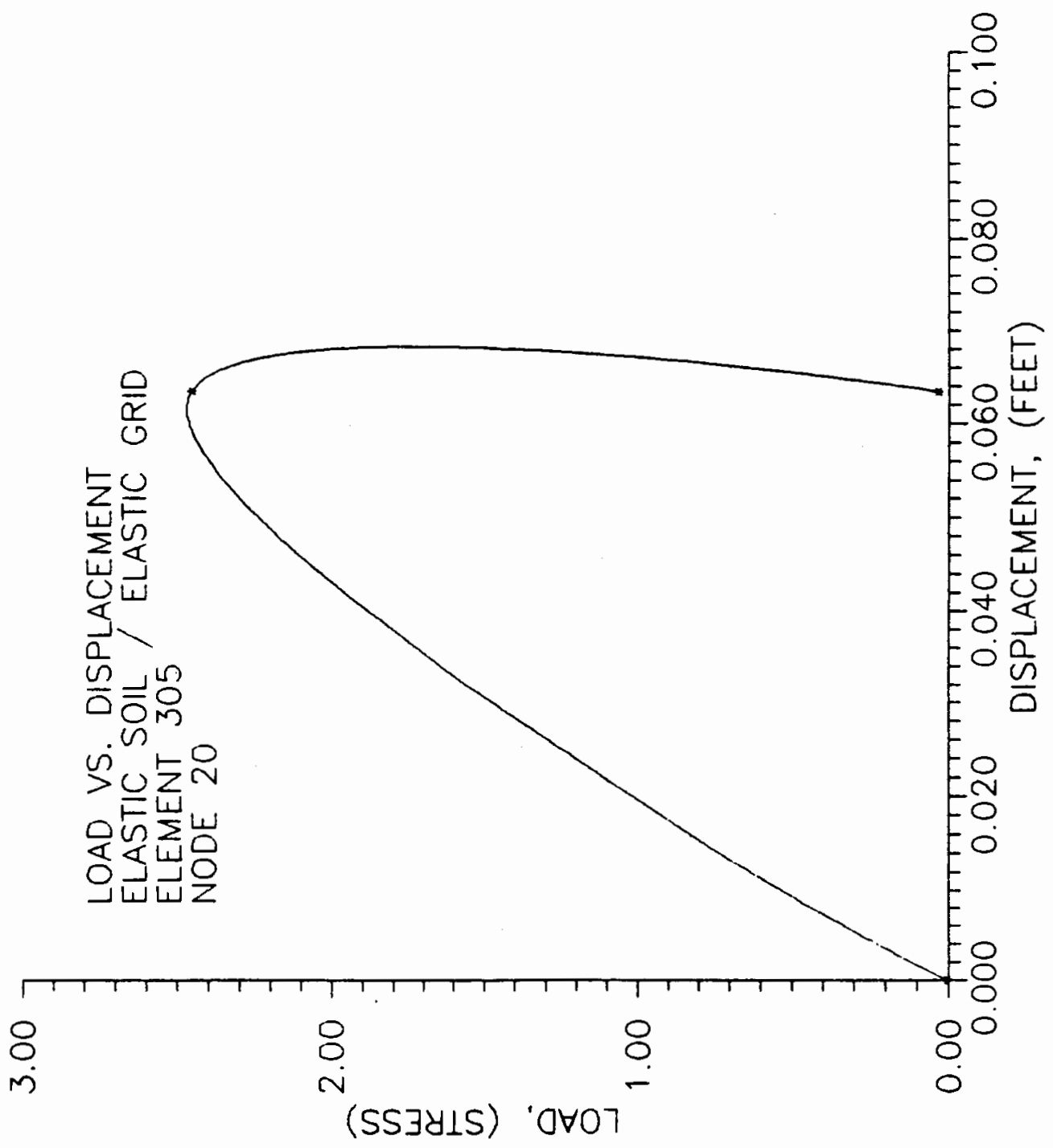




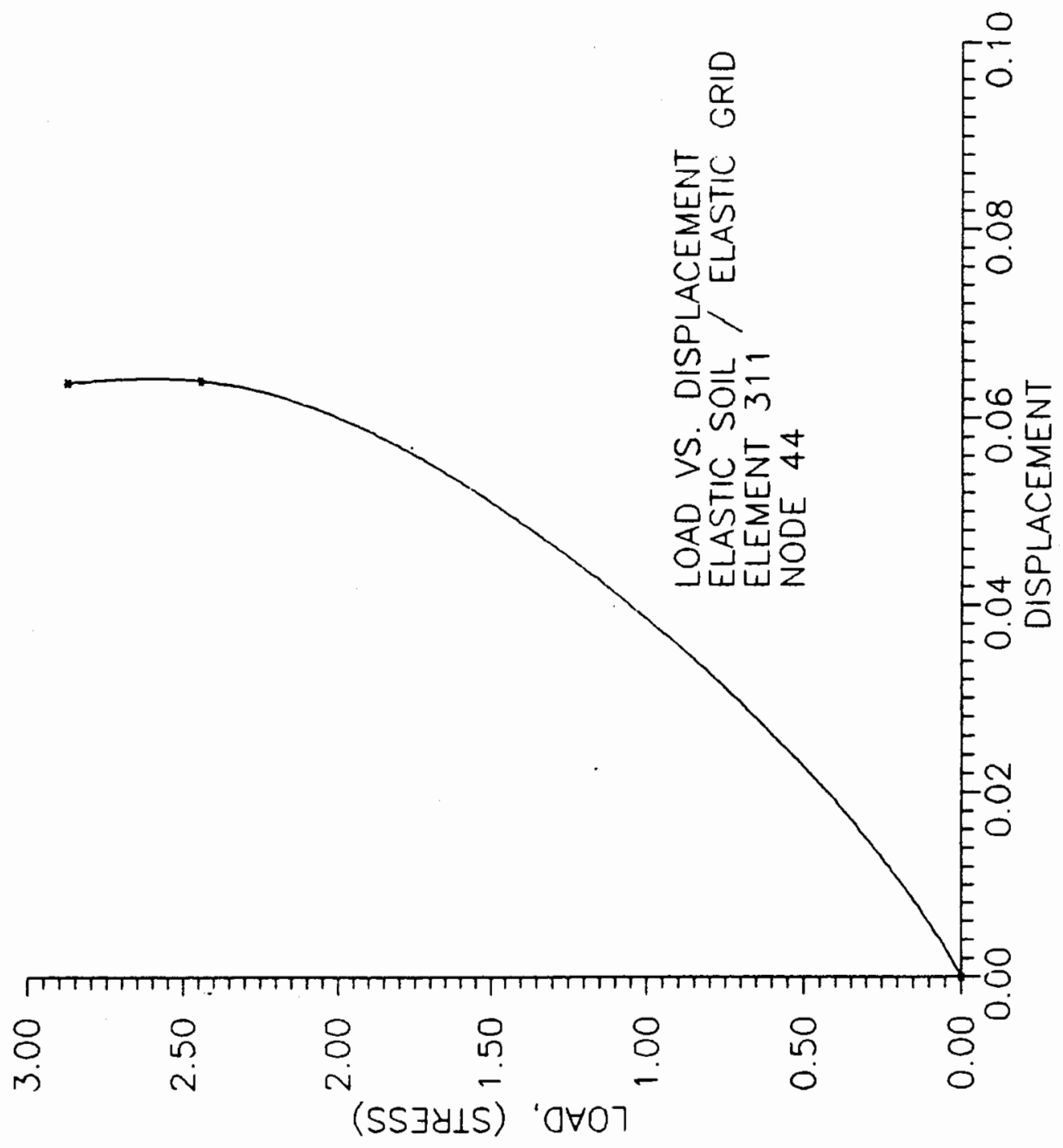




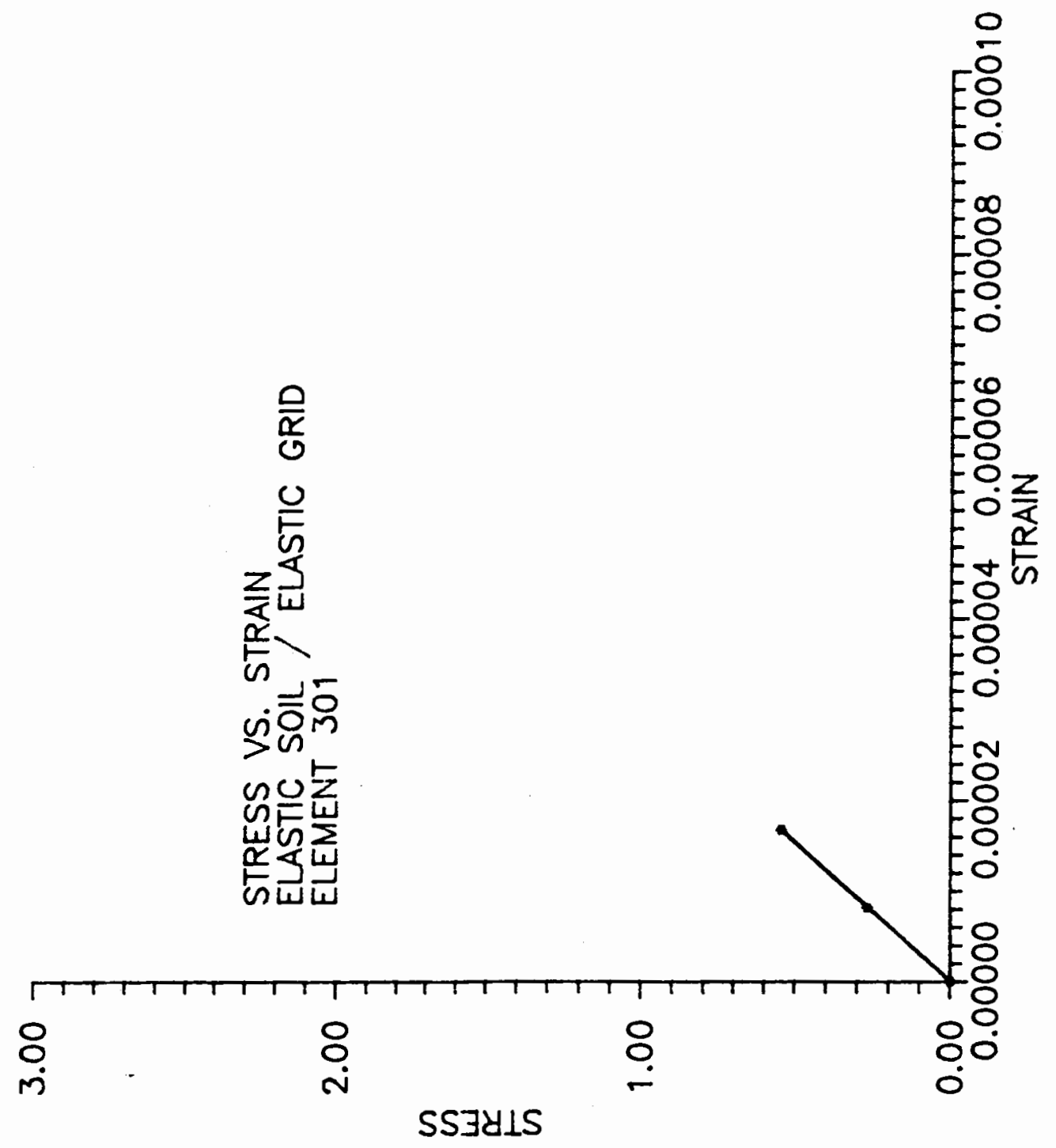




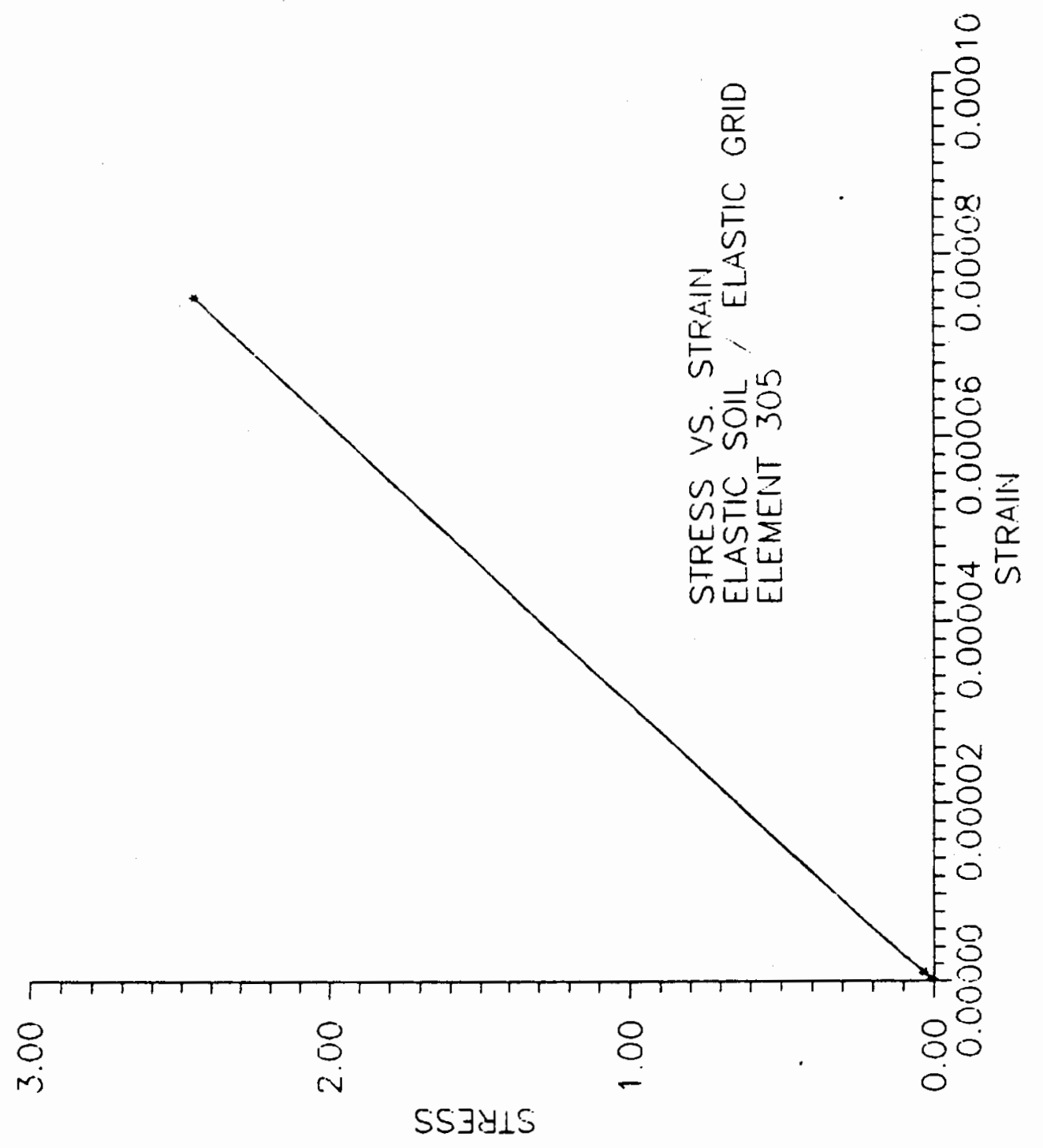




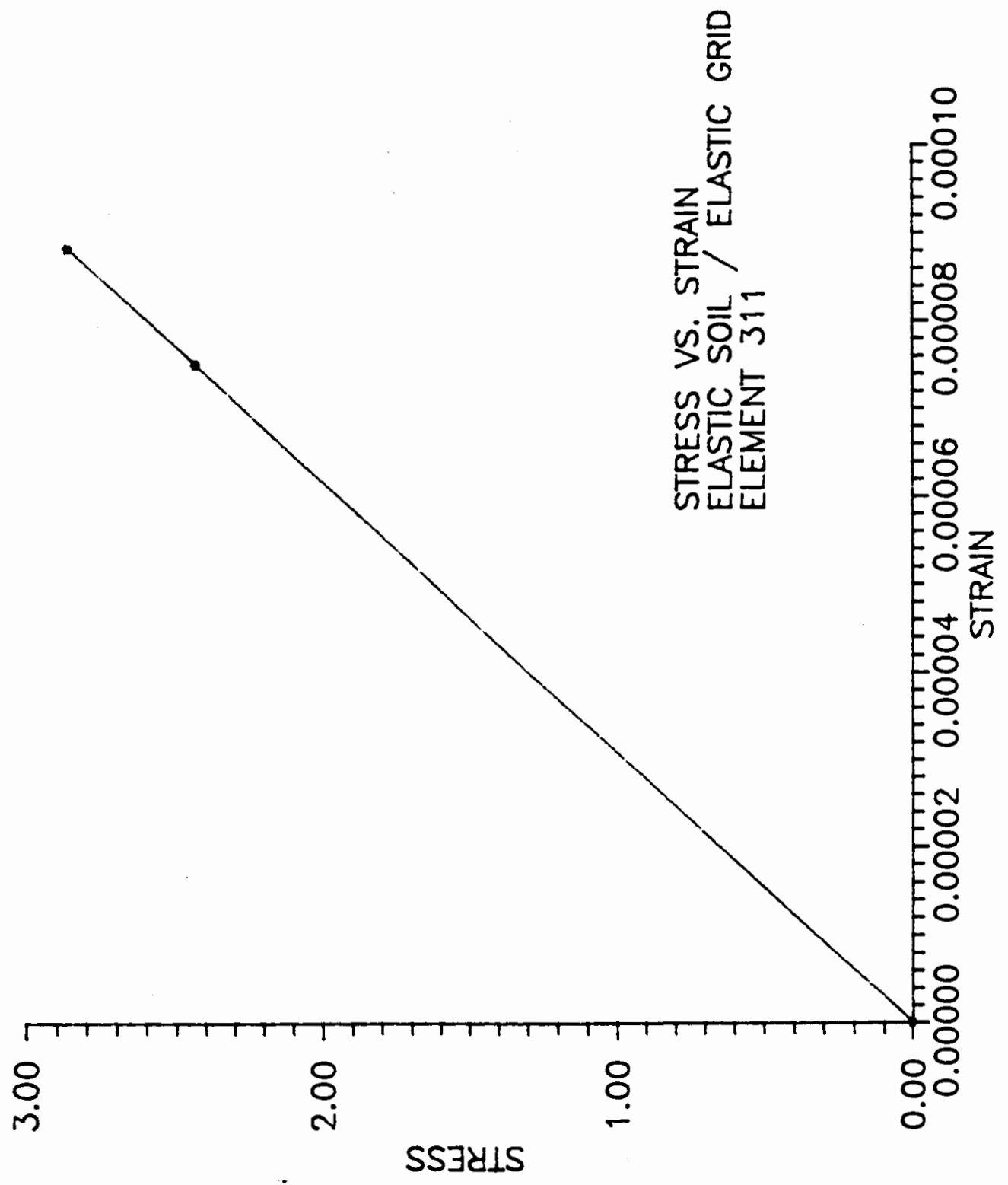




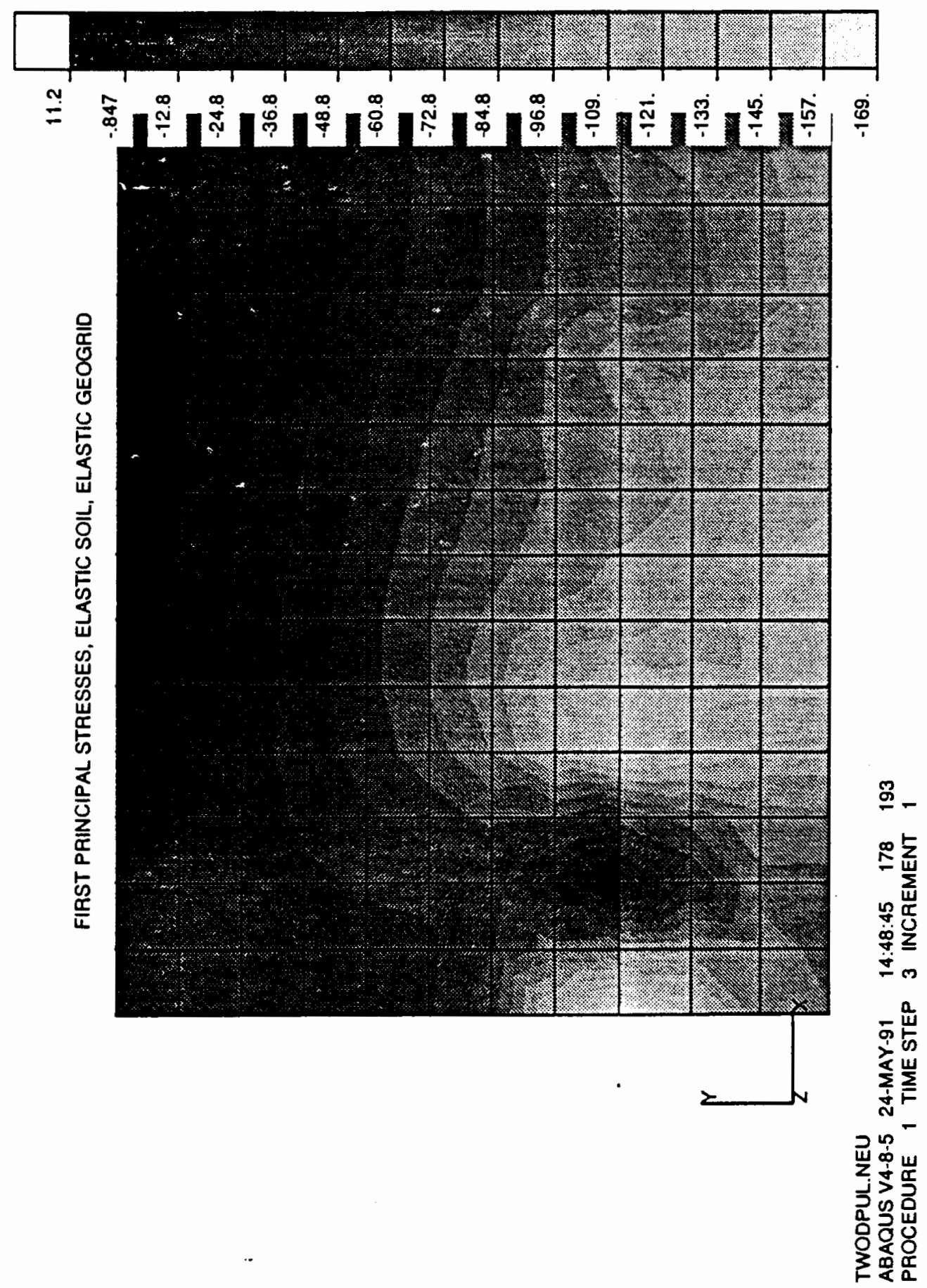




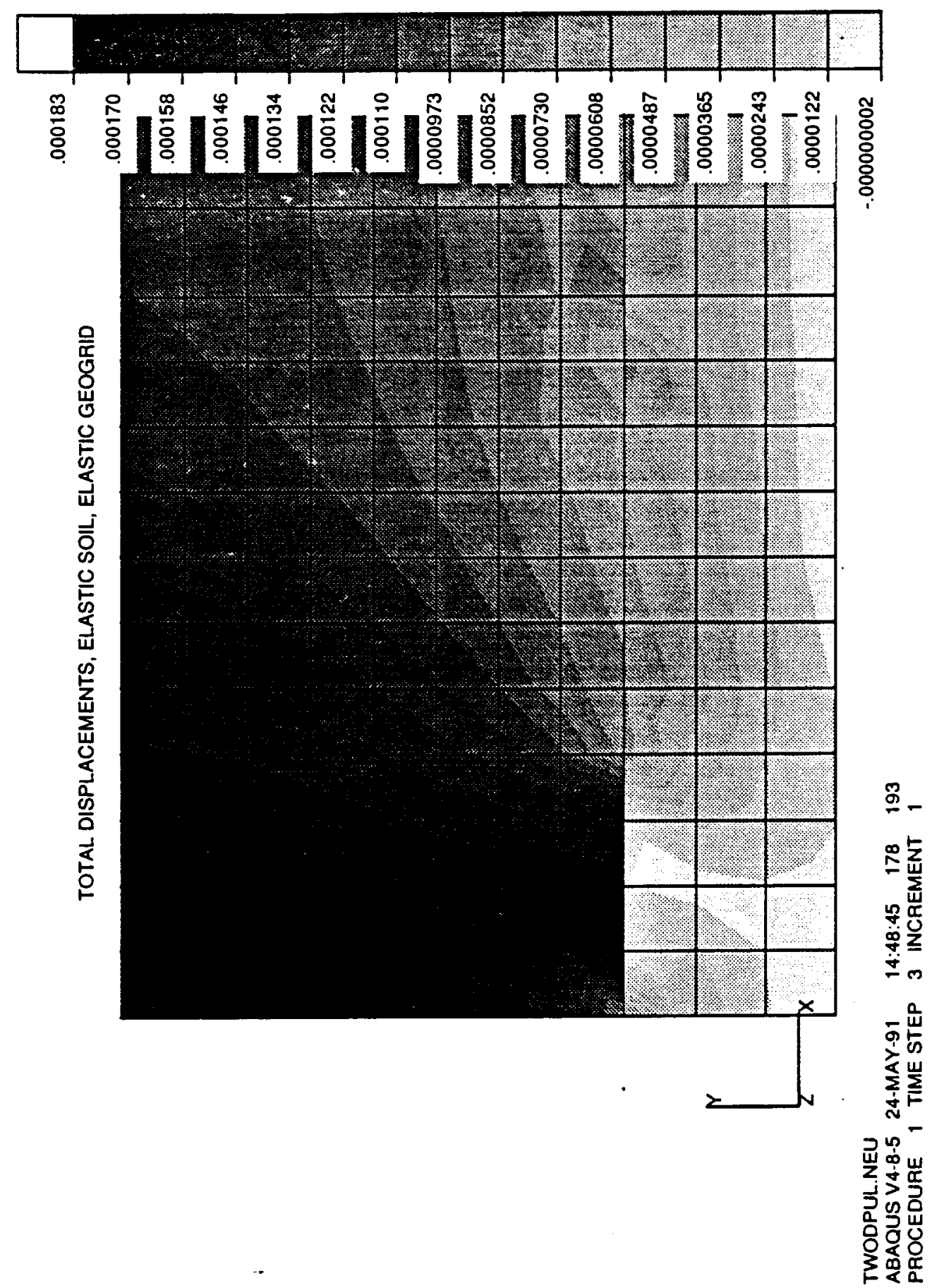




\section{APPENDIX L}

COMPUTER MODEL NUMBER TWO 
TEST23OUT. DAT

PULTEST23. INP

ELASTIC SOIL

ELASTIC / PLASTIC GRID

ELEMENT 301

ELEMENT 305

$\begin{array}{lccc}\text { STP } & \text { STRESS (S11) } & \text { STRAIN (E11) } & \text { DISPLACEMENT (U1) } \\ 1 \text { i } 1 & -2.4024 \mathrm{E}-4 & -7.3921 \mathrm{E}-9 & 2.6427 \mathrm{E}-7 \\ 2 \mathrm{i} 11 & 6.4592 \mathrm{E}+1 & 1.9875 \mathrm{E}-3 & 2.0000 \mathrm{E}-2 \\ 3 \mathrm{i} 1 & 6.6500 \mathrm{E}+1 & 2.0462 \mathrm{E}-3 & 3.0000 \mathrm{E}-2 \\ 4 \mathrm{i} 1 & 6.5896 \mathrm{E}+1 & 2.0276 \mathrm{E}-3 & 4.0000 \mathrm{E}-2\end{array}$

(NODE 20)

STP

STRESS ( 11 )

STRAIN (E11)

DISPLACEMENT (U1)

1 i 1

$7.0769 \mathrm{E}-3$

2. $1775 E-7$

2. $2713 \mathrm{E}-7$

2 i 11

$4.2282 E+1$

1. $3010 E-3$

1. $9367 \mathrm{E}-2$

3 i 1

$4.3583 E+1$

1. $341 O E-3$

$2.9349 E-2$

4 i 1

4. $3154 E+1$

1. $3278 E-3$

3. $9354 \mathrm{E}-2$ 
ELEMENT 311

(NODE 44)

STP

1 i 1

2 i 11

3 i 1

4 i 1

\section{STRESS ( 111$)$}

$2.0776 \mathrm{E}-4$

4. $8800 E+O$

5. $4674 \mathrm{E}+\mathrm{O}$

$5.8315 E+0$

\section{STRAIN (E11)}

6. $3928 E-9$

1. $5015 \mathrm{E}-4$

1. $6823 E-4$

1. $7943 \mathrm{E}-4$ DISPLACEMENT (U1)

$2.0189 E-7$

1. $8915 \mathrm{E}-2$

$2.8881 \mathrm{E}-2$

3. $8894 \mathrm{E}-2$ 


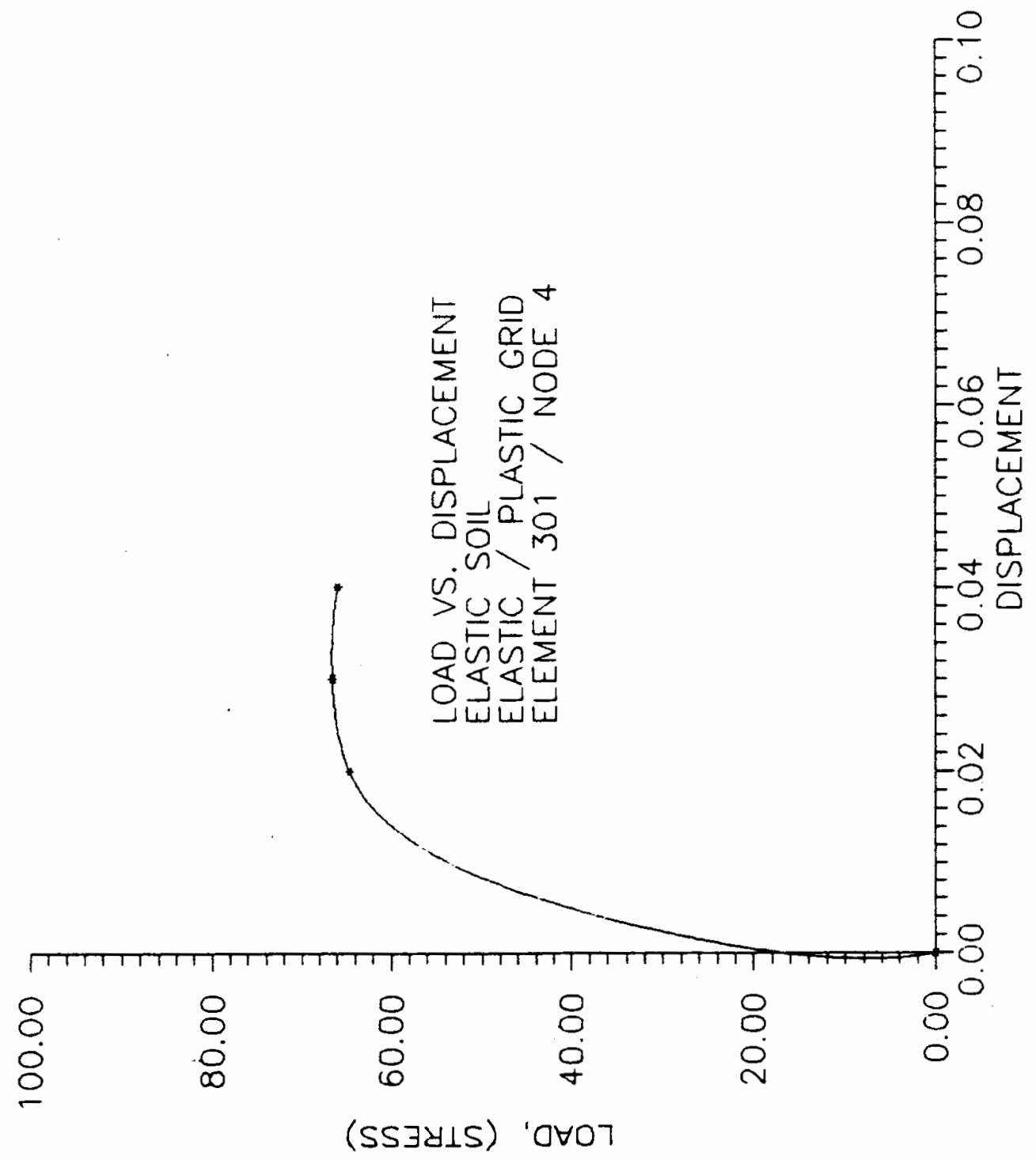




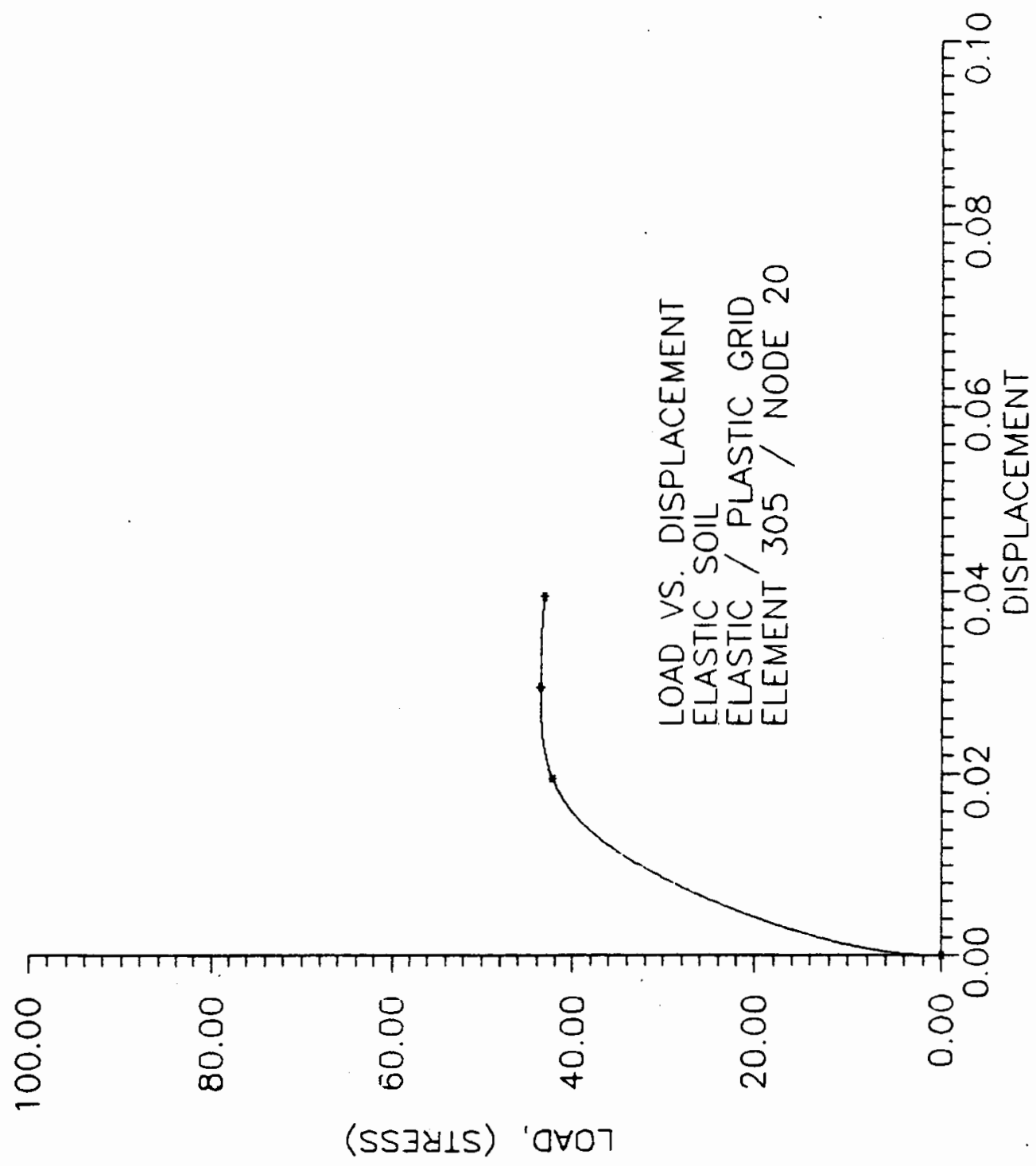




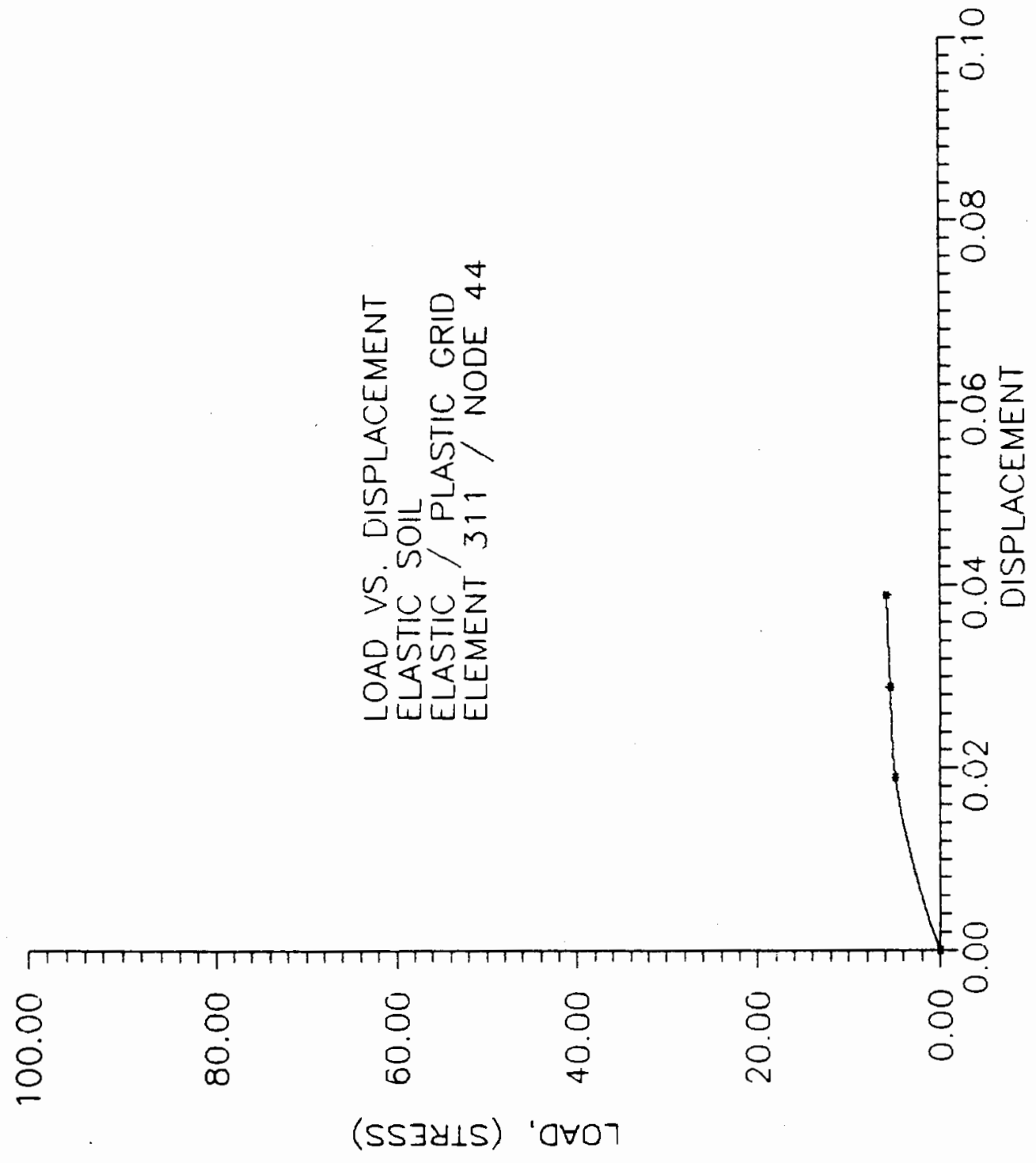




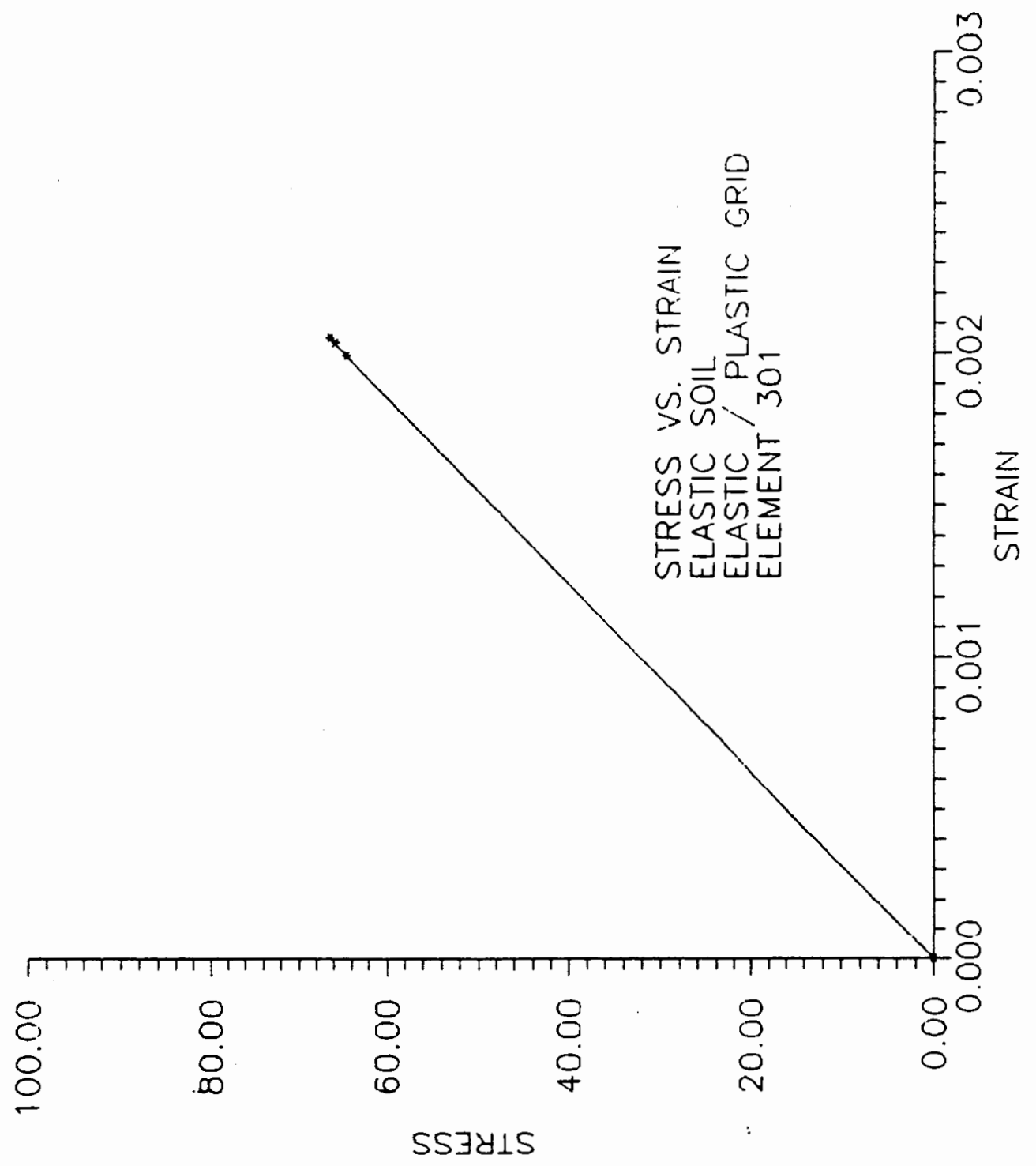




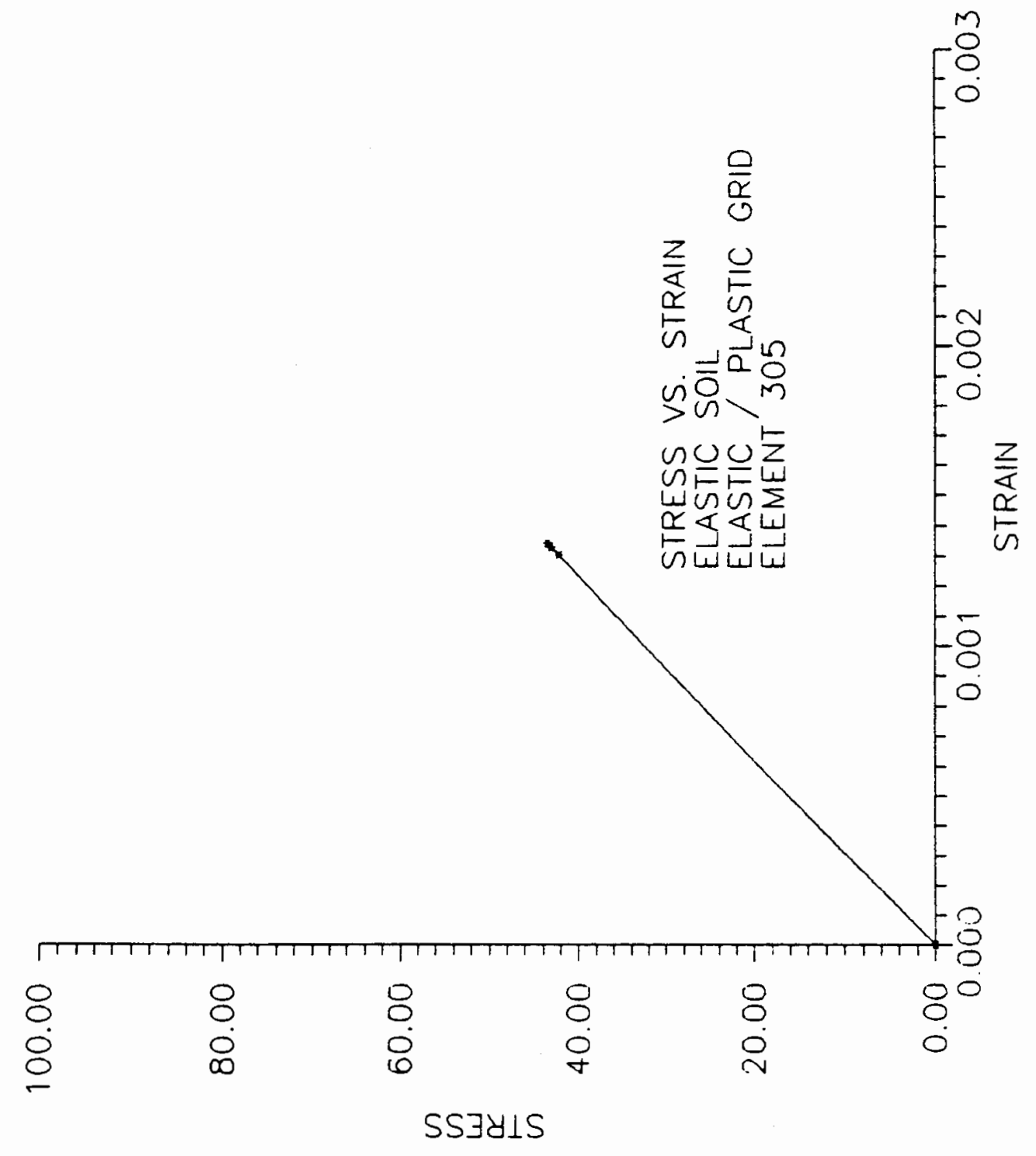




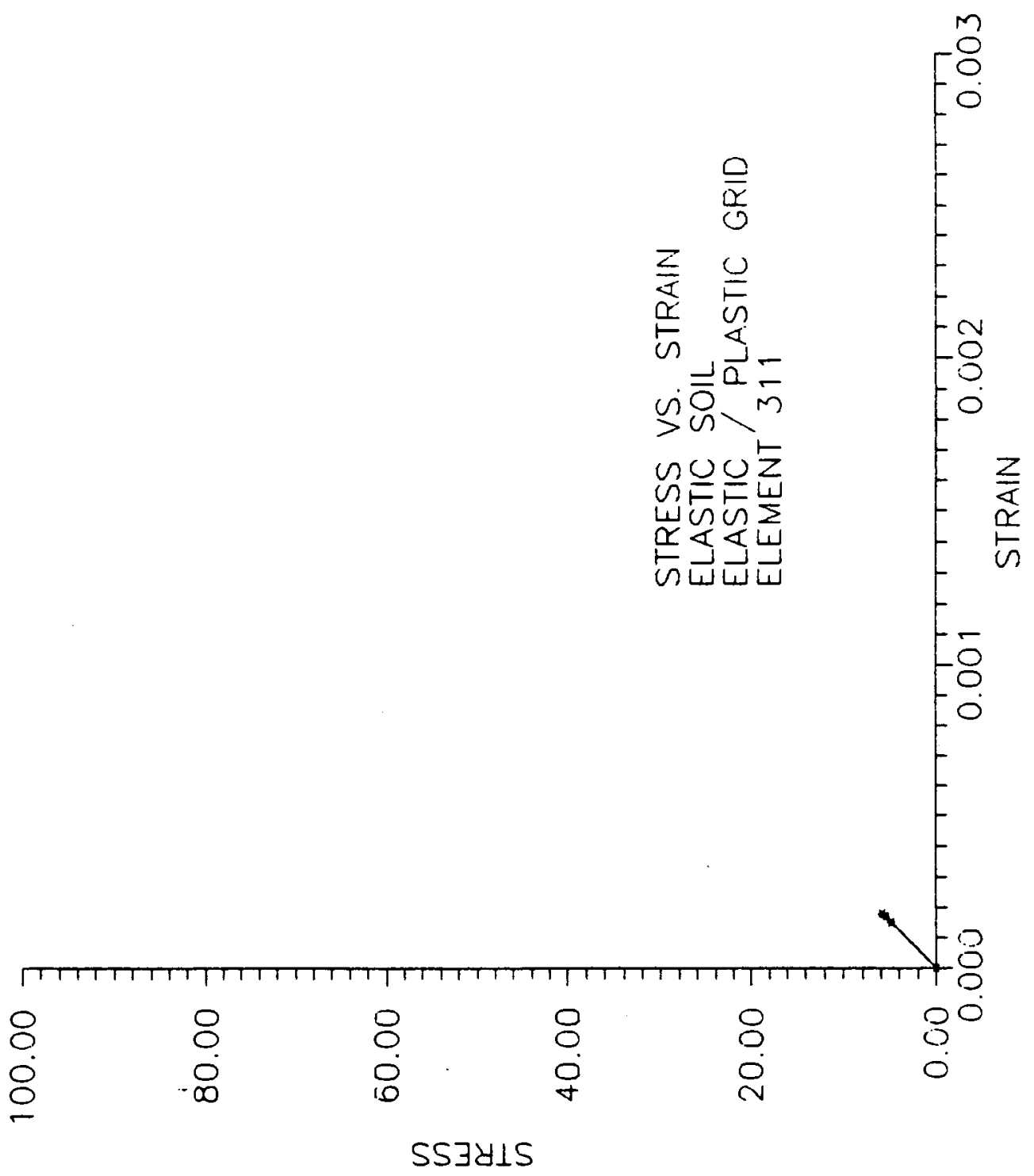




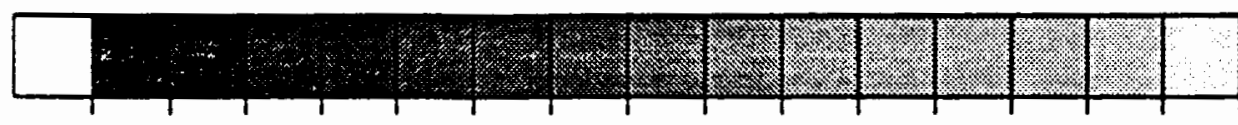

吕

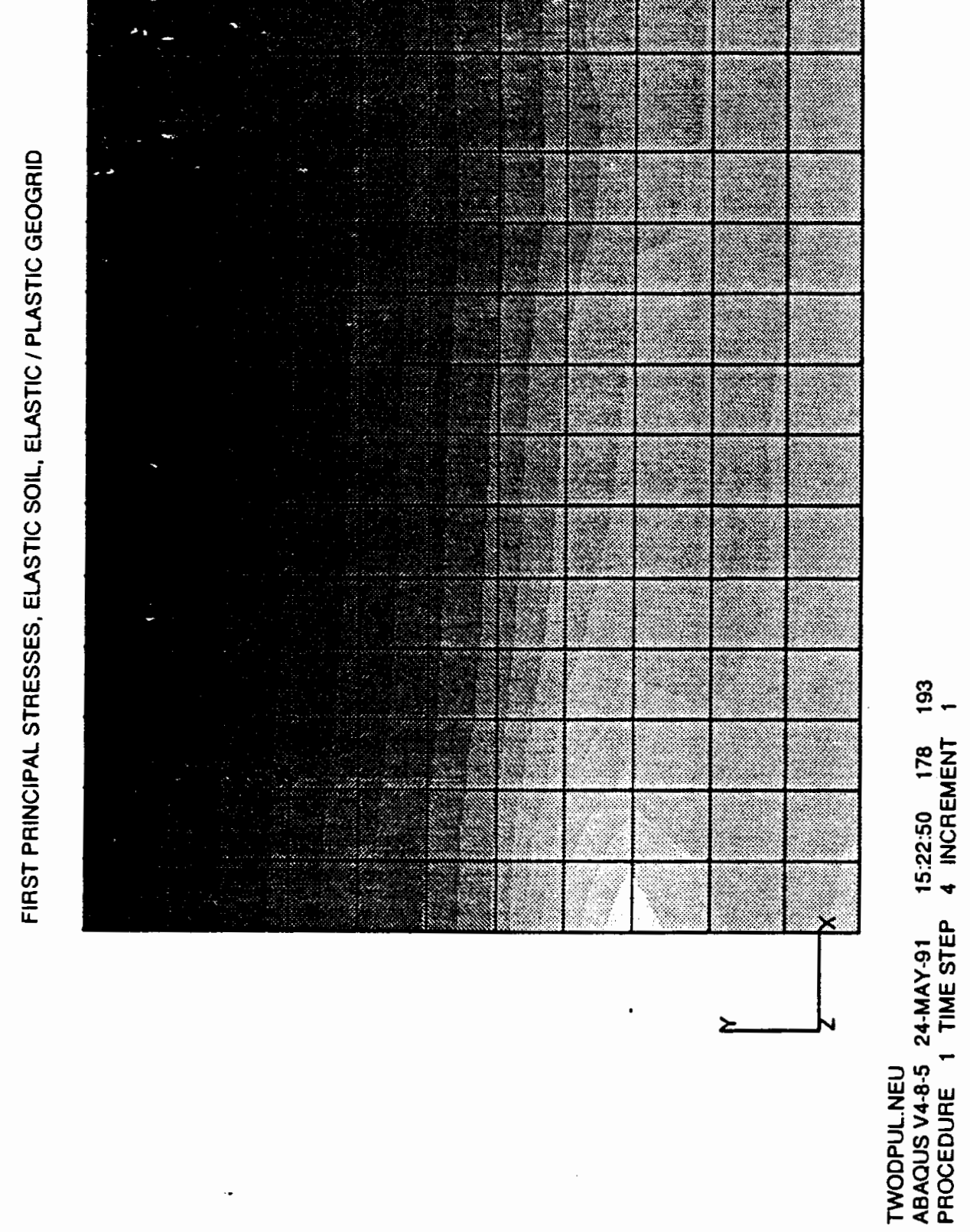




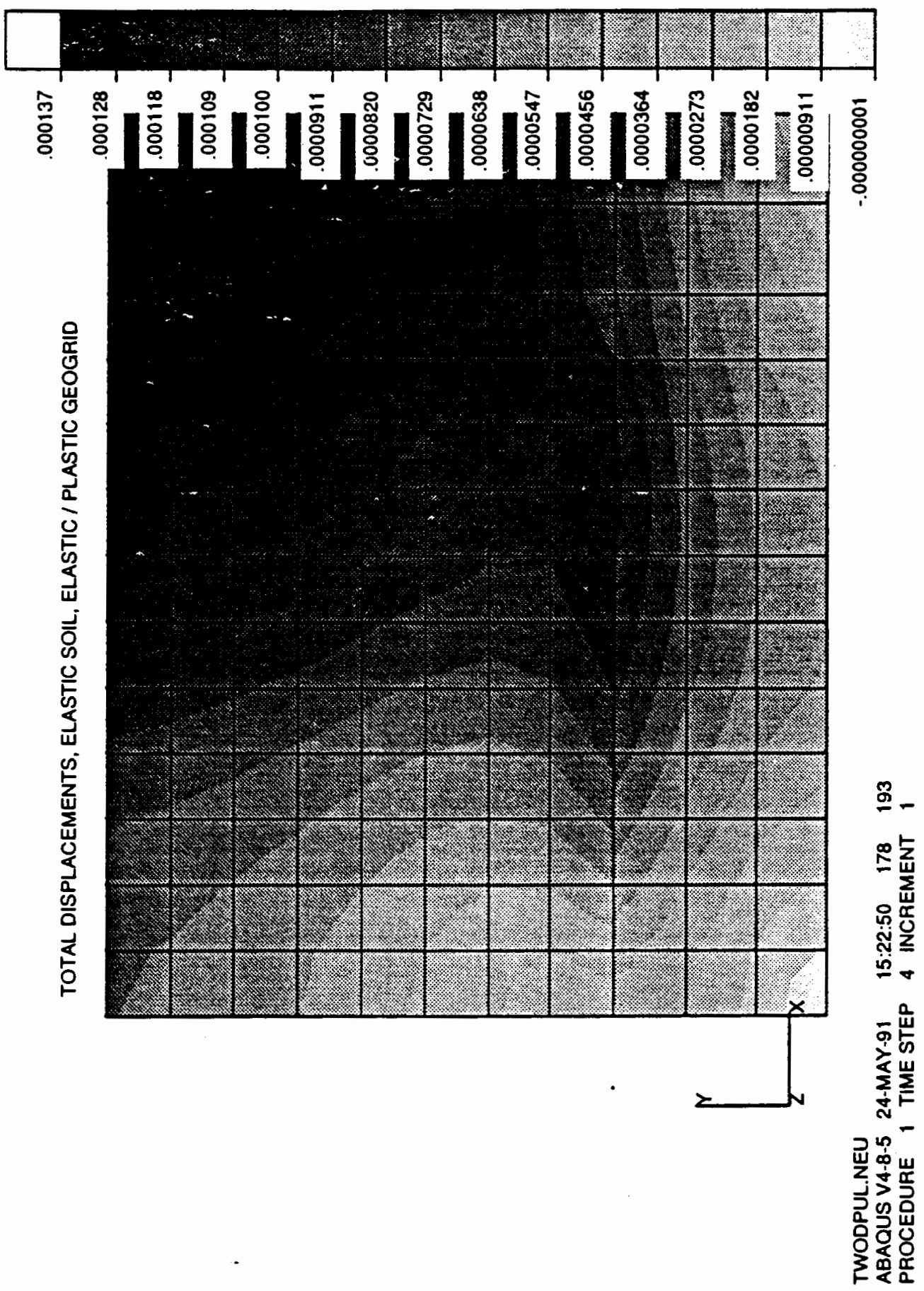


APPENDIX M

COMPUTER MODEL NUMBER THREE 
TEST22OUT.DAT

PULTEST22. INP

VON MISES (ELASTIC / PLASTIC) SOIL

ELASTIC / PLASTIC GRID

ELEMENT 301

(NODE 4)

STP STRESS ( 11 ) STRAIN (E11) DISPLACEMENT (U1)

1 i $-2.4024 E-4 \quad-7.3921 \mathrm{E}-9 \quad 2.6427 \mathrm{E}-7$

2 i $13 \quad 7.1221 \mathrm{E}+1 \quad 2.1914 \mathrm{E}-3 \quad 1.9774 \mathrm{E}-2$

3 i $\quad 7.5185 \mathrm{E}+1 \quad 2.3134 \mathrm{E}-3 \quad 3.9763 \mathrm{E}-2$

$4 i 1 \quad 8.2888 \mathrm{E}+1 \quad 2.5504 \mathrm{E}-3 \quad 5.9745 \mathrm{E}-2$

$\begin{array}{llll}5 \text { i } & 7.0864 \mathrm{E}+1 & 2.1804 \mathrm{E}-3 & 7.9782 \mathrm{E}-2\end{array}$

ELEMENT 305

(NODE 20)

STP

STRESS ( 11 ) STRAIN (E11) DISPLACEMENT (U1)

1 i $12.0769 \mathrm{E}-3 \quad 2.1775 \mathrm{E}-7 \quad 2.2713 \mathrm{E}-7$

2 i 13

$4.8671 \mathrm{E}+1$

1. $4976 \mathrm{E}-3$

1. $9068 \mathrm{E}-2$

3 i 1

5. $1717 \mathrm{E}+1$

$1.5913 E-3$

$3.9016 \mathrm{E}-2$

4 i 1

6. $2385 E+1$

1. $9195 \mathrm{E}-3$

5. $8910 \mathrm{E}-2$

5 i 1

$4.9935 \mathrm{E}+1$

1. $5365 E-3$

7. $9058 \mathrm{E}-2$ 
ELEMENT 311

(NODE 44)

STP

1 i 1

2 i 13

3 i 1

4 i 1

5 i 1
STRESS (S11)

$2.0776 \mathrm{E}-4$

$1.0822 \mathrm{E}+1$

1. $2748 \mathrm{E}+1$

2. $2006 \mathrm{E}+1$

1. $7011 \mathrm{E}+1$
STRAIN (E11)

6. $3928 E-9$

3. $3299 \mathrm{E}-4$

$3.9225 E-4$

$6.7711 \mathrm{E}-4$

$5.2343 \mathrm{E}-4$
DISPLACEMENT (U1)

$2.0189 E-7$

1. $8512 \mathrm{E}-2$

3. $8418 \mathrm{E}-2$

$5.8161 \mathrm{E}-2$

$7.8474 \mathrm{E}-2$ 


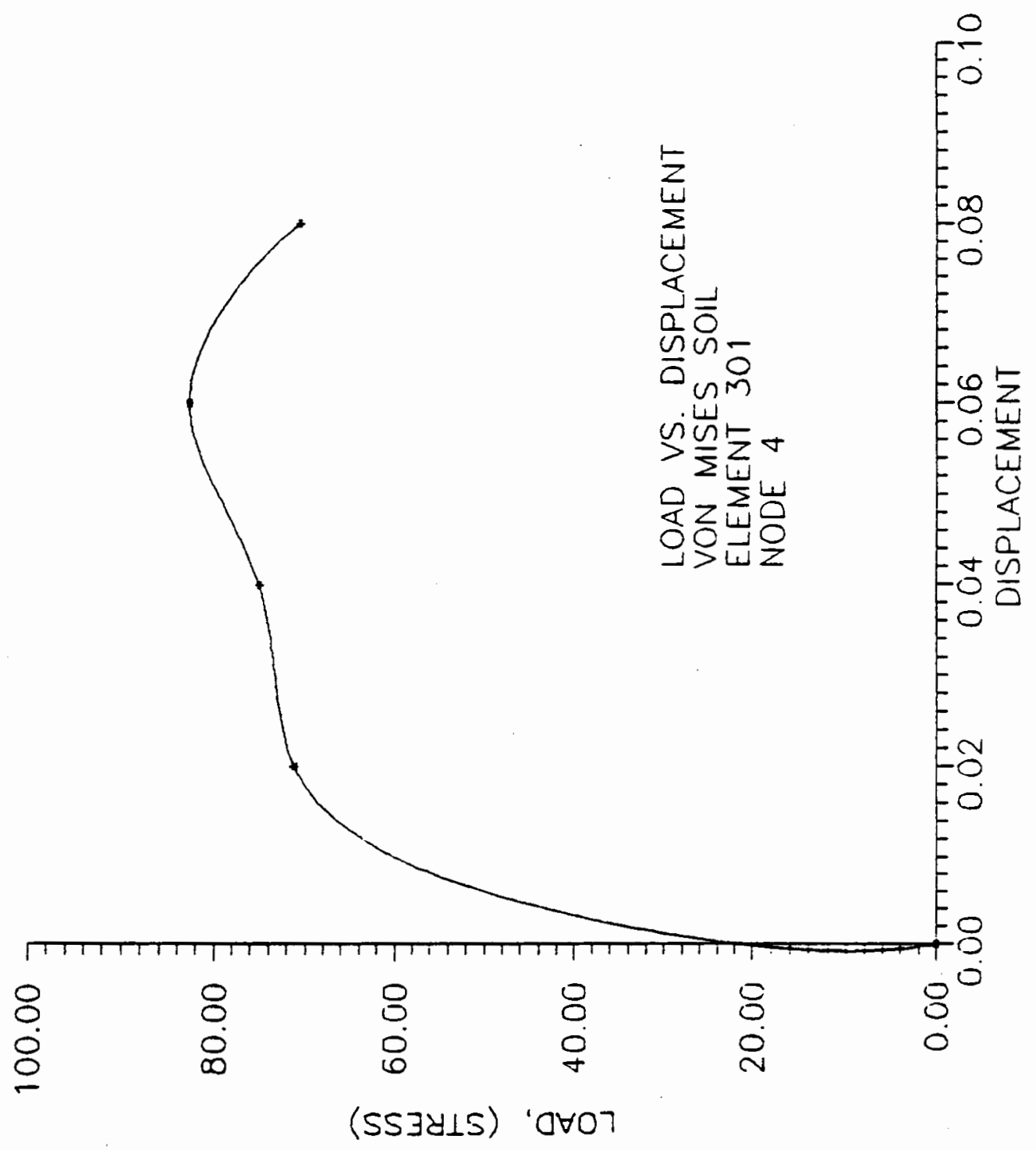




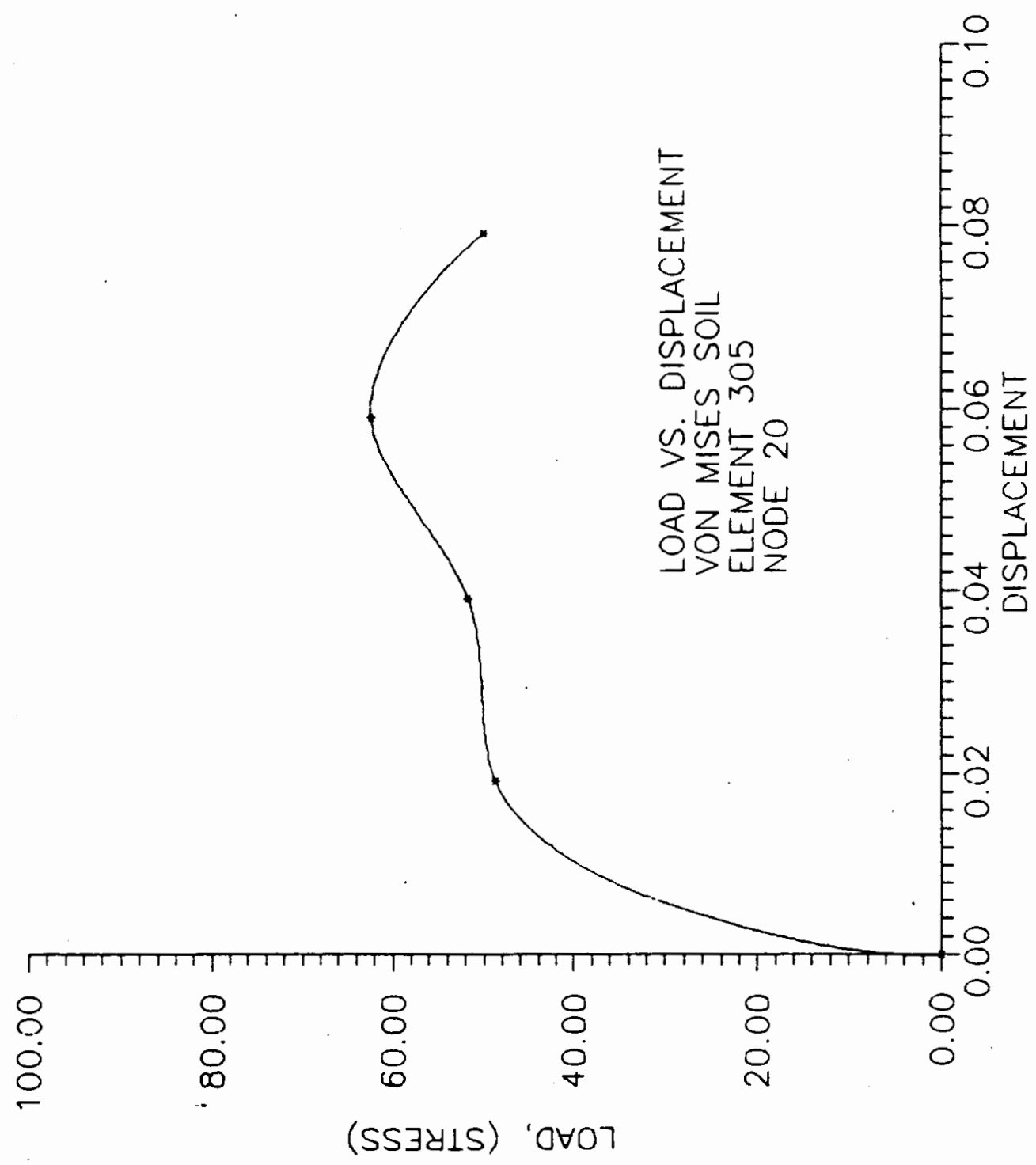



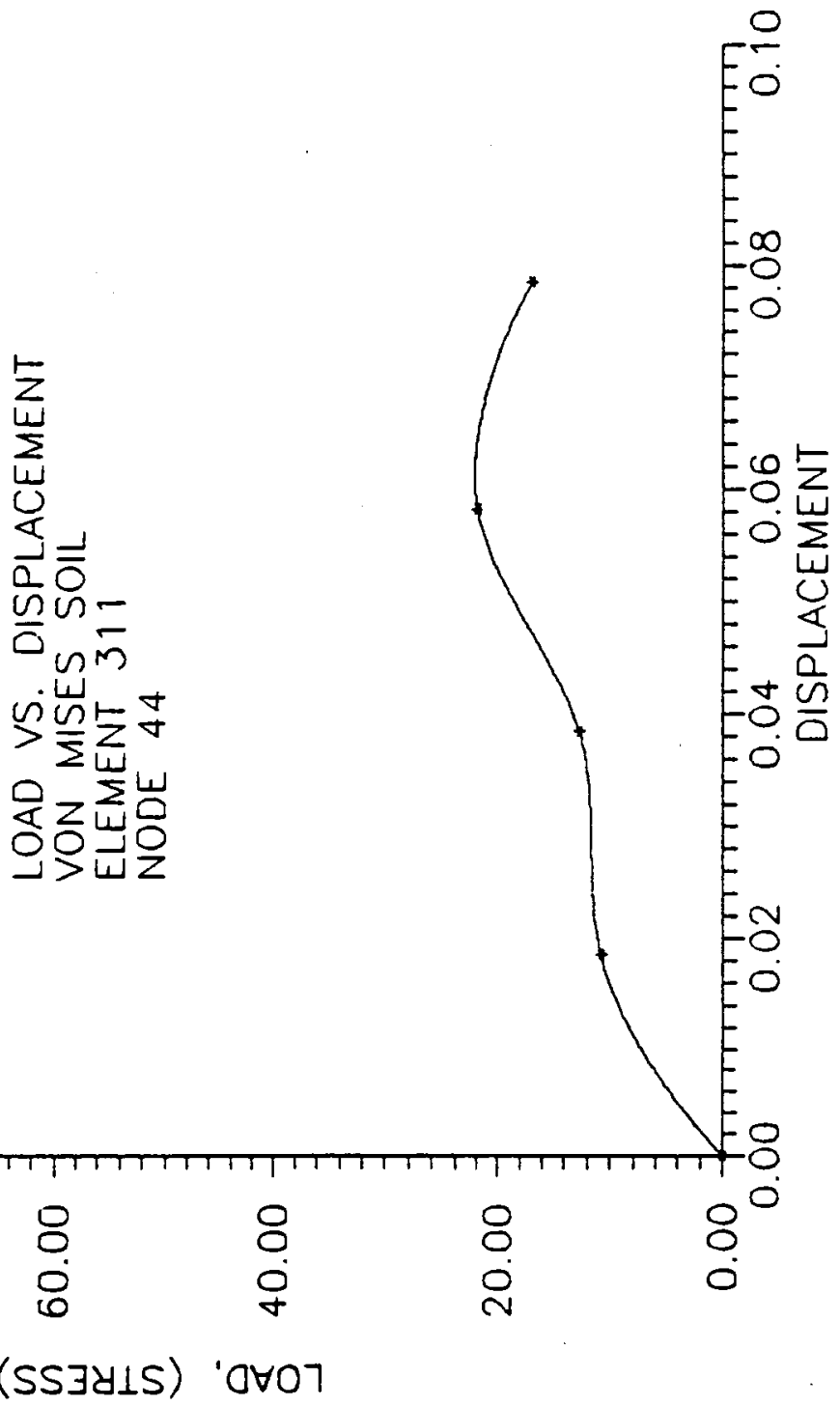


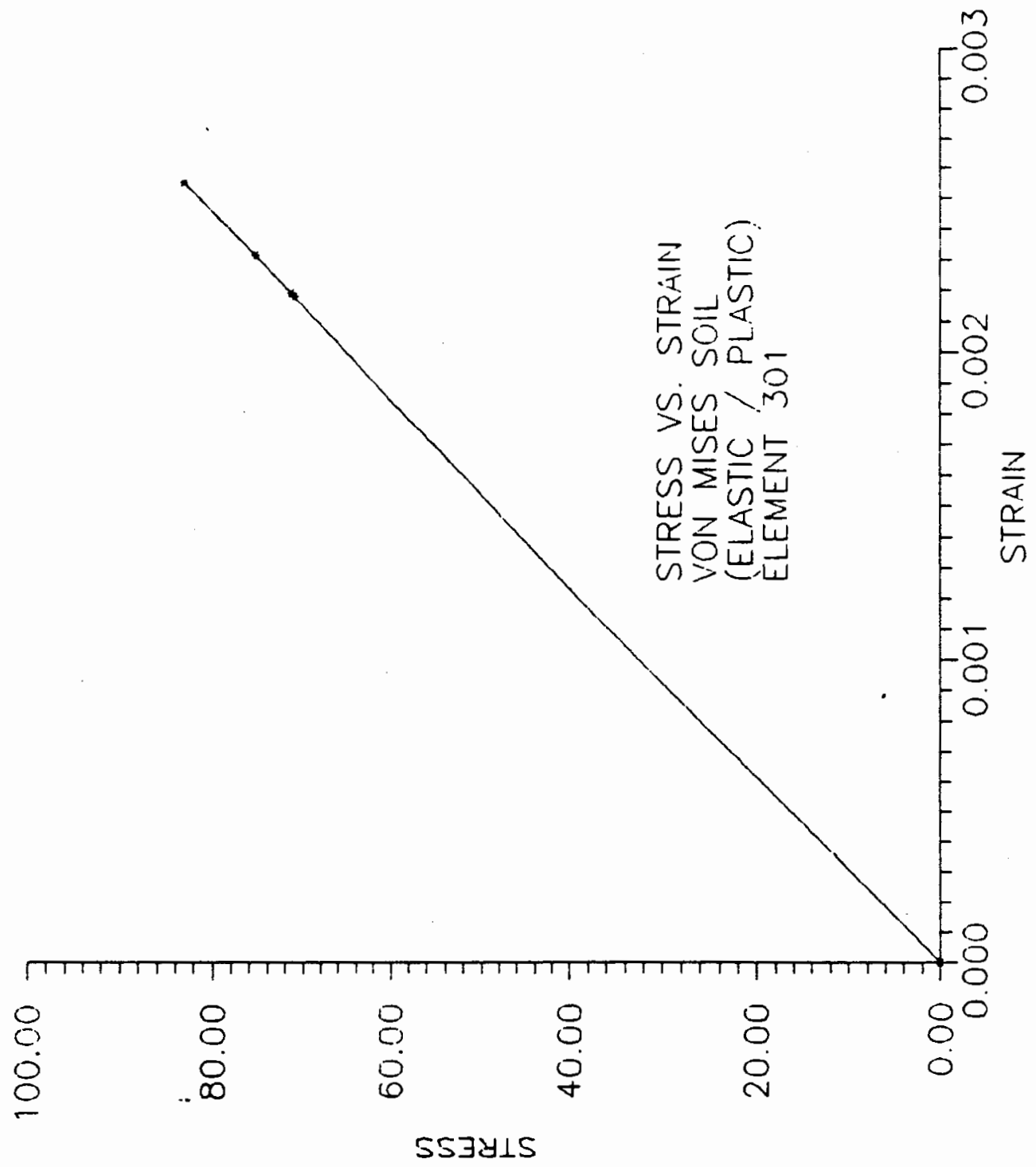




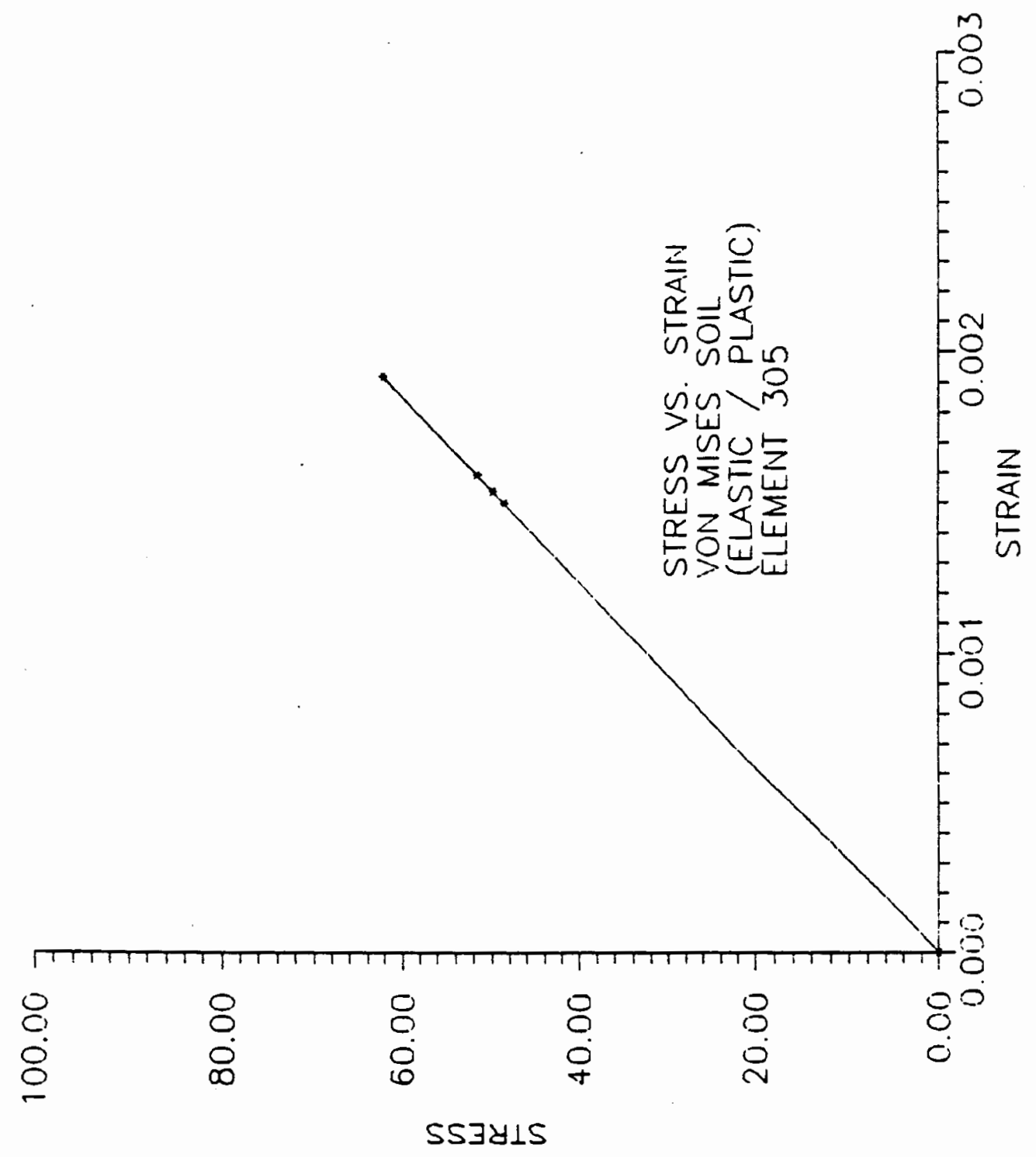




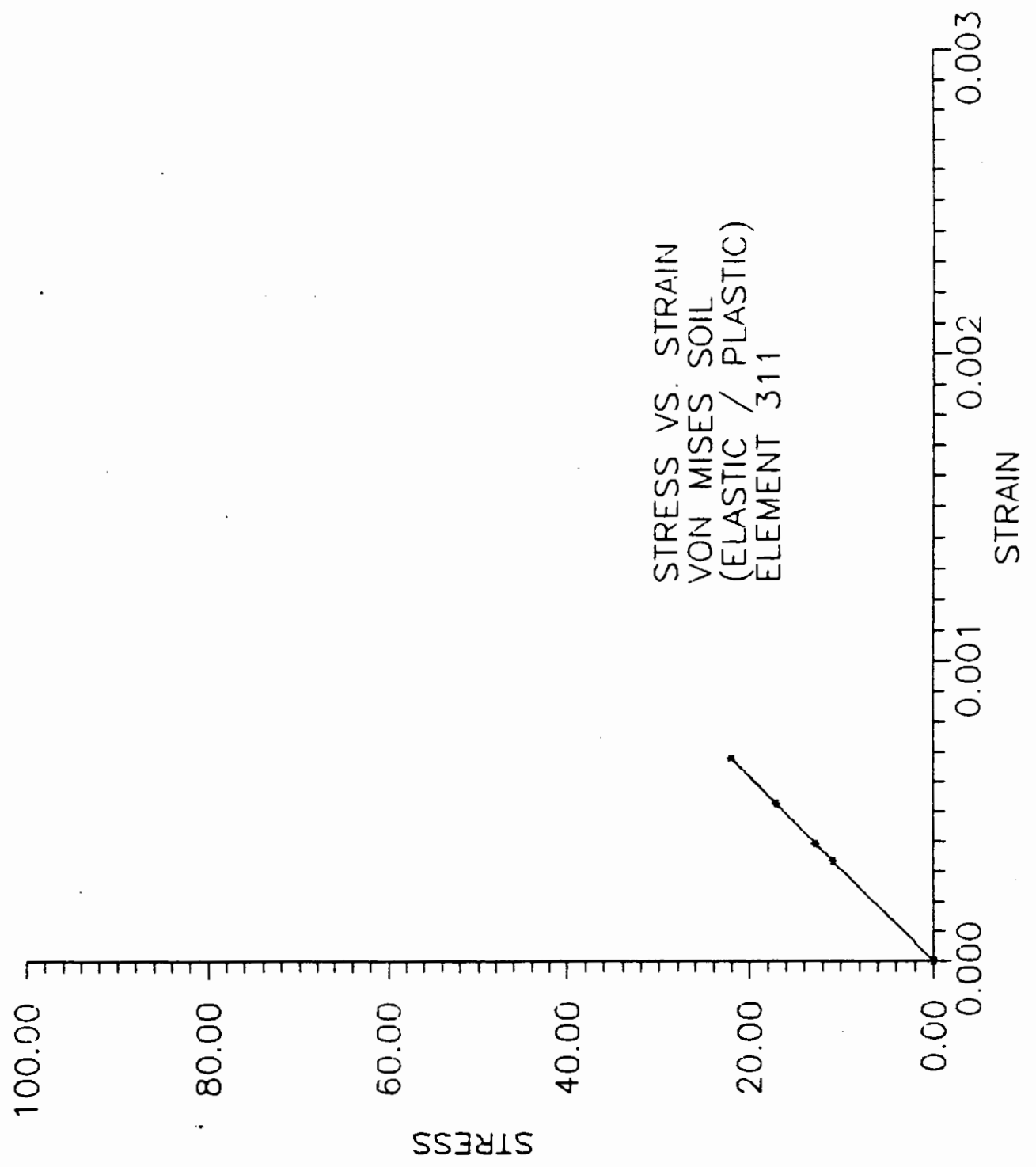




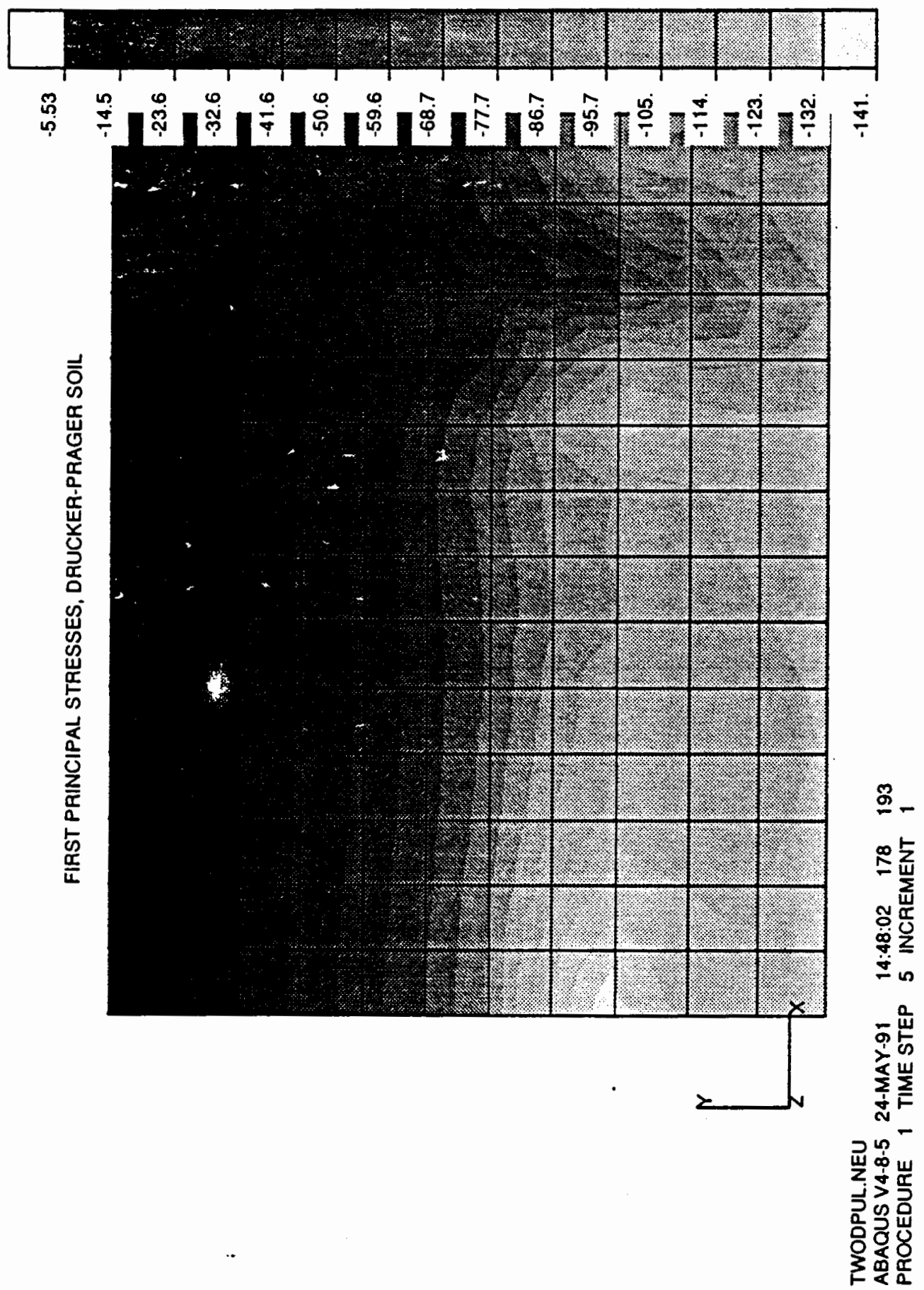




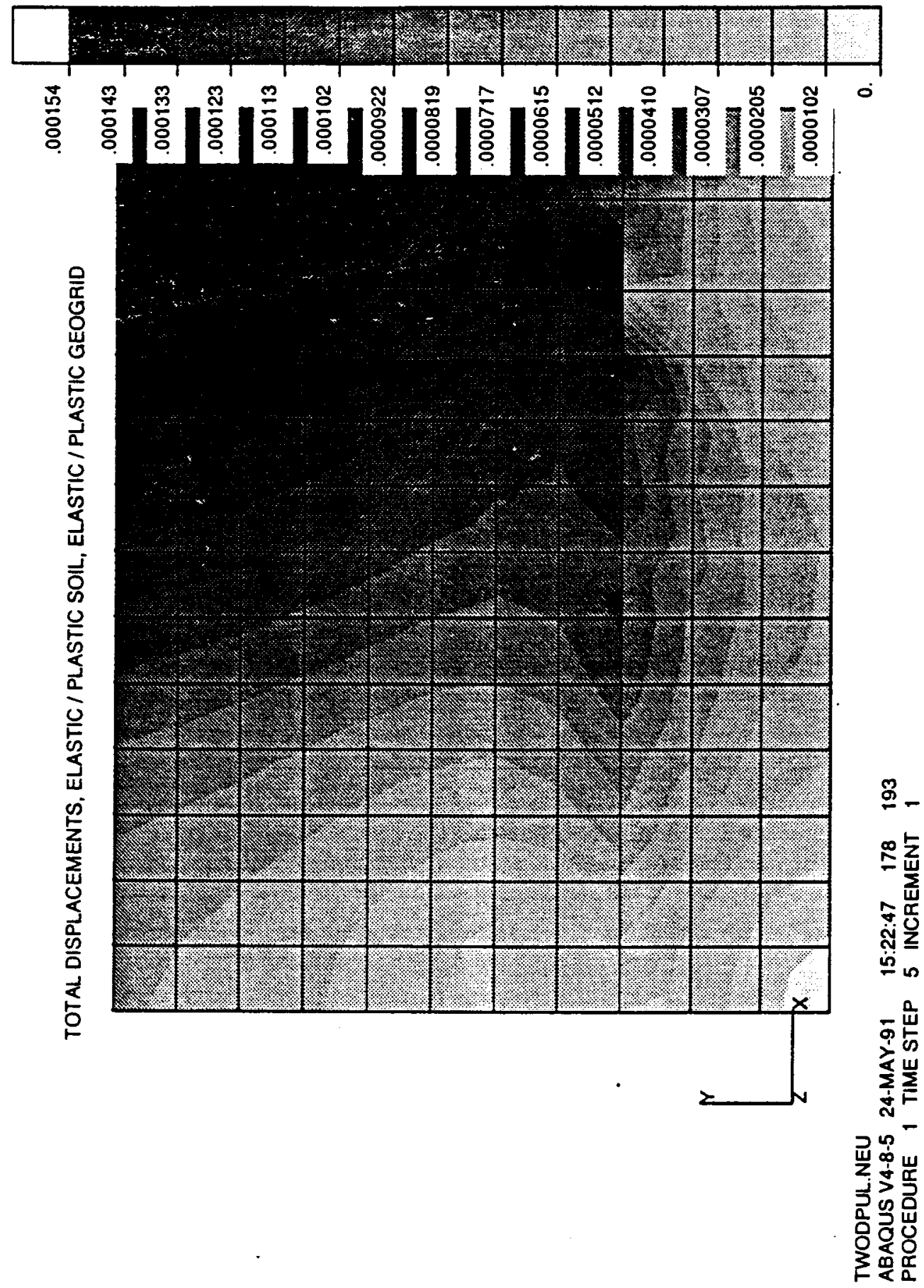


APPENDIX N

COMPUTER MODEL NUMBER FOUR 
TEST2OOUT.DAT

PULTEST20. INP

DRUCKER PRAGER SOIL

ELASTIC / PLASTIC GRID

ELEMENT 301

ELEMENT 305

$\begin{array}{lccc}\text { STP } & \text { STRESS (S11) } & \text { STRAIN (E11) } & \text { DISPLACEMENT (U1) } \\ 1 \text { i } 1 & 2.5838 E-3 & -7.9503 \mathrm{E}-8 & 2.8422 \mathrm{E}-6 \\ 2 \text { i } 17 & 7.0507 \mathrm{E}+1 & 2.1694 \mathrm{E}-3 & 1.9777 \mathrm{E}-2 \\ \text { 3i } 1 & 7.5147 \mathrm{E}+1 & 2.3122 \mathrm{E}-3 & 3.9763 \mathrm{E}-2 \\ 4 \text { i } 1 & 8.1175 \mathrm{E}+1 & 2.4977 \mathrm{E}-3 & 5.9750 \mathrm{E}-2 \\ 5 \text { i } 1 & 7.1003 \mathrm{E}+1 & 2.1847 \mathrm{E}-3 & 7.9781 \mathrm{E}-2\end{array}$

(NODE 4) 
ELEMENT 311

(NODE 4)

STP

STRESS ( 111$)$ STRAIN (E11) DISPLACEMENT (U1)

1 i 1

$2.0826 \mathrm{E}-3$

$6.4079 \mathrm{E}-8$

$2.2680 E-6$

2 i 17

$1.1148 \mathrm{E}+1$

$3.4302 \mathrm{E}-4$

$1.8524 \mathrm{E}-2$

3 i 1

1. $2716 \mathrm{E}+1$

3. $9127 \mathrm{E}-4$

3. $8421 \mathrm{E}-2$

4 i 1

2. $1645 E+1$

$6.6599 \mathrm{E}-4$

$5.8205 E-2$

5 i 1

1. $6940 \mathrm{E}+1$

5. $2122 \mathrm{E}-4$

7. $8469 \mathrm{E}-2$ 


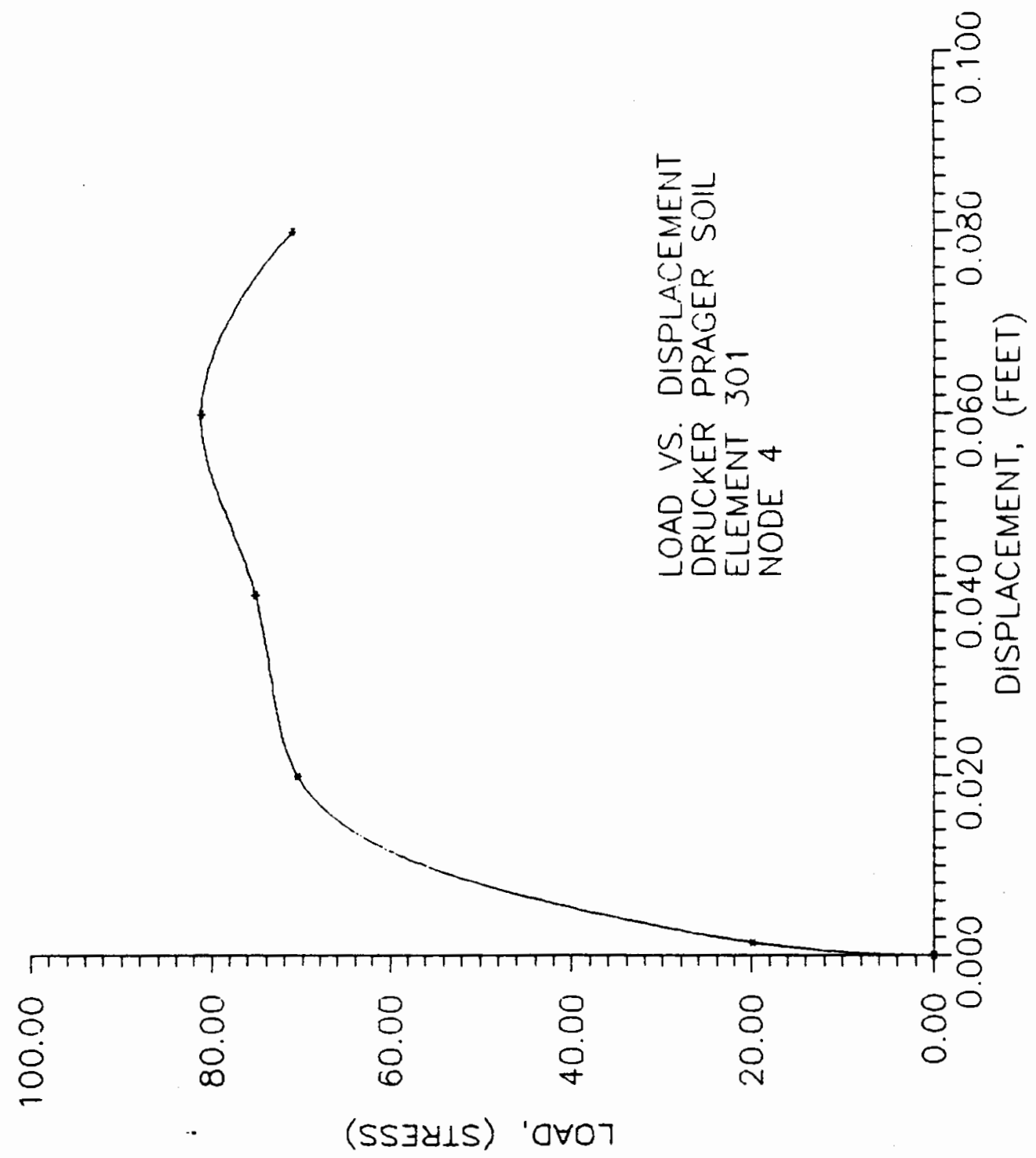




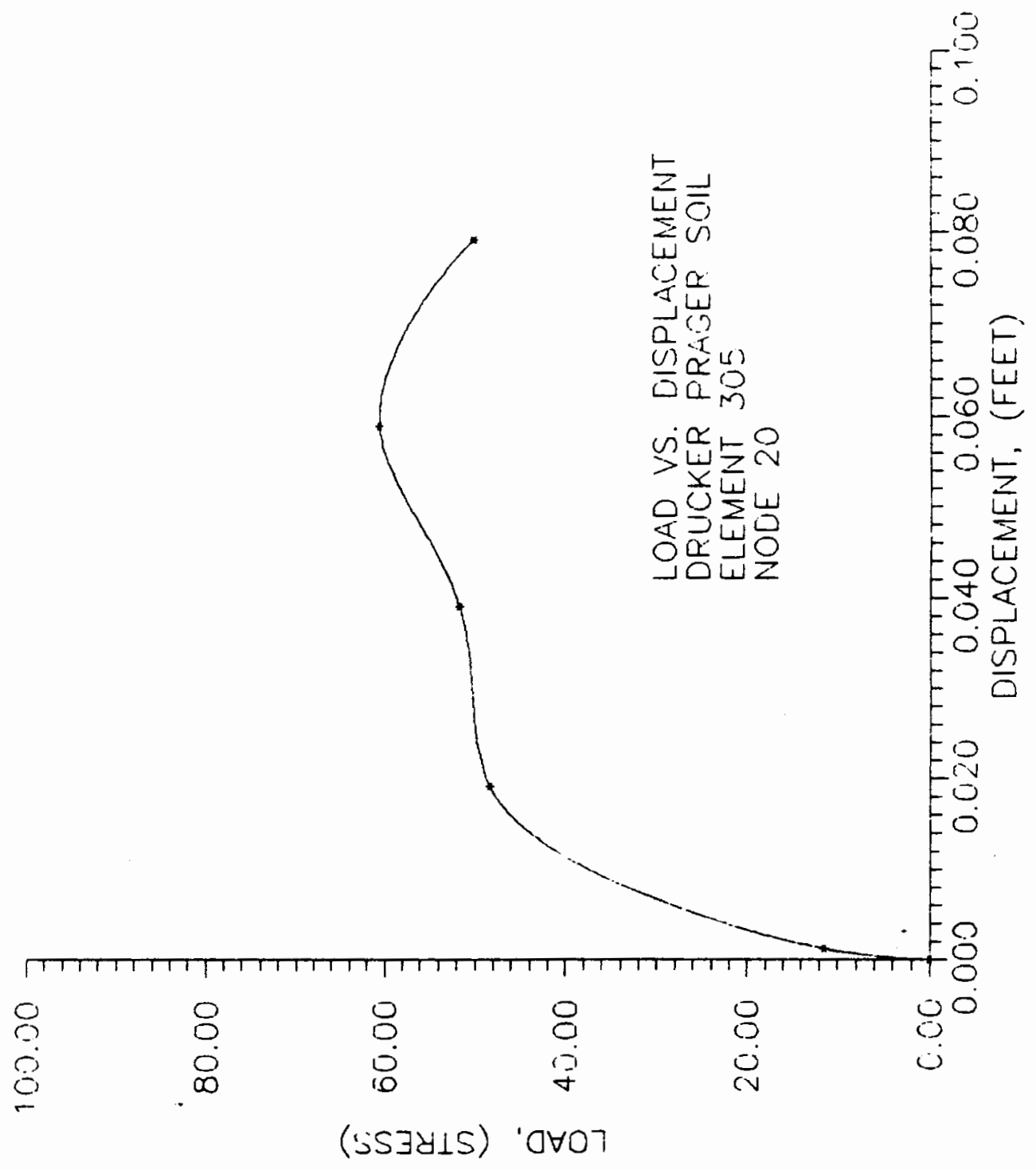



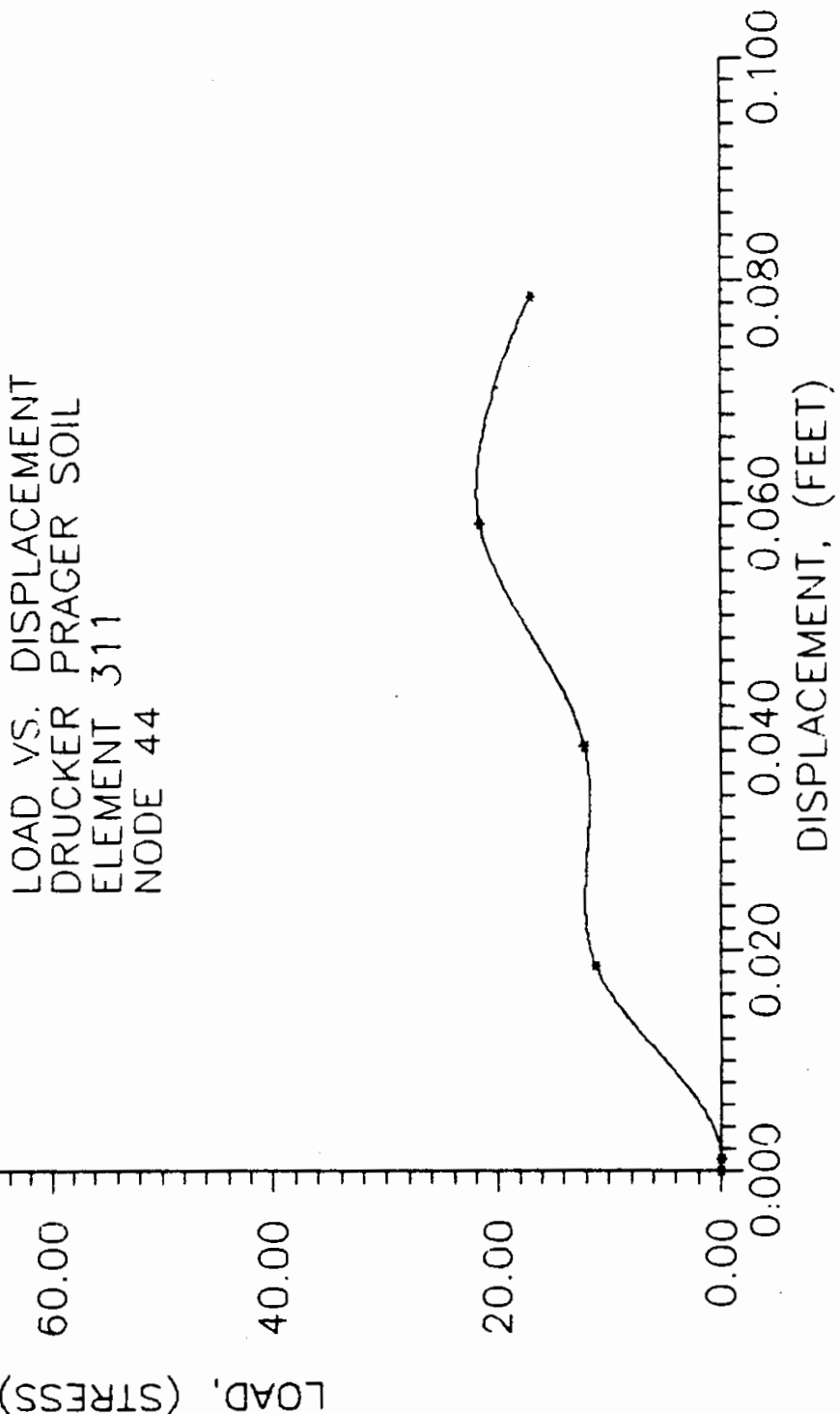


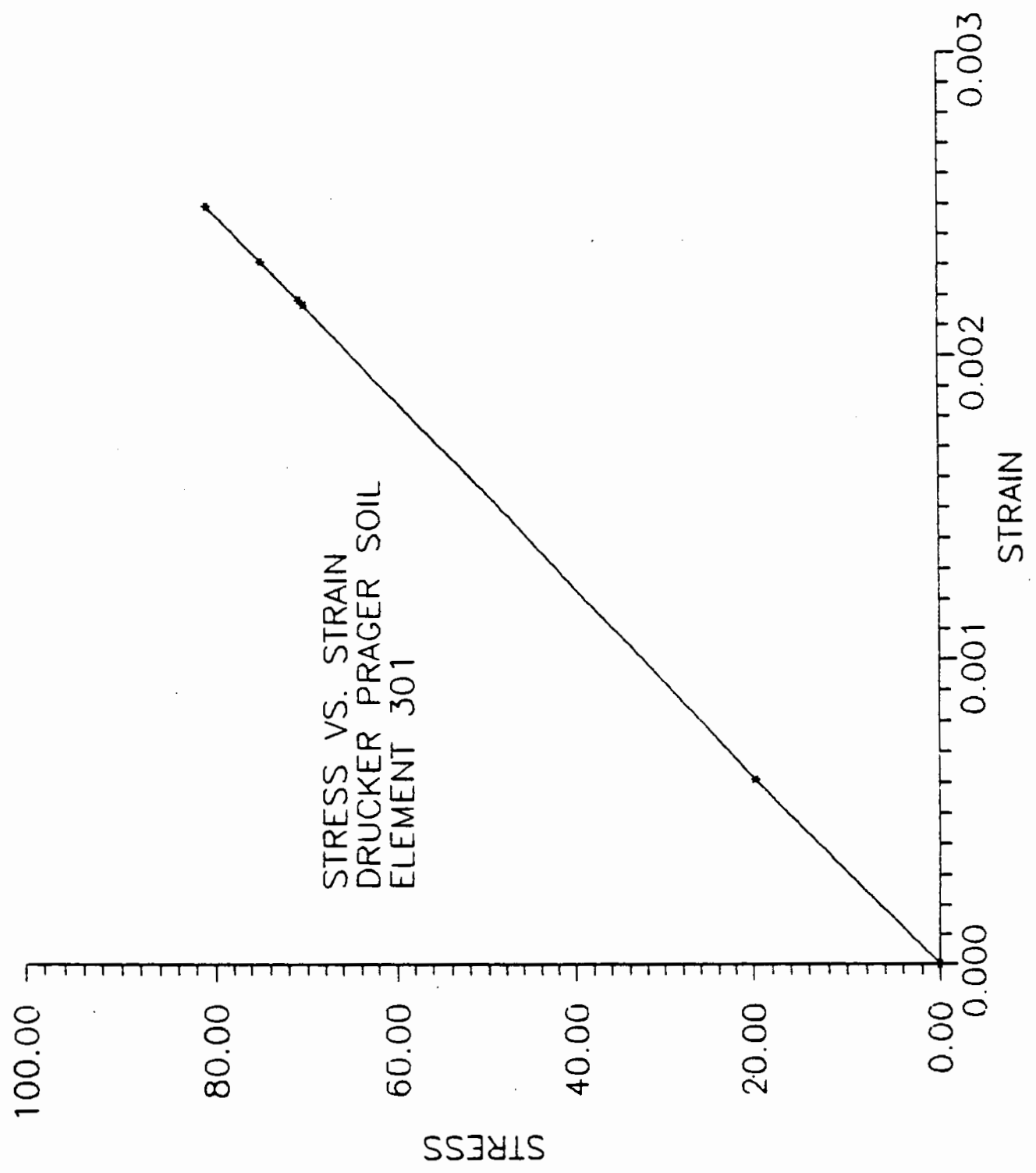




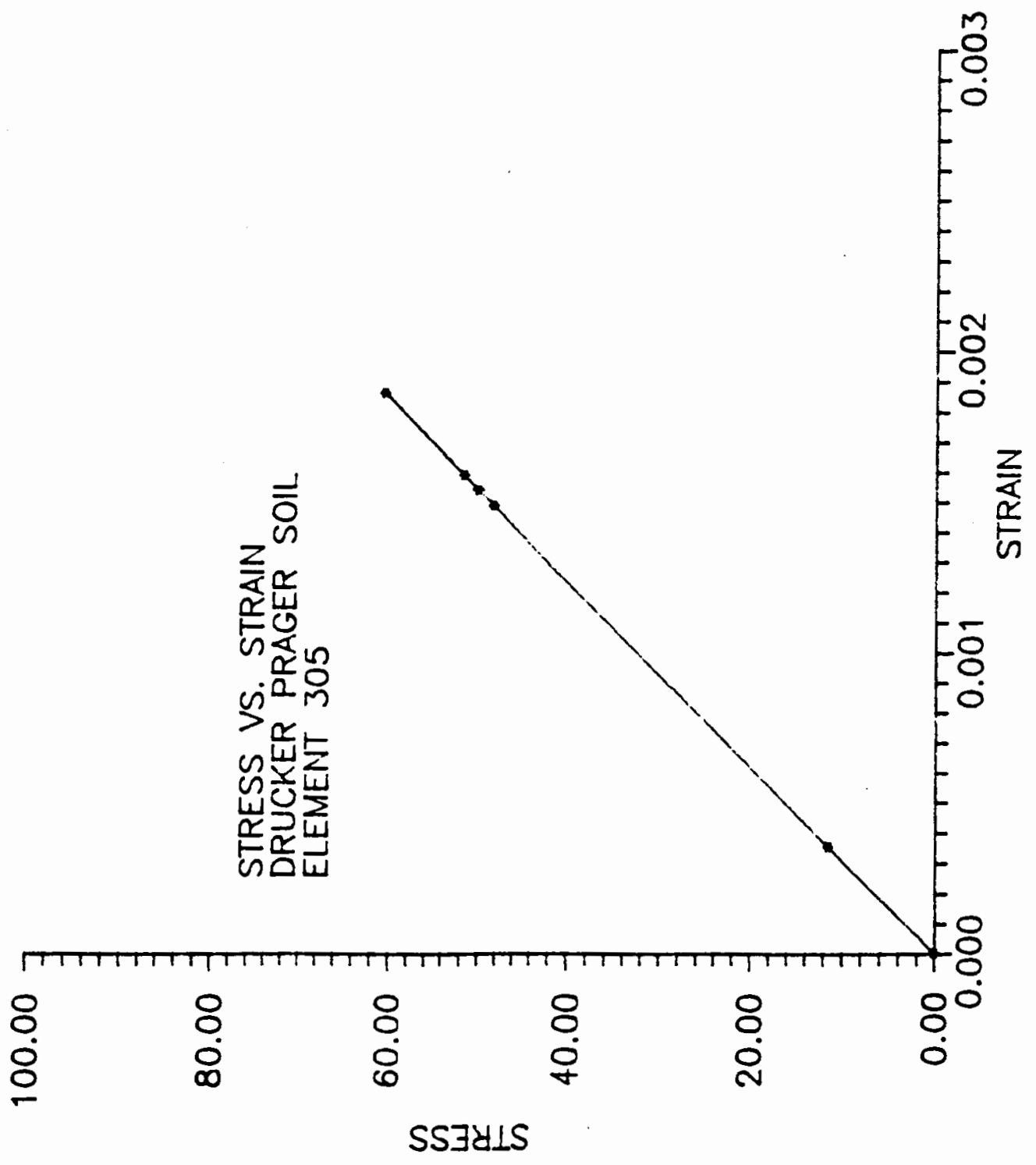




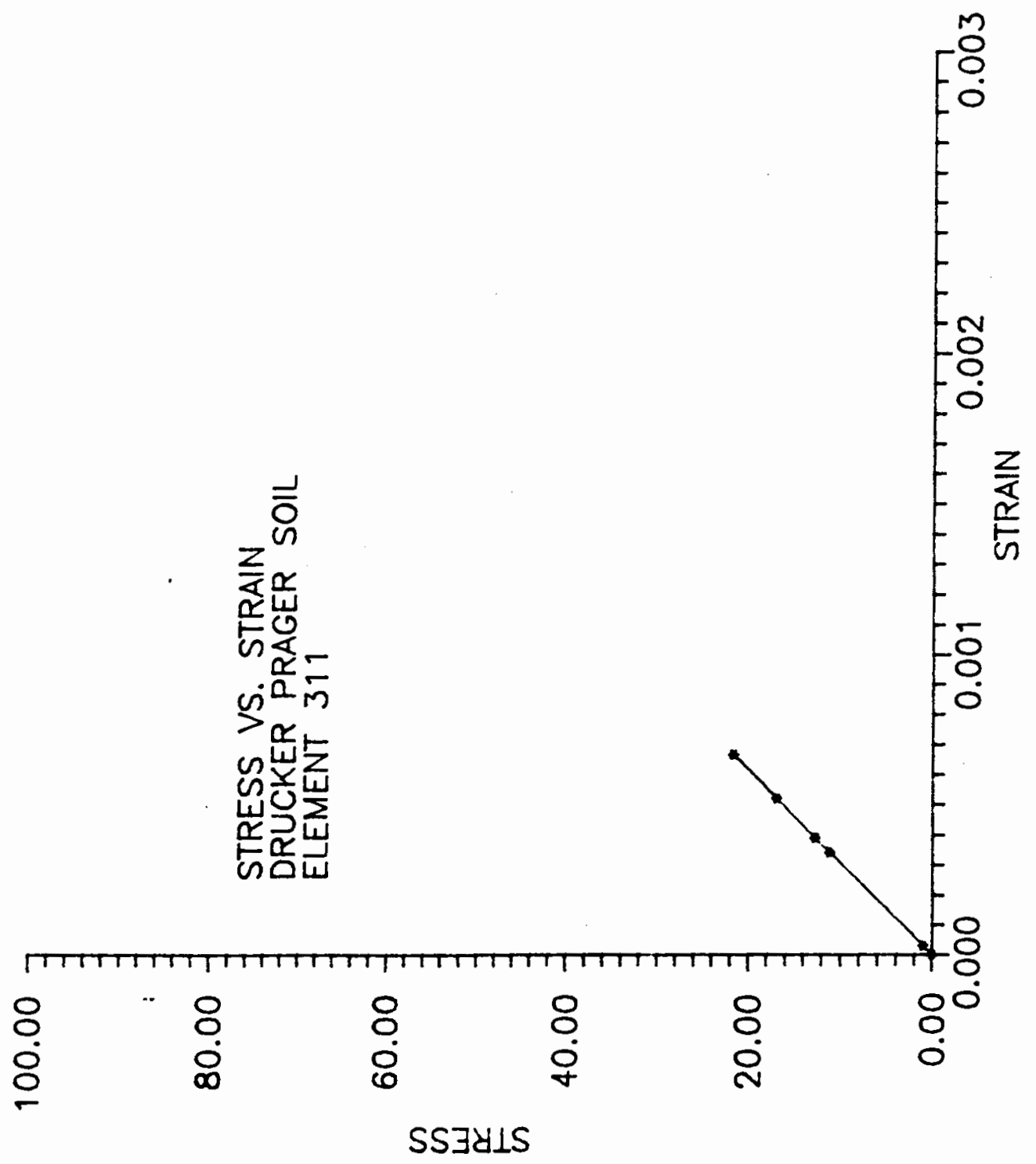




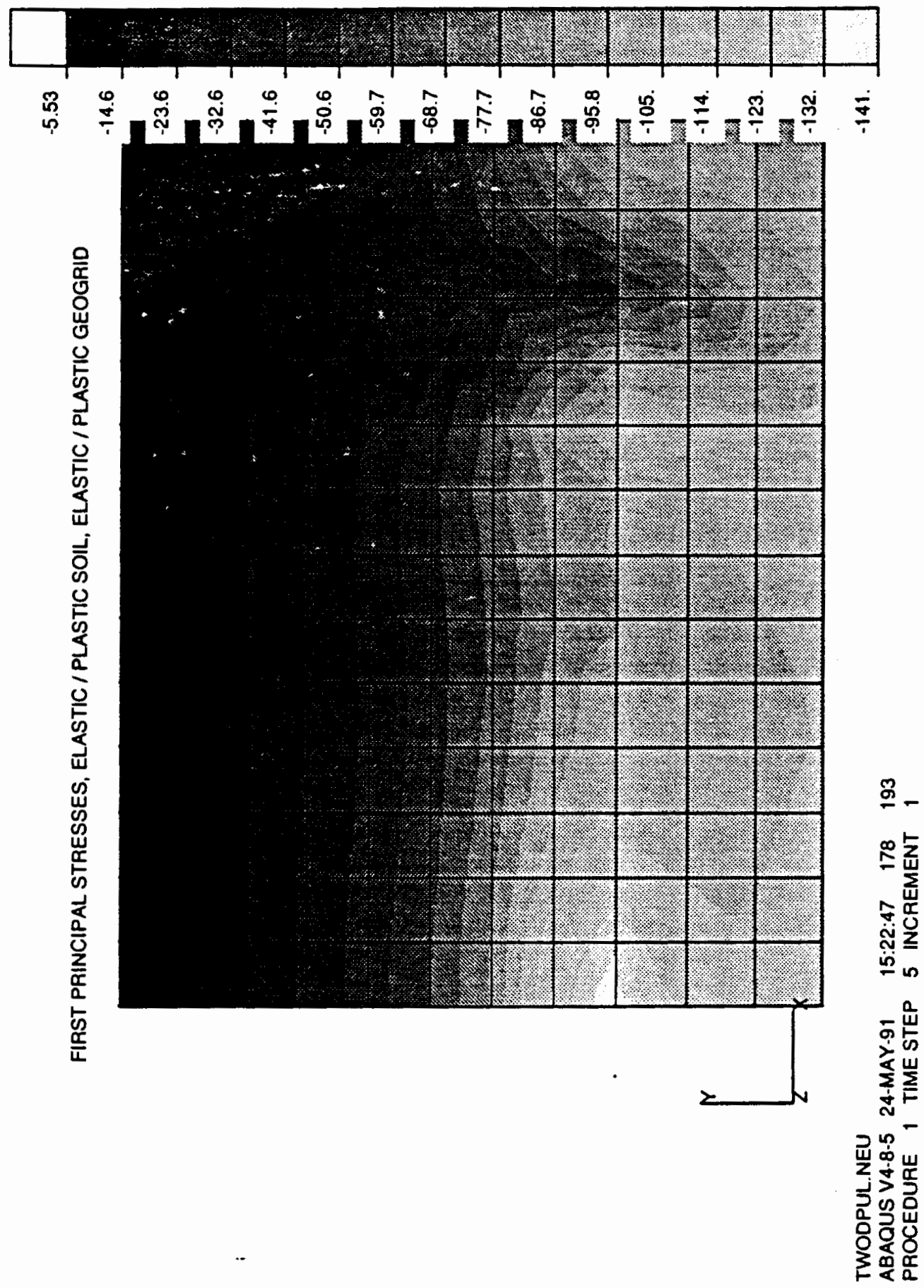




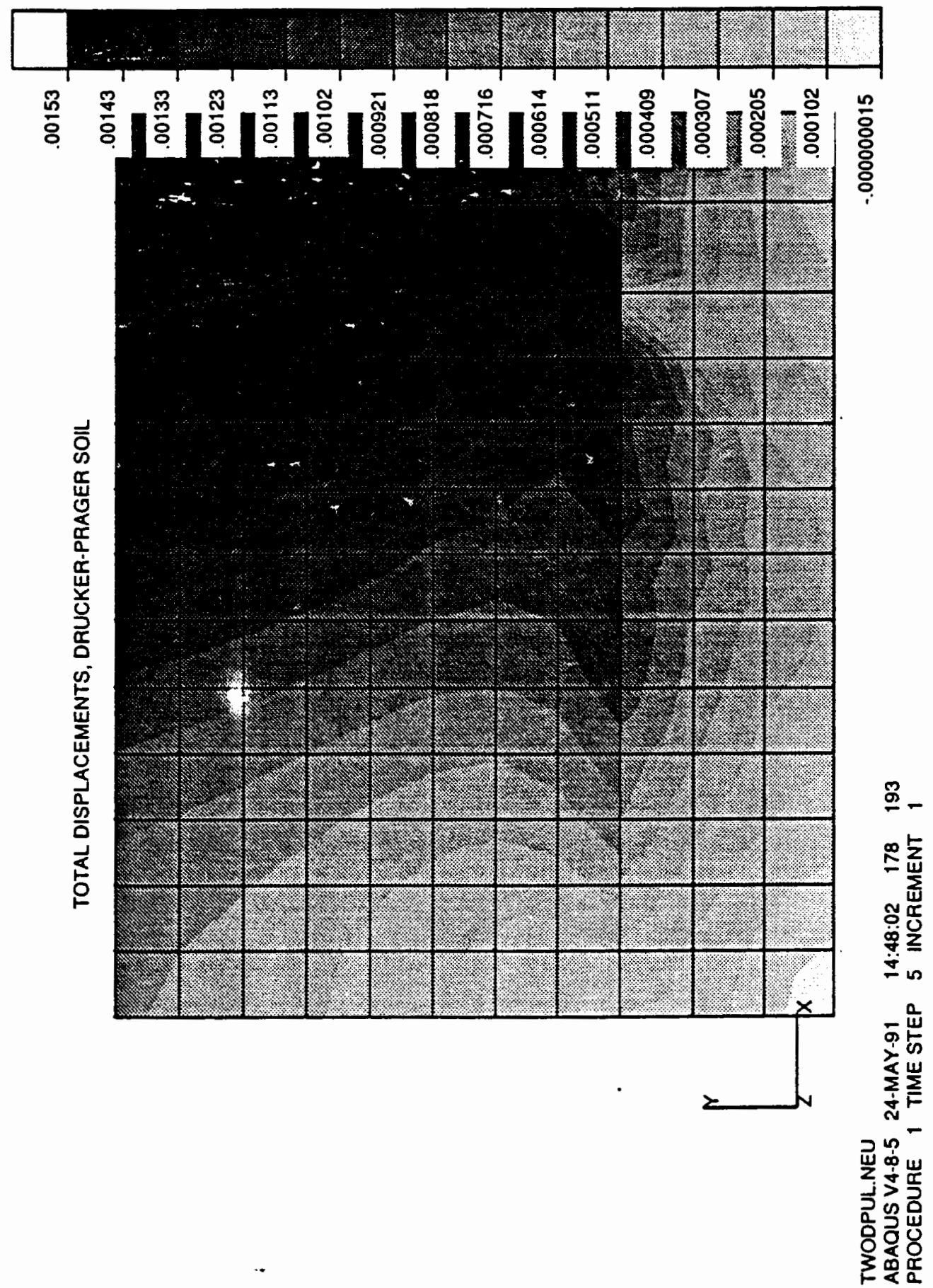


APPENDIX 0

DRUCKER-PRAGER INPUT DATA 
*HEADING, UNSYMM

TWODPUL . NEU

*PREPRINT, ECHO=NO, HISTORY $=$ NO, MODEL $=$ NO

** DATACHECK

** NEUTRAL FILE GENERATED ON: 10-SEP-90 09:06:31 PATABA

VERSION: 3.1

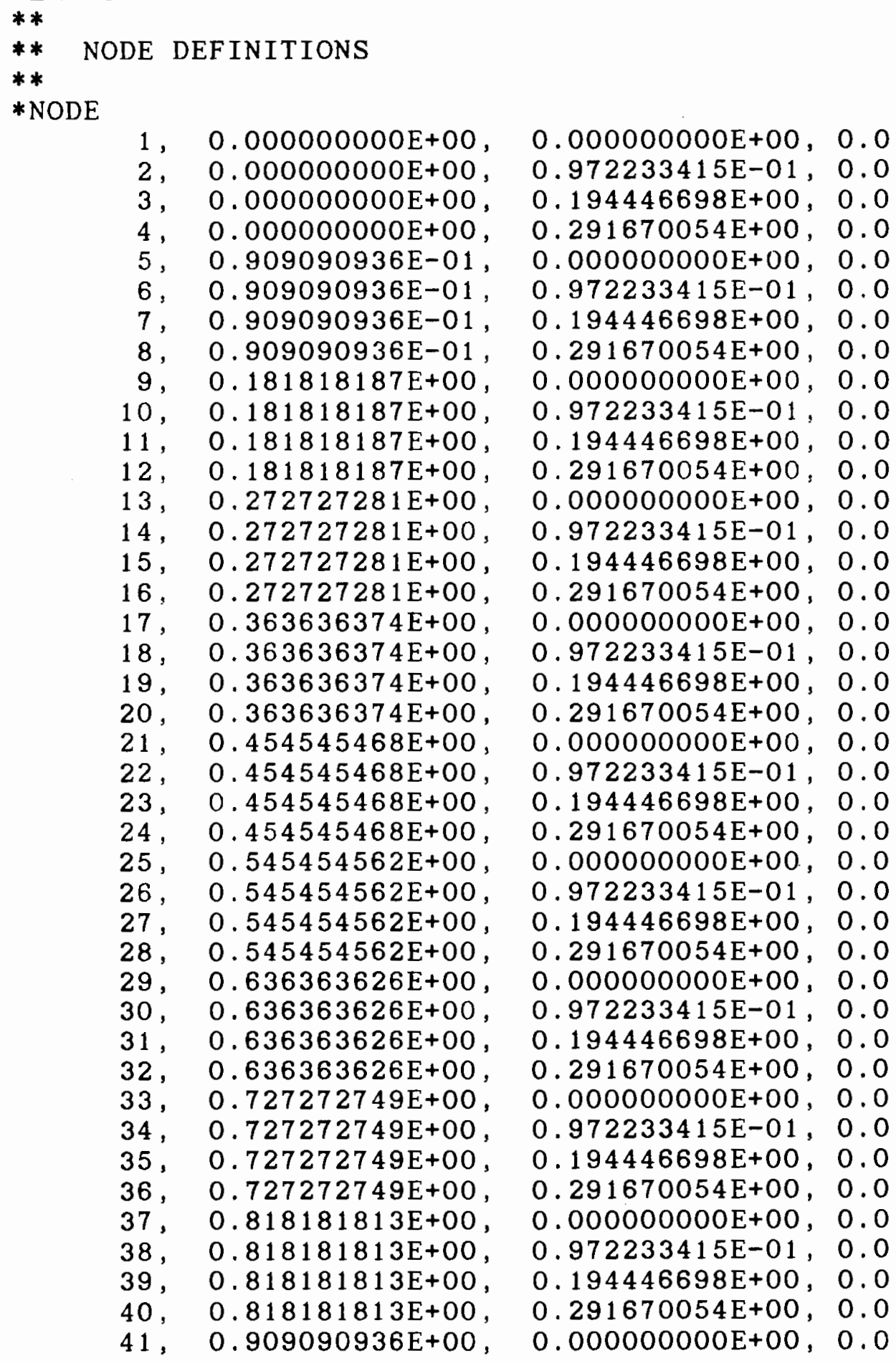




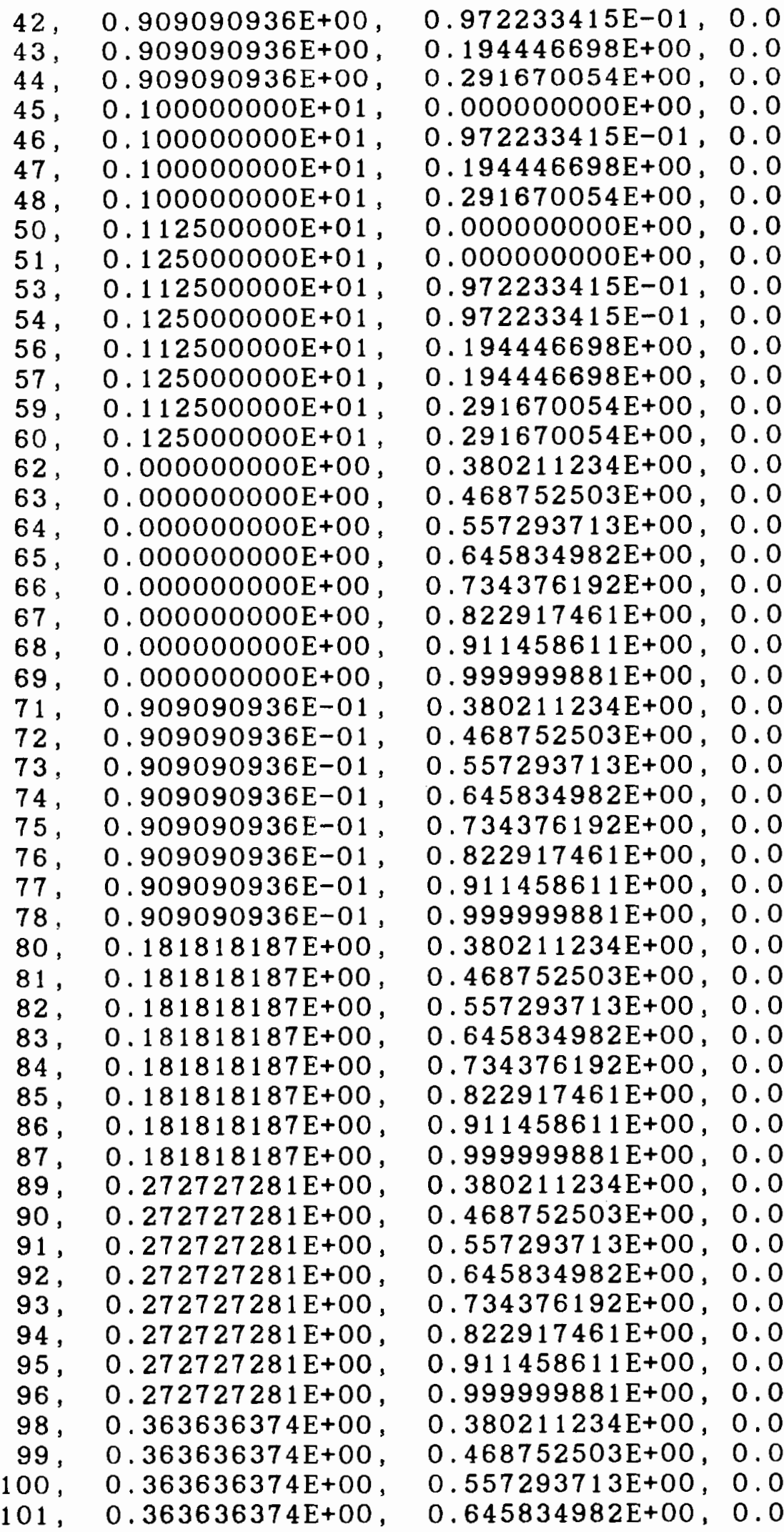




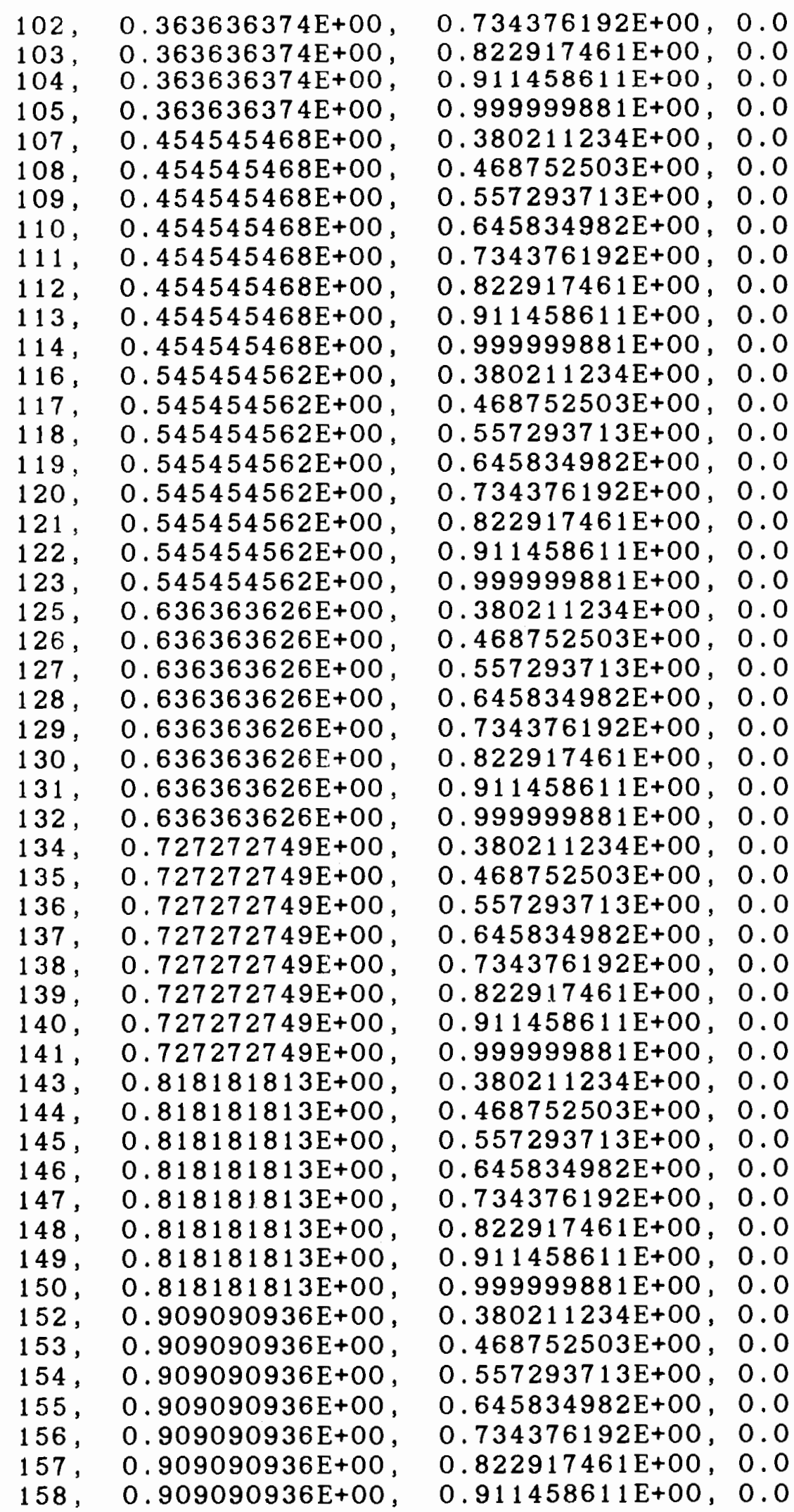




\begin{tabular}{|c|c|c|c|}
\hline 159, & $0.909090936 E+00$ & $0.999999881 E+00$ & 0.0 \\
\hline 161, & $0.100000000 E+01$ & $0.380211234 E+00$ & 0.0 \\
\hline 162, & $0.100000000 E+01$ & $0.468752503 \mathrm{E}+00$ & 0.0 \\
\hline 163, & $0.100000000 E+01$ & $0.557293713 \mathrm{E}+00$ & 0.0 \\
\hline 64, & $0.100000000 E+01$ & $0.645834982 E+00$ & 0.0 \\
\hline 165 & $0.100000000 E+01$ & $0.734376192 \mathrm{E}+00$ & 0.0 \\
\hline 166 & $0.100000000 E+01$ & $0.822917461 \mathrm{E}+00$ & 0.0 \\
\hline 67 & $0.100000000 E+01$ & $0.911458611 \mathrm{E}+00$ & 0.0 \\
\hline 168 & $0.100000000 E+01$ & $0.999999881 \mathrm{E}+00$ & 0. \\
\hline 173 & $0.112500000 E+01$ & $0.380211234 E+00$ & 0.0 \\
\hline 174, & $0.125000000 E+01$ & $0.380211234 \mathrm{E}+00$ & 0.0 \\
\hline 176, & $0.112500000 \mathrm{E}+01$ & $0.468752503 E+00$ & 0.0 \\
\hline 177, & $0.125000000 E+01$ & $0.468752503 E+00$ & 0.0 \\
\hline 179, & $0.112500000 E+01$ & $0.557293713 \mathrm{E}+00$ & 0.0 \\
\hline 180 & $0.125000000 E+01$ & $0.557293713 E+00$ & 0.0 \\
\hline 182, & $0.112500000 \mathrm{E}+01$ & $0.645834982 \mathrm{E}+00$ & 0.0 \\
\hline 183, & $0.125000000 E+01$ & $0.645834982 \mathrm{E}+00$ & 0.0 \\
\hline 185, & $0.112500000 E+01$ & $0.734376192 \mathrm{E}+00$ & 0.0 \\
\hline 186 & $0.125000000 E+01$ & $0.734376192 \mathrm{E}+00$ & 0.0 \\
\hline 188, & $0.112500000 E+01$ & $0.822917461 \mathrm{E}+00$ & 0.0 \\
\hline 189 & $0.125000000 E+01$ & $0.822917461 \mathrm{E}+00$ & 0.0 \\
\hline 191, & $0.112500000 E+01$ & $0.911458611 \mathrm{E}+00$ & 0.0 \\
\hline 192, & $0.125000000 E+01$ & $0.911458611 \mathrm{E}+00$ & 0.0 \\
\hline 194 & $0.112500000 E+01$ & $0.999999881 \mathrm{E}+00$ & 0.0 \\
\hline 195 & $0.125000000 E+01$ & $0.999999881 \mathrm{E}+00$ & 0.0 \\
\hline 201, & 0 & .291670054 & 0 \\
\hline 202, & $0.909090936 E-01$ & .291670054 & 0 \\
\hline 203 & 0.181818187 & .291670054 & 0 \\
\hline 204, & 0.272727281 & .291670054 & 0 \\
\hline 205, & 0.363636374 & .291670054 & 0 \\
\hline 206 & 0.454545468 & .291670054 & 0 \\
\hline 207 & 0.545454562 & .291670054 & 0 \\
\hline 208 & 0.636363620 & .291670054 & 0 \\
\hline 209 & 0.727272749 & .291670054 & 0 \\
\hline 210, & 0.818181813 & .291670054 & 0 \\
\hline 211, & 0.909090936 & .291670054 & 0 \\
\hline 212 & 1.0 & .291670054 & 0 \\
\hline 213, & 1.0 & .291670054 & 0 \\
\hline 214, & 0.909090936 & .291670054 & 0 \\
\hline 215 & 0.818181813 & .291670054 & 0 \\
\hline 216, & 0.727272749 & .291670054 & 0 \\
\hline 217 & 0.636363620 & .291670054 & 0 \\
\hline 218 & 0.545454562 & .291670054 & 0 \\
\hline 219 & 0.454545468 & .291670054 & 0 \\
\hline 220 & 0.363636374 & .291670054 & 0 \\
\hline 221 & 0.272727281 & .291670054 & 0 \\
\hline 222 & 0.181818187 & .291670054 & 0 \\
\hline 223 & $0.909090936 \mathrm{E}-01$ & .291670054 & 0 \\
\hline 22 & 0.0 & .291670054 & 0 \\
\hline 225 & -.9 & .291670054 & 0 \\
\hline
\end{tabular}


*** ELEMENT DEFINITIONS

*ELEMENT, TYPE=CPE4

$117,68,77, \quad 78,69$

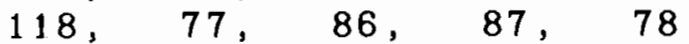

$119, \quad 86, \quad 95, \quad 96,87$

$120, \quad 95,104,105,96$

$121,104,113,114,105$

$122,113,122,123,114$

$123,122,131,132,123$

$124,131,140,141,132$

$125,140,149,150,141$

$126,149,158,159,150$

$127,158,167,168,159$

$142, \quad 167, \quad 191,194,168$

$143,191,192,195,194$

*ELEMENT, TYPE $=$ CPE4 , ELSET $=$ PID3

$1, \quad 1, \quad 5, \quad 6, \quad 2$

$2, \quad 5, \quad 9, \quad 10, \quad 6$

$3, \quad 9, \quad 13, \quad 14, \quad 10$

$4, \quad 13,17,18,14$

$5, \quad 17, \quad 21, \quad 22, \quad 18$

$6, \quad 21,25,26,22$

$7, \quad 25, \quad 29, \quad 30,26$

$8, \quad 29, \quad 33, \quad 34, \quad 30$

$9, \quad 33, \quad 37, \quad 38, \quad 34$

$10, \quad 37, \quad 41, \quad 42, \quad 38$

$11, \quad 41,45,46,42$

$12, \quad 2, \quad 6, \quad 7, \quad 3$

$13, \quad 6, \quad 10, \quad 11, \quad 7$

$14, \quad 10, \quad 14,15,11$

$15, \quad 14, \quad 18, \quad 19, \quad 15$

$16, \quad 18, \quad 22, \quad 23, \quad 19$

$\begin{array}{llll}17, & 22, & 26, & 27, \\ 18, & 23\end{array}$

$18, \quad 26, \quad 30, \quad 31,27$

$19, \quad 30, \quad 34, \quad 35, \quad 31$

$20, \quad 34, \quad 38, \quad 39, \quad 35$

$21, \quad 38, \quad 42, \quad 43, \quad 39$

$22, \quad 42, \quad 46, \quad 47, \quad 43$

$23, \quad 3, \quad 7,202,201$

$24, \quad 7, \quad 11,203,202$

$25, \quad 11, \quad 15,204,203$

$26, \quad 15, \quad 19,205,204$

$27, \quad 19, \quad 23,206,205$

$28,23,27,207,206$

$29, \quad 27, \quad 31,208,207$

$30, \quad 31, \quad 35, \quad 209,208$

$31, \quad 35, \quad 39, \quad 210, \quad 209$

$32, \quad 39, \quad 43, \quad 211, \quad 210$

$33,43,47, \quad 212,211$ 
$34, \quad 45, \quad 50, \quad 53,46$

$35, \quad 50, \quad 51,54,53$

$36, \quad 46, \quad 53, \quad 56,47$

$37, \quad 53,54,57,56$

$38, \quad 47, \quad 56, \quad 59,212$

$39, \quad 56, \quad 57,60,59$

$40,224,223, \quad 71,62$

$41,223, \quad 222,80, \quad 71$

$42, \quad 222, \quad 221, \quad 89, \quad 80$

$43,221,220, \quad 98, \quad 89$

$44,220,219, \quad 107,98$

$45,219,218,116,107$

$46,218,217,125,116$

$47,217,216,134,125$

$48,216,215,143,134$

$49, \quad 215,214, \quad 152,143$

$50,214,213, \quad 161, \quad 152$

$51, \quad 62, \quad 71, \quad 72,63$

$52, \quad 71, \quad 80, \quad 81, \quad 72$

$53,80,89, \quad 90,81$

$54, \quad 89, \quad 98,99,90$

$55, \quad 98, \quad 107, \quad 108,99$

$56,107,116,117,108$

$57,116,125,126,117$

$58,125,134,135,126$

$59, \quad 134, \quad 143, \quad 144,135$

$60,143,152,153,144$

$61,152,161,162,153$

$62, \quad 63, \quad 72, \quad 73,64$

$63, \quad 72, \quad 81, \quad 82, \quad 73$

$64, \quad 81,90, \quad 91,82$

$65,90,99,100,91$

$66,99,108,109,100$

$67,108,117,118,109$

$68,117,126,127,118$

$69, \quad 126, \quad 135,136,127$

$70,135,144,145,136$

$71,144,153,154,145$

$72, \quad 153,162,163,154$

$73,64, \quad 73, \quad 74,65$

$74, \quad 73, \quad 82, \quad 83, \quad 74$

$75, \quad 82, \quad 91, \quad 92, \quad 83$

$76, \quad 91,100,101,92$

$77,100,109,110,101$

$78,109,118,119,110$

$79, \quad 118,127,128,119$

$80,127,136,137,128$

$81,136,145,146,137$

$82, \quad 145,154,155,146$

$83,154,163,164,155$

$84,65, \quad 74, \quad 75,66$ 


\begin{tabular}{|c|c|c|c|c|}
\hline $\begin{array}{l}85, \\
86\end{array}$ & $\begin{array}{l}74, \\
83\end{array}$ & $\begin{array}{l}83, \\
92\end{array}$ & $\begin{array}{l}84, \\
93\end{array}$ & $\begin{array}{l}75 \\
84\end{array}$ \\
\hline 87, & 92, & 101, & 102, & 93 \\
\hline 88, & 101, & 110 , & 111, & 102 \\
\hline 89, & 110 , & 119, & 120, & 111 \\
\hline 90, & 119 , & 128, & 129 , & 120 \\
\hline 91, & 128, & 137, & 138, & 129 \\
\hline 92, & 137 , & 146, & 147, & 138 \\
\hline 93, & 146 , & 155, & 156 , & 147 \\
\hline 94, & 155, & 164, & 165, & 156 \\
\hline 95, & 66 & 75 & 76 , & 67 \\
\hline 96, & 75 , & 84, & 85, & 76 \\
\hline 97, & 84, & 93, & 94, & 85 \\
\hline 98, & 93 , & 102, & 103, & 94 \\
\hline 99, & 102, & 111, & 112 , & 103 \\
\hline 100, & 111, & 120, & 121 , & 112 \\
\hline 101, & 120 , & 129 , & 130, & 121 \\
\hline 102, & 129, & 138, & 139, & 130 \\
\hline 103 & 138, & 147, & 148, & 139 \\
\hline 104, & 147 , & 156, & 157 , & 148 \\
\hline 105, & 156, & 165, & 166, & 157 \\
\hline 106, & 67, & 76 & 77 & 68 \\
\hline 107, & 76 , & 85, & 86 , & 77 \\
\hline 108, & 85, & 94, & 95 & 86 \\
\hline 109, & 94 & 103, & 104, & 95 \\
\hline 110 , & 103, & 112 , & 113 , & 104 \\
\hline 111, & 112 , & 121, & 122, & 113 \\
\hline 112, & 121, & 130, & 131, & 122 \\
\hline 113, & 130 , & 139, & 140 , & 131 \\
\hline 114, & 139, & 148, & 149, & 140 \\
\hline 115, & 148, & 157, & 158, & 149 \\
\hline 116, & 157 , & 166, & 167 , & 158 \\
\hline 117 & 68 & 77 & 78 & 69 \\
\hline 118, & 77, & 86, & 87 , & 78 \\
\hline 119, & 86 , & 95, & 96 , & 87 \\
\hline 120, & 95, & 104, & 105, & 96 \\
\hline 121, & 104, & 113, & 114, & 105 \\
\hline 122, & 113, & 122, & 123 , & 114 \\
\hline 123, & 122 , & 131, & 132, & 123 \\
\hline 124, & 131, & 140 & 141, & 132 \\
\hline 125, & 140 , & 149, & 150, & 141 \\
\hline 126, & 149, & 158 & 159, & 150 \\
\hline 127, & 158, & 167 & 168, & 159 \\
\hline 128, & 213 & 59 & 173, & 161 \\
\hline 129, & 59 & 60 & 174, & 173 \\
\hline 130 & 161, & 173 & 176, & 162 \\
\hline 131 & 173, & 174, & 177 , & 176 \\
\hline 132, & 162, & 176 & 179, & 163 \\
\hline 133, & 176, & 177 & 180, & 179 \\
\hline 134 & 163 & 179, & 182, & 164 \\
\hline 135 & 179 , & 180 & 183, & 182 \\
\hline
\end{tabular}


$136, \quad 164, \quad 182, \quad 185, \quad 165$

$137,182,183,186,185$

$138,165,185,188,166$

$139, \quad 185, \quad 186, \quad 189, \quad 188$

$140,166,188,191,167$

$141, \quad 188,189,192,191$

$142, \quad 167,191,194,168$

$143,191,192,195,194$

*ELEMENT , TYPE=C1D2, ELSET $=$ PID2

$300, \quad 4,225$

$301, \quad 8, \quad 4$

$302, \quad 12, \quad 8$

$303, \quad 16, \quad 12$

$304,20,16$

$305, \quad 24,20$

$306, \quad 28, \quad 24$

$307, \quad 32, \quad 28$

$308, \quad 36, \quad 32$

$309, \quad 40, \quad 36$

$310,44,40$

$311,48,44$

*ELEMENT, TYPE $=\mathrm{C} 1 \mathrm{D} 2, \quad \mathrm{ELSET}=\mathrm{PID} 6$

$312, \quad 59, \quad 48$

*ELEMENT, TYPE=ISL21, ELSET=PID4

$401, \quad 4, \quad 8$

$402, \quad 8, \quad 12$

$403, \quad 12, \quad 16$

$404, \quad 16, \quad 20$

$405, \quad 20, \quad 24$

$406, \quad 24, \quad 28$

$407, \quad 28, \quad 32$

$408, \quad 32, \quad 36$

$409, \quad 36, \quad 40$

$410, \quad 40, \quad 44$

$411, \quad 44,48$

*INTERFACE, ELSET=PID4

1

*FRICTION

$.40,125000,800$

*SLIDE LINE, TYPE=LINEAR, ELSET $=$ PID4

$225,201,202,203,204,205,206,207,208,209,210,211,212,59,60$

*ELEMENT, TYPE=ISL2 1 , ELSET=PID5

$414,48,44$

$415,44,40$

$416, \quad 40, \quad 36$

$417, \quad 36, \quad 32$

$418, \quad 32, \quad 28$

$419,28,24$

$420,24, \quad 20$

$421, \quad 20, \quad 16$

$422, \quad 16,12$ 
$\begin{array}{rrr}423, & 12, & 8 \\ 424, & 8, & 4\end{array}$

*INTERFACE, ELSET=PID5

1

*FRICTION

*SLIDE LINE, TYPE=LINEAR, ELSET=PID5

$60,59,213,214,215,216,217,218,219,220,221,222,223,224,225$

*NSET, NSET $=\mathrm{BOT}$

$201,202,203,204,205,206,207,208,209,210,211,212$

*NSET, NSET $=$ TOP

$224,223,222,221,220,219,218,217,216,215,214,213$

*NSET, NSET $=$ MID

$225,4,8,12,16,20,24,28,32,36,40,44,48,59$

**NORMAL

**PID5, TOP , $0,1,0$

**NORMAL

**PID4, BOT , $0,-1,0$

*SOLID SECTION, ELSET=PID3, MATERIAL=SOIL1

*MATERIAL, NAME = SOIL1

*ELASTIC

$40000, .33$

*DRUCKER PRAGER

$40 ., 7695,0$.

*YIELD

$750,0.0$

*SOLID SECTION, ELSET=PID2, MATERIAL=GRID

*MATERIAL , NAME =GRID

* ELASTIC

$32500, .45$

* PLASTIC

$650,0.0$

$1100, .03$

$3120, .10$

*SOLID SECTION, ELSET=PID6, MATERIAL=SOFT

*MATERIAL, NAME $=$ SOFT

*ELASTIC

$10, .15$

*STEP, CYCLE $=35$, INC $=50$, SUBMAX, AMP $=$ RAMP

*STATIC, PTOL $=10$

*DLOAD

PID7 , P3 , 1440.0

*DLOAD

PID3, BY , -99.0

*BOUNDARY, OP=NEW

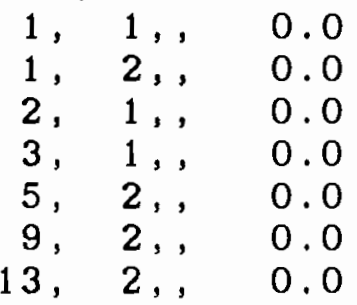




\begin{tabular}{|c|c|c|}
\hline 17, & 2, & 0.0 \\
\hline 21, & 2, & 0.0 \\
\hline 25, & 2, & 0.0 \\
\hline 29, & 2, & 0.0 \\
\hline 33, & 2, & 0.0 \\
\hline 37, & $2,$, & 0.0 \\
\hline 41, & 2, & 0.0 \\
\hline 45 & 2, & 0.0 \\
\hline 50, & 2, & 0.0 \\
\hline 51, & 1, & 0.0 \\
\hline 51, & 2, & 0.0 \\
\hline 54, & 1, & 0.0 \\
\hline 57, & 1, & 0.0 \\
\hline 60 , & 1, , & 0.0 \\
\hline 62, & 1, & 0.0 \\
\hline 63 , & 1, , & 0.0 \\
\hline 64 , & $1,$, & 0.0 \\
\hline 65 , & 1, , & 0.0 \\
\hline 66 , & 1, & 0.0 \\
\hline 67, & 1, , & 0.0 \\
\hline 68, & 1, , & 0.0 \\
\hline 69 , & 1, & 0.0 \\
\hline 174, & 1, & 0.0 \\
\hline 177 , & 1, & 0.0 \\
\hline 180 , & 1, & 0.0 \\
\hline 183, & 1, , & 0.0 \\
\hline 186 , & 1, , & 0.0 \\
\hline 189, & 1, & 0.0 \\
\hline 192 , & 1, & 0.0 \\
\hline 195, & 1, & 0.0 \\
\hline 201, & 1, , & 0.0 \\
\hline 4 & 3, & 0.0 \\
\hline 8, & 3, , & 0.0 \\
\hline 12, & 3, & 0.0 \\
\hline 16 & 3, & 0.0 \\
\hline 20 & 3, & 0.0 \\
\hline 24 & 3, & 0.0 \\
\hline 28, & 3, & 0.0 \\
\hline 32 , & 3, & 0.0 \\
\hline 36 , & 3, , & 0.0 \\
\hline 40 & 3, & 0.0 \\
\hline 44 & 3, & 0.0 \\
\hline 48 & 3, & 0.0 \\
\hline 59 , & 3, & 0.0 \\
\hline 224, & 1, & 0.0 \\
\hline 225, & 2, & 0.0 \\
\hline 225, & 3, & 0.0 \\
\hline
\end{tabular}

*EL FILE, POSITION=CENTRIODAL, FREQ $=10$ 
*EL PRINT, POSITION=CENTROIDAL, FREQ=10, ELSET=PID2 *NODE FILE, FREQ $=10$, NSET $=$ MID

$\mathrm{U}$

* END STEP

**

$* *$

**

*STEP, NLGEOM, CYCLE $=35$, INC=50, SUBMAX, MONOTONIC *STATIC, PTOL $=100$

*BOUNDARY, OP=MOD

$$
225, \quad 1,,-.02
$$

*EL FILE, POSITION=CENTROIDAL, FREQ $=10$

$S$

SINV

E

*NODE FILE, FREQ $=10, \quad$ NSET $=$ MID

$\mathrm{U}$

*END STEP

$* *$

*⿻一

$* *$

*STEP, NLGEOM, CYCLE $=35$, INC $=50$, SUBMAX, MONOTONIC *STATIC, PTOI 100

*BOUNDARY , OP=MOD

$$
225, \quad 1,,-.04
$$

*EL FILE, POSITION=CENTROIDAL, FREQ $=10$

$S$

SINV

E

*EL PRINT, POSITION=CENTROIDAL，FREQ=10, ELSET=PID2 S

E

*NODE FILE, FREQ $=10$, NSET $=$ MID

$\mathrm{U}$

*END STEP

$* *$
$* *$
$* *$
$* *$
$* *$
$* *$

*STEP, NLGEOM, CYCLE=35, INC=50, SUBMAX, MONOTONIC *STATIC, PTOL $=100$

*BOUNDARY , OP=MOD

$$
225, \quad 1, \quad-.06
$$

*EL FILE, POSITION=CENTROIDAL, FREQ $=10$

$S$ 
SINV

$\mathrm{E}$

*EL PRINT, POSITION=CENTROIDAL, FREQ=10, ELSET=PID2 $\mathrm{S}$

$\mathrm{E}$

*NODE FILE, FREQ $=10$, NSET $=$ MID

$\mathrm{U}$

*END STEP

\section{$* *$}

$* *$

$* *$

*STEP, NLGEOM, CYCLE=35, INC=50, SUBMAX, MONOTONIC *STATIC, PTOL $=100$

*BOUNDARY , OP=MOD

$$
225,1,-.08
$$

*EL FILE, POSITION=CENTROIDAL, FREQ $=10$

$\mathrm{S}$

SINV

$\mathrm{E}$

*EL PRINT, POSITION=CENTROIDAL, FREQ=10, ELSET=PID2 $S$

$\mathrm{E}$

*NODE FILE, FREQ $=10, \quad$ NSET $=$ MID

$\mathrm{U}$

*END STEP

\section{**}

$* *$

**

*STEP, NLGEOM, CYCLE $=35$, INC $=50$, SUBMAX, MONOTONIC *STATIC, PTOL $=100$

*BOUNDARY , OP=MOD

$$
225,1,-.10
$$

*EL FILE, POSITION=CENTROIDAL, FREQ $=10$

$S$

SINV

$\mathrm{E}$

*EL PRINT, POSITION=CENTROIDAL, FREQ=10, ELSET=PID2 $\mathrm{S}$

E

*NODE FILE, FREQ $=10$, NSET $=$ MID

$\mathrm{U}$

*END STEP

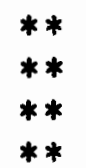

*STEP, NLGEOM, CYCLE $=35$, INC $=50$, SUBMAX, MONOTONIC *STATIC, PTOL $=150$

*BOUNDARY , OP=MOD 


$$
225, \quad 1,,-.12
$$

*EL FILE, POSITION=CENTROIDAL, FREQ $=10$

$\mathrm{S}$

SINV

E

*EL PRINT, POSITION=CENTROIDAL, FREQ=10, ELSET=PID2 $\mathrm{S}$

$\mathrm{E}$

*NODE FILE, FREQ $=10$, NSET $=$ MID

U

*END STEP

**

**

$* *$

**

*STEP, NLGEOM, CYCLE $=35$, INC $=50$, SUBMAX, MONOTONIC *STATIC, PTOL $=120$

*BOUNDARY, OP=MOD

$$
225, \quad 1,,-.14
$$

*EL FILE, POSITION=CENTROIDAL, FREQ $=10$

$S$

SINV

$\mathrm{E}$

*EL PRINT, POSITION=CENTROIDAL, FREQ $=10$, ELSET $=$ PID2 $\mathrm{S}$

E

*NODE FILE, FREQ $=10$, NSET $=$ MID

$\mathrm{U}$

*END STEP 
APPENDIX P

ADJUSTED MODEL OUTPUT DATA 


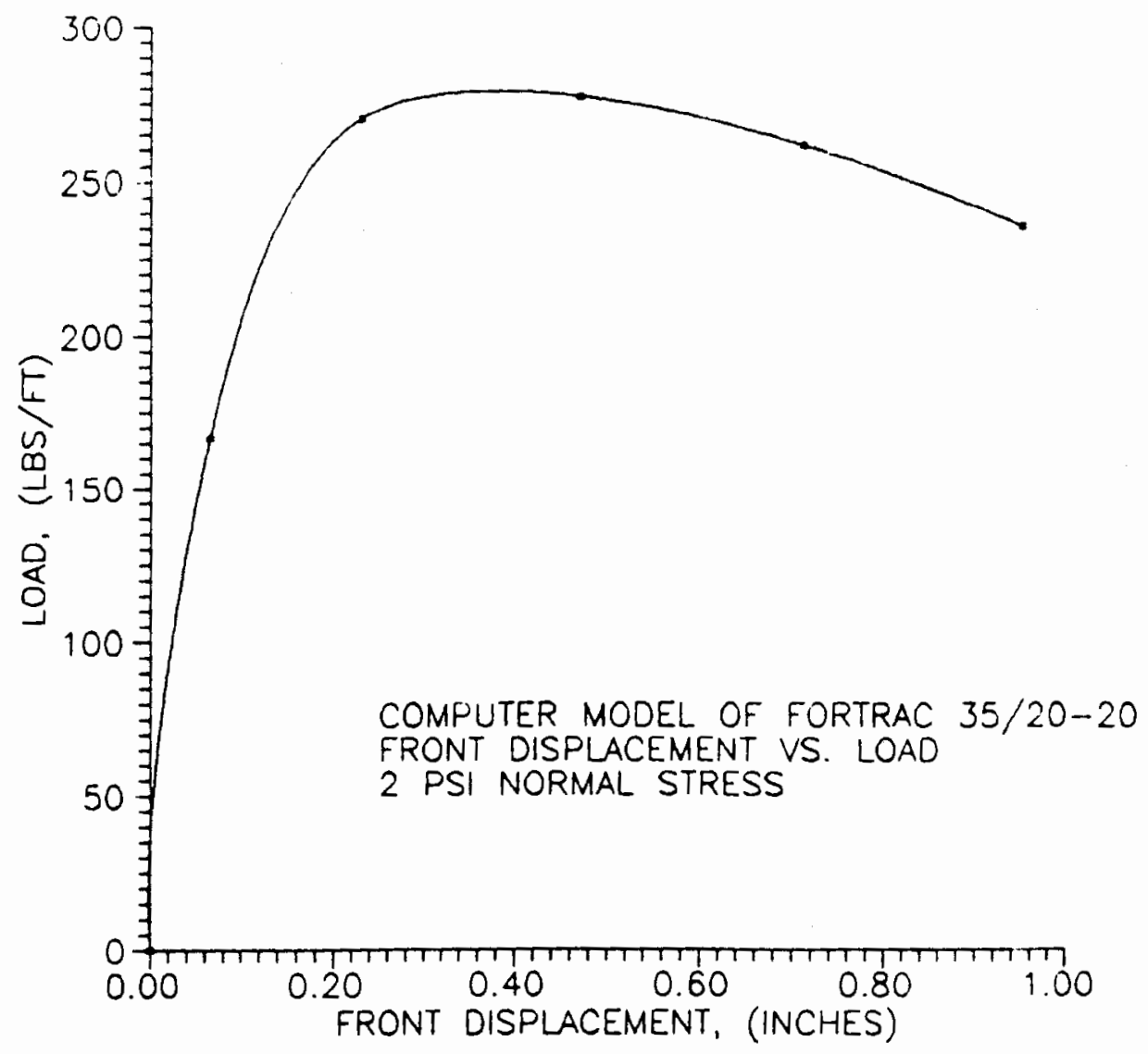

2 PSI NORMAL STRESS

FRONT DISPLACEMENT (IN) VS. STRESS

$\begin{array}{rr}0 & 0 \\ 0.064991 & 166.16 \\ 0.230004 & 269.56 \\ 0.46974 & 276.61 \\ 0.710328 & 260.78 \\ 0.9513 & 234.83\end{array}$




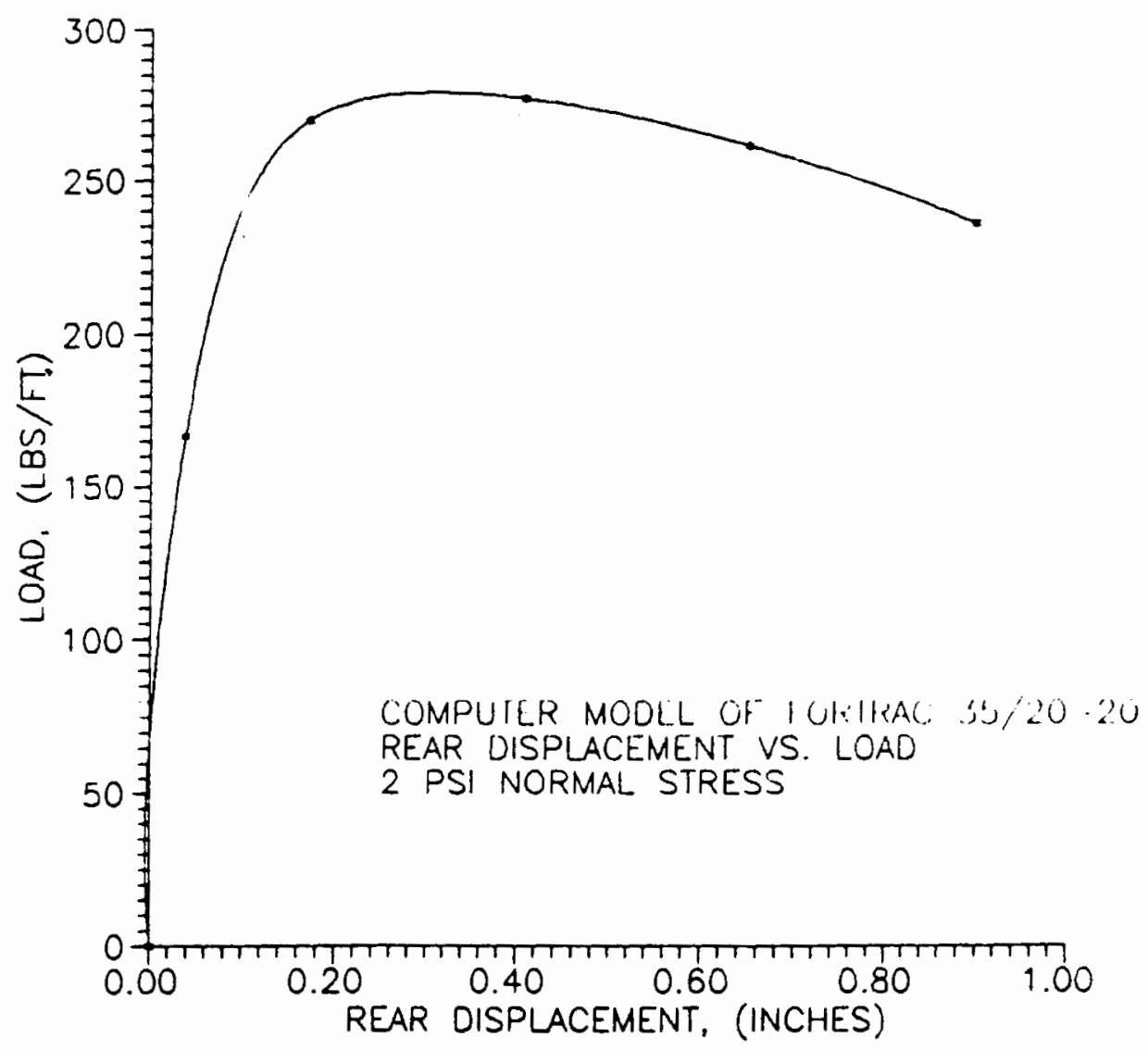

2 PSI NORMAL STRESS

REAR DISPLACEMENT (IN) VS. STRESS

0.038201

0

0.173316

166.16

0.409764

269.56

0.652176

276.61

0.901104

260.78

234.83 


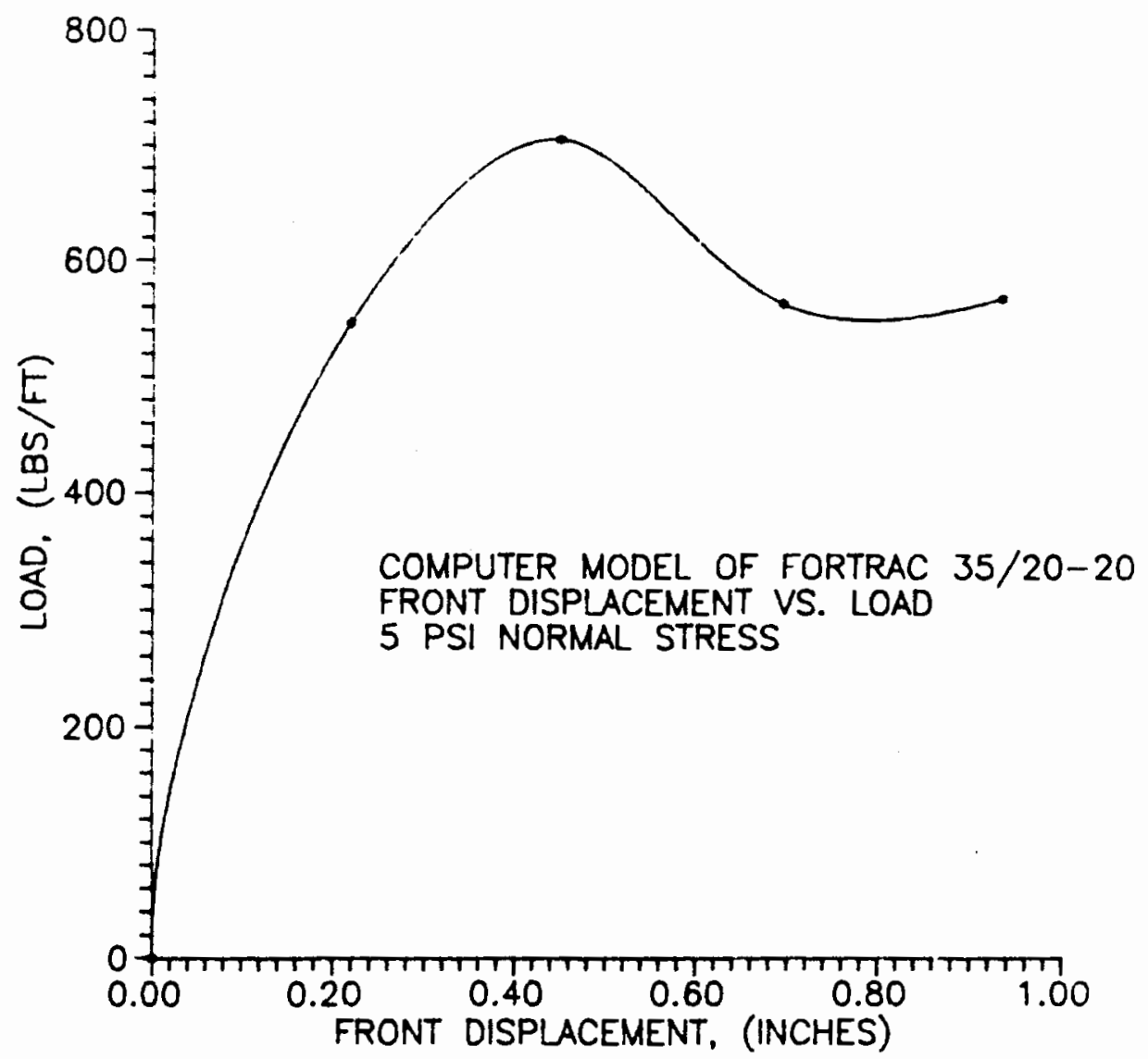

5 PSI NORMAL STRESS

$\begin{array}{crr}\text { FRONT DISPLACEMENT } & \text { VS. } & \text { STRESS } \\ 0.000003 & & 0 \\ 0.21966 & & 546.35 \\ 0.449184 & & 705.04 \\ 0.69456 & & 562.81 \\ 0.934368 & & 567.83\end{array}$




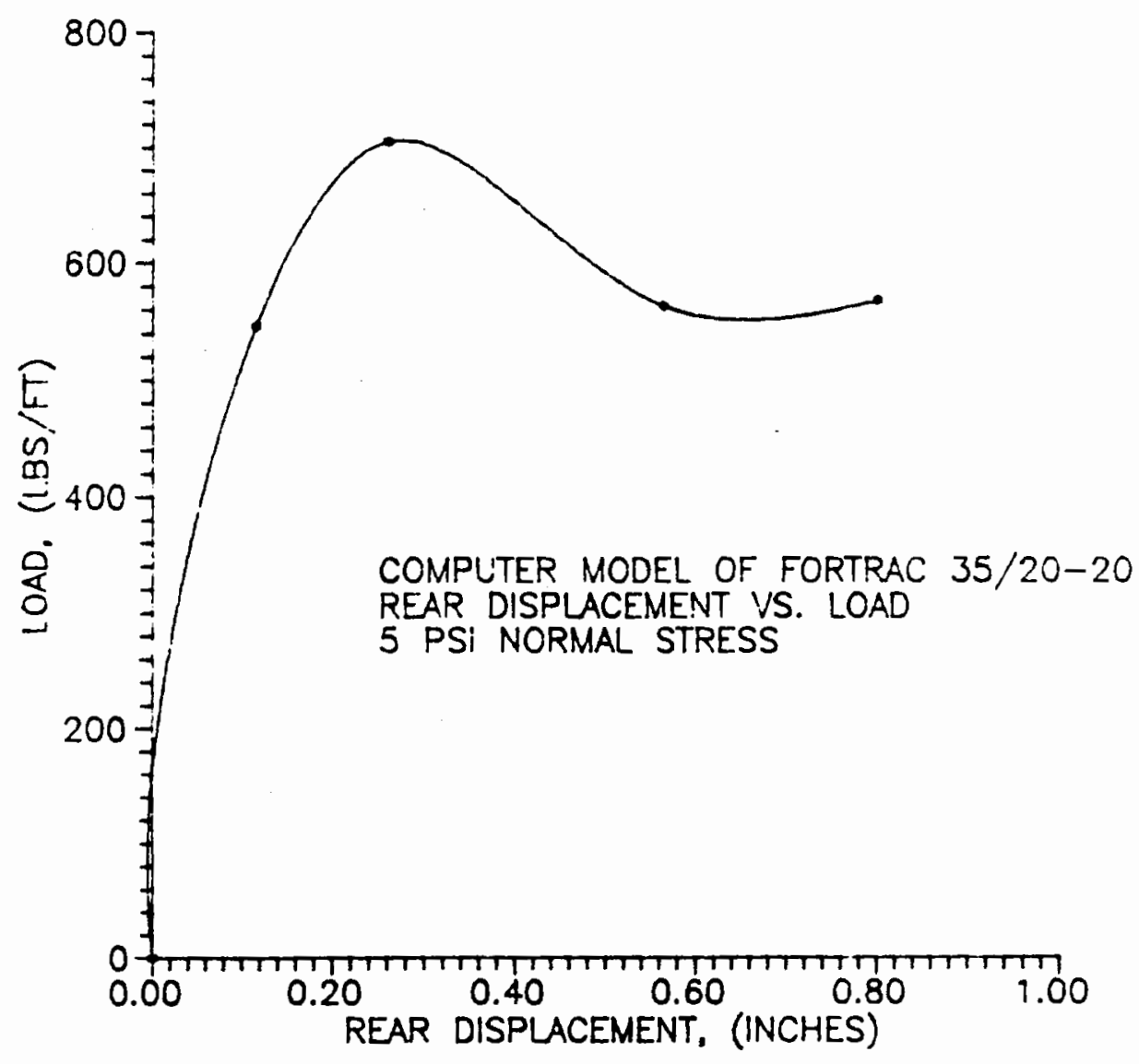

5 PSI NORMAL STRESS

$\begin{array}{rrr}\text { REAR DISPLACEMENT } & \text { (IN) VS. } & \text { STRESS } \\ 0.00001 & & 0 \\ 0.116240 & & 546.35 \\ 0.26028 & & 705.04 \\ 0.56483 & & 562.81 \\ 0.80126 & & 567.83\end{array}$




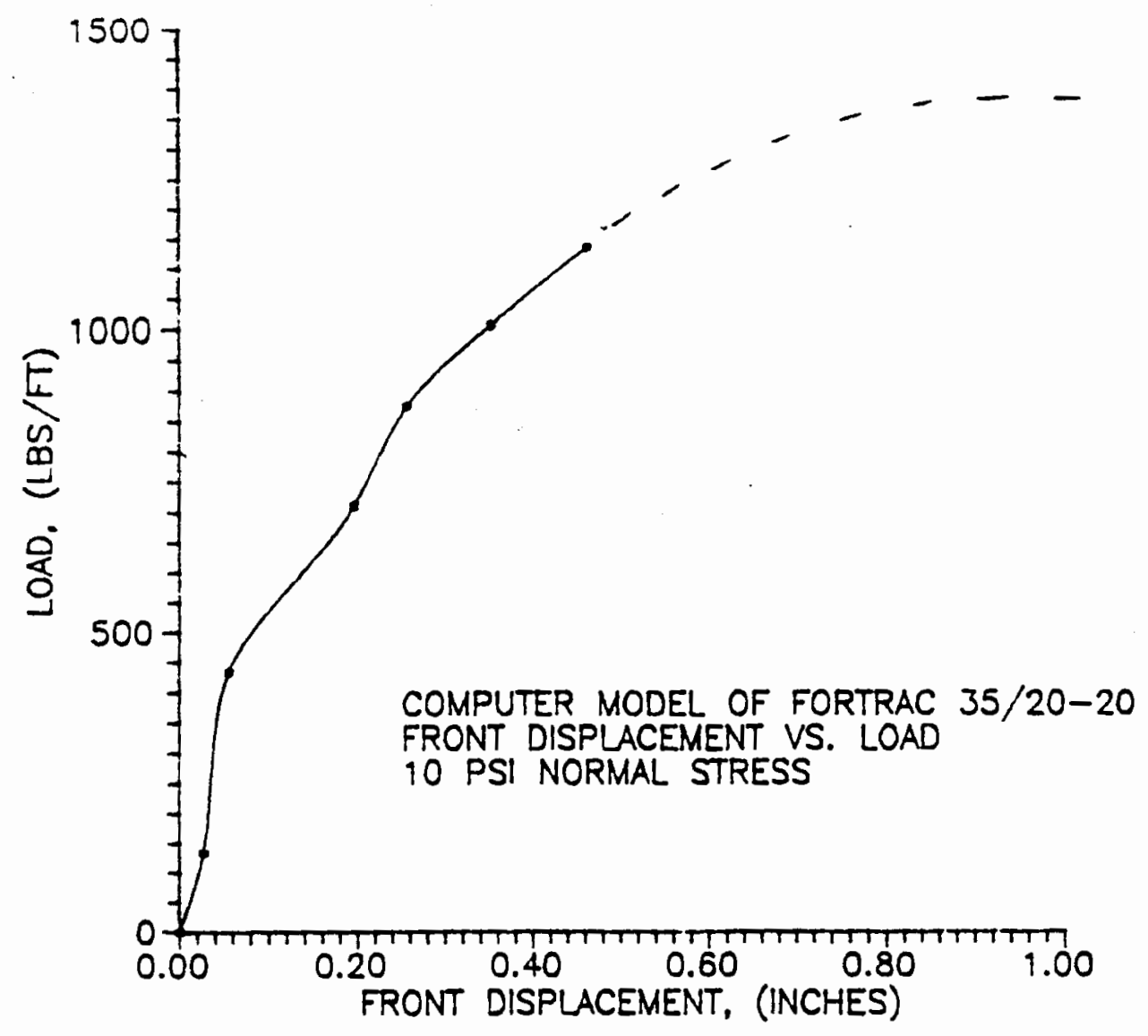

10 PSI NORMAL STRESS

FRONT DISPLACEMENT (IN) VS. STRESS

$$
\begin{array}{r}
-0.00001 \\
0.026686 \\
0.054957 \\
0.19608 \\
0.256896 \\
0.351912 \\
0.462012
\end{array}
$$

$$
\begin{array}{r}
133.55 \\
433.6 \\
711.08 \\
875.73 \\
1007 \\
1134.7
\end{array}
$$




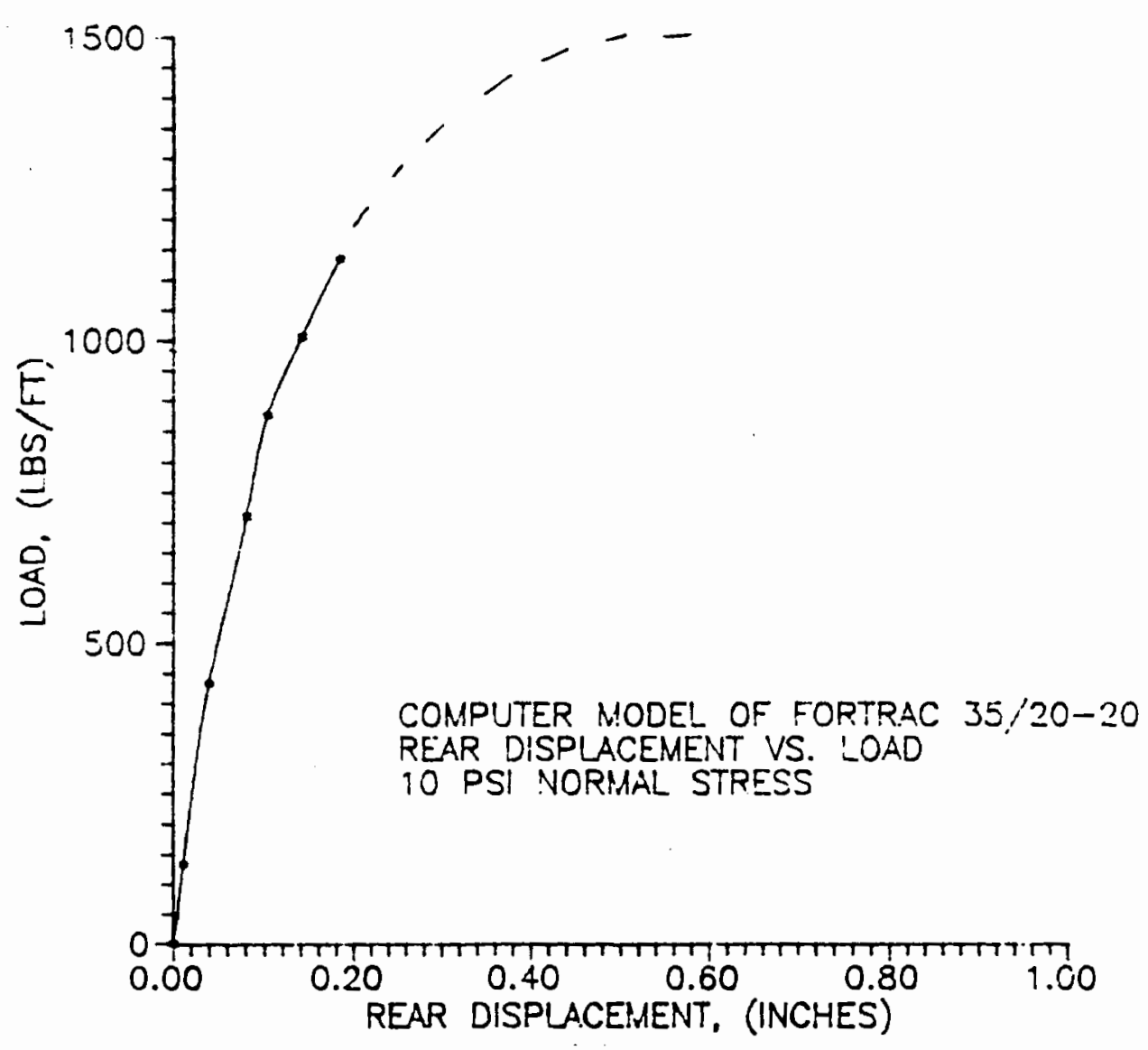

10 PSI NORMAL STRESS

$\begin{array}{rrr}\text { REAR DISPLACEMENT } & \text { (IN) VS. } & \text { STRESS } \\ 0.000014 & 0 \\ 0.011028 & & 0 \\ 0.039025 & 133.55 \\ 0.080138 & 433.6 \\ 0.102754 & 711.08 \\ 0.140676 & 875.73 \\ 0.183203 & 11007 \\ & & 1134.7\end{array}$




\section{NOTATION AND ABBREVIATIONS}

$\mathrm{AC}$

ASTM

BYU

$\mathrm{c}$

$\mathrm{cm}$

d

DC

E

F

f $t$.

ft./min.

in.

Inc.

in. /min.

$\mathbf{K}$

$\mathrm{kN}$

$\mathrm{kN} / \mathrm{m}$

$\mathrm{kN} / \mathrm{sq} \cdot \mathrm{m}$

Ko

$\mathrm{Ks}$

lbs./ft.
Alternating Current.

American Standard Testing Methods .

Brigham Young University.

Cohesion.

Centimeter.

Thickness of transverse rib.

Direct Current.

Young's Modulus.

Tensional force.

Foot.

Feet per minute.

Inch.

Incorporated.

Inches per minute.

Ratio of flow stresses in triaxial tension to flow stresses in triaxial compression.

Kilonewton.

Kilonewton per meter.

Kilonewton per square meter.

Horizontal earth pressure coefficient.

Stiffness in stick.

Pounds per cubic foot.

Pounds per foot. 
lbs./sq. ft. Pounds per square foot.

mi 1

$\mathrm{mm}$

$\mathrm{mm} / \mathrm{m}$ in .

no.

$\mathrm{Pp}$

ps $\mathrm{f}$

ps i

$\operatorname{SCS}$

SP

$\mathrm{t} / \mathrm{sq} \cdot \mathrm{m}$

V

$\mathrm{X}$

$+1-$

"

a

$\delta^{\prime}$

$\Phi^{\prime}$

$\emptyset^{\prime}$

$\varnothing$

$\bar{\tau}$

$\tau, \tau$

$\circ$

$\beta$
.001 inches.

Millimeter.

Millimeter per minute.

Number

Passive pressure.

Pounds per square foot.

Pounds per square inch.

Soil Conservation Service.

Poorly graded sand.

Tons per square meter.

Volts.

By .

Plus or minus.

Inches ,

Coefficient of interaction.

Effective angle of soil-fabric bond stress.

Effective angle of shearing resistance for unreinforced soil.

Effective soil friction angle.

Soil friction angle.

Equivalent shear stress limit.

Shear stress components.

Normal stress.

Material friction angle.

Dilation angle. 